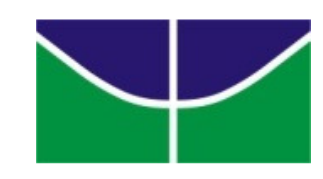

Universidade de Brasília - UnB

Faculdade de Economia, Administração e Contabilidade - FACE

Programa de Pós-Graduação em Administração - PPGA

\title{
INOVAÇÃO NO PROCESSO DE COMPRA DE MEDICAMENTOS: \\ ESTUDO DE CASO DO MINISTÉRIO DA SAÚDE
}

Dayse Karenine de Oliveira Carneiro

\author{
Brasília - DF
}

2016 


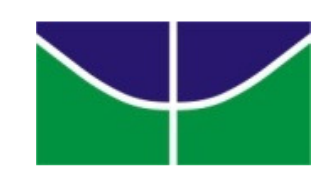

Universidade de Brasília - UnB

Faculdade de Economia, Administração e Contabilidade - FACE

Programa de Pós-Graduação em Administração - PPGA

\section{INOVAÇÃO NO PROCESSO DE COMPRA DE MEDICAMENTOS: ESTUDO DE CASO DO MINISTÉRIO DA SAÚDE}

Dayse Karenine de Oliveira Carneiro

Dissertação apresentada ao Programa de Pós-Graduação em Administração (PPGA), da Faculdade de Economia, Administração e Contabilidade (FACE), da Universidade de Brasília (UnB), como requisito parcial para obtenção do título de Mestre em Administração Pública.

Orientador: Prof. Dr. Pedro Carlos Resende Junior

Brasília - DF 


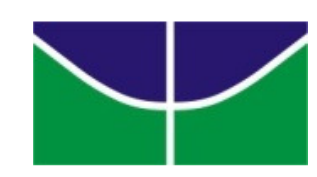

Universidade de Brasília - UnB

Faculdade de Economia, Administração e Contabilidade - FACE

Programa de Pós-Graduação em Administração - PPGA

\section{DISSERTAÇÃO APROVADA PELA \\ COMISSÃ̃O EXAMINADORA:}

Prof. Dr. Pedro Carlos Resende Junior

Orientador

Prof. Dr. Antônio Isidro-Filho

Membro Interno

Prof. Dr. João Souza Neto

Membro Externo

Prof. Dr. Rodrigo Rezende Ferreira

Suplente

\section{Brasília - DF}

2016 


\section{DEDICATÓRIA}

A Deus, pela força e por todas as conquistas no decorrer dos últimos anos.

Ao meu marido Robevany Martins Borges, pelo amor incondicional e por sempre me lembrar que sou mais forte do que penso ser. 


\section{AGRADECIMENTOS}

A minha mãe Divaneide e a minha irmã Diana, pelo amor e apoio durante toda a vida.

Ao meu pai José Maria, in memoriam e com imensas saudades. Nesta jornada, eu chorei, vibrei e busquei forças que me permitiram chegar até aqui. Saiba que a superação de mais essa etapa da minha vida é a maior prova de que o senhor fez muito por mim e, por isso, sou eternamente grata por tudo.

Ao Professor Doutor Pedro Carlos Resende Junior, agradeço imensamente por tudo que me ensinou pacientemente no decorrer dos últimos anos e principalmente por ter acreditado em mim.

Ao Professor Doutor Antônio Isidro-Filho, por ter me acolhido no Núcleo de Estudos e Pesquisas em Inovação e Estratégia e pelas valorosas contribuições sobre inovação no setor público.

Ao Professor Doutor João Souza Neto, por aceitar o convite para fazer parte da banca e pelas considerações que me fizeram refletir sobre a importância dessa pesquisa.

À turma do Mestrado Profissional em Administração Pública da UnB, em especial às amigas June e Alice. A amizade que construímos possui grande valor para mim e quero levála para a vida inteira.

Aos professores e funcionários do Programa de Pós-Graduação em Administração da UnB, que durante todo o curso não mediram esforços para o aprendizado e suporte administrativo, essenciais à boa condução das atividades acadêmicas.

Aos servidores do Departamento de Logística em Saúde e da Coordenação-Geral de Gestão e Planejamento Logístico, pelo apoio e pela ajuda na coleta de dados da pesquisa.

Ao Ministério da Saúde, pelo apoio institucional que viabilizou a realização desse mestrado. 
E por fim, à Universidade de Brasília, através da Faculdade de Economia, Administração e Contabilidade e do Programa de Pós-Graduação em Administração, por ter me conferido a oportunidade de estudar em um dos cursos de mestrado mais conceituados do país. 


\section{RESUMO}

A implementação de inovações no setor público oferece oportunidades de modernização da gestão pública, com o intuito de proporcionar relevantes melhorias de eficiência, eficácia e efetividade das ações do Estado. $\mathrm{O}$ objetivo da presente pesquisa consiste em analisar a inovação no processo de compras governamentais de medicamentos e insumos para a saúde do Ministério da Saúde (MS). A partir da literatura que discute a inovação no setor público proposta pelos autores Bloch et al. (2009), Bloch (2011) e De Vries, Bekkers \& Tummers (2015), foi realizada análise de conteúdo proveniente de dois grupos focais com gestores e usuários da inovação, que revelou a oportunidade de caracterizar a inovação do MS; identificar dimensões e variáveis da literatura presentes e ausentes no fenômeno; e por fim, novas variáveis relacionadas ao tipo de inovação desenvolvida. Foi aplicado questionário com os usuários da inovação do MS, que identificou a relação entre as variáveis de inovação presentes no fenômeno e três fatores principais considerados representantes de dimensões da inovação no setor público: características e resultados da inovação; práticas de gestão e percepções sobre o ambiente organizacional para promoção de inovações; e, práticas relativas ao processo de inovação no MS. Ademais, foi feita uma proposição de indicadores de inovação no processo de compras governamentais, que demonstrou o desempenho da inovação no contexto do referido órgão.

Palavras-chave: Inovação no setor público; Compras governamentais; Modelos de inovação no setor público; Indicadores de inovação. 


\begin{abstract}
The implementation of public sector innovations offers opportunities for modernization of public management, in order to provide relevant improvements in efficiency, effectiveness and effectiveness of state actions. The objective of the present research is to analyze the innovation in the public procurement process of medicines and health inputs of the Ministry of Health in Brazil. From the literature that analyzes the public sector innovations proposed by the authors Bloch et al. (2009), Bloch (2011) and De Vries, Bekkers \& Tummers (2015), a content analysis from two focal groups with managers and users of innovation was carried out, which revealed the opportunity to characterize the innovation; identify dimensions and variables of literature present and absent in the phenomenon; and finally, new variables related to the type of innovation developed. A questionnaire was applied with all the users of innovation, which identified the relationship between the innovation variables present in the phenomenon and three main factors considered as representatives of innovation dimensions in the public sector: characteristics and results of innovation; management practices and perceptions about the organizational environment to promote innovation; and, practices related to the innovation process. In addition, a proposal was made of innovation indicators in the public procurement process, which demonstrated the performance of innovation in this context.
\end{abstract}

Keywords: Public sector innovation; Public procurement; Frameworks of public sector innovation; Innovation indicators. 


\section{LISTA DE FIGURAS}

Figura 1 - Modelo de inovação no setor público proposto por Bloch et al. (2009).

Figura 2 - Modelo heurístico da inovação no setor público proposto por De Vries, Bekkers e Tummers (2015) 50

Figura 3 - Modelo para análise da inovação no setor público 53

Figura 4 - Desenho da pesquisa

Figura 5 - Nuvem de palavras referente ao Grupo Focal 1 realizado com gestores do MS .....89 Figura 6 - Nuvem de palavras referente ao Grupo Focal 2 realizado com os usuários do PEC no MS 90

Figura 7 - Dados referentes às áreas dos respondentes do questionário envolvidos com o processo de compra do Ministério da Saúde

Figura 8 - Dados referentes à questão sobre facilidade de uso da inovação

Figura 9 - Dados referentes à questão 2 sobre vantagem relativa da inovação

Figura 10 - Dados referentes à questão 3 sobre compatibilidade da inovação com outros sistemas do MS .95

Figura 11 - Dados referentes à questão 4 sobre a percepção do PEC enquanto uma inovação no setor no processo de compras do MS

Figura 12 - Dados referentes à questão 5 sobre os benefícios intangíveis gerados ao MS pela inovação no processo de compras 97

Figura 13 - Dados referentes à questão 6 sobre as melhorias geradas nos processos de trabalho dos servidores envolvidos com as compras de medicamentos 98

Figura 14 - Dados referentes à questão 7 sobre as melhorias geradas nos processos de compras dos medicamentos adquiridos pelo MS para distribuição aos Estados e Municípios 99 
Figura 15 - Dados referentes à questão 8 sobre a transparência da informação geradas nos processos de compras dos medicamentos do MS

Figura 16 - Dados referentes à questão 9 sobre a sustentabilidade da inovação no processo de compras de medicamentos do MS

Figura 17 - Dados referentes à questão 10 sobre investimento em inovação do MS

Figura 18 - Dados referentes à questão 11 sobre apoio para o desenvolvimento de inovações (por meio de ações de educação, incentivos à diversidade)

Figura 19 - Dados referentes à questão 12 sobre a disponibilização de infraestrutura tecnológica para inovação no MS 104

Figura 20 - Dados referentes à questão 13 sobre a percepção que os gestores são as principais fontes de inovação dentro do MS 105

Figura 21 - Dados referentes à questão 14 sobre a percepção que os servidores são as principais fontes de inovação dentro do MS 106

Figura 22 - Dados referentes à questão 15 sobre o desenvolvimento de inovações para atender a prioridades políticas 107

Figura 23 - Dados referentes à questão 16 sobre atuação em rede do MS com outras organizações para o desenvolvimento de inovações 108

Figura 24 - Dados referentes à questão 17 sobre observância da legislação por parte do MS para o desenvolvimento de inovações

Figura 25 - Dados referentes à questão 18 sobre utilização de inovações que estão sendo adotadas por outras organizações públicas com perfil compatível 110 Figura 26 - Dados referentes à questão 19 sobre disponibilidade de recursos para investimento em inovação 
Figura 27 - Dados referentes à questão 20 sobre aplicação da gestão de riscos para o desenvolvimento de inovações no MS

Figura 28 - Dados referentes à questão 21 sobre existência de barreiras para o desenvolvimento de inovações no MS

Figura 29 - Dados referentes à questão 22 sobre existência de facilitadores para o desenvolvimento de inovações no MS

Figura 30 - Dados referentes à questão 23 sobre existência de autonomia ao servidor para o desenvolvimento de inovações no MS

Figura 31 - Dados referentes à questão 24 sobre estímulo à criatividade para o desenvolvimento de inovações no MS 116

Figura 32 - Dados referentes à questão 25 sobre formação de equipes multidisciplinares para o desenvolvimento de inovações no MS

Figura 33 - Dados referentes à questão 26 sobre o comprometimento com o trabalho para o desenvolvimento de inovações no MS

Figura 34 - Dados referentes à questão 27 sobre a satisfação com o trabalho para o desenvolvimento de inovações no MS

Figura 35 - Dados referentes à questão 28 sobre o compartilhamento de conhecimento sobre inovação dentro do MS

Figura 36 - Dados referentes à questão 29 sobre o desenvolvimento de estratégia para inovação dentro do MS

Figura 37 - Dados referentes à questão 30 sobre o desenvolvimento de atividades para difusão da inovação 121

Figura 38 - Dados referentes à questão 31 sobre as atividades de colaboração e aprendizado para inovação 
Figura 39 - Dados referentes à questão 32 sobre a cultura organizacional favorecendo o

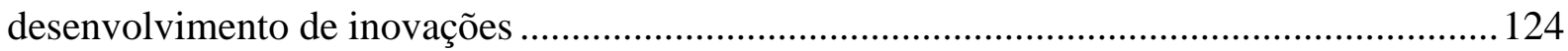

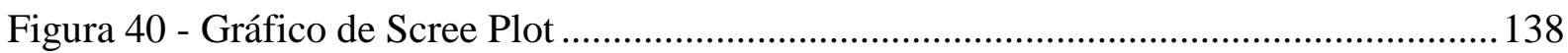




\section{LISTA DE TABELAS}

Tabela 1 - Gastos do DLOG com medicamentos e insumos para saúde de 2011 a 2015 ........ 26

Tabela 2 - Retornos e artigos selecionados nas bases CAPES e PROQUEST …....................27

Tabela 3 - Tipologias da inovação para o setor público ...........................................................45

Tabela 4 - Sistematização da definição, categorias, descrição e variáveis propostas por Bloch (2011) e Bloch et al. (2009) sobre inovação no setor público

Tabela 5 - Sistematização da definição, categorias, descrição e variáveis propostas por De Vries, Bekkers e Tummers (2015) sobre inovação no setor público 52

Tabela 6 - Protocolo do estudo de caso, conforme Yin (2015) 58

Tabela 7 - Sistematização das questões, objetivos, dimensões e variáveis dos grupos focais .67 Tabela 8 - Resultados da análise de conteúdo referente à inovação nas compras governamentais de medicamentos do MS, segundo gestores do MS

Tabela 9 - Resultados da análise de conteúdo referente à inovação nas compras governamentais de medicamentos do MS, segundo usuários da inovação do MS 83

Tabela 10 - Resultados da análise dos dados do questionário aplicado no MS 123

Tabela 11 - Resultados da análise dos dados no DLOG e outras áreas do MS 126

Tabela 12 - Teste de correlação entre as variáveis proveniente da aplicação do questionário no MS 132

Tabela 13 - Testes de KMO e esfericidade de Barlett 136

Tabela 14 - Matriz de comunalidades 136

Tabela 15 - Variância total explicada 139

Tabela 16 - Comunalidades

Tabela 17 - Variância total explicada referente à análise fatorial rotacionada 141

Tabela 18 - Matriz de padrão ${ }^{\mathrm{a}}$ 141 
Tabela 19 - Nova matriz de padrão ${ }^{\mathrm{a}}$

Tabela 20 - Fatores e variáveis agrupadas

Tabela 21 - Estatísticas de confiabilidade

Tabela 22 - Estatísticas de item-total

Tabela 23 - Estatísticas de confiabilidade

Tabela 24 - Estatísticas de item-total.

Tabela 25 - Estatísticas de confiabilidade

Tabela 26 - Estatísticas de item-total

Tabela 27 - Definição das categorias e descrição para proposição dos indicadores dos resultados da inovação nas compras governamentais 148

Tabela 28 - Indicador de economicidade e formas de mensuração

Tabela 29 - Dados do indicador preço econômico de referência dos anos de 2011 a 2013 ... 151

Tabela 30 - Dados do indicador preço econômico de referência dos anos de 2014 e 2015 ... 151

Tabela 31 - Indicadores de eficiência da inovação nas compras governamentais. 154

Tabela 32 - Tempo médio de tramitação dos processos de compra de medicamentos realizados de 2011 a 2015 155

Tabela 33 - Indicadores de eficácia e formas de mensuração 157

Tabela 34 - Indicadores de sustentabilidade da inovação nas compras governamentais

Tabela 35 - Dados do indicador de sustentabilidade da inovação nas compras governamentais referente ao recurso papel 160

Tabela 36 - Indicadores de transparência da inovação e formas de mensuração 161

Tabela 37 - Indicadores de transparência da inovação nas compras governamentais 162 


\section{LISTA DE ABREVIATURAS E SIGLAS}
AFE - Análise Fatorial Exploratória
BM - Banco Mundial
CEME - Central de Medicamentos
CNMAF - Conferência Nacional de Medicamentos e Assistência Farmacêutica
CNS - Conselho Nacional de Saúde
DATASUS - Departamento de Informática do SUS
DLOG - Departamento de Logística em Saúde
DOU - Diário Oficial da União
EPP - Empresas de Pequeno Porte
MS - Ministério da Saúde
OCDE - Organização para a Cooperação e o Desenvolvimento Econômico
OEA - Organização dos Estados Americanos
OMC - Organização Mundial do Comércio
OMS - Organização Mundial da Saúde
P\&D - Pesquisa \& Desenvolvimento
PBM - Plano Brasil Maior
PEC - Processo Eletrônico de Compras
PNAF - Política Nacional de Assistência Farmacêutica
PNM - Política Nacional de Medicamentos
RDC - Regime Diferenciado de Contratações
SUS - Sistema Único de Saúde
TCU - Tribunal de Contas da União
TR - - Termo de Referência 


\section{SUMÁRIO}

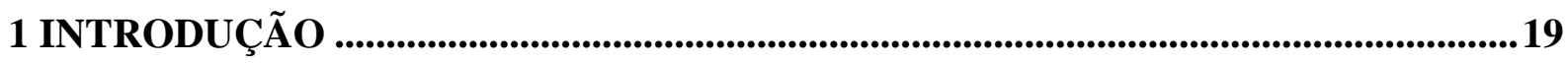

1.1 DEFINIÇÃO DO PROBLEMA

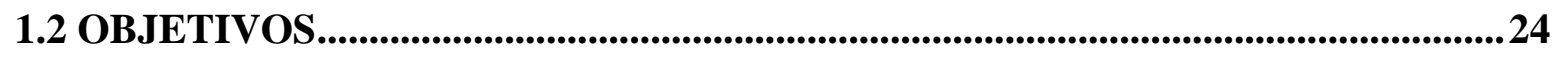

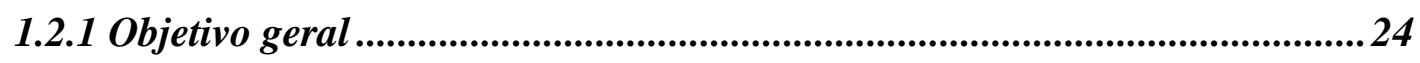

1.2.2 Objetivos específicos .......................................................................................24

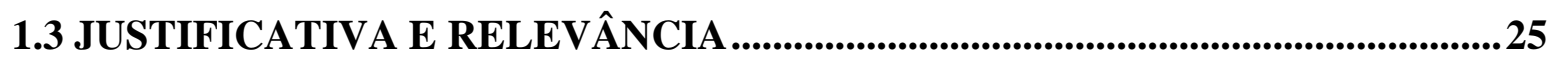

2 REFERENCIAL TEÓRICO ......................................................................................... 27

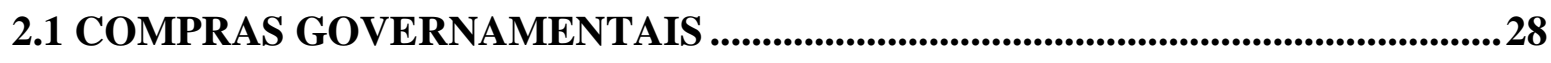

2.1.1 Desempenho nas compras governamentais .............................................33

2.1.2 Compras governamentais de medicamentos..............................................34

2.1.3 Política nacional de assistência farmacêutica ..............................................36

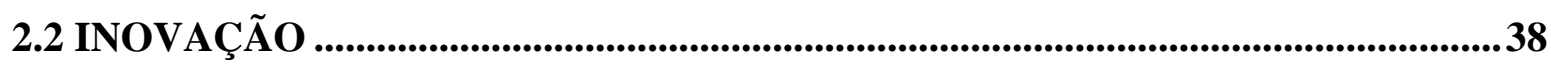

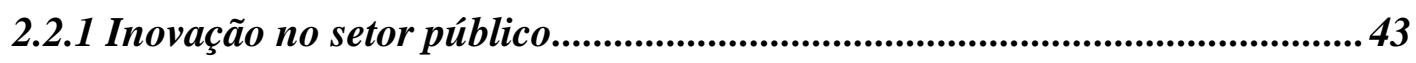

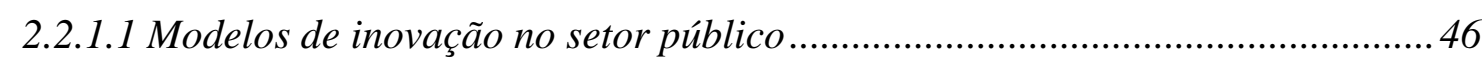

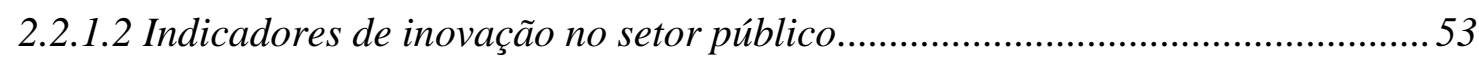


3.1 PROCEDIMENTOS DE COLETA DE DADOS..................................................58

3.2 PROCEDIMENTOS DE ANÁLISE DE DADOS.....................................................60

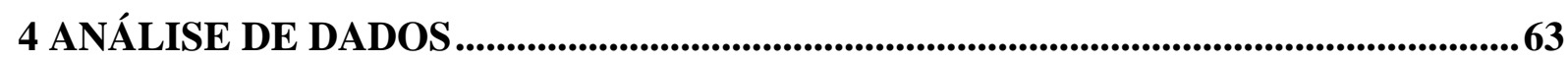

4.1 CARACTERIZAÇÃO DA INOVAÇÃo DESENVOLVIDA NO PROCESSO DE COMPRAS GOVERNAMENTAIS DE MEDICAMENTOS DO MS..............................63

4.2 ANÁLISE DE DADOS OBTIDOS COM OS GRUPOS FOCAIS .............................65

4.3 ANÁLISE DE DADOS OBTIDOS COM OS QUESTIONÁRIOS .............................90

4.4 PROPOSIÇÃO E ANÁLISE DOS INDICADORES DE INOVAÇÃo NAS COMPRAS GOVERNAMENTAIS ......................................................................................147

4.4.1 Indicador de economicidade.............................................................................149

4.4.2 Indicadores de eficiência ...............................................................................152

4.4.3 Indicadores de eficácia .................................................................................156

4.4.4 Indicadores de sustentabilidade ....................................................................158

4.4.5 Indicadores de transparência ......................................................................161

5 CONCLUSÕES E RECOMENDAÇÕES .........................................................................163

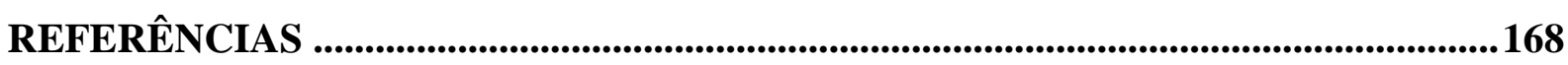

APÊNDICE A - CARTA DE APRESENTAÇÃO DA PESQUISADORA AO MINISTÉRIO DA SAÚDE ...............................................................................175

APÊNDICE B - ROTEIRO DOS GRUPOS FOCAIS.......................................................177

APÊNDICE C - MÉTODO PARA CÁLCULO COMPLETO DO CVC ..........................180 
APÊNDICE D - FORMULÁRIO DE VALIDAÇÃo DE QUESTIONÁRIO EM PESQUISA CIENTÍFICA ACADÊMICA ...............................................................182

APÊNDICE E - Planilha de CÁlCUlo de VAlidaÇão de CONTEúdo (CVC) …......................................................................................................................... 187

APÊNDICE F - Planilha daS MÉdias de CÁlCULO dE VAlidação de CONTEÚDO (CVC) ........................................................................................195

APÊNDICE G - QUESTIONÁRIO APLICADO AOS SERVIDORES DO MS .............197 APÊNDICE H - RESULTADOS DOS TESTES DE NORMALIDADE ..........................203 APÊNDICE I - RESULTADOS DO TESTE DE MANN-WHITNEY...............................206 


\section{INTRODUÇÃO}

Nas últimas décadas, influenciada pela crise da burocracia weberiana e pelos ideais da New Public Management (NPM), a Administração Pública buscou a implementação de um modelo gerencial e, com isso, a máquina pública passou a utilizar-se da modernização das suas ações e operar, principalmente, na busca pela efetividade das políticas públicas (Hood, 1991; Abrucio, 1997).

No contexto brasileiro, esse processo de reorientação tem se pautado no direcionamento de um Estado capaz de formular políticas públicas e de ser cada vez mais presente, o que desencadeou um processo de reformulação das instituições, as quais vêm se tornando cada vez mais complexas em suas estruturas e suas atribuições (Matos Pinto, 2015).

Silva Neto e Ribeiro (2012) corroboram com esse entendimento quando afirmam que a transição para o Estado Nacional contemporâneo, cuja conjuntura é representada, principalmente, por fatores críticos como a nova economia (globalização, tecnologia e conhecimento) e a nova gestão pública (eficiência, flexibilidade, resultado, aprendizado organizacional e social, controle social, responsabilidade); impõe aos gestores que atuam neste Estado o uso de tecnologia de gestão mais apropriada à agregação de valor social e à redução e otimização dos recursos requeridos pelos processos responsáveis por tal agregação.

Desde 1995, substanciado pelos ideais do Plano Diretor da Reforma do Estado, viu-se, paulatinamente, a promoção de uma Administração Pública Gerencial, também denominada de Gerencialismo, pela qual Bresser-Pereira (2006) buscou um realinhamento do Estado, voltando-o para o atendimento das necessidades do cidadão, sendo utilizado como estratégia para obtenção de resultados e incentivar a inovação. A ideia é modernizar a gestão pública, com vistas a ampliar as capacidades institucionais do Estado como promotor do desenvolvimento e do bem comum e, nesse sentido, a inovação surge como parte de um 
processo dinâmico de evolução que envolve uma série de atividades inovativas (De Vries, Bekkers \& Tummers, 2015).

No início de 2016, o Brasil aprovou o novo marco legal para a inovação, denominado de Código de Ciência, Tecnologia e Inovação, conforme Lei ${ }^{\circ}$ 13.243, de 11 de janeiro de 2016, que apresenta estímulos à inovação e a define como a introdução de novidade ou aperfeiçoamento no ambiente produtivo e social que resulte em novos produtos, serviços ou processos ou que compreenda a agregação de novas funcionalidades ou características a produto, serviço ou processo já existente, resultando em melhorias e em efetivo ganho de qualidade ou desempenho.

A partir dessa premissa, a busca por inovações no setor público pode ser entendida como um esforço contínuo do Estado e das mais diversas áreas de atuação, no sentido de entregar um produto ou serviço, ou ambos, de maior valor agregado ao seu destinatário. Assim, a inovação é fruto da necessidade que o governo tem, de prestar serviços públicos de maneiras novas, sem deixar de lado a eficiência, eficácia e efetividade.

Nesse contexto, insere-se o Ministério da Saúde (MS), que é responsável pelo Sistema Único de Saúde (SUS), a maior política social no país, e um dos maiores sistemas públicos de saúde do mundo e que tem em seus objetivos estratégicos dos seus planejamentos 2011-2015 e 2016-2019, a Política Nacional de Assistência Farmacêutica (PNAF), cuja premissa básica é o fornecimento gratuito aos medicamentos e insumos para a saúde.

Os medicamentos e insumos para a saúde fornecidos pelo SUS à população brasileira são adquiridos pela União, Estados ou Municípios. Entretanto, o MS realiza aquisições de alguns desses medicamentos e insumos também de modo centralizado, isto é, em nome da União, e os distribui aos Estados e Municípios para utilização na rede.

Observou-se que, historicamente a área de compras do MS atuava de forma reativa, realizando cada compra pontualmente de acordo com o solicitado pela respectiva área 
demandante - áreas técnicas do MS responsáveis pelas diversas políticas públicas de saúde dentro do órgão. Este modelo, todavia, não se mostrava suficiente e, em 2010, foi implantada uma nova metodologia na área de compras, mediante planejamento de todos os medicamentos a serem adquiridos, com detalhamento de diversas informações e desenvolvimento de sistemas de informação capazes de acompanhar em tempo integral e de forma eletrônica a sistematização do planejamento das demandas do MS, os processos de compras, o controle do estoque, a distribuição e o consumo desses insumos.

Para tal, foi criada uma área específica para realizar esta atividade, o Departamento de Logística em Saúde (DLOG). O Departamento está vinculado à Secretaria Executiva (SE) do MS, e teve inicialmente suas competências definidas pelo Decreto $\mathrm{n}^{\circ} .7 .336$, de 19 de outubro de 2010, sendo responsável pela cadeia logística de medicamentos e insumos para a saúde. A cadeia logística aqui referida compreende o planejamento logístico, a compra, a armazenagem e a distribuição dos medicamentos e insumos para a saúde.

Essa reestruturação regimental revela o Estado enquanto agente inovador, que atua, neste caso, através do MS e do DLOG, responsável legalmente instituído, e que implementou uma metodologia inovadora na área de compras, adotando um software denominado Processo Eletrônico de Compras (PEC), o qual foi regulamentado pela Portaria $n^{\circ} 2.758$, de 18 de novembro de 2013, e consiste num conjunto de documentos e atos processuais organicamente acumulados de forma eletrônica no curso de um processo de compra de bens e serviços do MS.

Essa ferramenta foi criada com o intuito de otimizar o processo de compra e garantir o eficaz abastecimento dos medicamentos e insumos para a população usuária do SUS, aliada ainda à busca da efetividade na utilização dos recursos públicos, evitando com isso, desperdícios ao erário. 
Contudo, passados aproximadamente três anos da implementação dessa inovação no DLOG, faz-se necessário analisar suas características e efeitos a partir da percepção dos stakeholders diretamente envolvidos e, portanto, a proposta desse trabalho consiste em analisar a inovação no processo de compras governamentais de medicamentos e insumos para a saúde do MS.

Diante da diversidade de definições na literatura, o conceito de inovação analisado neste trabalho é entendido como sendo uma ideia, prática ou objeto novo para a unidade adotante, seja ela empresa, governo, associação, entre outros. Com isso, uma vez a ideia sendo nova para o adotante, o que se apresenta no caso do PEC, então sua utilização pelo MS é considerada uma inovação (Rogers, 2003).

Por conseguinte, com base nesta proposição, objetiva-se uma análise da inovação desenvolvida nos processos de compras governamentais de medicamentos e insumos para saúde do MS, através do DLOG, identificando as dimensões, os atributos e resultados relacionados com essa inovação, e, com isso, gerar oportunidades de melhorias de produtividade, que além de agregar qualidade à gerência e à performance do Departamento, pode fortalecer a expansão de uma cultura de inovação, transparência e accountability na Administração Pública.

\subsection{DEFINIÇÃO DO PROBLEMA}

As compras governamentais de medicamentos e insumos para a saúde realizadas pelo MS, através do DLOG, podem ser utilizadas como instrumento de fortalecimento da gestão do SUS, tanto ao promover uma economia no orçamento público, como também ao garantir a regularidade e segurança no recebimento desses insumos pelos pacientes.

No entanto, no decorrer dos últimos anos, os órgãos de controle vêm realizando diversas auditorias no DLOG, com o intuito de apurar como estão sendo realizadas essas 
compras e com isso, evitar danos ao erário e garantir o abastecimento dos medicamentos e outros insumos para a saúde. Fato que pode ser percebido através do Relatório Sistêmico de Fiscalização da Saúde, elaborado pelo Tribunal de Contas da União (TCU), em 26 de março de 2014, e que aponta problemas graves, complexos e recorrentes referentes à falta de medicamentos e insumos para a saúde adquiridos pelo MS e distribuídos para os 26 Estados e o Distrito Federal.

Essas compras apresentam um grande desafio, uma vez que implicam numa maior responsabilidade do MS, através do DLOG, no sentido de assegurar contratos em quantitativos e prazos que garantam a oferta permanente de um medicamento que, na sua falta, acarreta riscos de desabastecimento dos medicamentos na rede pública, que por sua vez, pode causar prejuízos graves à saúde dos usuários, como retrocesso em tratamentos, possíveis quadros de invalidez ou agravamento das condições do paciente decorrentes da interrupção do fármaco, ou, em casos extremos, até mesmo à morte de pacientes.

Observa-se historicamente que as primeiras iniciativas para o desenvolvimento da inovação no setor público ocorreram a partir de pressões para melhora da transparência em procedimentos administrativos e processos de tomada de decisão, bem como para o melhoramento dos serviços prestados ao cidadão (European Commission, 2005). Essas pressões estão alinhadas com os fatores supracitados que representam os desafios às compras governamentais de medicamentos realizadas pelo MS, já que as mesmas visam garantir a inviolabilidade ao direito à vida, como ao dever do Estado de desenvolver políticas que visem à redução de doenças e outros agravos e ao acesso universal e igualitário a serviços para a proteção, promoção e recuperação da saúde.

Isidro-Filho, Guimarães e Perin (2011) corroboram com esse entendimento quando apontam que há consenso entre estudiosos do construto inovação quanto ao caráter complexo 
e dinâmico das inovações em serviços de saúde, em especial no que se refere aos determinantes e às mudanças decorrentes de inovações nesse contexto.

Tais desafios e complexidade proporcionam um ambiente favorável à introdução de inovações no setor público, no entanto, apesar do desenvolvimento da inovação para melhoria na gestão das compras do MS, decorridos três anos dessa implementação, faz-se necessário analisar e compreender a inovação em toda a sua amplitude, e assim identificar as dimensões relacionadas com a mesma a partir da percepção dos stakeholders diretamente envolvidos.

Dessa forma, a partir da iniciativa de inovação adotada no MS e com base nos problemas relatados, formula-se a seguinte pergunta de pesquisa: que dimensões inovativas estão envolvidas no processo de compras governamentais de medicamentos e insumos para a saúde do MS?

\subsection{OBJETIVOS}

Com o intuito de oferecer respostas ao problema proposto, seguem os objetivos geral e específicos da presente pesquisa.

\subsubsection{Objetivo geral}

Analisar a inovação no processo de compras governamentais de medicamentos e insumos para a saúde do MS.

\subsubsection{Objetivos específicos}

a) Caracterizar a inovação desenvolvida no processo de compras governamentais de medicamentos do MS;

b) Identificar as dimensões e variáveis de inovação presentes e ausentes no fenômeno;

c) Identificar os fatores relacionados com o fenômeno de inovação do MS; 
d) Propor indicadores de inovação no processo de compras governamentais; e

e) Analisar o fenômeno do MS a partir dos indicadores de inovação propostos.

\subsection{JUSTIFICATIVA E RELEVÂNCIA}

A necessidade de compreensão da inovação, especialmente no contexto do setor público de saúde, torna-se relevante diante da efetiva necessidade de abastecimento dos medicamentos e insumos para a saúde na rede pública, para o atendimento à população, em cumprimento às Políticas Nacionais de Saúde, em especial à PNAF. A partir das demandas de abastecimento apresentadas pelas políticas, executam-se todas as atividades relacionadas com as compras governamentais desses insumos realizadas pelo MS, através do DLOG.

A centralização da aquisição dos medicamentos e outros insumos para a saúde foi uma alternativa pactuada entre o MS e os gestores das unidades federadas. Esta centralização além de considerar os custos envolvidos no tratamento medicamentoso, em nível ambulatorial, visa obter melhores preços em proveito de um aumento da necessidade de aquisição, bem como contratos estáveis, regularidades das entregas e pagamentos, e redução de processos administrativos.

Os preços obtidos pelo MS qualificam a gestão do SUS, tanto ao promover uma economia no orçamento público, como também no atendimento dos pacientes, que poderão contar com maior segurança no recebimento regular do medicamento. Por outro lado, a compra centralizada implica em maior responsabilidade do MS, especialmente do DLOG, no sentido de assegurar contratos em quantitativos e prazos que garantam a oferta permanente do medicamento.

Diante da centralização das atividades de compras governamentais de alguns medicamentos e outros insumos para a saúde no MS, a gestão dessas compras apresenta inúmeras especificidades que fazem com que a compra desses produtos exijam substanciais e 
continuados investimentos, o que demonstra representatividade quanto ao montante financeiro dispendido nessas contratações desde a criação do DLOG, de acordo com Tabela 1.

Tabela 1 - Gastos do DLOG com medicamentos e insumos para saúde de 2011 a 2015

\begin{tabular}{cc}
\hline Ano & Valor $(\mathbf{R} \$)$ \\
\hline 2011 & $4.118 .204 .841,13$ \\
2012 & $3.424 .026 .975,47$ \\
2013 & $3.272 .239 .728,67$ \\
2014 & $5.759 .139 .316,13$ \\
2015 & $8.156 .648 .442,10$ \\
\hline
\end{tabular}

Fonte: Elaborada pela autora, a partir dos dados do software Comprasnet.

Todo esse contexto apresenta condição suficiente para explicar a necessidade da análise da inovação implementada no MS, através do DLOG, pois conhecer os fatores externos, internos e condições de enquadramento que influenciam essa inovação poderá permitir, entre outras coisas, que o mesmo desenvolva planos de ação para a área de forma mais justificada, já que será possível identificar as forças e fragilidades advindas dessa inovação, além de contribuir para a melhor alocação de recursos públicos para futuras ações de inovação no setor público.

Ademais, ressalta-se que importantes estudos têm sido realizados para analisar a inovação, embora estes estudos sejam escassos no setor público, o que reflete a necessidade de análise do processo de inovação nesse setor, bem como melhorias das metodologias utilizadas para tal, fato que se torna mais incipiente quando se trata de inovações nas compras governamentais (Management Advisory Committee, 2010; Pihir \& Detelj, 2015; De Vries, Bekkers, \& Tummers, 2015). 


\section{REFERENCIAL TEÓRICO}

Este capítulo se propõe a descrever as teorias e os modelos relevantes que foram utilizados como referencial teórico e para o desenvolvimento dessa pesquisa.

Dessa forma, esse referencial teórico foi definido com base em pesquisas realizadas em periódicos científicos nas bases de dados Portal de Periódicos CAPES e PROQUEST, e a busca utilizou as seguintes palavras-chave, em português e inglês: compras governamentais; compras governamentais de medicamentos; inovação; inovação no setor público; modelos de inovação no setor público e indicadores de inovação no setor público. A palavra-chave Política Nacional de Assistência Farmacêutica foi pesquisada apenas em português por se tratar de uma política referente aos medicamentos exclusiva do SUS.

Inicialmente a busca selecionou artigos de 2010 a 2016, cujos resultados se apresentam na Tabela 2.

Tabela 2 - Retornos e artigos selecionados nas bases CAPES e PROQUEST

\begin{tabular}{|c|c|c|c|c|}
\hline Palavras-chave & $\begin{array}{c}\text { CAPES } \\
\left(n^{\circ} \text { de }\right. \\
\text { retornos }) \\
\end{array}$ & $\begin{array}{l}\text { Quantidade artigos e } \\
\text { livros selecionados }\end{array}$ & $\begin{array}{c}\text { PROQUEST } \\
\left(n^{\circ} \text { de }\right. \\
\text { retornos }) \\
\end{array}$ & $\begin{array}{l}\text { Quantidade artigos e } \\
\text { livros selecionados }\end{array}$ \\
\hline Compras governamentais & 124 & 8 & 81 & 6 \\
\hline $\begin{array}{l}\text { Compras governamentais de } \\
\text { medicamentos }\end{array}$ & 42 & 5 & 12 & 3 \\
\hline $\begin{array}{l}\text { Política Nacional de } \\
\text { Assistência Farmacêutica }\end{array}$ & 63 & 3 & 17 & 0 \\
\hline Inovação & 2.987 & 8 & 453 & 5 \\
\hline Inovação no setor público & 522 & 7 & 144 & 2 \\
\hline $\begin{array}{l}\text { Modelos de inovação no } \\
\text { setor público }\end{array}$ & 137 & 4 & 87 & 2 \\
\hline $\begin{array}{l}\text { Indicadores de inovação no } \\
\text { setor público }\end{array}$ & 366 & 2 & 121 & 1 \\
\hline
\end{tabular}

Fonte: Elaborada pela autora em 18 de agosto de 2016.

Após a primeira seleção, foram adicionados livros e outros artigos seminais a partir do uso da técnica denominada de snowball ou bola de neve, com a seleção de autores citados em pelo menos dois textos anteriormente selecionados. Com base nestes critérios, foram obtidos e utilizados para a construção do referencial teórico 52 artigos, agrupados em sete categorias 
temáticas: compras governamentais, com 14 artigos; compras governamentais de medicamentos, com 8 artigos; Política Nacional de Assistência Farmacêutica, com 3 artigos; inovação, com 13 artigos; inovação no setor público, com 9 artigos; modelos de inovação no setor público, com 6 artigos; e, por fim, indicadores de inovação, com 3 artigos.

\subsection{COMPRAS GOVERNAMENTAIS}

Pela perspectiva acadêmica tradicional, as compras governamentais podem ser definidas como o processo pelo qual o governo busca obter materiais, serviços e equipamentos necessários ao seu funcionamento em conformidade com as normas e leis em vigor (Farrel \& Stuart, 1983; Baily, 2000). Mesmo que as compras e contratações do setor público visem prioritariamente o cumprimento das diversas metas governamentais, é incontestável que o emprego mais articulado do potencial econômico e estratégico dessa demanda pode proporcionar vários outros objetivos associados também ao desenvolvimento (Squeff, 2014; Schooner \& Yukins, 2009).

Apesar da discussão por parte da literatura sobre o papel econômico e estratégico que as áreas de compras governamentais vêm assumindo desde 1990 até os dias atuais, pouco foi tratado sobre a estrutura e o processo de compras das organizações do setor público. Baily (2000) corrobora com essa ideia quando afirma que a compra é vista pela organização bemsucedida de hoje como uma atividade de importância estratégica considerável. Assim, no decorrer do tempo, os processos de compra se tornaram mais complexos e dependentes de recursos vultosos, dinâmicos, interconectados e inovadores.

Dessa forma, observa-se uma crescente busca pela alta qualidade, menor custo, maior rapidez e flexibilização das compras e contratações governamentais, o que demonstra uma constante preocupação dos gestores no uso eficiente dos recursos públicos que representam uma parcela orçamentária importante, e o seu bom gerenciamento é uma alternativa 
complementar para o aumento da eficiência na utilização dos gastos públicos e para melhorar o desempenho das organizações governamentais (Varge Maldonado, 2008).

De acordo com Câmara e Frossard (2010), a compra dentro de uma perspectiva mais ampla, realiza-se por intermédio de um contrato bilateral, com direitos, obrigações e com pagamento de preço, como contraprestação da transferência do domínio do bem.

Existe um paralelismo entre a compra governamental e a privada, pois a premissa básica é a busca pelo menor preço, com garantia de qualidade; porém a primeira requer procedimentos específicos para garantir a eficácia da mesma, como por exemplo, a legislação. Já na iniciativa privada esses procedimentos são de livre escolha (Varge Maldonado, 2008).

Com relação à premissa básica das compras, Farrel e Stuart definem a compra sob a ótica administrativa nos seguintes termos:

\footnotetext{
Mesmo em bases diferentes a compra é por si própria, uma verdadeira função administrativa. Envolve ela a administração de materiais de uso corrente, desde a determinação de fontes de fornecimento e "vias de fornecimento", passando pelo almoxarifado, até a entrega final nos pontos de produção, conforme se fizer necessário. Em todos os estágios há decisões a serem tomadas, quanto à qualidade, quantidade, cronogramas, origem e custo. Reconhece-se, assim, que a oferta de produtos de qualidade, em quantidades adequadas e adquiridos por um preço razoável são aspectos-chave na viabilização econômica das unidades (Farrel \& Stuart, 1983, p. 25).
}

Fernandes (2014) ratifica esse entendimento sobre as compras governamentais quando afirma que as mesmas compreendem procedimentos com características e componentes de caráter comercial, envolvendo a negociação de proposta de preço e o caráter jurídico-legal, sujeitando-se a controles, à interposição de recursos e à aplicação de sanções administrativas.

Com relação ao aspecto legal, o serviço público brasileiro se utiliza de extensa legislação com finalidade de oferecer meios para a regulamentação da oferta e dos processos de aquisição. A Lei no 8.666/93, de 21 de julho de 1993, estabelece normas gerais sobre 
licitações, define compras como toda aquisição remunerada de bens para fornecimento de uma só vez ou parceladamente e tem como objetivo principal selecionar a proposta mais vantajosa para a Administração com relativa qualidade de aquisições e/ou contratações. Com isso, de acordo com a legislação brasileira vigente, as compras governamentais têm por finalidade suprir os materiais ou serviços necessários, em quantidades e qualidades certas, a preço adequado, e no momento certo.

Além da Lei no 8.666/93, a utilização do poder de compras governamentais como objetivo de intervenção no domínio produtivo está explícita no Regime Diferenciado de Contratações (RDC) e na Lei Geral da Microempresa. O primeiro foi instituído com o objetivo de ampliar a eficiência nas contratações governamentais e a competitividade, buscando promover a troca de experiências, tecnologia e incentivar a inovação tecnológica. Já a segunda, assegura nas licitações públicas da União a preferência de contratação de Microempresas e Empresas de Pequeno Porte (EPPs) como critério de desempate.

Como diretriz, a partir de 2008, o governo brasileiro definiu que as compras governamentais são instrumentos prioritários para impulsionar a economia, estabelecendo para isso, metas de aumento da taxa de investimento no País, a elevação dos gastos com pesquisa e o crescimento na participação das exportações brasileiras (Moreira \& Vargas, 2009; Cruz \& Dantas, 2008). Daí decorre que, no Brasil, o setor de compras governamentais movimentou recursos estimados entre $15 \%$ a $20 \%$ do PIB e, portanto, tem relevância econômica nos gastos da Administração Pública e mobilizam setores importantes da economia, que se ajustam às demandas previstas nos editais de licitação (Biderman \& Macedo, 2008; Freitas, 2012).

Nesse sentido, a utilização do poder de compra das organizações públicas como instrumento de promoção do desenvolvimento social e econômico é amplamente discutido e adotado por diversos países, além de ser reconhecido por diversos órgãos internacionais - 
Organizações dos Estados Americanos (OEA), Banco Mundial (BM) e Organização Mundial do Comércio (OMC) - os quais legitimam o uso desse importante mecanismo como integrante dos planos governamentais.

Sendo os processos de compras governamentais altamente regulados em cada país, com as suas devidas particularidades, os últimos anos têm evidenciado uma tendência internacional de convergência em torno de alguns princípios centrais - competição aberta e efetiva; conduta ética e justa das partes envolvidas; transparência e accountability e igualdade de condições de competição, todos decorrentes da própria atuação regulatória da OMC.

Este movimento recente reflete o reconhecimento do impacto que estes processos podem ter nas relações comerciais internacionais e, nesse cenário, diversos países têm incorporado mais recentemente o conceito de Value for Money ou valor agregado, que se refere às vantagens socioeconômicas tangíveis ou intangíveis obtidas nas compras e contratações governamentais, e implica essencialmente que o Estado, como comprador, deve assegurar que as análises anteriores à efetivação da compra se estendam além do preço para garantir que os resultados obtidos sejam os melhores para a sociedade (Squeff, 2014; Schooner, Gordon \& Clark, 2008).

Com isso, além de ser um suporte da atuação governamental, o fato das compras governamentais serem reconhecidas como instrumento de desenvolvimento econômico e social, levam-nas a serem vistas como instrumentos de política pública, já que além de suprir a Administração Pública dos bens e serviços necessários à execução dessas políticas públicas, a expansão de critérios tradicionais das compras, incorporando elementos de impacto social, parece ser pertinente e legitima ao potencializar as ações dos governos fundamentadas na inclusão social (Oliveira \& Santos, 2015).

Ademais, as compras governamentais podem ser utilizadas para o desenvolvimento de novos produtos, o que apresenta especial relevância quando as metas das políticas incluem o 
aumento em investimento em Pesquisa e Desenvolvimento (P\&D) e a promoção da inovação. Os benefícios percebidos podem ser resumidos na indução de uma demanda por produtos com tecnologias mais avançadas e a redução do risco inerente às atividades de $\mathrm{P} \& \mathrm{D}$ no país. Com isso, surgem oportunidades para melhorias na qualidade dos serviços públicos e, consequentemente, da produtividade da economia (Sousa \& Oliveira, 2010).

Observa-se, portanto, nos últimos anos, que a possibilidade do uso mais estratégico das compras governamentais e o aproveitamento desse potencial econômico têm ganhado destaque no cenário nacional, como ilustram os Planos Brasil Maior (PBM), que explicita entre seus instrumentos o poder de compra governamental, a promoção do desenvolvimento sustentável e o uso da margem de preferência de até $25 \%$ para os produtos com tecnologia nacional; e o Plano Inova Empresa, que também indica o uso do poder de compra, especialmente por meio de aquisições estratégicas, voltadas para o fomento à inovação e competitividade empresarial (Squeff, 2014).

No que se refere à gestão das compras governamentais, o desenvolvimento organizacional eficiente passa, necessariamente, pela melhoria dos processos internos de gestão, e pela definição de um modelo de gestão capaz de otimizar os processos e procedimentos relativos às compras realizadas, que as tornem mais claras e transparentes e de fácil verificação pelos agentes envolvidos (Varge Maldonado, 2008).

De acordo com esse contexto, o gestor público tem uma grande responsabilidade de definir as regras do jogo para assegurar a livre concorrência, sem perder de vista o interesse do governante em dispor do melhor produto/serviço pelo melhor preço possível. Assim, as compras governamentais produzem um efeito cascata sobre os fornecedores, multiplicando investimentos nas mais diversas áreas, podendo transformar-se numa ferramenta importante de produção de desenvolvimento, sob indução da esfera pública, mas com repercussão 
estendida para toda a sociedade, nomeadamente com impactos na iniciativa privada (Oliveira \& Santos, 2015).

\subsubsection{Desempenho nas compras governamentais}

No âmbito das compras governamentais e para uma gestão que preza por resultados e que busca administrar seus recursos de forma mais eficiente, faz-se necessário dotar a Administração Pública de meios mais eficientes e efetivos de executar e controlar as suas aquisições. Nesse sentido, Schooner, Gordon e Clark (2008) definiram alguns indicadores de desempenho e resultados das compras governamentais, os quais são divididos em dois grupos principais.

O primeiro grupo trata do objetivo final e maior das compras governamentais, que é a satisfação das necessidades dos usuários e, para tal, os referidos autores utilizam as seguintes métricas: a própria satisfação final do usuário; economicidade, que impõe adoção da solução mais conveniente e eficiente sob o ponto de vista da gestão dos recursos públicos; valor agregado, que consiste na consideração de fatores como qualidade, desempenho passado do fornecedor, vantagens e desvantagens de determinada compra; eficiência, a qual é definida como o meio pelo qual as compras governamentais são conduzidas e possui como objetivo principal a contratação dos bens e serviços de forma rápida e que busca evitar desperdícios; e a prevenção de riscos, com a utilização de processos eficazes para o gerenciamento de riscos que permitam seu tratamento e a prevenção de crises.

E o segundo grupo analisa os processos de compras governamentais e como os mesmos subsidiam a tomada de decisão do gestor público, e nele se apresentam as métricas de: integridade do sistema de compras governamentais como forma de combate à corrupção; uniformidade, que se refere à padronização de normas e procedimentos; transparência ou acesso às informações que envolvem as compras governamentais; accountability, termo que 
envolve responsabilização, prestação de contas e mecanismos de controle e; e por fim, a competição, a qual é vista como uma forma de se obter o melhor valor para as compras governamentais e também de combater à corrupção.

\subsubsection{Compras governamentais de medicamentos}

No Brasil, os processos de compra de medicamentos obedeceram a um modelo centralizado de gestão até 1997, realizados pela Central de Medicamentos (CEME), apesar da descentralização das ações de saúde no setor público ter-se iniciado em 1990. A extinção desse órgão, aliada à publicação da Política Nacional de Medicamentos (PNM) em 1998, reforçou a política de descentralização proposta para o SUS, transferindo responsabilidades de operacionalização da gestão da assistência farmacêutica para os Estados e Municípios. Com isso, os problemas de gestão e de financiamento somaram-se aos de logística de abastecimento no quadro dos grandes desafios da PNAF dentro do SUS (Bevilacqua, Farias \& Blatt, 2011; Kornis, Braga, \& Zaire, 2008).

Observou-se na revisão de literatura que se apresenta restrita a produção acadêmica sobre as compras governamentais de medicamentos, embora essas tenham se destacado como um ponto crítico, entre outros, na gestão do setor de saúde, dada a pressão gerada pelo contato direto entre o paciente e suas necessidades não toleraram a escassez dos referidos insumos.

Além disso, a oferta de medicamentos de qualidade, em quantidades adequadas, adquiridos por um preço razoável, são aspectos-chave na viabilização econômica das organizações públicas responsáveis pelas compras dos mesmos, porém não se apresenta como uma tarefa de fácil realização (Luiza, Castro, \& Nunes, 1999).

Dessa forma, as compras governamentais de medicamentos são realizadas obedecendo à legislação vigente, através de processo licitatório, com concorrência entre participantes. Contudo, considerando que os recursos são finitos, o desafio dos gestores públicos é planejar 
o processo de compra dos medicamentos para que a qualidade do insumo adquirido não seja prejudicada pela economia.

Conforme a Lei n 5.991 , de 17 de dezembro de 1973, os medicamentos são produtos farmacêuticos, tecnicamente obtidos ou elaborados, com finalidade profilática, curativa, paliativa ou para fins de diagnóstico. Entretanto, pretende-se focar essa pesquisa nas compras de medicamentos e insumos para a saúde, pois a disponibilidade e o acesso aos mesmos constituem parâmetros que permitem medir a qualidade dos serviços de saúde oferecidos pelo SUS.

De acordo com as informações do TCU, extraídas do Relatório Sistêmico para Fiscalização da Saúde, em 2015, foram gastos cerca de R \$ 9,1 bilhões com a subfunção 303 Suporte Profilático e Terapêutico, que abrange as ações voltadas para a produção, distribuição e suprimento de drogas e produtos farmacêuticos em geral, dos quais $21 \%$ foram transferidos para estados e municípios. Esse valor gasto com a referida subfunção representou $10,5 \%$ dos gastos totais da Função Saúde no mesmo ano.

Sendo assim, para World Health Organization (2000), os medicamentos são apontados como um importante indicador de qualidade dos serviços de saúde, já que o abastecimento regular na rede pública é considerado um dos elementos que interferem na efetividade dos programas de saúde e o contrário - um abastecimento irregular - promove o descontentamento da população, desmotivação dos profissionais de saúde e até o agravamento das condições de saúde dos usuários.

De fato, o abastecimento regular de medicamentos na rede pública é considerado um dos elementos que interfere na efetividade de um programa de saúde e a efetividade desse abastecimento depende da qualidade da execução das compras governamentais. Diante desse cenário, no Brasil a compra de medicamentos no setor público vem agora encontrar uma 
pressão popular a favor de uma gestão mais comprometida e responsável, o que alia necessariamente o quesito qualidade ao custo (Bermudez, 2006).

O tema das compras e fornecimento públicos de medicamentos, face às dificuldades de acesso aos mesmos pela maioria da população, atraiu a atenção pública e os centros de tomada de decisão, deixando de ser uma preocupação exclusiva das corporações profissionais de saúde e de segmentos organizados da sociedade, os quais sempre pleitearam políticas de expansão do acesso da população aos medicamentos essenciais.

Nesse sentido, Novaes, Gonçalves e Simonetti (2006) concluem que a redução dos custos de compra dos medicamentos, a remoção de diferentes obstáculos durante esses processos de compra, o estabelecimento de maiores interações com os fornecedores, a redução dos custos de produção e a diminuição dos custos com armazenagem e distribuição desses medicamentos são alguns dos objetivos primordiais que se deseja alcançar através da gestão eficaz das áreas de compras de medicamentos das organizações de saúde públicas que integram o SUS.

Ademais, as questões trazidas pelas compras governamentais de medicamentos e a necessidade de serem promovidas ações públicas efetivas capazes de viabilizar a expansão do acesso da população aos mesmos não são questões novas na agenda dos gestores nas três esferas de governo. Por isso, essa questão assume graves conotações devido às distorções na produção e no acesso aos medicamentos, apesar do Brasil ser um dos maiores mercados farmacêuticos do mundo (Oliveira, Labra, \& Bermudez, 2006).

\subsubsection{Política nacional de assistência farmacêutica}

Nos últimos anos, principalmente nos países em desenvolvimento, as questões relativas aos medicamentos e à Assistência Farmacêutica vêm ganhando espaço na agenda governamental e na sociedade, em função da ampliação da abrangência terapêutica dos 
medicamentos, de modo que atualmente existem produtos para quase todas as enfermidades. Além disso, esses produtos estão cada vez mais seguros e eficazes, contribuindo para aumentar a expectativa e a qualidade de vida (World Health Organization, 2000).

Nesse contexto, o Brasil, desde 1964, possui políticas de medicamentos essenciais para a população, dentre as quais se destacou na época a Relação Básica e Prioritária de Produtos Biológicos e Materiais, para uso farmacêutico humano e veterinário (Decreto $\mathrm{n}^{\circ}$ 53.612/1964).

A partir daí foram desenvolvidas diversas políticas e iniciativas do governo brasileiro no sentido de assegurar a aquisição de medicamentos voltada à assistência farmacêutica pública, culminando em 1998 na PNM, considerada o primeiro posicionamento formal e abrangente do governo sobre a questão dos medicamentos.

A PNM foi formulada com base nas diretrizes da Organização Mundial de Saúde (OMS) e expressa as principais diretrizes para o setor com o objetivo de garantir a necessária segurança, eficácia e qualidade dos produtos farmacêuticos, a promoção do uso racional e o acesso da população àqueles considerados essenciais (Brasil, 1999). Dessa forma, a PNM prevê a articulação de um conjunto de atividades que envolvem desde o desenvolvimento de recursos humanos e tecnológicos até a promoção do acesso da população aos medicamentos essenciais.

Em conjunto com a PNM e como parte integrante da Política Nacional de Saúde, a PNAF foi concebida a partir das deliberações da $1^{\text {a }}$ Conferência Nacional de Medicamentos e Assistência Farmacêutica (CNMAF), realizada no período de 15 a 18 de setembro de 2003 e aprovada por meio da Resolução no 338/2004 do Conselho Nacional de Saúde (CNS). Transcorridos 12 anos de PNAF, pode-se observar consolidação como uma política de saúde do SUS, articulada com outras políticas e desenvolvendo estratégias para promover acesso da população aos medicamentos. 
Desde 2005, observa-se um fortalecimento da descentralização da PNAF, com o aumento das transferências de recursos para compras de medicamentos aos Estados, Municípios e Distrito Federal, realizado através do MS. Nesse sentido, estudo de Vieira (2009) aponta que o gasto do MS com a referida Política e seus programas apresenta um crescimento de $525 \%$ no período de 2003 a 2007.

O aumento do gasto do SUS com as compras de medicamentos está em consonância com a tendência de aumento observada em vários países e dentro dessa tendência de crescimento, verifica-se que a centralização de alguns itens se deu por questões econômicas, pois sendo os medicamentos adquiridos de forma centralizada, apresenta-se o aumento da escala e possibilita maior margem para a negociação de preços (Vieira \& Zucchi, 2013).

Esses mesmos autores apontam que no contexto no qual se encontra inserida a PNAF, há um grande caminho a ser percorrido pelo Brasil para garantia de acesso a medicamentos através da compra e do uso racional; contudo, avanços já ocorreram. Para tal, faz-se necessário despender mais esforços com a finalidade de melhorar a gestão da Assistência Farmacêutica, com o objetivo de garantir o uso eficiente dos recursos alocados para a compra de medicamentos e a sustentabilidade dentro do SUS.

\subsection{INOVAÇÃO}

Inovação é um conceito explorado por distintas perspectivas teóricas, destacando-se a Economia, a Sociologia e a Administração, com o objetivo de entregar um produto ou serviço de maior valor agregado ao seu destinatário, sendo compreendida por alguns como o motor para o desenvolvimento econômico e social, a solução para os problemas sociais, e o remédio para a falta de competitividade (Schumpeter, 1982; Resende Junior, Guimarães, \& Bilhim, 2013; Oliveira, Santana, \& Gomes, 2014). 
O conceito de inovação foi proposto por Schumpeter (1982), que o definiu como o processo de produzir outras coisas, ou os mesmos objetos, por método diferente, combinando esses materiais e forças diversamente. Para esse autor, o processo de fazer novas combinações constituiria o princípio da inovação, a qual se caracteriza como o mecanismo capaz de alavancar o processo de desenvolvimento econômico, sendo o impulso fundamental que coloca e mantém a máquina capitalista em movimento.

Na visão original de Schumpeter (1982), as inovações circunscreviam-se às grandes firmas privadas, cabendo algum grau de importância, mas em níveis secundários, a surtos de inovação em firmas pequenas e médias, às pesquisas em laboratórios de universidades ou organizações governamentais e em algumas estatais.

A partir das ideias apresentadas pelo referido autor, o conceito de inovação recebeu contribuições e críticas dos autores denominados neo-schumpeterianos, os quais apresentam a relevância da inovação como geradora de instrumentos para a ampliação da competitividade das empresas, permitindo a apropriação das vantagens absolutas de custo e qualidade, que conduzem à ampliação de seus mercados (Kon, 2004).

Nelson e Winter (1977) afirmam que a maior parte da literatura sobre mudança tecnológica estabelece uma nítida distinção entre invenção e inovação, sendo este último termo empregado num sentido mais restrito e referindo-se à decisão de testar tecnologias na prática. Já a invenção tecnológica é considerada derivada de inventores independentes, que buscam vínculos com firmas ou buscar a criação de novas empresas, com o objetivo de implementá-la. Essa distinção segue Schumpeter na Theory of Economic Development.

Uma abrangência maior dessa definição foi trazida à tona por Freeman (1984), que vinculou explicitamente as instituições sociais como suporte às inovações e à política tecnológica. Para ele, apesar de incerto, o processo de inovação é irreversível e permanente, 
pois a mudança tecnológica é um aspecto decisivo do ambiente da firma, onde, muitas vezes, a opção pela falta de inovação implica seu próprio desaparecimento.

Corroborando com Schumpeter (1982), a maior preocupação de Kline e Rosenberg (1986) recai sobre a inovação enquanto um processo particular, que se desenrola no tempo e está circunscrito a um sistema, em que fatores relacionados aos contextos setorial e social e a variáveis mais específicas da organização não devem escapar às análises, na medida em que modelos demasiadamente reducionistas obscurecem as peculiaridades da real dinâmica inovativa.

Dosi (1988) avança nessa crítica e enfatiza que existem problemas extremamente sérios no uso das ferramentas e modelos neoclássicos na análise da dinâmica econômica, ou em economias que são stricto sensu dinâmicas, mas ainda suficientemente complexas. Ele utiliza uma definição do processo de inovação mais próxima à ótica da firma e se refere essencialmente à procura, à experimentação, ao desenvolvimento, à imitação e à adoção de novos produtos e processos, bem como às novas formas de organização. Decorre daí que, o que não é conhecido com alguma precisão, pressupõe atividades de busca e experimentação, o que envolve também alguma percepção de oportunidades técnicas e econômicas ainda inexploradas.

A partir das críticas e contribuições neo-schumpeterianas, a literatura apresenta vários estudos que apresentam diversos conceitos de inovação, bem como algumas taxonomias que buscam ordenar os tipos e as características da mesma.

A Organização para a Cooperação e o Desenvolvimento Econômico (OCDE) desenvolveu o Manual de Oslo, publicado originalmente em 1992, e é dedicado à mensuração e interpretação da inovação com o objetivo principal de melhorar a compreensão do processo de inovação e seus impactos econômicos. De acordo a OECD (1997), a inovação é enfocada em termos de interação entre as oportunidades de mercado, a base de conhecimentos e as 
competências das empresas. Ainda, classifica inovação em quatro tipos: inovação de produto - produtos e serviços inteiramente novos e melhorias importantes nos existentes; inovação de processo - melhorias significativas no processo de produção e substituição; inovação organizacional - desenvolvimento de melhores práticas gerenciais; e por fim, inovação de marketing - mudanças no composto de marketing, que corresponde ao mix produto, preço, promoção e colocação (Oliveira, Santana, \& Gomes, 2014).

Entre os estudos voltados à investigação do fenômeno da inovação, destaca-se desde o início dos anos 2000, uma aplicação setorial em particular que trata do conjunto de estudos que investigam a inovação no setor de serviços. Nos dias atuais, as pesquisas sobre inovações em atividades de serviços são as que possuem crescimento mais acelerado entre todos os estudos sobre inovação, face ao declínio observado na participação econômica de tradicionais setores industriais, registrado a partir da década de 1970 (Drejer, 2004; Kim et al., 2012).

Gallouj e Weinstein (1997) investigaram a inovação no setor de serviços e classificaram, de forma sistemática, a literatura de acordo com três abordagens principais: a abordagem de assimilação, que afirma que a inovação em serviços está diretamente relacionada à adoção e utilização de plataformas tecnológicas, o que atualmente está em declínio, por acarretar em um viés tecnicista; a abordagem de demarcação ou diferenciação, que procura identificar as particularidades da natureza e organização da inovação em serviços e argumenta a formulação de um modelo de análise próprio para os serviços; e, por fim, a abordagem de integração ou sintetização, que explora os aspectos convergentes entre produtos e serviços e propõe uma estrutura conceitual comum.

Com base nessas abordagens, Gallouj e Weinstein (1997) propõem tipos de inovação, diferenciados em função de sua intervenção nas características ou nas competências citadas, quais sejam: inovação radical, que envolve a criação de produtos totalmente novos e que requeiram competências totalmente distintas, tanto do cliente quanto do produtor; inovação de 
melhoria, que resulta da alteração de alguma característica do produto, supostamente para melhor, sem alterar o sistema como um todo; inovação incremental por substituição ou adição de características, que resulta da substituição ou da adição de uma determinada característica técnica ou competência necessária para a produção ou o uso do produto; inovação ad hoc, que é definida como a construção social interativa de uma solução para um problema particular apresentado por determinado cliente; inovação por recombinação, que está relacionada com a criação de novos produtos a partir de diferentes combinações de características ou produtos existentes em novos usos; e por fim, a inovação por formalização, que está relacionada com a visibilidade das formas anteriormente descritas, ou seja, refere-se ao processo de nomear um determinado serviço e organizar sua sequência, tanto quando essa sequência envolve características físicas ou de serviços como competências.

Além das várias abordagens e definições de inovação, Rogers (2003) analisa o processo de difusão da inovação, o qual já é estudado há mais de 30 anos e tem nesse autor um dos expoentes mais importante. Ele aborda a adoção de inovações tecnológicas e define difusão como o processo pelo qual a inovação é comunicada através de certos canais ao longo do tempo entre os membros de um sistema social e possui quatro elementos principais: inovação, que é definida com uma ideia, prática ou projeto que é percebido como novo pela unidade adotante; canais de comunicação, que são meios específicos para comunicação da inovação na organização; tempo, no qual se define o critério do tempo no processo inovaçãodifusão; e por fim, o sistema social, que é definido como um conjunto de unidades interligadas envolvidas na resolução conjunta de problemas para alcançar um objetivo comum. 


\subsubsection{Inovação no setor público}

Apesar da abordagem schumpeteriana da inovação considerar a firma como o lócus e o lucro como o principal advento da mesma, esse conceito tem sido constantemente ampliado e atualmente a lógica inovativa considera também a dinâmica da inovação no setor público e nas áreas sociais.

Nesse setor, a inovação possui um caráter bastante peculiar, pois o papel do Estado em uma sociedade contemporânea é amplo. Nelson e Yates (1978) afirmam que existem diferenças importantes entre a inovação no setor público e privado, já que no setor privado a lógica do lucro prevalece e no setor público, elementos como retorno social e ganhos para a sociedade precisam estar presentes.

Halvorsen (2005) realiza uma análise do Estado inovador e autor da ação inovadora, e classifica a inovação conforme seguinte tipologia: serviços, processos, administrativa e organizacional, sistema, mudança radical de racionalidade e, por fim, concepção, que implica em novas estratégias e objetivos.

Osborne e Brown (2013) ressaltam a utilização da inovação nos serviços públicos, fornecendo uma visão geral das questões-chave sob uma perspectiva multidisciplinar que englobam: contexto para a inovação; reforma do serviço público; desafios de mudança gerencial; Tecnologia de Informação e Comunicação (TIC); e, por fim, governo eletrônico. Todos esses fatores influenciam diretamente no desenvolvimento da inovação, que para os referidos autores é uma questão central para que o setor público possa explorar o potencial de criar serviços públicos eficientes e eficazes.

Ainda sob a ótica da inovação no setor público, observa-se o Estado como um agente indutor e facilitador da atividade privada e, com isso, tem-se claro que o setor público não é o agente inovador, mas o facilitador da inovação. Não obstante, observa-se Estado como um relevante agente econômico, que atua em áreas de caráter social e áreas estratégicas 
importantes para a atividade econômica do país, se apresentando assim como um agente inovador e responsável pela inovação (Oliveira, 2014).

Bloch (2011) desenvolveu o Manual de Copenhagen, que se propõe a analisar a inovação no setor público, com a elaboração de métricas para promoção da mesma. Para esse autor, inovação é definida pela implementação de uma significativa mudança na forma da organização operar ou fornecer seus produtos. Essa inovação deve ser nova para a organização que a utiliza, porém pode ter sido desenvolvida por outra organização. Além de definir inovação, o supracitado autor classificou os principais tipos de inovação, em consonância com a classificação realizada pela OCDE no Manual de Oslo, os quais são: produto, processo, organizacional e de comunicação.

Em consonância com a definição de Bloch (2011), para De Vries, Bekkers \& Tummers (2015), a maioria dos artigos e livros analisados utilizam a definição de inovação no setor público baseada em Rogers (2003), que a compreende como uma ideia, prática ou objeto que é entendido como novo para a unidade adotante, com o objetivo de criar valor público. Para esses autores os principais tipos de inovação no setor público são: processo, que se subdivide em administrativo ou tecnológico; produto ou serviço; governança; e, conceitual.

A Tabela 3 sistematiza as principais tipologias, bem como as definições associadas a cada uma, de acordo com visão dos autores Bloch (2011) e De Vries, Bekkers e Tummers (2015), com vistas a descrever e compreender o comportamento das organizações que inovam. 
Tabela 3 - Tipologias da inovação para o setor público

\begin{tabular}{|c|c|c|}
\hline \multicolumn{2}{|r|}{ Bloch (2011) } & De Vries, Bekkers \& Tummers (2015) \\
\hline Produto ou serviço & $\begin{array}{l}\text { Introdução de um bem ou serviço novo ou } \\
\text { significativamente melhorado em comparação com os já Produto ou serviço } \\
\text { existentes na organização }\end{array}$ & Criação de novos serviços ou produtos públicos \\
\hline Processo & $\begin{array}{l}\text { Implementação de um método novo ou significativamente } \\
\text { melhorado de produção ou entrega de bens e serviços em } \\
\text { comparação com os já existentes na organização }\end{array}$ & $\begin{array}{l}\text { Criação de novas formas organizacionais, a } \\
\text { introdução de novos métodos de gerenciamento e } \\
\text { novos métodos de trabalho } \\
\text { Criação ou uso de novas tecnologias, introduzidas } \\
\text { na organização para prestar serviços aos usuários e } \\
\text { cidadãos }\end{array}$ \\
\hline Comunicação & $\begin{array}{l}\text { Implementação de um novo método para promoção da } \\
\text { organização que influenciem o comportamento de Conceitual } \\
\text { indivíduos e de outras organizações }\end{array}$ & $\begin{array}{l}\text { Introdução de novos conceitos, estruturas de } \\
\text { referência ou novos paradigmas que ajudama } \\
\text { reformular a natureza dos problemas específicos, } \\
\text { bem como suas possíveis soluções }\end{array}$ \\
\hline Organizacional & $\begin{array}{l}\text { Implementação de um novo método de gestão } \\
\text { organizacional que difere significativamente dos métodos Governança } \\
\text { já existentes na organização }\end{array}$ & $\begin{array}{l}\text { Desenvolvimento de novas formas e processos que } \\
\text { visam resolver problemas sociais específicos }\end{array}$ \\
\hline
\end{tabular}

Fonte: Elaborada pela autora, adaptado de Bloch (2011) e De Vries, Bekkers e Tummers (2015).

Entre as políticas públicas voltadas para o desenvolvimento de soluções inovadoras, destaca-se a alternativa da utilização das compras governamentais enquanto instrumento de indução de inovações. Caracteriza-se assim, uma forma de atuação na qual os clientes governamentais, através da definição de parâmetros específicos em suas compras, podem induzir inovações e, por consequência, interferir de maneira proativa no ritmo e na direção do desenvolvimento empresarial e econômico (Moreira \& Vargas, 2009).

A União Europeia reconheceu a utilização das compras governamentais enquanto instrumento de inovação e como provedoras de mercados pioneiros para novos produtos intensivos em conhecimento e as definem como compras de bens e serviços que ainda não existem, precisam ser aperfeiçoados, ou que requer pesquisa e inovação para atender às necessidades especificadas pelos usuários (European Comission, 2005).

Há muitas outras definições e suportes teóricos ligados ao termo inovação e, portanto, neste trabalho, pretende-se utilizar o conceito de inovação apresentado por Rogers (2003), que está em consonância com os conceitos de inovação no setor público trazidos pelos autores Bloch (2011) e De Vries, Bekkers e Tummers (2015), como sendo uma ideia, prática ou objeto que é entendido como novo para a unidade adotante, no caso em questão o governo, com o intuito de criar valor público. Ressalta-se que não se leva em consideração se a ideia é 
realmente nova do ponto de vista se foi preliminarmente descoberta ou utilizada, mas a percepção do novo e a reação a essa novidade.

\subsubsection{Modelos de inovação no setor público}

A partir da década de 1990, a mudança de contexto e a emergência de novas abordagens e modelos para a análise da inovação também tiveram como consequência a criação, a revisão e a atualização dos instrumentos internacionais de mensuração e análise das atividades de inovação. A intensidade e frequência de criação e atualizações dessa produção geraram uma grande proliferação de modelos de análise, mas também são reveladoras da necessidade de entendimento sobre as novas abordagens da inovação (Adams, Bessant, \& Phelps, 2006; APSII, 2011; Saunila \& Ukko, 2012).

Nesse contexto, surgiram abordagens sistematizadas e modelos que podem medir a eficiência e efetividade dos sistemas de inovação, com vistas a alcançar maior compreensão de sua dinâmica e construir indicadores capazes de fornecer um panorama das demandas e os fatores que influenciaram essas inovações.

O setor público não difere desse contexto e a revisão de literatura desenvolvida apontou um conjunto de pesquisas e instituições que investigaram o fenômeno da inovação nesse setor, porém dentre todos os estudos analisados, foram selecionadas as pesquisas desenvolvidas pelos autores De Vries, Bekkers e Tummers (2015) e Bloch et al. (2009), por apresentarem maior aderência ao lócus e ao fenômeno investigado neste trabalho.

Bloch et al. (2009) desenvolveram um framework como base para medição da inovação em organizações públicas em nível organizacional, o qual se adequa à realidade do MS, está ilustrado na Figura 1, e, portanto, encontra-se focado em elementos fundamentais das atividades de inovação nesse contexto. 
Esse modelo possui cinco elementos principais: entradas para a inovação, processos de inovação dentro da organização, saídas do processo de inovação, resultados gerais da inovação e fatores externos ou condições estruturais que afetam a inovação em organizações do setor público (Bloch et al., 2009).

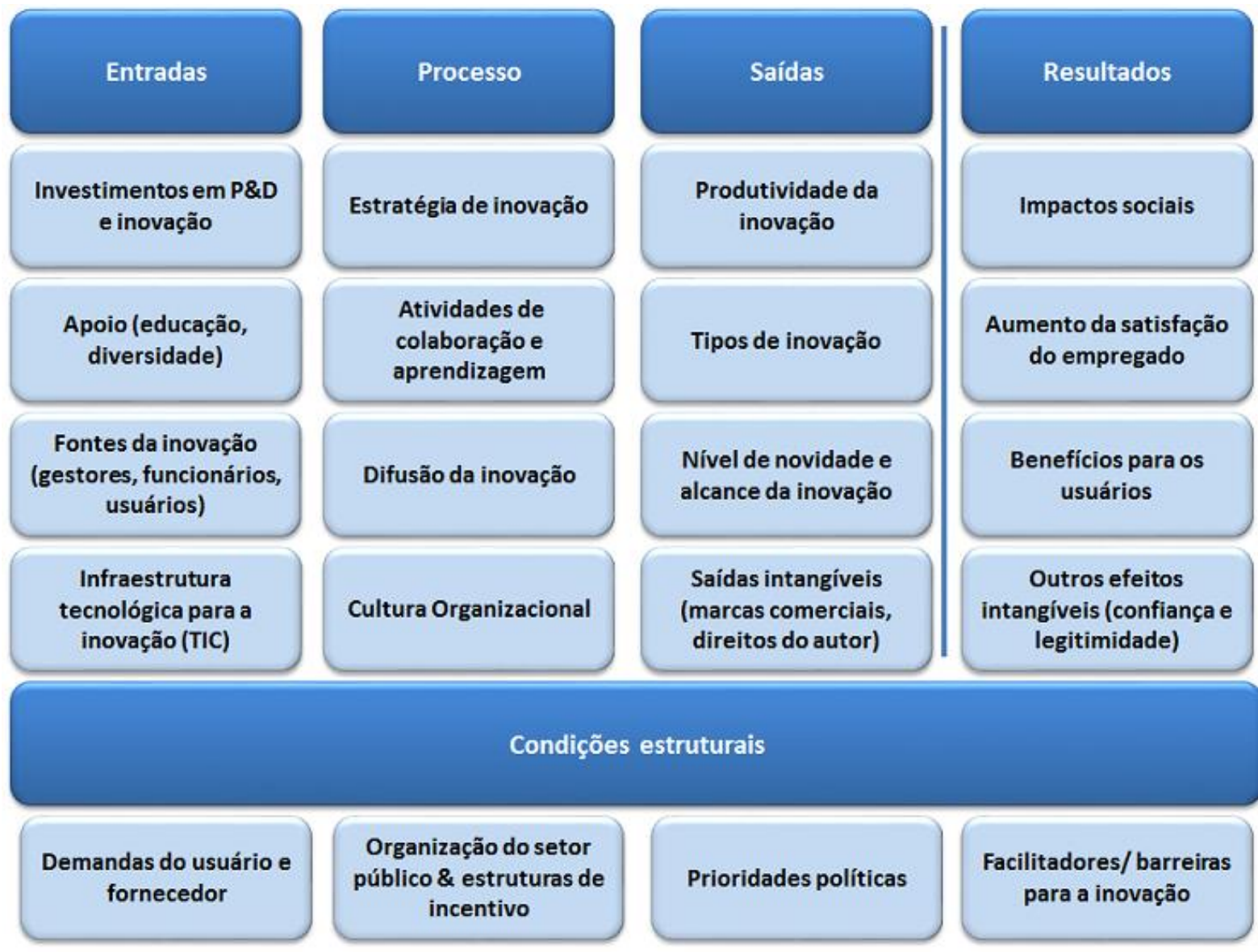

Figura 1 - Modelo de inovação no setor público proposto por Bloch et al. (2009)

Fonte: Elaborada pela autora, adaptado de Bloch et al. (2009).

Dentre os cinco elementos listados por Bloch et al. (2009) no referido modelo, as entradas para o processo de inovação em uma organização do setor público incluem os investimentos da organização em matéria de investigação, desenvolvimento e inovação, tais como compras de conhecimento de consultores ou despesas salariais e de formação de pessoal que trabalham com inovação.

O segundo elemento no modelo lida com o processo de inovação propriamente dito em organizações do setor público, ou seja, como a organização formulou uma estratégia dessa 
inovação explícita e envolveu esforços sistemáticos, no sentido de promover e avaliar os esforços para criação de incentivos adequados para tal dentro da organização.

Quanto aos elementos de saída, estes podem ser definidos como os bens, serviços ou outras atividades entregues pelas organizações do setor público, e apresentam como saída principal as próprias inovações - execução efetiva das mudanças nos serviços ou em outras partes das operações da organização pública.

Já os elementos resultados, são aqueles que apresentam os efeitos ou consequências finais resultantes das atividades das organizações do serviço público. E por fim, os principais fatores externos ou condições estruturais que afetam as organizações do setor público no que tange à inovação são: a estrutura geral dessas organizações, incentivo que a organização recebe para inovar, a influência política e as necessidades dos fornecedores e usuários.

A Tabela 4 consolida os principais conceitos, categorias, variáveis propostas por Bloch et al. (2009) e Bloch (2011), como resultado de suas análises referentes à inovação no setor público. 
Tabela 4 - Sistematização da definição, categorias, descrição e variáveis propostas por Bloch (2011) e Bloch et al. (2009) sobre inovação no setor público

\begin{tabular}{|c|c|c|c|}
\hline Definição de inovação & Dimensão & Descrição & Variável \\
\hline \multirow{6}{*}{$\begin{array}{l}\text { Inovação no setor público é a } \\
\text { implementação de uma significativa } \\
\text { mudança na forma da organização } \\
\text { pública operar ou de fornecer seus } \\
\text { produtos }\end{array}$} & Tipos de inovação & $\begin{array}{l}\text { São relacionados com a classificação das atividades de } \\
\text { inovação, baseadas no Manual de Oslo, e adaptadas ao } \\
\text { setor público }\end{array}$ & $\begin{array}{l}\text { Produto } \\
\text { Processo } \\
\text { Organizacional } \\
\text { Comunicação }\end{array}$ \\
\hline & Entradas para inovação & $\begin{array}{l}\text { São os fatores que levam à inovação e podem resultar } \\
\text { de uma variedade de meios numa organização pública }\end{array}$ & $\begin{array}{l}\text { Investimento em Pesquisa \& Desenvolvimento e Inovação } \\
\text { Apoio (educação, diversidade) } \\
\text { Fontes de inovação (gestores, funcionários, usuários) } \\
\text { Infraestrutura Tecnológica para Inovação (TIC) } \\
\text { Estratégia para inovacão }\end{array}$ \\
\hline & Processo de inovação & $\begin{array}{l}\text { Explicita como ocorre o processo de inovação na } \\
\text { organização pública }\end{array}$ & $\begin{array}{l}\text { Colaboração e atividades de aprendizagem } \\
\text { Difusão da inovação } \\
\text { Cultura organizacional }\end{array}$ \\
\hline & Saídas da inovação & $\begin{array}{l}\text { São os bens, serviços ou outras atividades entregues } \\
\text { pela organização pública que inova }\end{array}$ & $\begin{array}{l}\text { Produtividade da inovação } \\
\text { Tipos de inovação } \\
\text { Nível de novidade e alcance da inovação } \\
\text { Saídas intangíveis (marcas comerciais, direitos do autor) }\end{array}$ \\
\hline & Resultados da inovação & $\begin{array}{l}\text { Estão relacionados com os resultados mais amplos das } \\
\text { atividades das organizações do setor público que } \\
\text { inovam }\end{array}$ & $\begin{array}{l}\text { Impactos sociais } \\
\text { Melhoria para o empregado } \\
\text { Benefício para os usuários } \\
\text { Outros efeitos intangíveis (confiança, legitimidade) }\end{array}$ \\
\hline & Condições estruturais & $\begin{array}{l}\text { São os fatores ou condições externas que influenciamo } \\
\text { processo e os resultados de uma organização pública } \\
\text { inovadora }\end{array}$ & $\begin{array}{l}\text { Demandas dos usuários e fornecedores } \\
\text { Organização do setor público \& estruturas de incentivo } \\
\text { Prioridades políticas } \\
\text { Facilitadores e barreiras para inovação }\end{array}$ \\
\hline
\end{tabular}

Fonte: Elaborada pela autora.

Em consonância com a necessidade de analisar a inovação no setor público, De Vries, Bekkers e Tummers (2015) desenvolveram um modelo que consolidou uma revisão de literatura sistemática de 181 artigos e livros que tratam de inovação nesse setor. A partir dessa revisão, os autores apresentaram um modelo heurístico, que relaciona os fatores influentes e antecedentes, tipos e características, bem como os resultados da inovação no setor público, os quais se apresentam na Figura 2. 


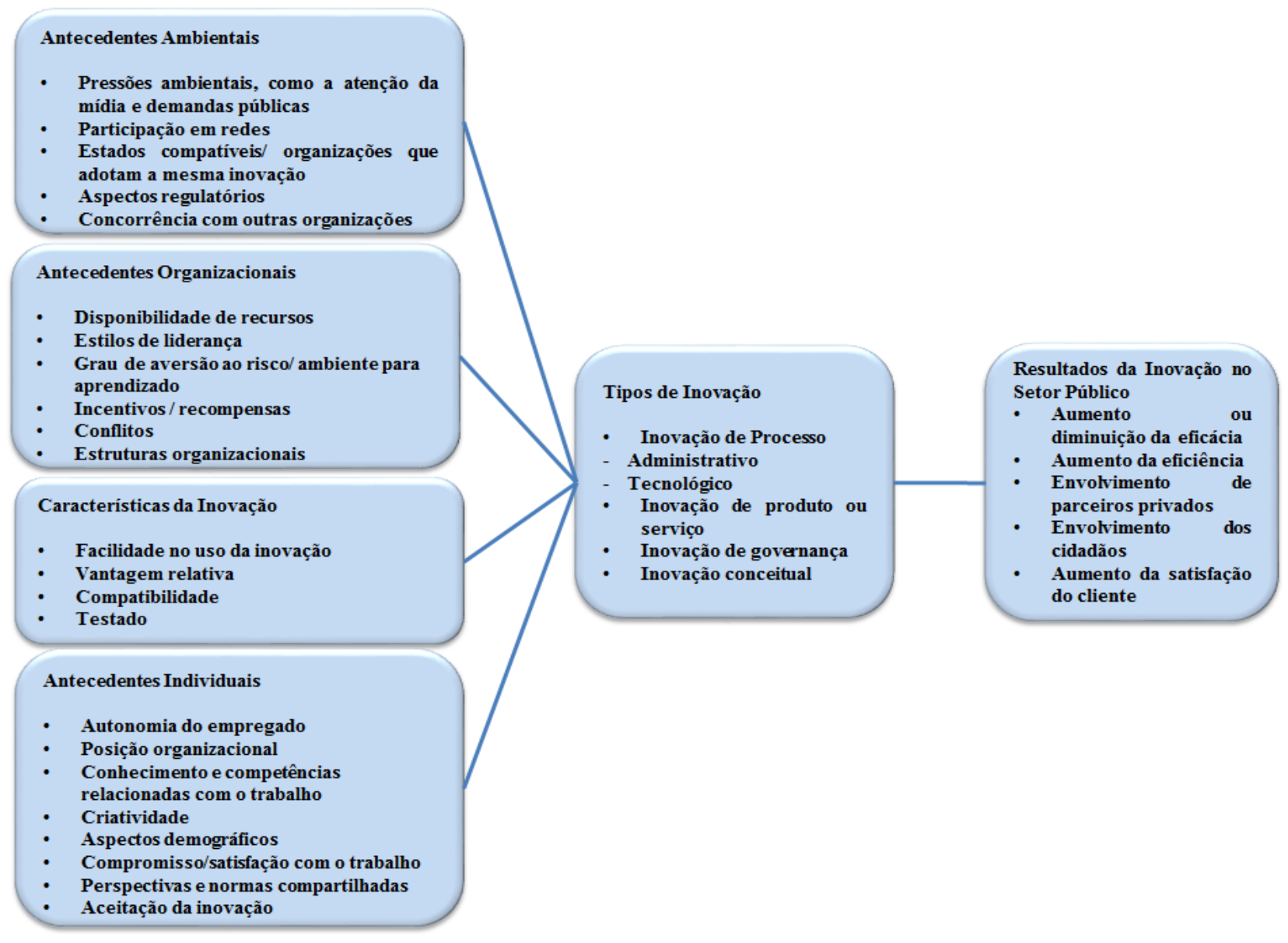

Figura 2 - Modelo heurístico da inovação no setor público proposto por De Vries, Bekkers e Tummers (2015)

Fonte: Elaborada pela autora, adaptado de De Vries, Bekkers e Tummers (2015).

No modelo proposto, as variáveis que antecedem o processo de inovação foram divididas em quatro categorias principais: nível ambiental, que aborda o contexto externo e específico da organização; nível organizacional, que relaciona os aspectos estruturais e culturais da organização; nível de inovação, que apresenta os aspectos intrínsecos da inovação; e por fim, nível individual ou do empregado, que relaciona as principais características dos indivíduos que inovam.

Quanto às variáveis tipos de inovação, estas são necessárias para entender o comportamento das organizações que inovam, pois elas têm diferentes características e ao adotarem essas inovações, essas organizações não são afetadas da maneira idêntica. Para esses 
autores, os principais tipos de inovação são: processo, que se subdivide em administrativo e tecnológico; produto ou serviço; governança e conceitual.

As inovações de processo têm como objetivo a aumento da qualidade e eficiência dos processos internos ou externos. Essas inovações foram subdivididas em inovações de processo administrativo, que consistem na criação de uma nova forma organizacional, novos métodos de trabalho e técnicas de gerenciamento; e em inovações de processo tecnológico, as quais apresentam criação ou uso de novas tecnologias, introduzidas numa organização para ofertar serviços para usuários e cidadãos.

As inovações de produto ou serviço consistem na criação de novos serviços ou produtos públicos. Já as inovações de governança estão relacionadas com o desenvolvimento de novas formas e processos para atender problemas sociais específicos. E por fim, as inovações conceituais introduzem novos conceitos, estruturas de referência ou novos paradigmas, que ajudam a reformular a natureza dos problemas específicos, bem com as possíveis soluções.

Ao final, apresentam-se os principais resultados das inovações, que segundo De Vries, Bekkers e Tummers (2015), são definidos como os resultados substantivos da implementação de uma inovação que podem ser intencionais, não intencionais, positivos e negativos. Os principais tipos de resultados relatados são: aumento ou diminuição da eficácia, aumento da eficiência, envolvimento de parceiros privados, aumento da satisfação do cliente, envolvimento dos cidadãos e outros (segurança, justiça).

A Tabela 5 consolida os principais conceitos, categorias e variáveis desenvolvidas por De Vries, Bekkers e Tummers (2015) na revisão sistemática de literatura sobre inovação no setor público. 
Tabela 5 - Sistematização da definição, categorias, descrição e variáveis propostas por De Vries, Bekkers e Tummers (2015) sobre inovação no setor público

\begin{tabular}{|c|c|c|c|}
\hline Definição de inovação & Categoria & Descrição & Variável \\
\hline \multirow{24}{*}{$\begin{array}{l}\text { Inovação no setor público é compreendida } \\
\text { como uma ideia, prática ou objeto que é } \\
\text { entendido como novo para a unidade } \\
\text { adotante, como objetivo de criar valor } \\
\text { público }\end{array}$} & \multirow{5}{*}{ Antecedentes ambientais } & \multirow{5}{*}{$\begin{array}{l}\text { Relacionados com o contexto que a } \\
\text { organização pública opera para inovar }\end{array}$} & $\begin{array}{l}\text { Pressões ambientais, como a atenção da mídia e } \\
\text { demandas públicas }\end{array}$ \\
\hline & & & Participação em redes \\
\hline & & & $\begin{array}{l}\text { Estados compatíveis/organizações que adotam a } \\
\text { mesma inovação }\end{array}$ \\
\hline & & & Aspectos regulatórios \\
\hline & & & Concorrência com outras organizações \\
\hline & \multirow{5}{*}{$\begin{array}{l}\text { Antecedentes } \\
\text { organizacionais }\end{array}$} & \multirow{5}{*}{$\begin{array}{l}\text { Relacionados com os aspectos que } \\
\text { incluem as características e estrutura } \\
\text { da organização pública que inova }\end{array}$} & Disponibilidade de recursos \\
\hline & & & Estilos de liderança \\
\hline & & & $\begin{array}{l}\text { Grau de aversão ao risco/ambiente para aprendizado } \\
\text { Incentivos/recompensas }\end{array}$ \\
\hline & & & Conflitos \\
\hline & & & Estruturas organizacionais \\
\hline & \multirow{4}{*}{ Características da inovação } & \multirow{4}{*}{$\begin{array}{l}\text { Relacionadas com os atributos } \\
\text { intrínsecos da inovação }\end{array}$} & Facilidade no uso da inovação \\
\hline & & & Vantagem relativa \\
\hline & & & Compatibilidade \\
\hline & & & Testado \\
\hline & \multirow{8}{*}{ Antecedentes individuais } & \multirow{8}{*}{$\begin{array}{l}\text { Relacionados com as características } \\
\text { dos indivíduos que inovam }\end{array}$} & Autonomia do empregado \\
\hline & & & Posição organizacional \\
\hline & & & $\begin{array}{l}\text { Conhecimento e competências relacionadas com o } \\
\text { trabalho }\end{array}$ \\
\hline & & & Criatividade \\
\hline & & & Aspectos demográficos \\
\hline & & & Compromisso/satisfação como trabalho \\
\hline & & & Perspectivas e normas compartilhadas \\
\hline & & & Aceitação da inovação \\
\hline & Tipos de inovação & $\begin{array}{l}\text { Relacionados com a compreensão do } \\
\text { comportamento das organizações } \\
\text { públicas que inovam, em função das } \\
\text { mesmas apresentarem diferentes } \\
\text { características e não são afetadas de } \\
\text { maneira idêntica }\end{array}$ & $\begin{array}{l}\text { Processo: administrativo ou tecnológico } \\
\text { Produto ou serviço } \\
\text { Governança } \\
\text { Conceitual }\end{array}$ \\
\hline & Resultados da inovação & $\begin{array}{l}\text { Relacionados com os resultados } \\
\text { substantivos da implementação de } \\
\text { uma inovação, que podem ser } \\
\text { intencionais, não intencionais, } \\
\text { positivos ou negativos }\end{array}$ & $\begin{array}{l}\text { Aumento ou diminuição da eficácia } \\
\text { Aumento da eficiência } \\
\text { Envolvimento de parceiros privados } \\
\text { Envolvimento dos cidadãos } \\
\text { Aumento de satisfação do cliente }\end{array}$ \\
\hline
\end{tabular}

Fonte: Elaborada pela autora.

A partir da análise de conteúdo realizada sobre as proposições dos modelos escolhidos, seguem na Figura 3 as categorias consideradas significativas para a análise da inovação no contexto do setor público que serão objeto de estudo dessa pesquisa, tais como: antecedentes e condições estruturais para a inovação, que são proveniente das dimensões antecedentes ambientais, organizacionais e individuais propostas por De Vries, Bekkers e Tummers (2015) e das dimensões entradas e condições estruturais para a inovação propostas por Bloch et al. (2009); processo de inovação, oriunda da dimensão processo do modelo de Bloch et al (2009); saídas da inovação e seus tipos principais, propostos pelos supracitados 
autores; resultados da inovação, também relacionados nos dois modelos escolhidos; conceito de inovação elaborado por Rogers (2003), De Vries, Bekkers e Tummers (2015 e Bloch et al. (2009); e por fim, características da inovação, propostas por De Vries, Bekkers e Tummers (2015).

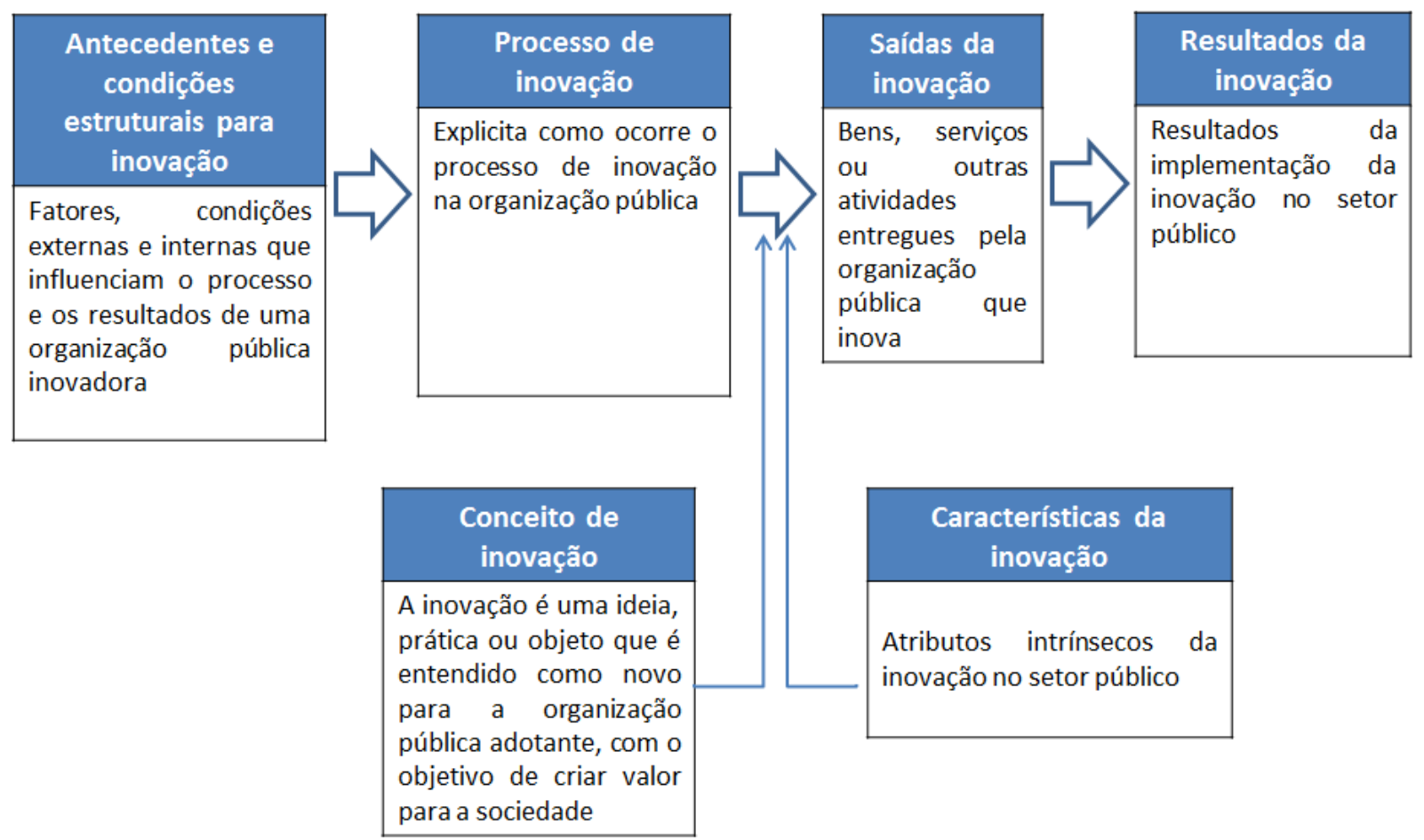

Figura 3 - Modelo para análise da inovação no setor público

Fonte: Elaborada pela autora, adaptado de De Vries, Bekkers e Tummers (2015), Bloch et al. (2009) e Rogers (2003).

Ademais, observou-se que a definição de inovação revela aspectos em comum nos supracitados autores, bem como algumas categorias se apresentam de forma semelhante, tais como: resultados da inovação; tipos de inovação; condições estruturais para a inovação; antecedentes da inovação; e, entradas para a inovação.

\subsubsection{Indicadores de inovação no setor público}

Apesar do desenvolvimento e da utilização de indicadores serem considerados como uma importante ferramenta para análise e interpretação de uma determinada realidade, 
verificam-se controvérsias na mensuração do desempenho no contexto do setor público (Federal, 2010).

O conceito de desempenho no setor público pode ser direcionado sob o enfoque organizacional, e, portanto, nesse trabalho será entendido por esforços empreendidos na direção de resultados a serem alcançados, os quais refletem o atendimento às necessidades dos stakeholders da organização: servidores, usuários dos serviços, fornecedores, sociedade e governo (Donaldson \& Preston, 1995; Federal, 2010).

Decorre daí que a medição de desempenho não se limita a apurar, por meio de indicadores, valores de medidas ou esforços de resultados, mas trata-se de uma mensuração agregada e ponderada que permitirá a geração de uma medida síntese de desempenho (Federal, 2010).

Os indicadores podem ser definidos como instrumentos de gestão essenciais nas atividades de monitoramento e avaliação da organização, e possuem duas funções principais: i) descrever por meio da geração de informações o comportamento dos acontecimentos; e, ii) atribuir um caráter valorativo que consiste em analisar as informações presentes com base nas anteriores (Federal, 2010).

Em consonância com o papel que a medição de desempenho passa a ter no setor público, com vistas a um aumento e produtividade das instituições públicas e aperfeiçoamento dos produtos e/ou serviços a serem entregues à população, nos últimos anos apresentou-se um crescente interesse em conceituar e medir a inovação no setor público de forma mais útil e menos complexa (Bloch et al., 2009; Bloch, 2011; Kattel et al., 2013).

Kattel et al. (2013) apontam que os primeiros esforços para medir a inovação ocorreram na iniciativa privada em 1933 e a medição nesse setor tem se desenvolvido no sentido de abordagens multidisciplinares e interdisciplinares, enquanto o impacto na produtividade é o aspecto fundamental estudado. No âmbito do setor público, vê-se uma 
tendência para enfatizar a produtividade, as despesas como $\mathrm{P} \& \mathrm{D}$, em relação ao $\mathrm{PIB}$, ou rankings com vários índices de mensuração de desempenho.

Além dessas tendências, no setor público, algumas iniciativas de mensuração vêm sendo desenvolvidas e nesse sentido destacam-se as Community Innovation Surveys (CIS), que consistem numa série de pesquisas realizadas pelos institutos nacionais de estatística em toda a União Europeia e têm como objetivo maior fornecer informações e dados sobre a inovação dos diferentes setores e regiões.

Apesar desses esforços, observa-se uma complexidade no desenvolvimento de indicadores para mensurar a inovação no setor público e essa se estende aos indicadores de resultados da inovação, ou seja, os impactos dessa inovação no desempenho da organização adotante (Bloch, 2011; Bugge, Mortensen, \& Bloch, 2011; Hughes, Moore, \& Kataria, 2011).

Para Bloch et al. (2009), um dos principais resultados esperados da inovação no setor público é a melhoria na entrega e/ou na qualidade dos serviços públicos e os principais resultados apontados por eles são: impactos sociais; melhoria para o empregado; benefícios para os usuários; e, outros efeitos intangíveis, tais como confiança e legitimidade.

Esses autores ressaltam que muitos conceitos de inovação são complexos de serem medidos e isso resulta em dois tipos de medidas: indicadores de inovação, os quais são baseados em dados diretamente coletados da organização; e por meio de questionários que abordem os conceitos através de perguntas aos stakeholders envolvidos com a inovação.

Em consonância com esse entendimento, De Vries, Bekkers e Tummers (2015) definem resultados de uma inovação como os resultados substantivos da implementação de uma inovação, e, a partir dessa definição, observa-se que os resultados da adoção da inovação no setor público são muito difusos e multifacetados em razão da variedade de objetivos e desafios que as organizações públicas vêm assumindo nos últimos anos. 
Outrossim, esses autores apontam na revisão de literatura realizada que a inovação se apresenta como um valor em si mesma e, por isso, os principais resultados encontrados são: o aumento ou diminuição da eficácia; o aumento da eficiência; o envolvimento dos parceiros privados; envolvimento dos cidadãos; o aumento da satisfação do cliente; e outros (segurança, justiça).

Contudo, o conhecimento sobre o desempenho do setor público e a forma como a inovação está relacionada com o desempenho é importante tanto para a compreensão da inovação, como para o desenvolvimento e avaliação de políticas públicas (Resende Junior, Guimarães, \& Bilhim, 2013). Portanto, apesar dos indicadores de inovação serem poucos explorados, faz-se necessário prosseguir nesta área de medição, mesmo com ciência de suas limitações. 


\section{MÉTODO}

Quanto aos meios de investigação, a pesquisa é considerada de campo, onde se realizou uma investigação empírica no local onde ocorreram os fenômenos inovativos ou que dispõe de elementos para explicá-los, no caso em tela o MS, seu departamento de compras de medicamentos e insumos para a saúde, o DLOG, e a inovação adotada pelo mesmo com o intuito de melhor gerir as suas atividades (Vergara, 2000).

A pesquisa adotou abordagens qualitativa e quantitativa, por meio de estudo exploratório e descritivo e com recorte temporal transversal. As duas abordagens utilizadas são justificadas pela possibilidade de usufruir da riqueza metodológica que advém da conciliação de dois métodos e como meio de proporcionar complementariedade nos meios para se analisar determinado fenômeno (Martin, 1990).

Dessa forma, a pesquisa foi conduzida em três etapas: a investigação documental e revisão da literatura; o desenvolvimento, o qual foi realizado através da construção do roteiro para realização dos grupos focais, desenvolvimento de questionário, sua validação e proposição de indicadores da inovação; e, por fim, a análise dos dados obtidos com a aplicação dos instrumentos desenvolvidos que empregou análise de conteúdo, métodos inferenciais estatísticos e levantamento de dados secundários.

Para a realização do estudo de caso no MS, foi desenvolvido um protocolo do estudo de caso, que segundo Yin (2015), é o conjunto de procedimentos e regras gerais a serem seguidas para a realização de um estudo de caso, o qual é uma técnica que busca examinar o fenômeno da inovação nas compras governamentais de medicamentos dentro do seu contexto, através da observação dos fatos exatamente como ocorrem no real. Assim, o protocolo elaborado contém quatro seções que seguem de acordo com Tabela 6. 
Tabela 6 - Protocolo do estudo de caso, conforme Yin (2015)

Etapas do Protocolo do Estudo de Caso

\section{A) Visão geral do estudo de caso}

Ver seção introdução, com ênfase nos itens 1.1, 1.2 e 1.3.

Ver Carta de Apresentação no apêndice A.

B) Procedimentos de coleta de dados

Ver item 3.1 da seção método.

C) Questões do estudo de caso

Ver apêndices B e G, com os instrumentos para coleta de dados.

D) Guia para o relatório do estudo de caso

Relatório técnico para o MS contendo cerca de $10 \%$ das páginas da dissertação e com foco nos resultados do estudo.

Fonte: Elaborada pela autora.

\subsection{PROCEDIMENTOS DE COLETA DE DADOS}

A investigação documental foi realizada em documentos, tais como regimentos, manuais de planejamento e de processos, bases de dados do Governo Federal relativas às compras governamentais de medicamentos, dados dos processos de compra obtidos através do PEC, relatórios de gestão e dos órgãos de controle, ligados ao MS e ao DLOG. Já a revisão de literatura, refere-se à coleta, leitura e interpretação de livros e artigos científicos sobre compras governamentais, compras governamentais de medicamentos e as políticas do MS que tratam de medicamentos, inovação no setor público, modelos que analisam a inovação no setor público e os indicadores de inovação no setor público.

Quanto ao desenvolvimento, para identificação dos atributos e das práticas de inovação nas compras governamentais, foi realizado um grupo focal, cuja amostra estava composta por gestores e servidores que atuam como chefes de divisão do Departamento e usuários da inovação dentro do MS. Essa primeira amostra apresentou os atores incumbidos de formular as diretrizes e implementar as ações das inovações no DLOG, assim como realizam a gestão e o acompanhamento dos projetos e programas envolvidos com a política de compras do MS, dentro do SUS. 
Para ratificar esses atributos e práticas, realizou-se outro grupo focal com os usuários da inovação dentro do MS. Gatti (2005) corrobora com a importância do grupo focal quando afirma que essa técnica é utilizada para identificar percepções, sentimentos, atitudes e ideias dos participantes a respeito de um determinado assunto, produto ou atividade, além de possibilitar ao pesquisador a apreensão de como os participantes interpretam a realidade, seus conhecimentos e experiências.

Com relação aos roteiros dos grupos focais, decidiu-se pela não realização de uma validação semântica e quanto ao conteúdo, uma vez que o instrumento criado para a análise da percepção dos gestores e usuários da inovação no MS foi aplicado de forma presencial pela pesquisadora, que se encontrava disponível para o esclarecimento de dúvidas durante a aplicação, minimizando, com isso, erros relacionados à falta de compreensão das questões por parte dos entrevistados.

Com base na análise documental, revisão de literatura e grupos focais, desenvolveu-se um questionário que proporcionou o levantamento dos dados sobre a percepção dos gestores e servidores do MS, envolvidos com o processo de compra e que utilizam a inovação nos seus processos de trabalho. Este instrumento de coleta foi validado por juízes especialistas em inovação, através do método de Coeficiente de Validação de Conteúdo (CVC) e validação semântica, pois se fez necessária uma avaliação das questões a serem aplicadas nos âmbitos teórico, prático e quanto à clareza de linguagem.

Posteriormente, a partir da revisão de literatura e análise documental, levantaram-se os parâmetros e dados para elaboração dos indicadores de inovação nas compras governamentais, com o objetivo de mensurar os resultados referentes às atividades e processos antes e após a adoção da inovação no MS. 


\subsection{PROCEDIMENTOS DE ANÁLISE DE DADOS}

A análise dos dados da etapa qualitativa dessa pesquisa se baseou na análise de conteúdo proposta por Bardin (2011), que se caracteriza por um conjunto de instrumentos metodológicos e se aplicam a discursos extremamente diversificados.

Para essa autora, a transformação dos dados coletados, ainda no seu estado bruto, em resultados de pesquisa, envolveu a utilização de determinados procedimentos para sistematizar, categorizar e tornar possível sua análise por parte do pesquisador. No caso em questão, utilizou-se da técnica de análise categorial, a partir da triangulação da análise documental; revisão de literatura dos principais conceitos e tipos de inovação no setor público, bem como os elementos dos modelos de inovação no setor público dos autores Bloch et al. (2009) e De Vries, Bekkers e Tummers (2015), escolhidos por melhor aderência ao fenômeno investigado (Capelle, Melo, \& Gonçalves, 2011).

No caso específico da análise de comunicações, são exigidos mecanismos apropriados para encontrar em dados obtidos por meio de entrevistas, mensagens e documentos em geral, informações que ilustrem, expliquem ou ajudem a revelar os fenômenos investigados. Por esses motivos, transcreveu-se os áudios dos dois grupos focais com auxílio da ferramenta Express Scribe Transcription Software Pro. Na sequência, os dados dos grupos focais transcritos foram analisados com a utilização do software Atlas.ti7.

Sendo assim, na fase de pré-análise, foram definidos os documentos a serem submetidos à análise e formulados objetivos para fundamentação da interpretação final. Em seguida, com auxílio do software Atlas.ti7, foi realizada a exploração do material, por meio da efetivação de procedimentos de codificação e categorização. Ao final, na etapa de tratamento dos resultados obtidos e interpretação, foram trabalhados os dados de forma a serem categorizados, significativos e válidos para identificar as categorias e variáveis dos modelos escolhidos para análise da inovação nas compras governamentais do MS. 
Já os dados oriundos dos questionários foram analisados por métodos inferenciais estatísticos e análise multivariada de dados, especificamente através da estatística descritiva e Análise Fatorial Exploratória (AFE), os quais evidenciaram a percepção dos stakeholders relacionados com o fenômeno investigado e o padrão de correlações existentes entre as variáveis, bem como utiliza esses padrões de correlações para agrupar suas variáveis em fatores, os quais são considerados representantes de dimensões dentro dos dados. Para consecução de tais análises, foi utilizado o software SPSS.

A Figura 4 corresponde à representação do desenho da pesquisa. As atividades foram numeradas numa sequência e as setas representam o seu fluxo, bem como a relação entre os distintos processos.

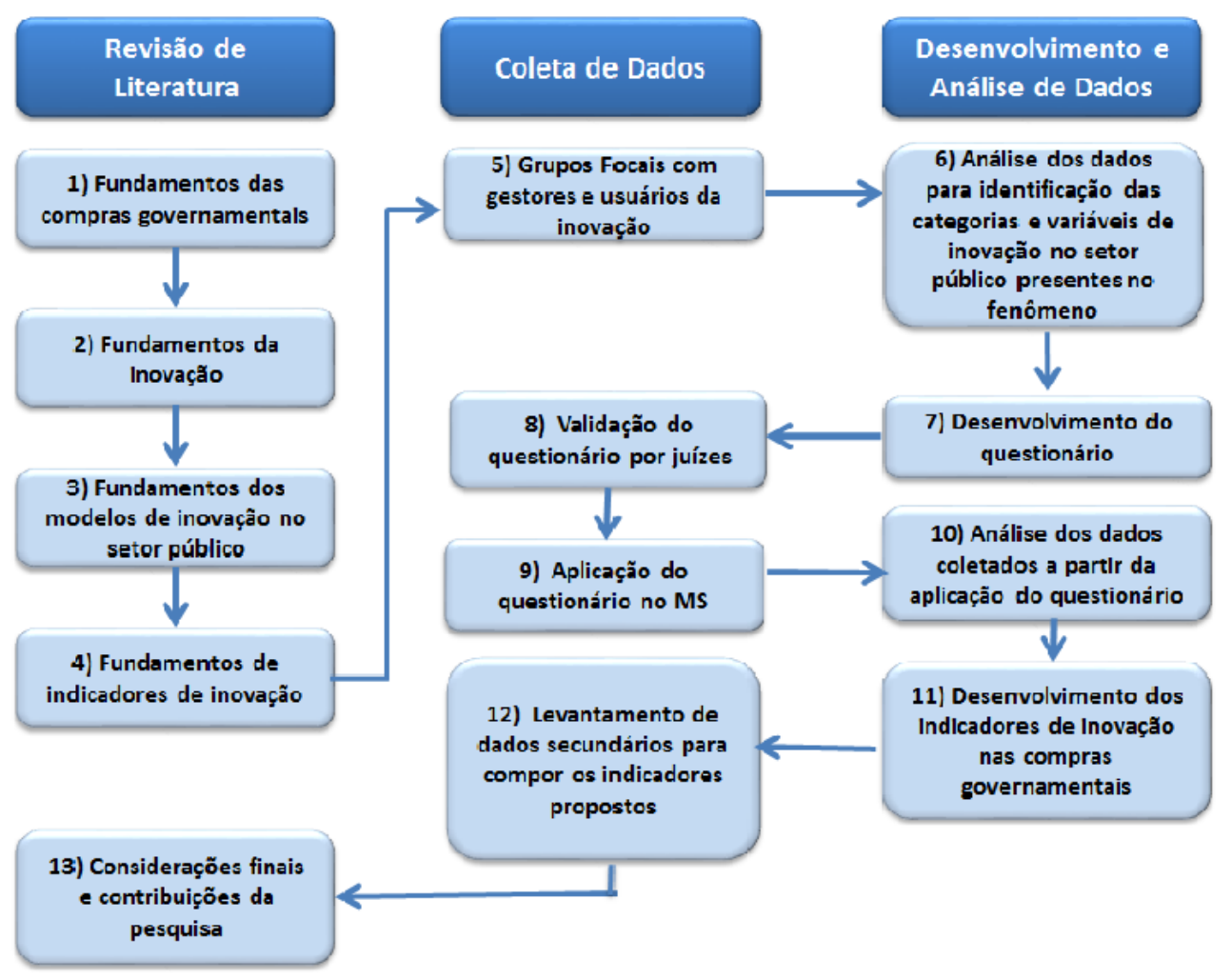

Figura 4 - Desenho da pesquisa

Fonte: Elaborada pela autora.

Quanto aos dados referentes aos indicadores de inovação propostos, os mesmos foram coletados através da análise documental em bases de dados e softwares do Governo Federal 
relativos às compras governamentais de medicamentos e nos dados dos processos de compra obtidos através da própria inovação adotada, no caso em questão o PEC. 


\section{ANÁLISE DE DADOS}

Nesta seção serão apresentados e discutidos os resultados dos estudos qualitativos e quantitativos realizados na presente pesquisa, bem como da proposição e análise dos indicadores provenientes da análise documental.

\subsection{CARACTERIZAÇÃO DA INOVAÇÃO DESENVOLVIDA NO PROCESSO DE COMPRAS GOVERNAMENTAIS DE MEDICAMENTOS DO MS}

A análise documental realizada apontou que o PEC foi regulamentado pela Portaria ${ }^{\circ}$. 2.758, de 18 de novembro de 2013, e consiste num software que organiza um conjunto de documentos e atos processuais organicamente acumulados, de forma eletrônica, no curso do processo de compra de medicamentos e insumos para a saúde realizados pelo MS.

Dessa forma, o PEC foi pensado para incorporar os fluxos administrativos típicos de um processo licitatório desses insumos para a saúde, desde a fase inicial, que consiste na elaboração do termo de referência até a homologação do certame, de forma eletrônica. No primeiro momento, após a sua implementação, esses fluxos reproduziram as ações executadas nos processos físicos. Ao longo do tempo, foram realizadas alterações a fim de se obter melhorias e agregar valor aos procedimentos, de acordo com a necessidade dos gestores e mudanças na legislação vigente à época.

Baseado na revisão de literatura e definição de Rogers (2003), o PEC pode ser definido como uma inovação, pois consiste numa prática que é entendida como nova para a unidade adotante, no caso em questão o MS e o DLOG, com o objetivo de criar valor nas compras governamentais de medicamentos e insumos para a saúde. Ressalta-se que o PEC, quando implementado, não era uma prática completamente nova do ponto de vista de descoberta preliminar, uma vez que já havia sido implementada experiência semelhante no 
Grupo Hospitalar Conceição, mas a percepção do novo se apresenta, já que tornou eletrônica a instrução processual das compras em tramitação no Ministério.

Bloch (2011) e De Vries, Bekkers e Tummers (2015) ratificam esse entendimento quando definem que inovação no setor público é a implementação ou adoção de uma significativa mudança na forma de operar e deve ser nova para a organização, porém pode ter sido desenvolvida por outra organização, fato que ocorreu na adoção do PEC, por se tratar de uma experiência de sucesso em outra organização pública da área da saúde.

De acordo com Gallouj e Weinstein (1997), a referida inovação está classificada dentro do setor de serviços, no contexto do setor público, e se caracteriza como incremental, por se tratar de uma adoção da plataforma tecnológica Business Process Management (BPM), baseada nos fluxos de compras de medicamentos e insumos para a saúde do MS. Os fluxos, por sua vez, são formados por uma sequência de tarefas, as quais são as etapas do processo de compra executadas individualmente por um usuário interno do sistema, constituindo-se, dessa forma, em um procedimento que compõe a instrução processual da compra dos referidos insumos.

Decorre dos tipos de inovação propostos por De Vries, Bekkers e Tummers (2015) que o PEC se caracteriza como uma inovação de processo tecnológico, pois o mesmo consiste num sistema informatizado que reúne todos os documentos eletrônicos e atos processuais ocorridos no curso de um determinado fluxo aquisitivo de bens ou de serviços. Para os referidos autores, esse tipo de inovação ocorre quando há "criação ou uso de novas tecnologias, introduzidas na organização para prestação de serviços aos usuários e cidadãos”.

Além disso, baseado nos tipos de inovação propostos por esses autores, a inovação se classifica também como inovação de processo administrativo, já que se caracteriza pela criação de um novo método de trabalho nas compras do MS, que se obteve com a tramitação eletrônica dos processos de compras, ao reorganizar a produção documental, o trâmite, a 
consulta e o arquivamento de forma digital desses processos, antes formalizados unicamente em papel.

Já pela definição de Bloch (2011), o PEC se caracteriza como uma inovação de processo, a qual consiste na inserção de um método para a prestação de serviços que é novo ou significativamente melhorado em comparação com os processos existentes na organização. Esse método novo pode envolver melhorias em equipamentos e em funções de apoio, tais como utilização de tecnologias da informação, o que ocorreu no caso do fenômeno estudado, quando da implementação de um software para gerenciar eletronicamente os documentos e processos relativos às referidas compras.

No entanto, a inovação supracitada também pode ser classificada como organizacional dentro da definição de Bloch (2011), já que a mesma implementou um novo método de organizar e gerenciar o trabalho no âmbito das compras governamentais de medicamentos e insumos para a saúde dentro do MS e do DLOG, substituindo o processo físico em papel pelo processo eletrônico para a instrução processual das referidas compras.

Ressalta-se ainda que tanto De Vries, Bekkers e Tummers (2015) quanto Bloch (2011) reconhecem que, na prática, esses tipos de inovação são geralmente interligados e, portanto, criam formas híbridas como uma inovação de processo administrativo e tecnológico ou uma inovação organizacional de processo, a título de exemplos. Entretanto, essas classificações servem como ferramentas analíticas úteis sobre as diferentes formas de inovação no setor público.

\subsection{ANÁLISE DE DADOS OBTIDOS COM OS GRUPOS FOCAIS}

Para avaliar os dados de natureza qualitativa, foram feitas transcrições de todo o conteúdo do áudio das entrevistas realizadas nos grupos focais em maio e junho de 2016, com o auxílio da ferramenta Express Scribe Transcription Software Pro. 
A análise dos dados oriundos dos grupos focais baseou-se na análise de conteúdo proposta por Bardin (2011), que se caracteriza por um conjunto de instrumentos metodológicos e se aplicam a discursos extremamente diversificados. Para essa autora, a transformação dos dados coletados, ainda no seu estado bruto, em resultados de pesquisa, envolve a utilização de determinados procedimentos para sistematizar, categorizar e tornar possível sua análise por parte do pesquisador.

Para tal, os dados das entrevistas transcritas foram analisados com a utilização do software Atlas.ti7, o qual permitiu a exploração do material, por meio da efetivação de procedimentos de categorização. Ao final, na etapa de tratamento dos resultados obtidos e interpretação, foram trabalhados os dados de forma a serem categorizados, significativos e válidos para identificar as categorias e variáveis presentes e ausentes na inovação nas compras governamentais de medicamentos e outros insumos para a saúde do MS.

Para o desenvolvimento das categorias a serem analisadas, realizou-se uma triangulação entre a revisão de literatura, que se referiu à coleta, leitura e interpretação de livros e artigos científicos sobre compras governamentais, inovação no setor público, modelos de análise da inovação no setor público; e, a investigação documental, que foi realizada em documentos, tais como regimentos, manuais de planejamento, de processos e relatórios, ligados ao referido órgão e as áreas envolvidas com o processo de compra de medicamentos.

A partir dessa triangulação, o roteiro dos dois grupos focais baseou-se nas seguintes categorias principais: conceito de inovação; características da inovação; antecedentes e condições estruturais para a inovação; processo de inovação; saídas da inovação e seus principais tipos; e, por fim, resultados da inovação. As questões, categorias e as respectivas variáveis seguem sistematizadas na Tabela 7. 
Tabela 7 - Sistematização das questões, objetivos, dimensões e variáveis dos grupos focais

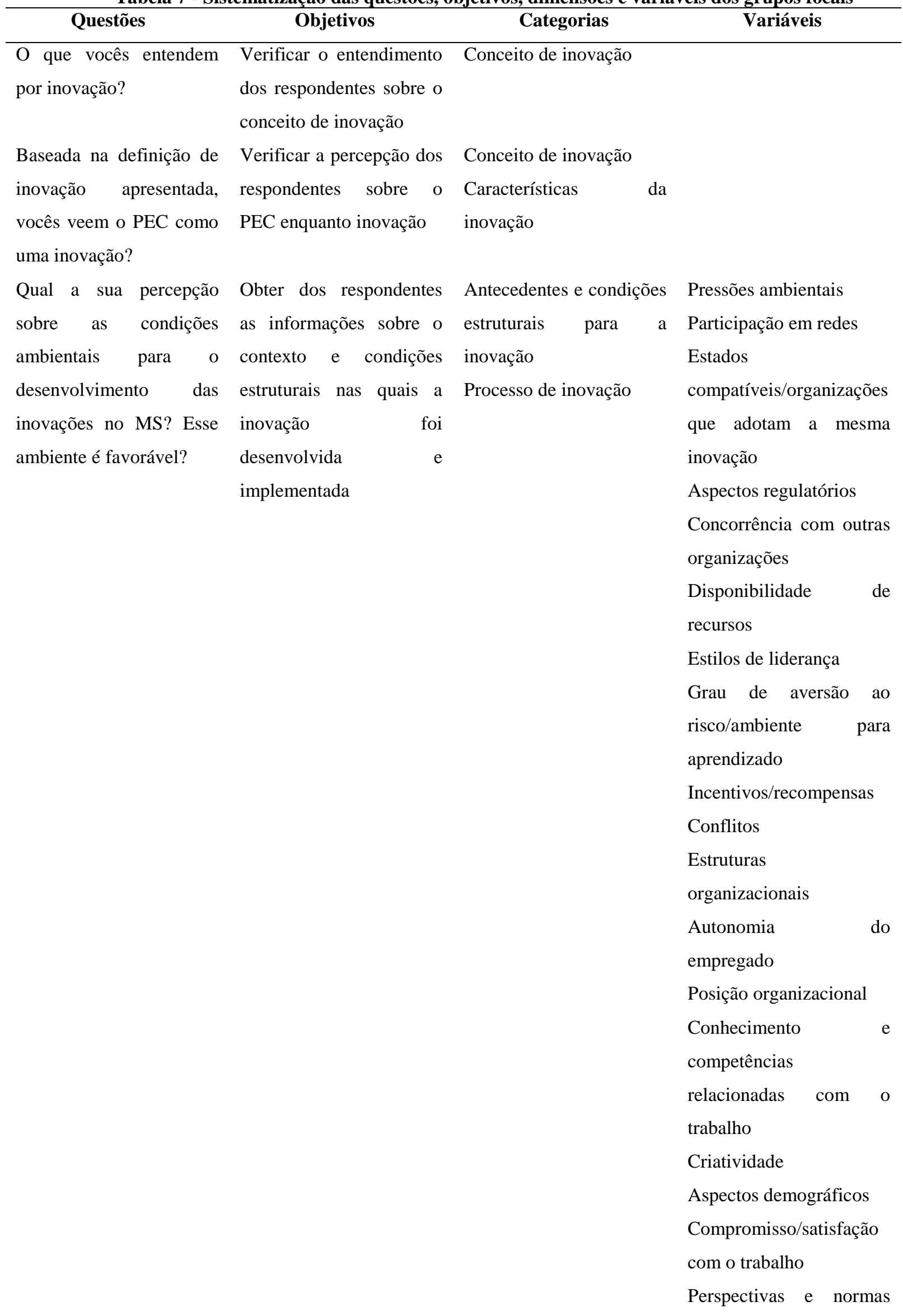




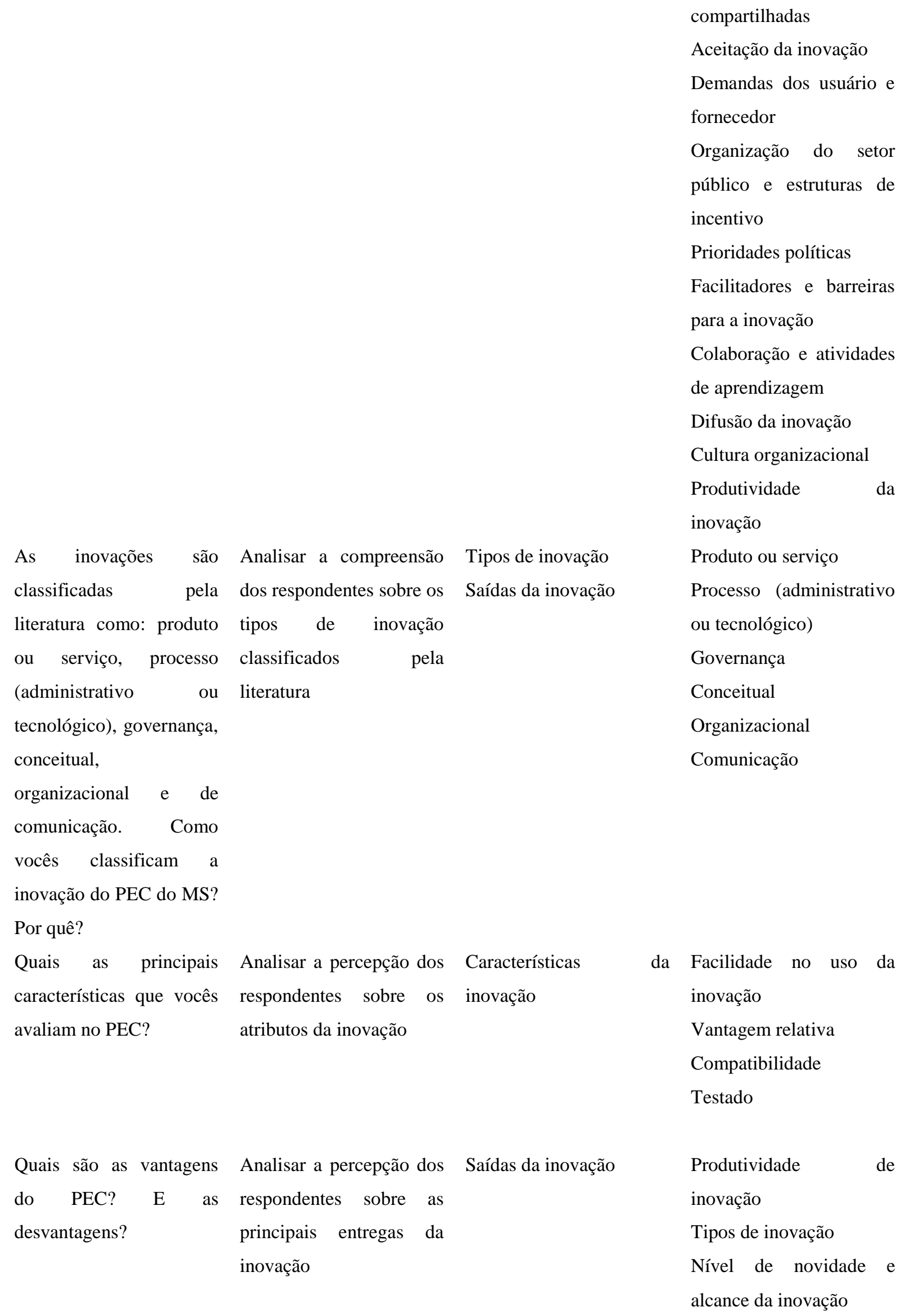




$\begin{array}{ll}\text { Quais os principais } & \text { Verificar a percepção dos } \\ \text { resultados que o PEC } & \text { respondentes sobre os } \\ \text { trouxe para o MS? } & \text { resultados que o PEC } \\ & \text { trouxe para os processos } \\ & \text { de compras do MS. }\end{array}$

Alguém prefere o Verificar a percepção dos processo de trabalho respondentes sobre os tradicional, com a fatores que levam às utilização do processo pessoas a utilizar ou não físico (papel)? Por quê? a inovação desenvolvida.
Saídas intangíveis

Resultados da inovação

Impactos sociais

Aumento da satisfação do empregado

Benefícios para os usuários

Outros efeitos intangíveis

Aumento ou diminuição

da eficácia

Aumento da eficiência

Envolvimento dos

parceiros privados

Envolvimento dos

cidadãos

Aumento da satisfação do

cliente

Resultados da inovação

Impactos sociais

Aumento da satisfação do

empregado

Benefícios para os usuários

Outros efeitos intangíveis Aumento ou diminuição da eficácia

Aumento da eficiência

Envolvimento dos

parceiros privados

Envolvimento dos

cidadãos

Aumento da satisfação do cliente

Fonte: Elaborada pela autora.

A partir dessa sistematização, foram definidos dois vetores, sendo que: (a) o vetor 1 corresponde às declarações dos gestores e usuários da inovação que refletem a presença das variáveis previamente identificadas pelos autores Bloch et al. (2009), Bloch (2011) e De Vries, Bekkers e Tummers (2015); enquanto no (b), o vetor 2, foram agrupadas declarações que indicam novas variáveis observadas no fenômeno de inovação do MS. 
Dessa forma, na seleção da amostra para esse grupo focal, buscou-se contemplar os gestores e servidores que atuam como chefes de divisão do DLOG, e são os atores incumbidos de formular as diretrizes e a gestão, bem como o acompanhamento dos projetos e programas envolvidos com a política de compras do MS, dentro do SUS, pressupondo-se que tais indivíduos deteriam visão sistêmica do rito e do PEC, sendo capazes de contribuições diversas sobre a inovação.

De um total de 12 gestores que atuam no DLOG e convidados a participarem do grupo focal, seis gestores, no total, compareceram. Essa técnica para coleta de dados foi realizada durante a primeira quinzena de maio de 2016, nas dependências do DLOG, no MS, em Brasília. O processo de coleta de dados contou com a permissão institucional do órgão, bem como com a permissão individual dos entrevistados, inclusive para a gravação. O critério empregado para a definição do número de participantes do grupo focal foi o de disponibilidade dos servidores, conforme agenda da organização.

A Tabela 8 apresenta os resultados sistematizados da análise de dados do grupo focal realizado com os gestores. Os números entre parênteses representam esses gestores, numerado de 1 a 6, os quais externaram ou verbalizaram concordância com as declarações transcritas. Em colchetes, foram indicados os autores e na sequência as variáveis identificadas na literatura pelos referidos autores, as quais cada uma das declarações destacadas se vincula. 
Tabela 8 - Resultados da análise de conteúdo referente à inovação nas compras governamentais de medicamentos do MS, segundo gestores do MS

O PEC trouxe uma redução de custos de protocolo, de cópias, pois antes com o processo físico aqui no Ministério tinha várias cópias do mesmo processo de compra em diferentes áreas. [De Vries et al. (2015) Vantagem relativa] [De Vries et al. (2015) Aumento da eficiência] [De Vries et al. (2015) Perspectivas e normas compartilhadas] [Bloch et al. (2009) - Produtividade da inovação] (1)

Eu acredito que o PEC é uma inovação, pois foi concebido para pegar os processos físicos, em papel, e transformá-los em processos eletrônicos. A partir do momento que você está fazendo aquilo de uma forma diferente, com mais celeridade, com redução de prazos, tentando reduzir o tempo da contratação, é uma inovação.

[De Vries et al. (2015) - Aumento da eficiência] [De Vries et al. (2015) - Aumento da eficácia] [ Bloch et al. (2009) - Produtividade da inovação] (2)

O PEC, enquanto inovação, está ligado com eficiência, melhoria. Nesse sentido, existe a inovação incremental e a de ruptura. A inovação incremental você vai melhorando aos poucos o seu dia-a-dia de trabalho, às vezes você nem percebe, mas você está melhorando o processo, está ganhando produtividade e melhorando os seus resultados. Às vezes nem sempre é um processo novo, mas você está melhorando o tempo, reduzindo a utilização de recursos.

[De Vries et al. (2015) - Aumento de eficiência] [De Vries et al. (2015) - Aumento de eficácia] [Bloch et al. (2009) - Produtividade da inovação] [Bloch et al. (2009) - Nível de novidade e alcance da inovação]

A inovação é a busca por fazer diferente alguma coisa que rotineiramente estava sendo realizada de
Eu acredito que o PEC é uma inovação dentro do setor público e do MS, já que objetiva reduzir o tempo da contratação, buscando transparência e segurança da informação.

[Transparência da informação] (2) (6)

Com o PEC, enfatiza-se a questão da sustentabilidade e ganho de produtividade, pois houve a redução do uso e custos com protocolo, papel e cópias. Antes aqui no Ministério você pegava um processo todo físico que tinha uma cópia no Departamento de Assistência Farmacêutica, pois lá estava o gestor do contrato; tinha outra cópia inteira na área demandante, e tinha várias outras cópias no DLOG. A tramitação do processo às vezes precisava ser feita de carro entre as sedes do MS. [Sustentabilidade] (1)

Quando você pensa no contexto da compra, além do ponto de vista da legalidade, está envolvida a transparência, a eficiência, só que hoje temos que levar em consideração também que o PEC nos gera uma questão de sustentabilidade. Um sistema bem construído, incorporando outros para ser apenas um, ele elimina papel de forma que o uso vai ser zero. E isso levando em consideração o contexto ambiental, junto com as outras preocupações de transparência e eficiência, tanto que os pilares do DLOG são: transparência, eficiência e legalidade. Então, atualmente os Órgãos de Controle vêm questionando muito os gestores, além dos fatores já citados, se de fato está utilizando algum método relacionado com a sustentabilidade nas compras, e o sistema gera isso de forma muito clara. [Sustentabilidade] [Transparência da informação] (3)

O fim maior disso tudo, a maior contribuição que a gente poderia ter para as compras governamentais, 
outra maneira ou a busca por outros resultados. Está ligada com eficiência, resultados e simplificação dos processos e pode ser incremental.

[De Vries et al. (2015) - Aumento da eficiência] [De Vries et al. (2015) - Aumento da eficácia] (2) (6)

Inovação é aquilo que foge do usual e com uma perspectiva de melhoria e a continuidade de algo que já existe, mas com a finalidade de mudança, em razão da sua simplicidade, da sua criatividade, mas algo que traga resultado, e o PEC trouxe isso. [De Vries et al. (2015) - Aumento da eficácia] [De Vries et al. (2015) - Criatividade] [De Vries et al. (2015) Facilidade no uso da inovação] [Bloch et al. (2009) Produtividade da inovação] [ Bloch et al. (2009) Benefícios para os usuários] (3)

Eu vejo a inovação como uma quebra de paradigma e isso significa que você vai para um patamar distinto e diferente do que você vivenciou. Eu estou numa rota e eu preciso seguir para algum ponto e se esse ponto nunca foi explorado antes, é um ponto novo. Inovar é caminhar rumo a um ponto ainda a se desbravar. Concordo que esteja ligada também a resultados. [De Vries et al. (2015) - Aumento da eficácia] (4)

Eu acho que inovação é renovar e está muito ligada à criatividade, pois para inovar você tem que ser muito criativo. Para inovar tem que trabalhar muito para aquilo, ver os pontos positivos e negativos, além de ter que trabalhar uma cultura muitas vezes, como foi feito com o PEC, acredito ser mais nesse sentido. Inovar é diferente de inventar, portanto nós inovamos com o PEC e não inventamos o PEC. [De Vries et al. (2015) - Criatividade] [Bloch et al. (2009) - Cultura organizacional] [Bloch et al. (2009) - Barreiras e facilitadores para a inovação] [Bloch et al. (2009) - Estratégia de inovação] (5) através do PEC, além da eficiência, é a questão da transparência. Para ter transparência, eu acho muito importante que os dados governamentais sejam abertos, e você colocar as coisas de forma eletrônica facilita que, no futuro, os dados das compras públicas sejam abertos. Eu acho que isso é uma inovação muito relevante. [Transparência da informação] (4)

Eu prefiro o PEC, e nós sentimos a diferença quando chega um processo físico alheio às atividades das compras do DLOG, pois nós já estamos tão acostumados com o eletrônico que eu nem lembro mais, pois não tem mais como pensar em pilhas e pilhas de papel, volumes e volumes para poder analisar, tramitar, e até a questão da transparência que a Lei de Acesso à Informação solicita que você disponibilize uma cópia de todo o processo e através do sistema a pessoa pode realizar vistas aos autos do processo de forma remota também. [Transparência da informação] 
Além do PEC ser uma inovação, ele proporcionou inovação de processos, pois a partir do momento que você tem todo o fluxo de compra e informação organizados, o DLOG conseguiu realizar atividades de avaliação, monitoramento, extrair dados confiáveis. A partir daí a gente conseguiu ter uma inovação gerencial também. Então, além de ele ser uma inovação, ele proporciona outros tipos de inovação para as nossas atividades diárias. [De Vries et al. (2015) - Aumento da eficácia] [De Vries et al. (2015) - Aumento da eficiência] [Bloch et al. (2009) - Benefícios para os usuários] [Bloch et al. (2009) Outros efeitos intangíveis (confiança)] (1) (6) De acordo com os conceitos de inovação trazidos pela literatura, o PEC é considerado uma inovação, pois você parte de um princípio de melhoria de um processo de compra, saindo do papelório; é uma mudança incremental, pois já existia uma base de compras e vislumbra logicamente a eficiência. [De Vries et al. (2015) - Aumento da eficiência] [De Vries et al. (2015) - Eficácia] [De Vries et al. (2015) - Vantagem relativa] (4)

O PEC foi um projeto que foi identificado um sistema próprio para essa área de compras, que já funcionava muito bem no Grupo Hospitalar Conceição todo e que era uma experiência de sucesso. Daí a gestora do DLOG na época, que já defendia tudo isso, foi lá conhecer e envolveu e Secretaria Executiva (SE), do MS, portanto não foi a $\mathrm{SE}$ que capitaneou isso. Ela envolveu a SE e disse que precisava de apoio, levando essa Secretaria para conhecer junto com ela a experiência, onde foram apresentados a solução e os resultados que o sistema poderia trazer ao DLOG. Então, além do DLOG, tinha a alta gestão do MS envolvida no projeto. Além disso, foi um processo muito participativo com todas as áreas do MS que utilizam o sistema. $\mathrm{Eu}$ acho que esses todos foram fatores que levaram ao sucesso do PEC no MS. [Bloch et al. (2009) - 
Fontes de inovação (Gestores)] [Bloch et al. (2009) Difusão da inovação] [Bloch et al. (2009) Organização do setor público e estrutura de incentivo] [Bloch et al. (2009) - Prioridades políticas] [De Vries et al. (2015) - Organizações compatíveis e adotando a mesma inovação] [Bloch et al. (2009) - Organização do setor público e estruturas de incentivo] [De Vries et al. (2015) Estilo de liderança] [De Vries et al. (2015) Compatibilidade] [Bloch et al. (2009) - Apoio] [De Vries et al. (2015) - Perspectivas e normas compartilhadas] [De Vries et al. (2015) - Aceitação da inovação] [Bloch et al. (2009) - Investimentos em inovação] [Bloch et al. (2009) - Estratégia de inovação] [De Vries et al. (2015) - Posição organizacional] (1)

Analisando quanto ao DLOG, eu acho o ambiente favorável à inovação e a mudança, tanto que a gente está num processo tentando integrar dois sistemas numa única plataforma. [Bloch et al. (2009) Investimentos em inovação] [Bloch et al. (2009) Apoio] [De Vries et al. (2015) - Autonomia do empregado] (2)

Eu acho que o MS é um universo de áreas, onde infelizmente cada área pensa por si só. Quando a gente trabalha com o PEC e quer abarcar todo o Ministério, pensando numa compra econômica, sustentável e transparente, às vezes a gente esbarra no interesse da área que o fluxo siga dessa forma, não naquele objetivo que deveria ser pensando como um todo. Então, a dificuldade às vezes é essa, pois a área técnica tem uma visão diferente da área de aquisição, e isso dificulta entrar num consenso, pois o sistema está ali pronto para receber as informações e te demonstrar essa inovação e esses pontos positivos. Só que a interferência humana nesse sentido começa a atrapalhar. E isso dificulta o andamento do sistema, pois sempre vai ter essa barreira. [Bloch et al. (2009) - Barreiras para a 
inovação] [De Vries et al. (2015) - Conflitos] [De Vries et al. (2015) - Diminuição da eficácia] (3) O sistema PEC foi feito de fato para inovar e para trazer celeridade, transparência, segurança jurídica nos atos, o que de fato isso hoje está acontecendo.

[De Vries et al. (2015) - Aumento da eficácia] [Bloch et al. (2009) - Outros efeitos intangíveis (Confiança)] [De Vries et al. (2015) - Aspectos regulatórios] [De Vries et al. (2015) - Aceitação da inovação] (3) (6)

O ambiente é favorável à inovação no sentido de o gestor falar que faça. Eu sou favorável e dou carta branca, mas quando você pega esse acesso que é dado e começa a trabalhar com quem de fato utiliza o PEC, aí é uma questão cultural, pois você verifica que o Executivo possui um grande número de pessoas que estão chegando numa fase de aposentar e são os mais novos que se colocam à disposição para realizar atividades visando inovação. Na minha coordenação, o PEC já existe há três anos, e essas pessoas mais velhas não gostam de utilizar o sistema e delegam funções para determinadas pessoas que não tem problema em utilizar, mas elas têm pavor. Então, é favorável do ponto de vista em que a Administração Pública apoia a ideia, mas é desfavorável quando as pessoas que alimentam o sistema utilizarem o mesmo, pois para elas é mais cômodo trabalhar com um monte de papel, do que só apertar um botão e levar o processo adiante.

[De Vries et al. (2015) - Conflitos] [Bloch et al. (2009) - Barreiras da inovação] [Bloch et al. (2009) Cultura organizacional] [De Vries et al. (2015) Estilos de liderança] (3)

O PEC, enquanto inovação, está ligado com eficiência, melhoria. Nesse sentido, existe a inovação incremental e a de ruptura. A inovação incremental você vai melhorando aos poucos o seu dia-a-dia de trabalho, às vezes você nem percebe, mas você está melhorando o processo, está 
ganhando produtividade e melhorando os seus resultados.

[Bloch et al. (2009) - Produtividade da inovação] [De Vries et al. (2015) - Aumento da eficácia] [De Vries et al. (2015) - Aumento da eficiência] (1) $\mathrm{O}$ que eu posso perceber é que num primeiro momento há um ambiente totalmente favorável para se implementar inovações. Já em amplo contexto, eu entendo que a gente esbarra em algumas dificuldades, por exemplo, a rotatividade de pessoal eu acredito que deve ser levada em consideração, e isso está ligado intimamente com a gestão da coisa, pois a cada ruptura de gestão havia uma rediscussão das questões, fluxo, entendimento mesmo, olha eu acho que não é por aqui, vamos mudar por ali, enfim, pela questão das condições estruturais e ambientais, que não é só relativo ao Departamento de Informática do SUS (DATASUS), mas são várias outras questões, como a conjuntura política, a participação de mais agentes nesse processo, que em um dado momento realmente você encontra barreiras, aí é a questão até de se falar em barreiras e facilitadores para a implantação do sistema, para a inovação, mas eu entendo que o ambiente inicialmente é favorável, no entanto, quando a coisa começa a ser discutida, há entraves, há dificuldades no processo.

[Bloch et al. (2009) - Barreiras e facilitadores da inovação] [Bloch et al. (2009) - Prioridades políticas] [Bloch et al. (2009) - Estrutura de incentivos] Bloch et al. (2009) - [Infraestrutura tecnológica para inovação] [Bloch et al. (2009) Fontes de inovação] [Bloch et al. (2009) - Apoio] [De Vries et al. (2015) - Estilos de liderança] (4) Desde a implementação do PEC houve um envolvimento com as áreas do MS muito favorável para que o início da utilização do sistema acontecesse de forma efetiva. Então, quando você participa de alguma inovação, no caso o PEC, você 
já sabe como vai funcionar, desde o início você já vai se conscientizando de que vai precisar usar e precisa aprender como funciona. Eu participei do processo desde o início e eu não enfrentei, nem observei, dificuldade ou que os usuários tiveram muita resistência. Já que foi falado nesse ponto de pessoas chaves, eu acho que tem muito a ver com a gestão, como que a gestão trabalhou na época com o PEC e como vai trabalhar agora outra inovação. Se a inovação parte da gestão, os gestores têm um papel muito forte e todo um aspecto influenciável na implantação da inovação.

[De Vries et al. (2015) - Estilos de liderança] [De Vries et al. (2015) - Perspectivas e normas compartilhadas] [Bloch et al. (2009) - Fontes de inovação (Gestores)] [De Vries et al. (2015) Atividades de colaboração e aprendizado] [ De Vries et al. (2015) - Melhoria para o empregado] [Bloch et al. (2009) - Estratégia para inovação] [Bloch et al. (2009) - Facilitadores para a inovação] [Bloch et al. (2009) - Organização do setor público e estruturas de incentivo] (5)

No meu entendimento, a maior inovação que nós tivemos aqui foi de governança ou organizacional, pois essa envolve todos os fatores existentes para melhorar as atividades da organização, pois a área de compras passou para um patamar mais elevado dentro do MS, e a questão da governança, pois foi mais um instrumento para melhorar a governabilidade do MS.

[Bloch et al. (2009) - Tipos de inovação] [Bloch et al. (2009) - Inovação organizacional] [De Vries et al. (2015) - Inovação de governança] (1)

Na minha percepção, eu acho que a nossa inovação é mais de processo, e acho que é administrativo e tecnológico. Processo, pois nós estamos trabalhando com fluxos, etapas definidas, atividades que nós estamos submetidos em parte, por ser uma área de compras, à Lei de Licitações vigente, e que pelo 
processo de compra ser um processo administrativo dentro do conceito da Administração Pública. E tecnológico, pois ao mesmo tempo em que ele está usando uma plataforma, com fluxos definidos num software, ele também define os atores responsáveis por essas atividades, com vistas a otimizar tempo e reduzir o tempo das atividades, buscando ao final uma redução dos prazos de contratação.

[Bloch et al. (2009) - Tipos de inovação] [De Vries et al. (2015) - Inovação de processo (administrativo e tecnológico)] (2)

Meu entendimento é que a inovação seja de processo administrativo, pois a inovação tecnológica na minha visão teria que estar atrelada a outra questão tecnológica. Administrativo, pois o DLOG tinha práticas anteriores que foram alteradas, inclusive de andamento do processo, para poder se adequar a essa nova realidade. Eu vejo uma inovação de processo administrativo dentro da sua essência, com a parte tecnológica, ou seja, a parte tecnológica está dentro do administrativo.

[Bloch et al. (2009) - Tipos de inovação] [De Vries et al. (2015) - Inovação de processo (administrativo)] (3)

Eu já vejo mais como uma inovação tecnológica do que administrativa, pois enfim, na minha cabeça a diferença entre o processo de compras que havia antes e o atual e esse novo é justamente a inserção do sistema e o sistema é tecnológico. Concordo com o seu entendimento que é parte dos dois, mas ao escolher um deles eu opto pela inovação de processo tecnológico.

[Bloch et al. (2009) - Tipos de inovação] [De Vries et al. (2015) - Inovação de processo (tecnológico)] (4)

Eu acho que temos vários tipos de inovação envolvidos com a questão do PEC, mas concordo que a inovação está mais focada no processo administrativo, pois foi o processo de compras 
inovado, embora esteja usando a tecnologia, mas eu vou focar mais no processo de compra de medicamentos do Ministério.

[Bloch et al. (2009) - Tipos de inovação] [ De Vries et al. (2015) - Inovação de processo administrativo] (5) (6)

Eu acho a principal característica do PEC, é o fato da gente ter acesso ao sistema de forma remota, ou seja, não precisamos estar necessariamente aqui no Ministério para acessar a plataforma e poder dar andamento a alguma atividade ou processo, ou seja, você tem um ganho de eficiência enorme. Você pode estar até em casa e realizar a tarefa sob sua responsabilidade e isso para mim é uma característica bem relevante.

[De Vries et al. (2015) - Aumento da eficiência] [Bloch et al. (2009) - Nível de novidade e alcance da inovação] [Bloch et al. (2009) - Melhoria para o empregado] [Bloch et al. (2009) - Benefício para os usuários] [De Vries et al. (2015) - Facilidade no uso da inovação] [Bloch et al. (2009) - Outros efeitos intangíveis - (legitimidade)] (2)

No contexto em que tudo no Ministério tem que acontecer na hora que é demandado, eu acho que a velocidade na resposta dessa informação através do PEC é que o torna extremamente essencial e de uso constante. Então, pelo fato das informações serem em tempo real e eu conseguir pegar essas informações na hora em que são solicitadas, isso é um grande ganho que a gente tem. A resposta da informação é mais rápida através do PEC.

[De Vries et al. (2015) - Aumento da eficiência] [Bloch et al. (2009) - Aumento da satisfação do empregado] [Bloch et al. (2009) - Benefício para os usuários] [De Vries et al. (2015) - Fácil uso da inovação] [Bloch et al. (2009) - Outros efeitos intangíveis (confiança e legitimidade)] (3)

Ressalto que o PEC trouxe o controle, através do monitoramento e avaliação, produtividade, 
agilidade, economicidade, transparência e melhoria das atividades gerenciais. [De Vries et al. (2015) Aumento da eficiência] [De Vries et al. (2015) Aumento da eficácia] [Bloch et al. (2009) Produtividade de inovação] (1) (5) (6)

Eu acredito que há muitas interferências humanas para a operacionalização do sistema, ou seja, as alterações no fluxo dos processos e do sistema não são muito bem avaliadas, antes de serem realizadas. Um sistema que foi criado para ser mais célere acaba, às vezes, sendo um processo mais burocrático por conta dessas intervenções.

[De Vries et al. (2015) - Diminuição da eficácia] (2) (3) (4) (6)

Como nós precisamos de determinadas informações, a parte de relatórios gerenciais do PEC é deficiente. Eu acho uma desvantagem a não existência de um manual de utilização do sistema.

[De Vries et al. (2015) - Diminuição da eficácia] (1) (2) (3) (5)

O principal resultado trazido pelo PEC foi a melhoria da comunicação e interação entre as áreas do DLOG e do Ministério. Uma vez sendo o processo físico, ele fica na sua mesa e você não pensa na sequência de atividades. Mas no PEC, todo mundo acompanha o tempo todo em que tarefa está, com quem está, quando vai terminar, a data que a pessoa recebeu o processo, que você pode entrar e visualizar a qualquer momento, qual a data fim que a pessoa tem para realizar aquela tarefa, se aquele processo está atrasado ou não. Portanto, o PEC mostra tudo isso e possibilita o controle e gestão das atividades do DLOG.

[Bloch et al. (2009) - Atividades de colaboração e aprendizado] (5)

Lógico que o PEC é melhor que o processo físico, pois já teve pregão que o fornecedor, em fase de recurso, veio pedir vistas do processo lá no passado, antes de 2009, e quando o pregoeiro dava as costas, 
o representante da empresa tirava a folha do processo e sumia com ela. Hoje a perspectiva de você poder trabalhar com um sistema eletrônico é de o fornecedor ter acesso ao sistema de forma eletrônica para visualizar o processo de seu interesse. Em vários órgãos da Administração Pública, as pessoas trabalham de casa, elas não precisam vir ao ambiente de trabalho físico para exercer a atividade laboral. Ter um sistema que te possibilita visualizar as suas atividades, do seu ambiente doméstico, é fantástico e o PEC proporciona isso. Voltar ao processo em papel, jamais, em comparação ao eletrônico, vamos inovar mais.

[De Vries et al. (2015) - Vantagem relativa] [Bloch et al. (2009) - Nível de novidade e alcance da inovação] [Bloch et al. (2009) - Melhoria para o empregado] [Bloch et al. (2009) - Benefício para os usuários] [De Vries et al. (2015) - Facilidade no uso da inovação] [De Vries et al. (2015) - Aceitação da inovação] [De Vries et al. (2015) - Autonomia do empregado] [Bloch et al. (2009) - Outros efeitos intangíveis (confiança e legitimidade)] [Bloch et al. (2009) - Envolvimento dos parceiros privados] (3) O principal resultado do PEC, diferentemente do que a gente esperava quando ele foi concebido, que seria apenas a redução de tempo de contratação dos medicamentos e uma entrega mais rápida dos mesmos aos usuários do SUS, foi a melhoria das atividades gerenciais do DLOG e do MS todo. Possibilitou as atividades de monitoramento, melhorou a dinâmica da reunião Sala de Situação, a cobrança por parte da SE, os trabalhos de avaliação do processo, onde se conseguiu enxergar os gargalos do processo e melhorar no ciclo de contratação posterior, conseguiu direcionar o trabalho da sua equipe, principalmente aquelas equipes que trabalham na instrução processual mesmo, o coordenador consegue acompanhar mais as 
atividades dos seus servidores e realizar um trabalho de gestão mais eficiente, o que eu acho que foi o maior ganho da ferramenta.

[Bloch et al. (2009) - Demandas dos usuários] [De Vries et al. (2015) - Pressões ambientais (demandas públicas)]

[De Vries et al. (2015) - Aumento da eficiência] [De Vries et al. (2015) - Aumento da eficácia] [Bloch et al. (2009) - Produtividade da inovação] [Bloch et al. (2009) - Impactos sociais] [Bloch et al. (2009) Benefícios para os usuários] (1) (2)

Fonte: Elaborada pela autora.

Quanto à seleção da amostra para o segundo grupo focal, buscou-se contemplar os servidores usuários do PEC dentro do MS, os quais são os atores incumbidos de realizar atividades referentes às compras de medicamentos e insumos para a saúde, tanto no DLOG quanto no MS, pressupondo-se que tais indivíduos utilizam a inovação nos seus processos de trabalho, e, portanto, deteriam uma visão diversa dos gestores, além de serem capazes de incrementar às contribuições sobre a inovação.

De uma população total de 366 servidores e usuários devidamente cadastrados no PEC, 12 foram convidados a participarem do grupo focal, sendo: 3 usuários do DLOG, 1 usuário da Secretaria Executiva, 1 usuário do Fundo Nacional de Saúde, 1 usuário da Subsecretaria de Planejamento e Orçamento, 1 usuário da Secretaria de Ciência, Tecnologia e Insumos Estratégicos, 1 usuário da Secretaria de Saúde Indígena, 1 usuário da Secretaria de Vigilância em Saúde, 1 usuário da Secretaria de Atenção à Saúde, 1 usuário do Gabinete do Ministro e, por fim, 1 usuário do Departamento de Assistência Farmacêutica.

Essa técnica para coleta de dados foi realizada durante a segunda quinzena de junho de 2016, com comparecimento de seis usuários, nas dependências do DLOG, no MS, em Brasília. O processo de coleta de dados contou com a permissão institucional do órgão, bem como com a permissão individual dos entrevistados, inclusive para a gravação. O critério 
empregado para a definição do número de participantes do grupo focal foi o de disponibilidade dos servidores usuários, conforme agenda da organização.

E na Tabela 9, constam as declarações dos usuários da inovação dentro do MS, os quais são numerados de 7 a 12, os quais externaram ou verbalizaram concordâncias com as declarações transcritas. Em colchetes, foram indicados os autores dos modelos e as variáveis identificadas na literatura pelos referidos autores, as quais cada uma das declarações destacadas se vincula, observando as mesmas classificações de vetor 1 e vetor 2 .

Tabela 9 - Resultados da análise de conteúdo referente à inovação nas compras governamentais de medicamentos do MS, segundo usuários da inovação do MS

Vetor 1
Eu já trabalhei em outros órgãos públicos com o processo
físico e o PEC veio para revolucionar mesmo quanto à
questão do tempo, de acessibilidade, pois antigamente a
gente tinha que ir à página tal do processo, se tivesse
errado um documento a gente tinha que retificar ali e
paginar tudo de novo, hoje não, a gente nomeia o
documento e insere no sistema e tudo fica mais fácil. A
gente sabe onde está o despacho tal, o Termo de
Referência. A demanda que a gente tem realmente é
muito grande e todos os dias chegam mais processos de
compra, então se torna muito mais rápido com o PEC. E
tem também a questão até do peso dos processos, tinha
que pegar os processos para transportar e guardar, com
muita poeira, então eu acho que o PEC veio para trazer
mais eficiência e agilidade nos processos. E criou a
possibilidade do acesso remoto para fornecedores e
usuários, onde nós podemos trabalhar até em casa.

[De Vries et al. (2015) - Aumento da eficiência] [De Vries et al. (2015) - Aumento da eficácia] [Bloch et al. (2009) - Produtividade da inovação] [De Vries et al. (2015) - Facilidade no uso da inovação] [Bloch et al. (2009) - Aumento da satisfação do empregado] [Bloch et al. (2009) - Benefícios para os usuários] [De Vries et al. (2015) - Envolvimento de parceiros privados] (7) (9) 
Eu já entrei no MS com o PEC rodando e, portanto, não participei dessa fase anterior do processo físico, mas no meu outro trabalho, no Ministério dos Transportes eu trabalhava e sentia a dificuldade que era tramitar em papel, que gera um fluxo absurdo de trabalho, de esforço, tanto das pessoas, como um gasto de papel, a questão ambiental também é muito importante, e o projeto Esplanada Sustentável está aí para a gente colocar isso em prática na nossa rotina. Então sem dúvida o PEC é uma inovação, pois não dá para imaginar o MS e seu setor de compras sem o PEC hoje.

[De Vries et al. (2015) - Aumento da eficiência] [De Vries et al. (2015) - Aumento da eficácia] [Bloch et al. (2009) - Produtividade da inovação] [De Vries et al. (2015) - Facilidade no uso da inovação] [Bloch et al. (2009) - Aumento da satisfação do empregado] [De Vries et al. (2015) - Vantagem relativa] [Bloch et al. (2009) Outros efeitos intangíveis (confiança e legitimidade)] (8) Então, o DLOG trouxe um avanço significativo dentro do MS, através do PEC, pois quando você se propõe a inovar dentro da Administração Pública, tem que tirar da cabeça das pessoas a questão do apego ao papel. O PEC foi muito inovador, pois é uma quebra de conceito quando eu vou lá e digo que a partir de agora eu não vou utilizar o papel, mas em momento nenhum em vou perder o processo.

[Bloch et al. (2009) - Nível de novidade e alcance da inovação] [Bloch et al. (2009) - Outros efeitos intangíveis (confiança e legitimidade)] (11)

O PEC é um exemplo de inovação dentro do MS, pois é um exemplo de superação em termos de cultura, de melhorar os processos de trabalho, de transparência e de controle. Só o fato de você não ter que ter o processo físico em mãos e dar andamento, e todo mundo ter a transparência da informação e o controle de onde o processo está, isso é um avanço muito grande. Então para mim e acho que para a SE também, é um avanço e foi uma das inovações mais importantes para o MS nos últimos anos.
Então eu acho que o PEC foi uma inovação e tanto e está caminhando para melhor. De acordo com a Lei de Acesso à Informação, um fornecedor quer ter acesso ao processo, então ele entra com esse pedido aqui no DLOG, e o gestor do PEC disponibiliza uma senha temporária, porém existem os momentos em que podemos disponibilizar de acordo com a Lei 8.666, pois na fase pré-licitatória você não pode disponibilizar informações estratégicas para os fornecedores, por exemplo.

[Transparência da informação] (7) (9) (12) 
[Bloch et al. (2009) - Cultura organizacional] [De Vries et al. (2015) - Aumento da eficiência] [De Vries et al. (2015) - Aceitação da inovação] [De Vries et al. (2015) Vantagem relativa] (7) (11) (12)

Eu vejo que, há dois anos que estou aqui no MS, já presenciei 4 diretores. Até hoje realmente eu vejo que o ambiente e as condições para inovação estão muito relacionados com a gestão de pessoas, pois você chega e um diretor trabalha de determinada forma, e aí passa para os coordenadores, que já têm as suas opiniões, sua forma de gerir, então tudo dificulta. E as coisas não vão acontecer dentro da estrutura, pois eu vejo que é muito político, pois dependendo do partido, pensa de determinada forma.

[Bloch et al. (2009) - Barreiras para a inovação] [Bloch et al. (2009) - Prioridades políticas] [De Vries et al. (2015) Estilos de liderança] [De Vries et al. (2015) - Conflitos] [Bloch et al. (2009) - Fontes de inovação (gestores)] (7) (9) (10) (12)

Todo esse contexto dentro do MS, onde cada um trabalha para si dentro da sua Secretaria, desfavorece o ambiente de inovação, pois você não consegue integrar as políticas e otimizar recursos, que é um dos principais alvos que a inovação poderia fomentar.

[Bloch et al. (2009) - Barreiras para a inovação] [ Bloch et al. (2009) - Prioridades políticas] [De Vries et al. (2015) Estilos de liderança] [Bloch et al. (2009) - Organização do setor público e estruturas de incentivo] [De Vries et al. (2015) - Conflitos] (8) (11)

$\mathrm{Eu}$ acho que o PEC é uma inovação no processo administrativo, mas tem uma questão organizacional, pois o MS antes do PEC, meio que sedimentou as normas, pois normalmente não encontramos os processos estruturados. O PEC e os fluxos dos processos foram construídos de forma eletrônica, então onde não tinha nada de norma e controle interno sobre a atividade de uma área sobre a outra, o PEC acabou servindo para estruturar.

[Bloch et al. (2009) - Tipos de inovação] [De Vries et al. (2015) - Inovação de processo (administrativo)] [Bloch et 
al. (2009) - Inovação organizacional] (7) (9) (12)

Facilidade de uso, eficiência, economicidade, transparência são vantagens do PEC, e uma das características que precisa ser melhorada é a questão de relatórios. Nós temos muitas informações no sistema, porém quando você precisa de uma análise mais gerencial para tomada de decisão, você tem que olhar vários despachos que estão inseridos no PEC para isso. Deixeme registrar também a estabilidade do sistema, tempo de resposta aos suportes técnicos e de manutenção, pois eu nunca vi no MS um tempo tão curto de resposta como no PEC.

[De Vries et al. (2015) - Aumento da eficiência] [De Vries et al. (2015) - Facilidade no uso da inovação] [Bloch et al. (2009) - Infraestrutura tecnológica para inovação] (7) (9) (10) (11) (12)

O processo em si ele não mudou tanto assim, então eu caracterizaria a inovação realizada através do PEC como de processo tecnológico. Foram introduzidas algumas mudanças administrativas, porém aparentemente o processo administrativo não foi tão mudado assim, mas até a forma de cobranças das pessoas, o tempo para realizar as tarefas, o workflow que está rodando por trás, ele se encaixaria nos dois, que é o administrativo e tecnológico.

[Bloch et al. (2009) - Tipos de inovação] [De Vries et al. (2015) - Inovação de processo (administrativo)] [De Vries et al. (2015) - Inovação de processo (tecnológico)] (8) (10) (11)

A questão de conseguirmos visualizar o processo em qualquer lugar do MS foi um grande ganho que o PEC trouxe; a questão da celeridade, economicidade foram outros grandes ganhos, mesmo a gente não tendo algumas informações gerenciais, indicadores e alguns relatórios, ajudou muito, pois antes você tinha que mandar a solicitação do processo para o arquivo do DLOG, folhear as informações e depois gerar um relatório ou um dado. E tudo isso facilitou e muito a questão da análise do processo. E às vezes você devolve um processo quatro 
vezes para a área no mesmo dia, o que representa agilidade, pois se fosse com o processo físico seria um dia apenas para chegar de um protocolo para o outro.

[De Vries et al. (2015) - Aumento da eficiência] [De Vries et al. (2015) - Aumento da eficácia] [Bloch et al. (2009) Produtividade da inovação] [Bloch et al. (2009) Benefícios para os usuários] (7) (8) (9) (10) (11) (12)

A inovação, como o PEC, precisa observar os aspectos legais, uma vez que nós digitalizamos os documentos para serem inseridos no processo eletrônico, porém a lei rege que tem um fluxo contínuo a ser seguido. Às vezes o limite legal impede os avanços em muitos aspectos, inclusive no controle social e impede também que o gestor realize alguns avanços que consideramos fundamentais.

[De Vries et al. (2009) - Aspectos regulatórios] [Bloch et al. (2009) - Barreiras da inovação] (8)

Fonte: Elaborada pela autora.

De acordo com a análise de conteúdo realizada e proveniente dos dois grupos focais, todas as categorias definidas, a partir dos referidos modelos, mostrou-se presente dos discursos dos entrevistados: conceito de inovação; características da inovação; antecedentes e condições estruturais para a inovação; tipos de inovação; saídas da inovação; e, por fim, resultados da inovação.

Dessa forma, apontou-se que as seguintes variáveis relativas ao modelo proposto por De Vries, Bekkers e Tummers (2015), não foram observadas no fenômeno de inovação do MS: participação em redes; concorrência com outras organizações; disponibilidade de recursos; grau de aversão ao risco; ambiente para aprendizado; incentivos; recompensas; estruturas organizacionais; posição organizacional; habilidades e conhecimentos relacionados ao trabalho; aspectos demográficos; compromisso e satisfação com o trabalho; inovação de produto ou serviço; inovação conceitual; e, por fim, envolvimento dos cidadãos. 
Já as variáveis apresentadas por Bloch et al. (2009) e Bloch (2011) que não foram observadas no PEC, pelos gestores e usuários dessa inovação dentro do MS foram: inovação de produto; inovação de serviço; inovação de comunicação; apoio (educação, diversidade); e, saídas intangíveis (marcas comerciais, direitos do autor).

Com a utilização do software Atlas.ti7, foi realizada a exploração do material do primeiro grupo focal através do tratamento de dados, o que evidenciou as palavras mais mencionadas pelos gestores, ou seja, as palavras mais significativas, dentre as quais se destacam: sustentabilidade, que foi mencionada três vezes; e transparência, que foi utilizada 15 vezes, de acordo com a nuvem de palavras criada pelo software NVIVO 11 Pro for Windows na Figura 5.

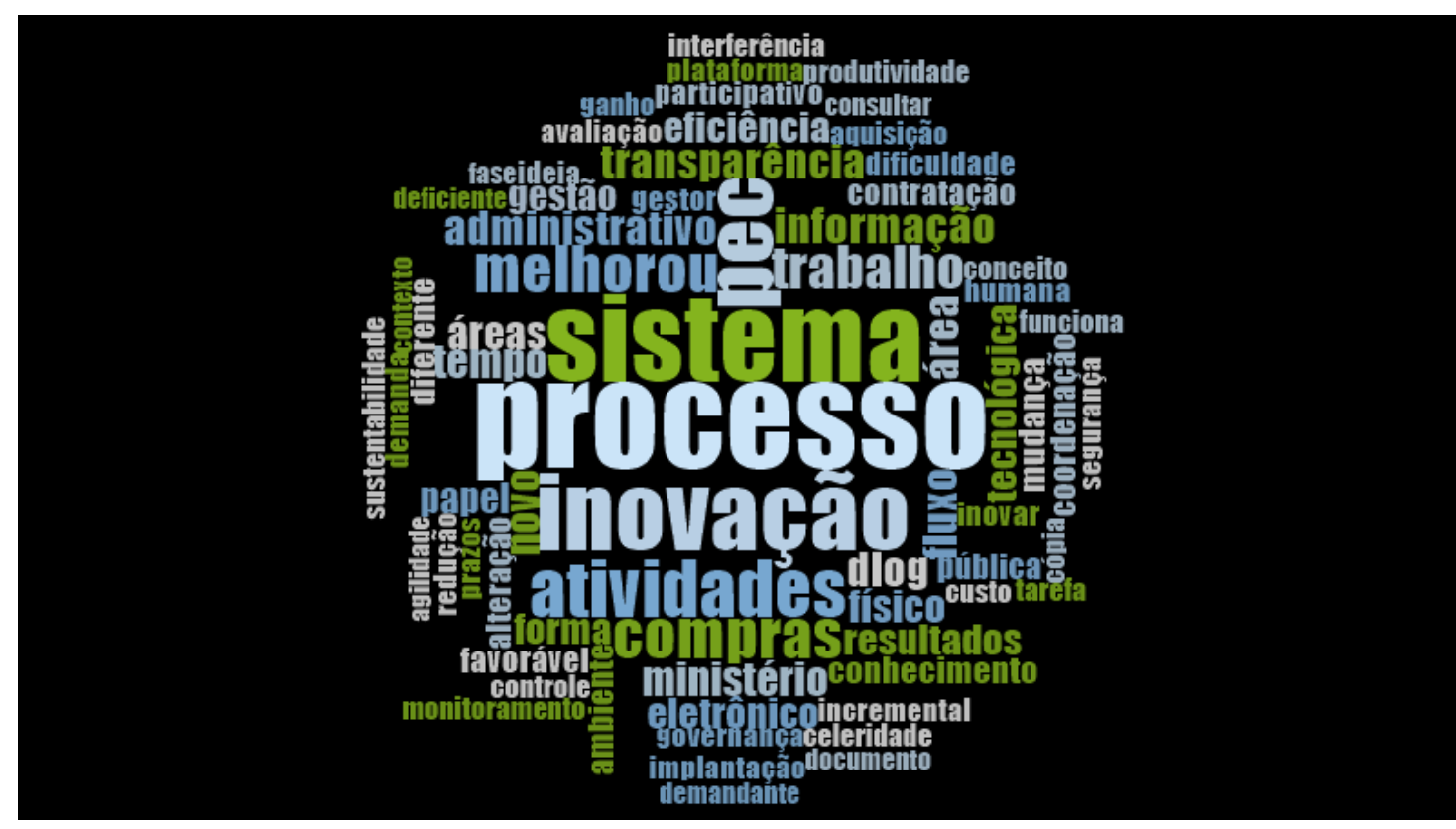

Figura 5 - Nuvem de palavras referente ao Grupo Focal 1 realizado com gestores do MS Fonte: Elaborada pela autora, a partir do software NVIVO 11 Pro for Windows.

Com relação ao grupo focal 2, também foi utilizado o software Atlas.ti7 para exploração do material, que evidenciou novamente a palavra transparência, sendo a mesma mencionada 10 vezes pelos usuários da inovação dentro do MS, conforme segue demostrado na nuvem de palavras criada pelo software NVIVO 11 Pro for Windows na Figura 6. 


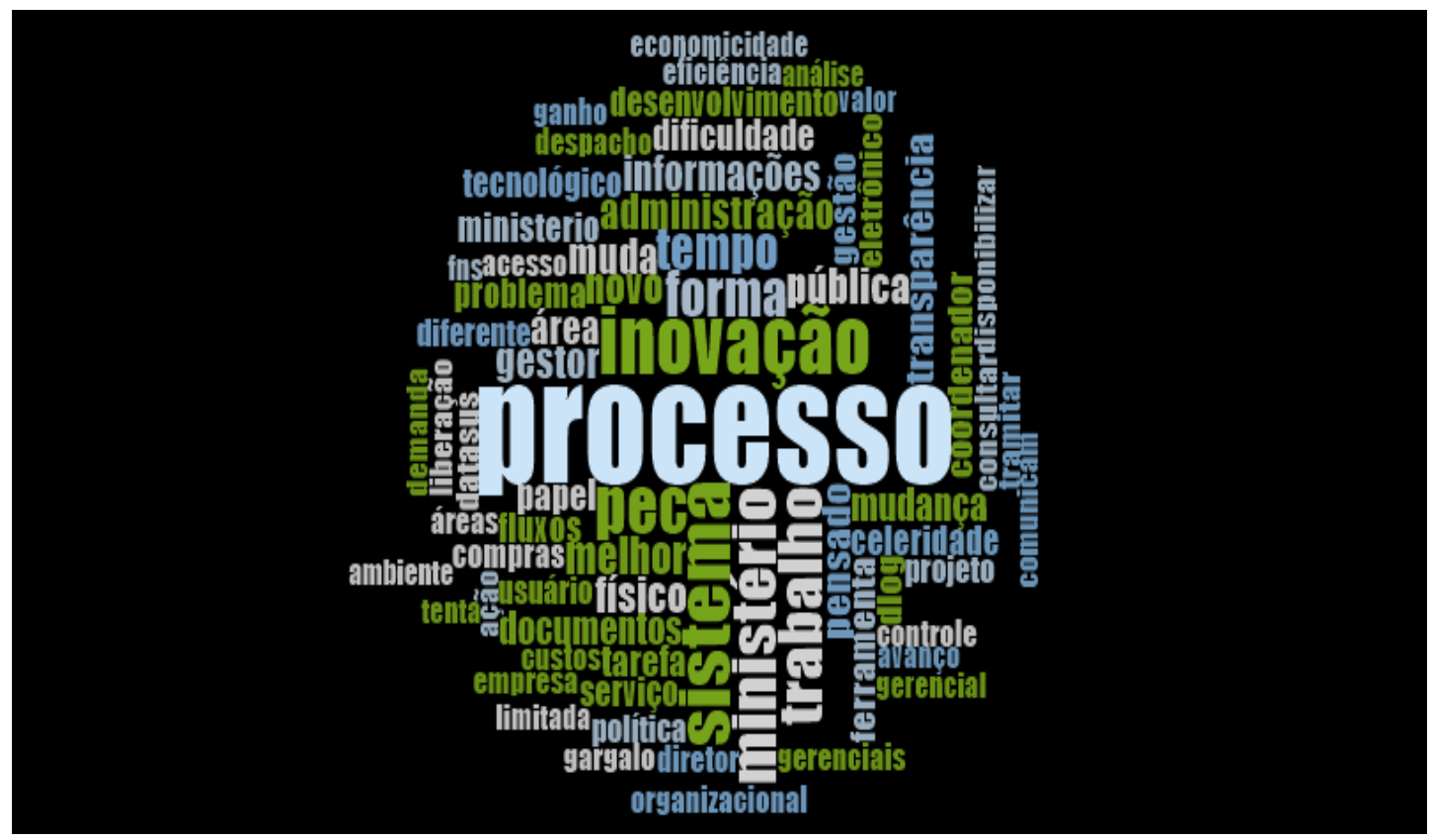

Figura 6 - Nuvem de palavras referente ao Grupo Focal 2 realizado com os usuários do PEC no MS Fonte: Elaborada pela autora, a partir do software NVIVO 11 Pro for Windows.

Com base nas análises geradas, os gestores responsáveis pelas compras governamentais dos medicamentos do MS e os usuários do PEC destacaram as seguintes novas variáveis referentes ao fenômeno de inovação do MS, as quais não foram observadas na literatura por De Vries, Bekkers e Tummers (2015) e Bloch et al. (2009), e por se tratarem de atributos do software PEC, foram classificadas na categoria características da inovação: sustentabilidade e transparência da informação.

Outrossim, as novas variáveis advindas dos grupos focais - sustentabilidade e transparência da informação - estão em consonância com dois desafios atuais da Administração Pública: o uso do poder de compra do governo para a promoção do desenvolvimento sustentável; e o acesso à informação pública para proporcionar transparência dos atos do governo e consequente melhoria da qualidade dos gastos públicos (Biderman \& Macedo, 2008; Lopes, 2007). 


\subsection{ANÁLISE DE DADOS OBTIDOS COM OS QUESTIONÁRIOS}

O questionário da pesquisa foi elaborado com base nas dimensões e variáveis apresentadas nos modelos dos autores De Vries, Bekkers e Tummers (2015) e Bloch et al. (2009), acrescidas das novas variáveis advindas dos grupos focais: sustentabilidade e transparência da informação.

Foram criadas inicialmente 42 perguntas para o questionário, categorizadas conforme três blocos principais: características e resultados da inovação, no caso em questão o PEC; práticas de gestão e percepções sobre o ambiente organizacional para promoção de inovações; e, por fim, práticas relativas ao processo de inovação no MS.

Para avaliação dos questionários, os mesmos foram submetidos a cinco juízes, todos especialistas em inovação, e sofreram validação de conteúdo conforme proposta de Cálculo de Validação de Conteúdo (CVC), de Hernandéz-Nieto (2002), para cada uma das 42 questões elaboradas inicialmente, de acordo com modelo de formulário enviado por e-mail, que consta no Apêndice D, bem como o inventário de cálculo completo do coeficiente de validação, que está disponível no Apêndice E.

Para validação de cada um dos itens do questionário, foi adotada a nota 8,00 como parâmetro de corte para cada uma das dimensões analisadas: 1) clareza da linguagem, 2) pertinência dos itens e 3) relevância teórica. Nas questões onde apenas uma das categorias obteve CVC médio abaixo de 8,00, as mesmas foram descartadas e não foram consideradas na versão final do questionário. Nas questões 16 e 33, a média das três categorias ficou abaixo de 8,00 e, portanto, as mesmas foram descartadas, conforme Apêndice F, no entanto, a questão 27 apresentou CVC médio de 0,79 , mas foi considerada para aplicação no questionário por estar próxima da nota de corte e ser uma variável relevante.

Após a validação pelo método do CVC e baseado nas contribuições dos juízes na coluna "observações" existente no formulário enviado, foi suscitado aos mesmos a 
colaboração através de sugestões para a elaboração do questionário. A partir dessas contribuições, foi realizada nova validação semântica das questões a serem aplicadas no MS. Essa validação trouxe algumas contribuições que levaram ao descarte das questões $3,16,17$, 24, 25 e 26 do questionário e incorporação das questões 28 e 29 nas questões 30 e 31, por se tratarem de variáveis relacionadas com as barreiras e facilitadores da inovação.

Dessa forma, a versão final do questionário utilizado contou com 32 questões relativas à inovação e 5 questões relativas ao perfil sociodemográfico dos respondentes, totalizando 37 questões, com preenchimento por meio de escala Likert de 7 níveis, variando de " Nunca" a “Sempre” ou "Não se Aplica", como se apresenta no Apêndice G.

Quanto à aplicação dos questionários, os mesmos foram enviados por e-mail para os usuários da inovação no DLOG e em todas as áreas relacionadas com o processo de compras governamentais de medicamentos dentro do MS. Para tal, foi utilizado o software FormSUS, o qual é um serviço oferecido pelo Departamento de Informática do SUS (DATASUS) para criação de formulários na web e é compatível com a legislação e com a Política de Informação e Informática do SUS.

No período de aplicação dos questionários, entre os meses de setembro e outubro de 2016, foram enviados 366 e-mails para os usuários cadastrados na utilização do software PEC no MS, dos quais 28 e-mails retornaram por não terem sido entregues aos destinatários e pelos usuários se encontrarem ausentes do órgão. Assim, dos 366 e-mails que se apresentaram como possíveis respondentes do questionário enviado, foram obtidas 104 respostas.

Do total de 104 questionários válidos, o que representa 28,41\% do total da população, as respostas apontam representatividade de todas as áreas do MS em que o processo de compra de medicamentos e insumos para a saúde perpassa, conforme demostra a Figura 7. 


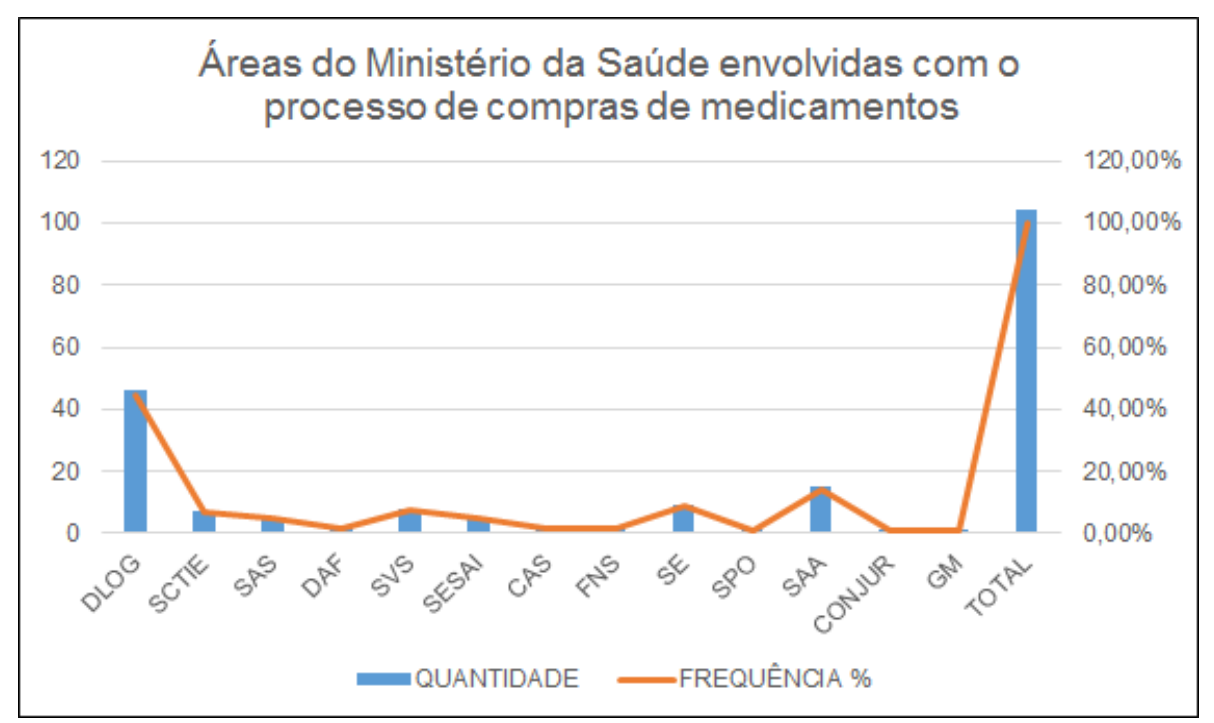

Figura 7 - Dados referentes às áreas dos respondentes do questionário envolvidos com o processo de compra do Ministério da Saúde

Fonte: Elaborada pela autora.

Em relação aos resultados obtidos com a aplicação do questionário no MS, estes foram analisados no software SPSS, com a utilização dos scripts para cálculo da estatística descritiva, cujos resultados finais se encontram nos gráficos e tabelas a seguir.

Primeiramente, quanto à variável facilidade de uso da inovação na Figura 8, que é atribuída por De Vries, Bekkers e Tummers (2015) como uma característica dessa inovação, 39,42\% dos usuários do PEC no MS percebem que o software apresenta uma interface de utilização simples e de fácil interação, o que corrobora os resultados apontados pelos referidos autores como sendo a característica mais mencionada em estudos que analisam esse atributo como relevante. 


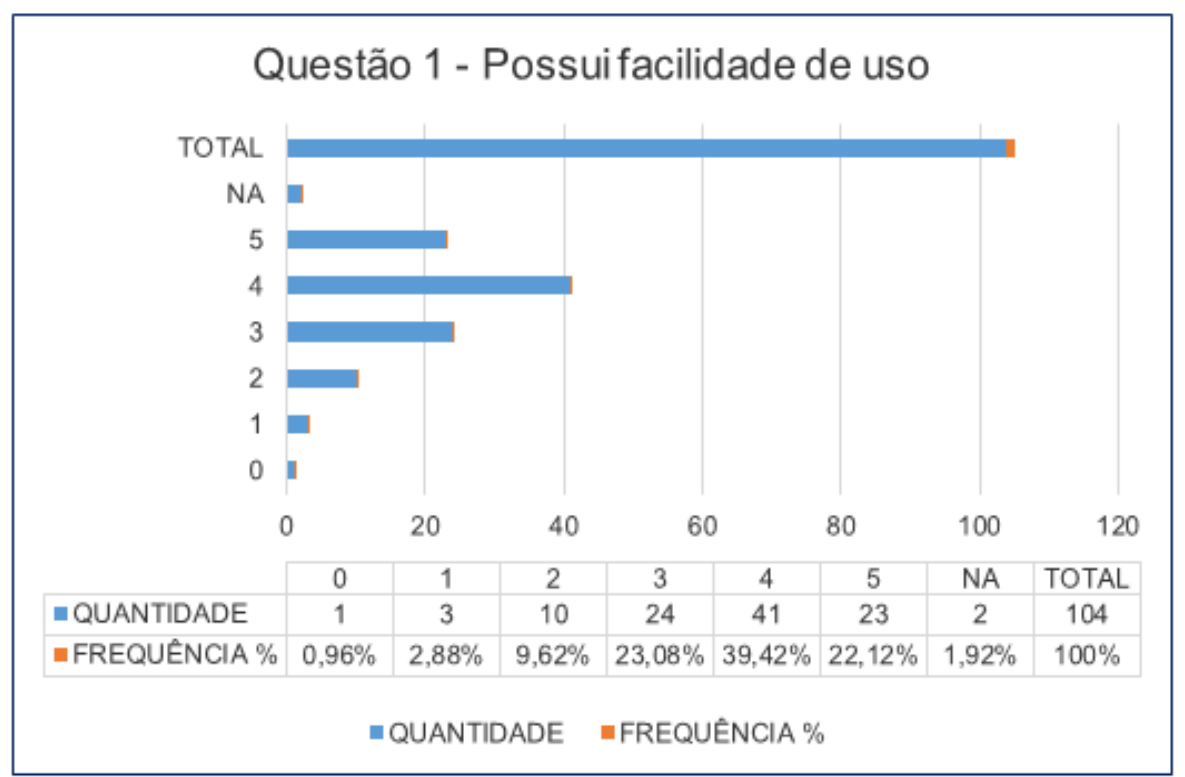

Figura 8 - Dados referentes à questão sobre facilidade de uso da inovação Fonte: Elaborada pela autora.

Já a variável vantagem relativa da inovação na Figura 9, que no caso específico do MS, apresentou uma mudança no processo físico das compras de medicamentos para o processo eletrônico, 46,15\% dos usuários da inovação percebe vantagem nessa mudança, o que ratifica a característica atribuída por De Vries, Bekkers e Tummers (2015) como importante numa inovação no setor público. Além dos supracitados autores, o estudo realizado por Korteland e Bekkers (2008), o qual apresenta uma inovação de governo eletrônico no setor policial, ressalta que os usuários perceberam forte vantagem relativa em relação ao serviço prestado anteriormente. 


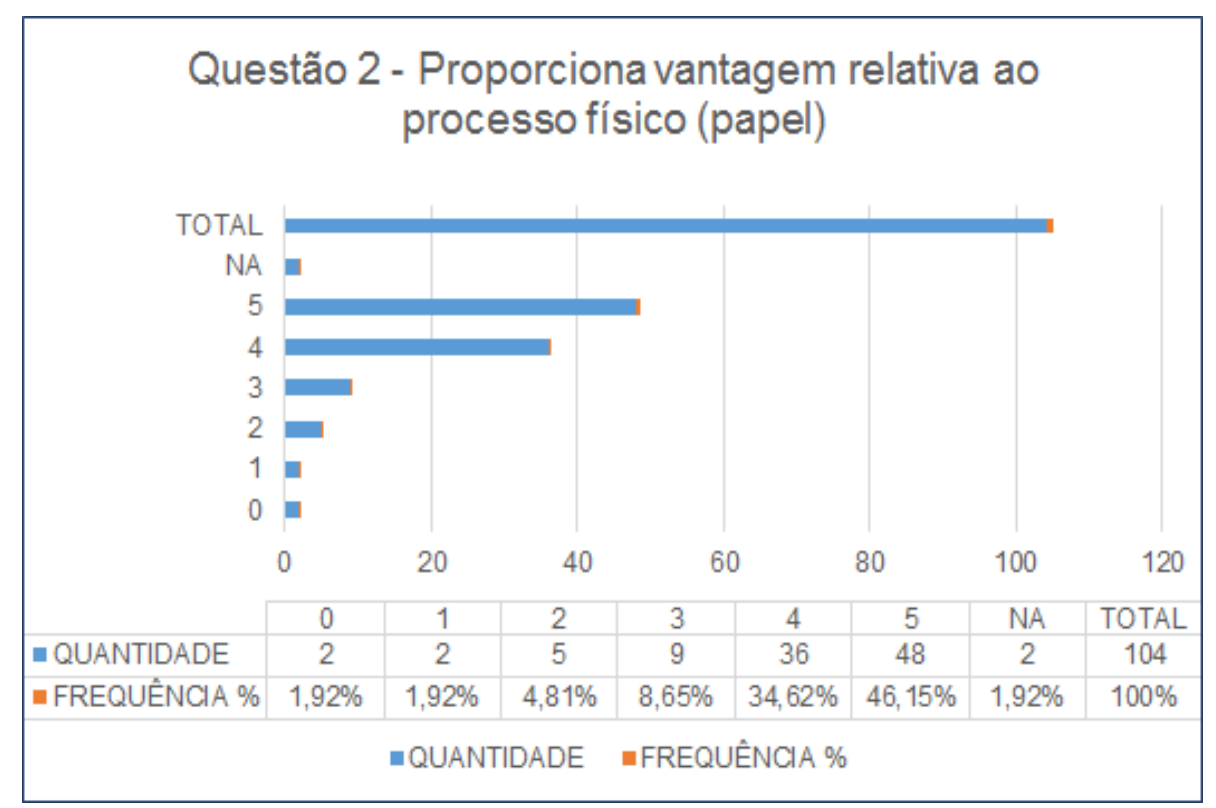

Figura 9 - Dados referentes à questão 2 sobre vantagem relativa da inovação Fonte: Elaborada pela autora.

Em relação à compatibilidade da inovação do software PEC em relação aos processos e outros softwares existentes no MS, os usuários apontaram uma baixa concordância quanto às respostas quando $15,38 \%$ afirmam que não há compatibilidade e 22,12\% afirmam que há compatibilidade, o que reflete um conhecimento assimétrico dos usuários em relação à adaptação da plataforma $B P M$ aos softwares existentes e utilizados no MS. Esses resultados sinalizam que a característica compatibilidade atribuída por De Vries, Bekkers e Tummers (2015) como relevante característica da inovação, não foi atestada pelos usuários da mesma no MS. 


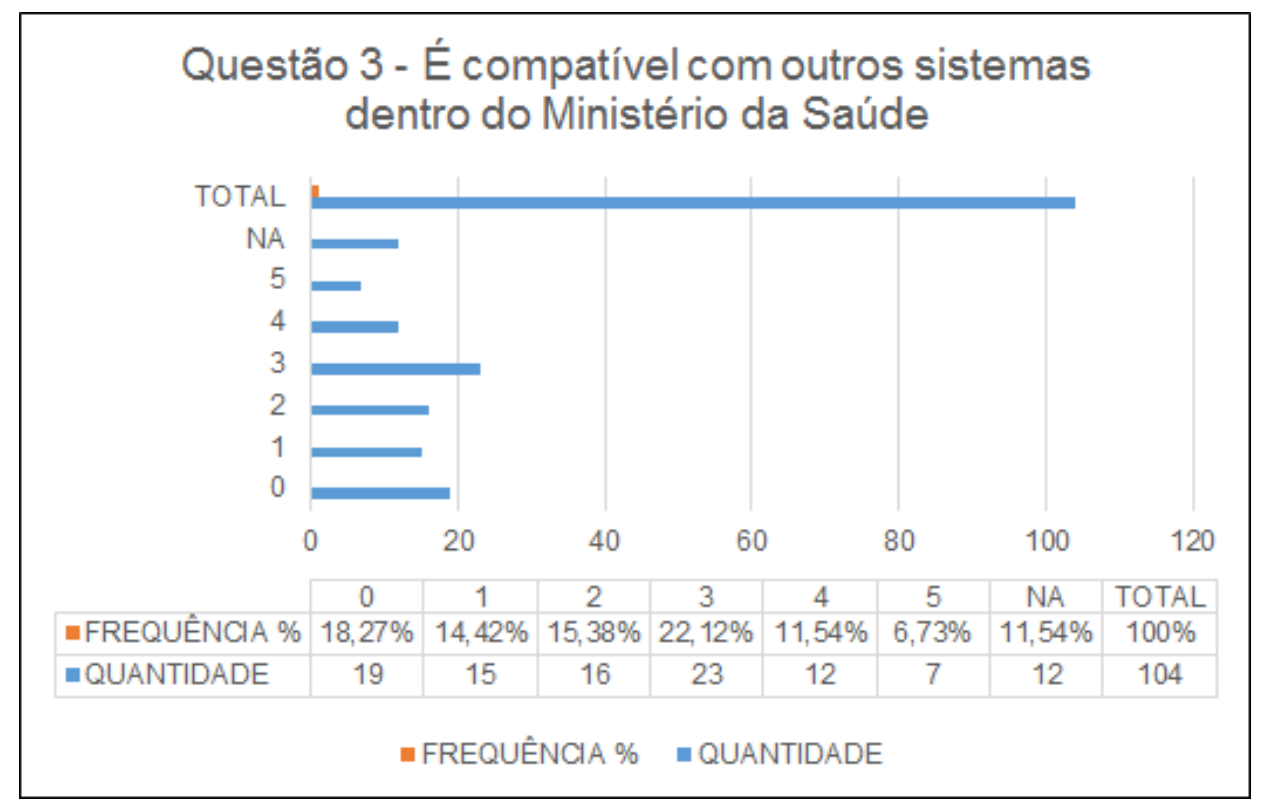

Figura 10 - Dados referentes à questão 3 sobre compatibilidade da inovação com outros sistemas do MS

Fonte: Elaborada pela autora.

Quanto à variável nível de novidade e alcance da inovação, 42,31\% dos usuários da inovação do MS percebem o PEC como uma inovação no setor público e nas compras governamentais de medicamentos e insumos para a saúde, de acordo com Figura 11, o que justifica o presente estudo e valida os conceitos propostos por Rogers (2003), De Vries, Bekkers e Tummers (2015) e Bloch (2011), quando afirmam que inovação no setor público é a introdução de um novo processo para a organização, o que de fato se apresentou no MS. 


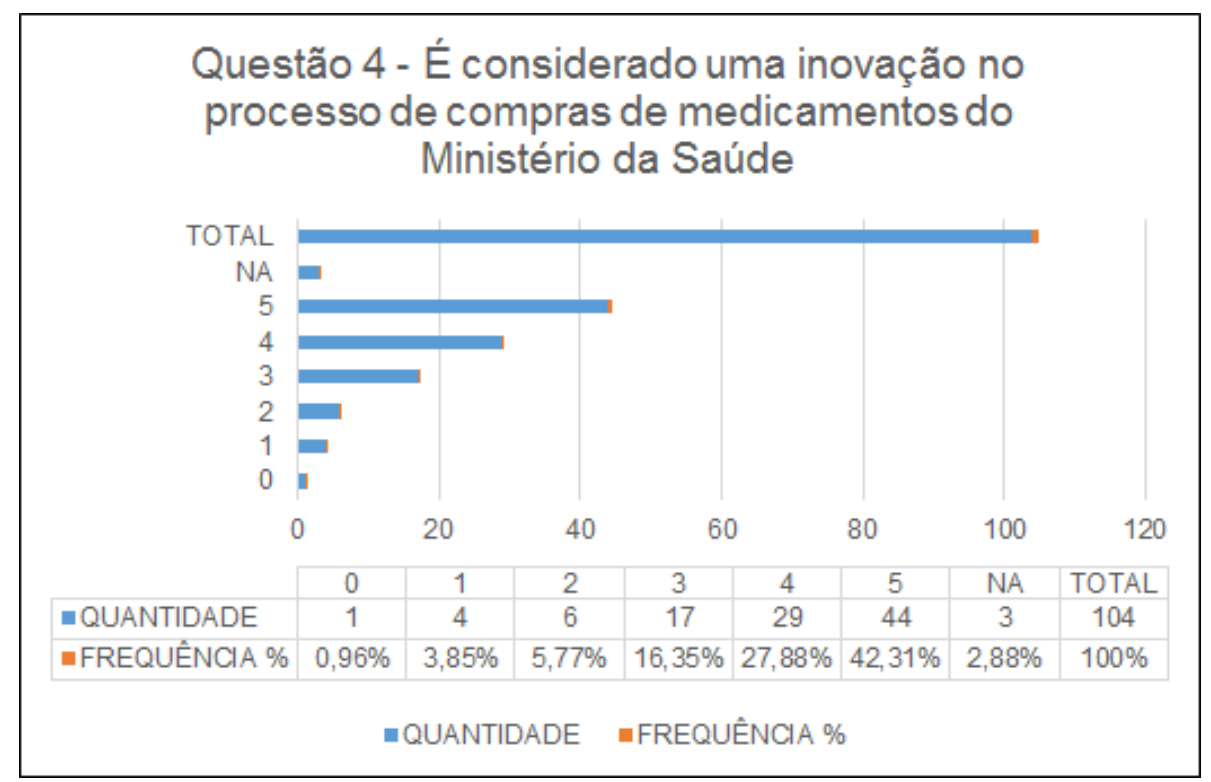

Figura 11 - Dados referentes à questão 4 sobre a percepção do PEC enquanto uma inovação no setor no processo de compras do MS

Fonte: Elaborada pela autora.

A capacidade da inovação implementada no MS de gerar benefícios intangíveis, tais como melhorias na segurança da informação, foi percebida como positiva por $32,69 \%$ dos usuários na Figura 12, o que corrobora as principais saídas da inovação apontadas por Bloch et al. (2009), as quais refletem a importância da gestão dos benefícios intangíveis no setor público, visando a capacidade de aumento de respostas das organizações desse setor aos desafios sociais atuais, de acordo com proposta de Tarapanoff (2006). 


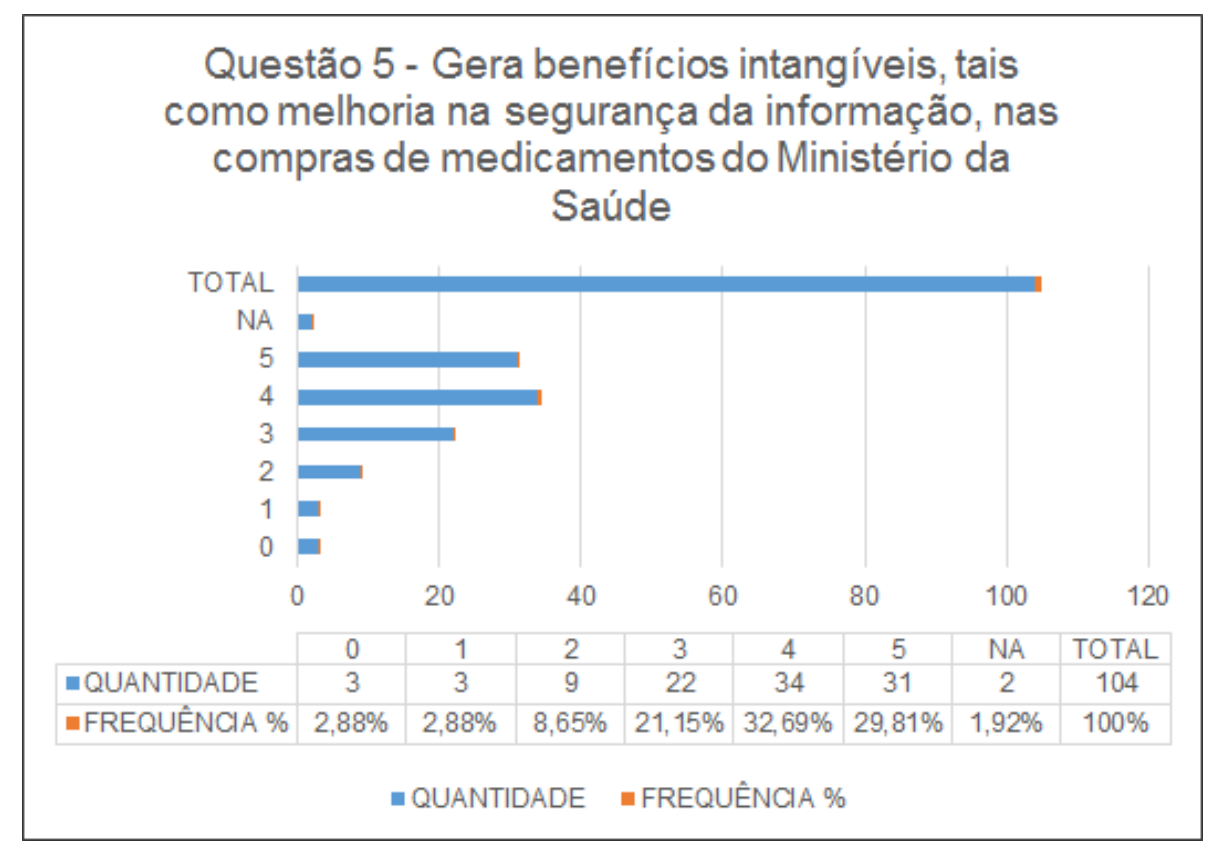

Figura 12 - Dados referentes à questão 5 sobre os benefícios intangíveis gerados ao MS pela inovação no processo de compras

Fonte: Elaborada pela autora.

Em relação à variável aumento da satisfação do empregado, no caso em tela do servidor do MS envolvido com o processo de compras de medicamentos, a Figura 13 apresenta que $37,5 \%$ e $36,54 \%$ apontaram as notas 4 e 5 da escala respectivamente, o que reflete a percepção de melhorias nos processos de trabalho com a utilização do processo eletrônico. Esses resultados corroboram com os apontamentos da FNQ (2015) sobre a importância das práticas de gestão de pessoas como forma de consolidar a inovação e uma cultura de inovação dentro das organizações. 


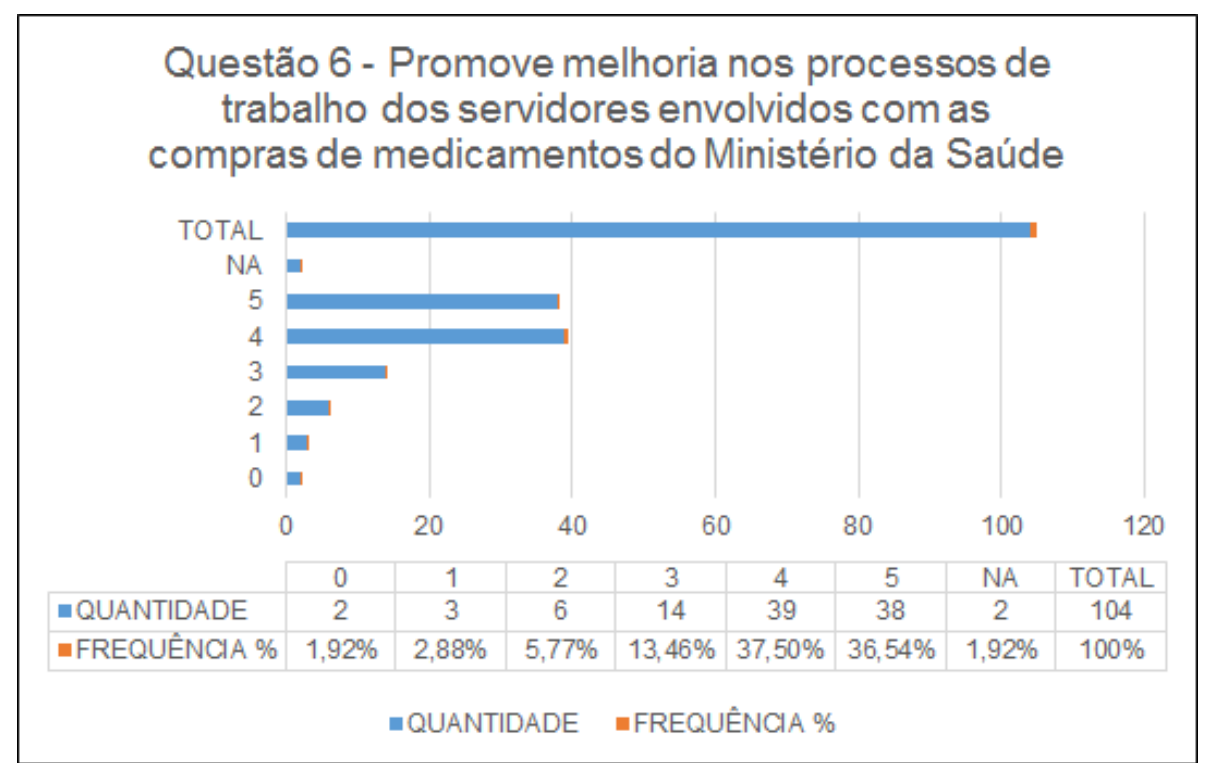

Figura 13 - Dados referentes à questão 6 sobre as melhorias geradas nos processos de trabalho dos servidores envolvidos com as compras de medicamentos Fonte: Elaborada pela autora.

Já em relação às melhorias no processo de compra dos medicamentos adquiridos pelo MS para posterior distribuição aos estados e municípios, 30,77\% dos usuários da inovação indicaram que o processo melhorou, de acordo com Figura 14, o que ratifica os discursos dos gestores e usuários dos grupos focais. Essa questão está relacionada com as variáveis: benefícios para os usuários e impactos sociais, ambas as propostas por Bloch et al. (2009), como relevantes resultados da inovação no setor público. 


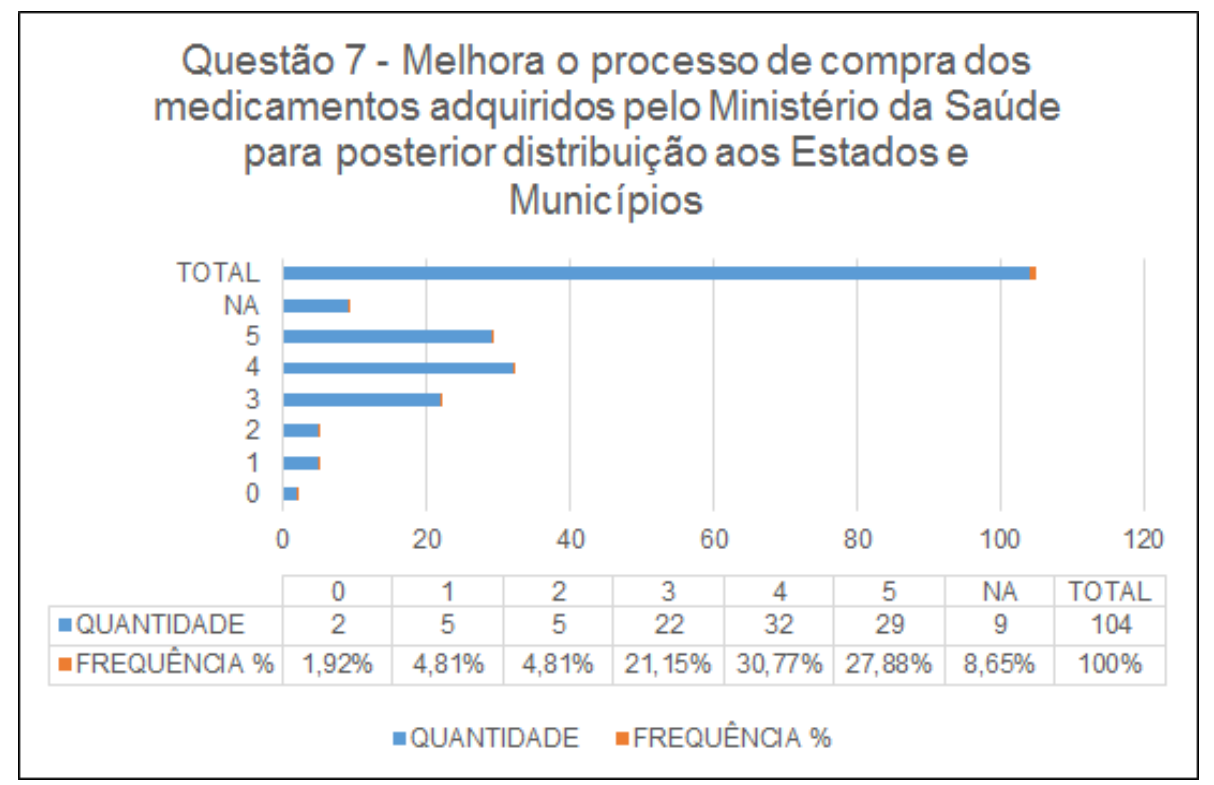

Figura 14 - Dados referentes à questão 7 sobre as melhorias geradas nos processos de compras dos medicamentos adquiridos pelo MS para distribuição aos Estados e Municípios Fonte: Elaborada pela autora.

A variável transparência da informação pública, advinda dos grupos focais que consta na Figura 15, como característica da inovação do MS, foi percebida por 32,69\% dos usuários do PEC, o que corrobora os resultados dos grupos focais e reforça a importância do acesso à informação pública para melhoria dos gastos públicos com medicamentos e insumos para a saúde, como se apresenta no artigo desenvolvido por Lopes (2007). 


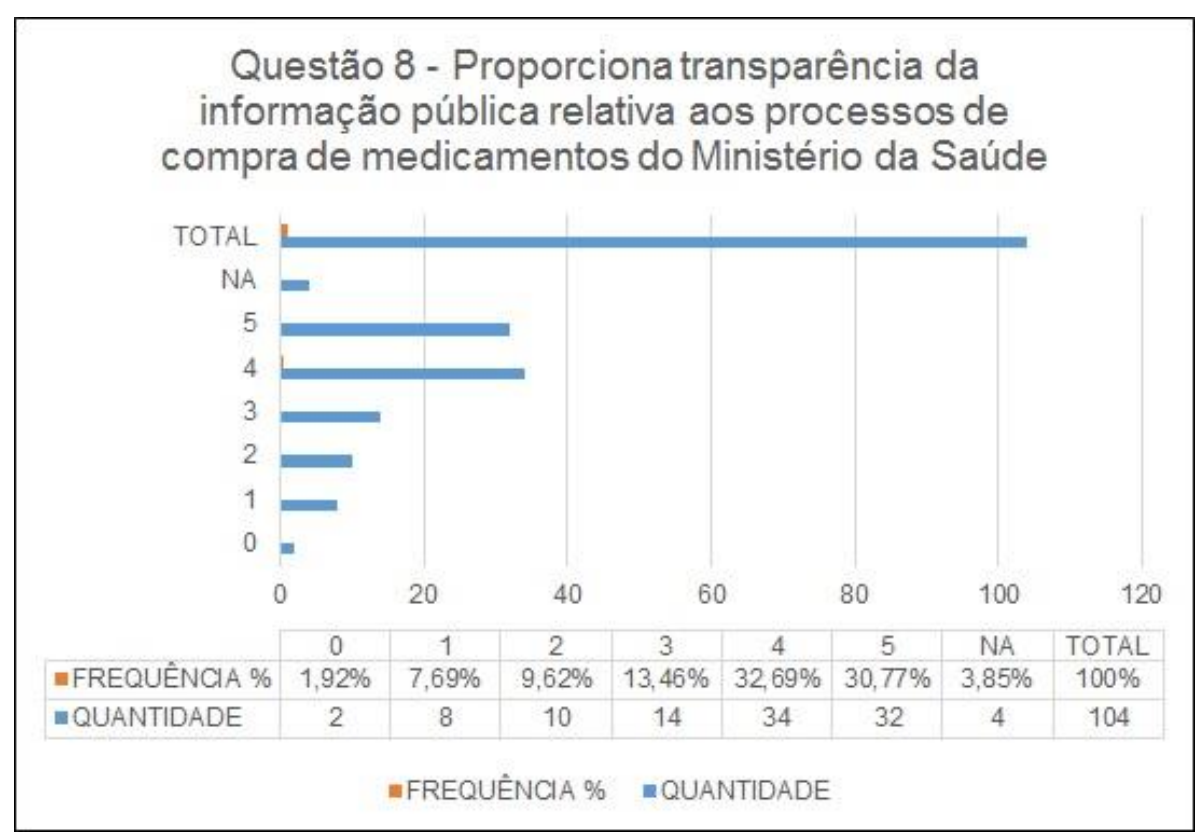

Figura 15 - Dados referentes à questão 8 sobre a transparência da informação geradas nos processos de compras dos medicamentos do MS

Fonte: Elaborada pela autora.

A outra variável proveniente dos grupos focais, a sustentabilidade, conforme Figura 16, foi apontada por $30,77 \%$ dos respondentes do questionário no MS, o que reflete o reconhecimento dessa característica na inovação do MS, no sentido de fomentar iniciativas para produção de bens e serviços sustentáveis e incorporar critérios de sustentabilidade ambiental nas compras governamentais de medicamentos, o que reflete o posicionamento de Valente (2011), sobre a relevância do marco legal das compras sustentáveis na Administração Pública. 


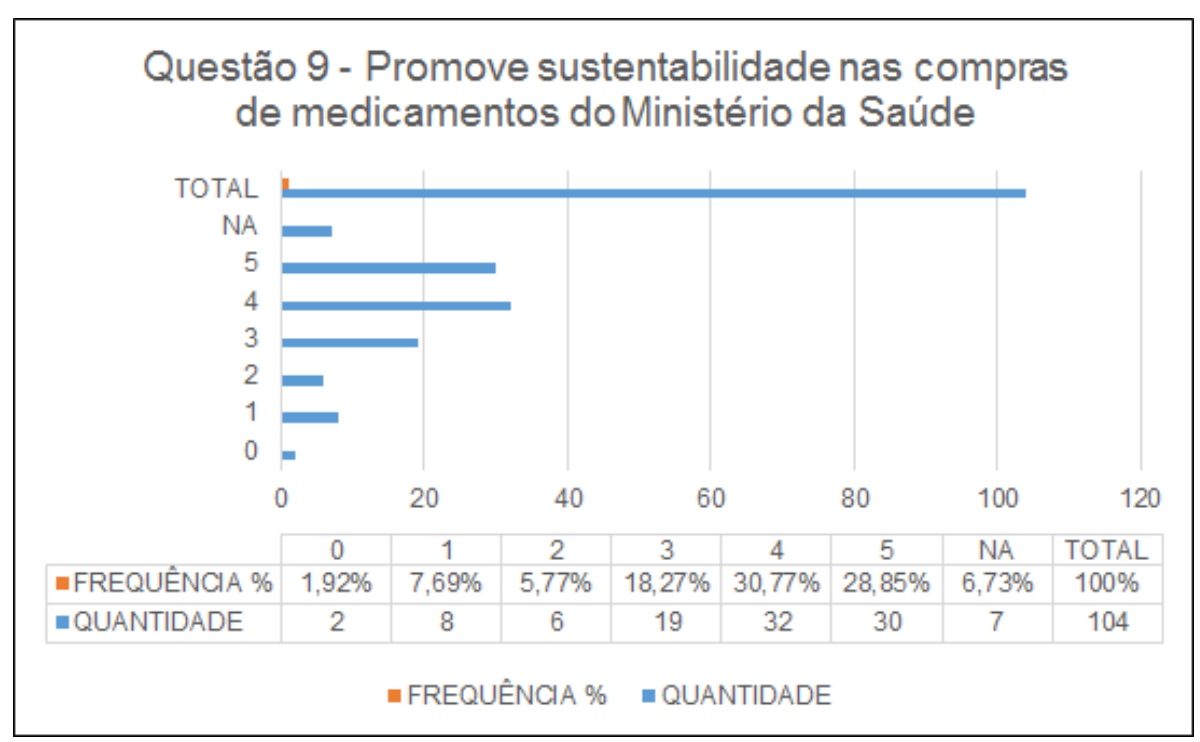

Figura 3 - Dados referentes à questão 9 sobre a sustentabilidade da inovação no processo de compras de medicamentos do MS

Fonte: Elaborada pela autora.

Quanto aos investimentos em inovação realizados pelo MS, 33,65\% dos usuários apontam que o MS realiza esses investimentos, porém 30,77\% afirmam que esse investimento não é significativo, o que reflete um conhecimento dessimétrico em relação ao nível de recursos destinados pelo órgão para o desenvolvimento de inovações, de acordo com Figura 17. Essa variável, proposta por Bloch et al. (2009) como um dos principais fatores antecedentes da inovação, está relacionada com os dispêndios com o desenvolvimento da inovação, consultorias, treinamentos, entre outros. 


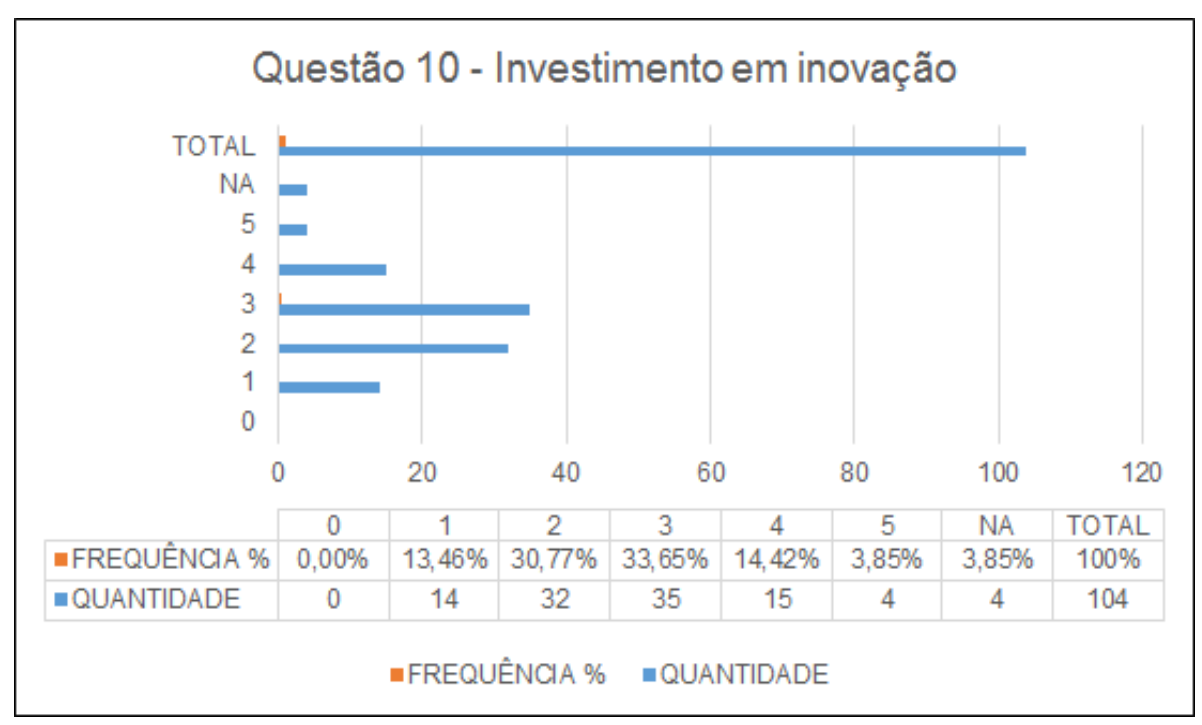

Figura 17 - Dados referentes à questão 10 sobre investimento em inovação do MS Fonte: Elaborada pela autora.

Em relação à variável apoio ao desenvolvimento de inovações, por meio de ações de educação e diversidade, que também consiste num antecedente da inovação proposto por Bloch et al. (2009), 35,58\% dos servidores que responderam ao questionário percebem que não possuem esse tipo de incentivo no MS, conforme explicitado na Figura 18, o que diverge da relevância desses aspectos apontados pelos referidos autores como características que aumentam a propensão da organização em inovar e os tipos de inovação que são desenvolvidas. 


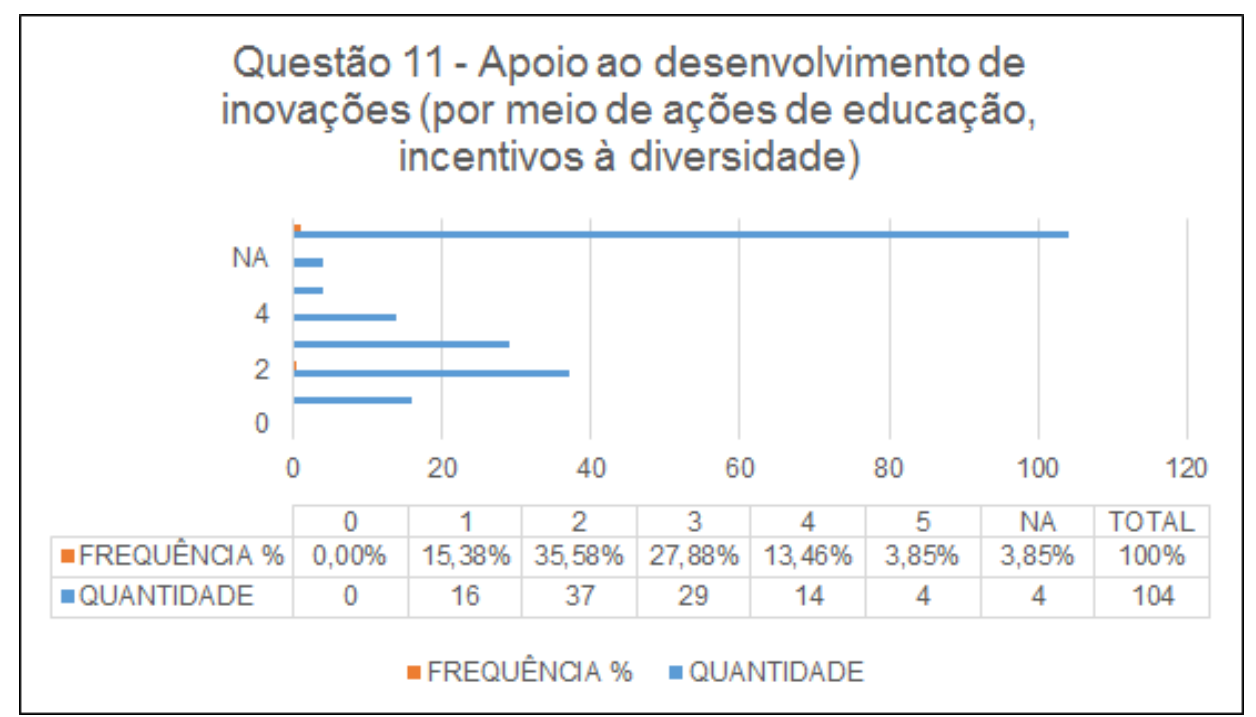

Figura 18 - Dados referentes à questão 11 sobre apoio para o desenvolvimento de inovações (por meio de ações de educação, incentivos à diversidade)

Fonte: Elaborada pela autora.

Já a Figura 19 aponta que 32,69\% dos respondentes respectivamente afirmam que o MS apresenta uma baixa disponibilização de infraestrutura tecnológica para o desenvolvimento de inovações dentro do órgão, e esses resultados corroboram a pesquisa sobre maturidade dos processos de gerenciamento de serviços de tecnologia da informação na Administração Federal Direta, realizada por Vitoriano e Souza Neto (2016), e que concluiu que os Ministérios analisados possuem uma baixa maturidade em todos os processos de Gerenciamento de Serviços de Tecnologia da Informação (GSTI). 


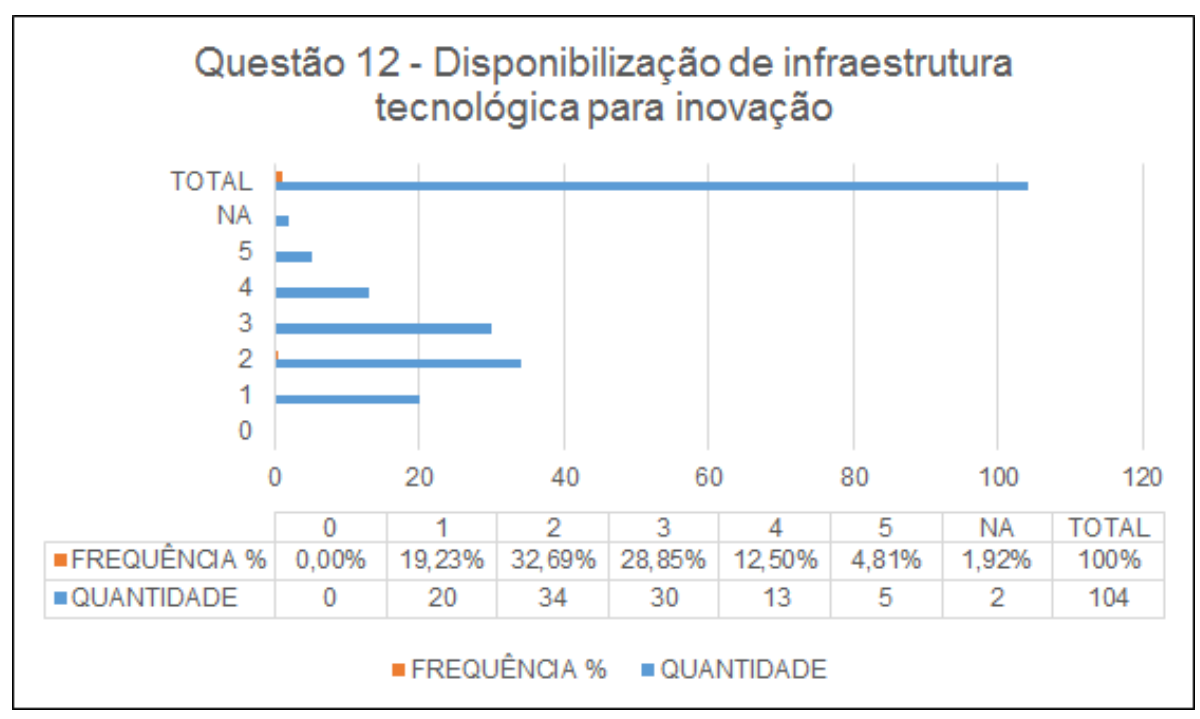

Figura 19 - Dados referentes à questão 12 sobre a disponibilização de infraestrutura tecnológica para inovação no MS

Fonte: Elaborada pela autora.

E a percepção do gestor como principal fonte de inovação dentro do órgão, apresenta que 25,96\% dos respondentes, de acordo com Figura 20, apontaram não perceber o gestor como ator relevante para o desenvolvimento de inovações no MS, porém as respostas refletem uma baixa concordância em relação ao aspecto do papel da liderança para o fomento dessas inovações, o que para o FNQ (2015) se configura como a atuação e o envolvimento dos líderes das organizações como aspecto fundamental para a construção de uma cultura inovadora. 


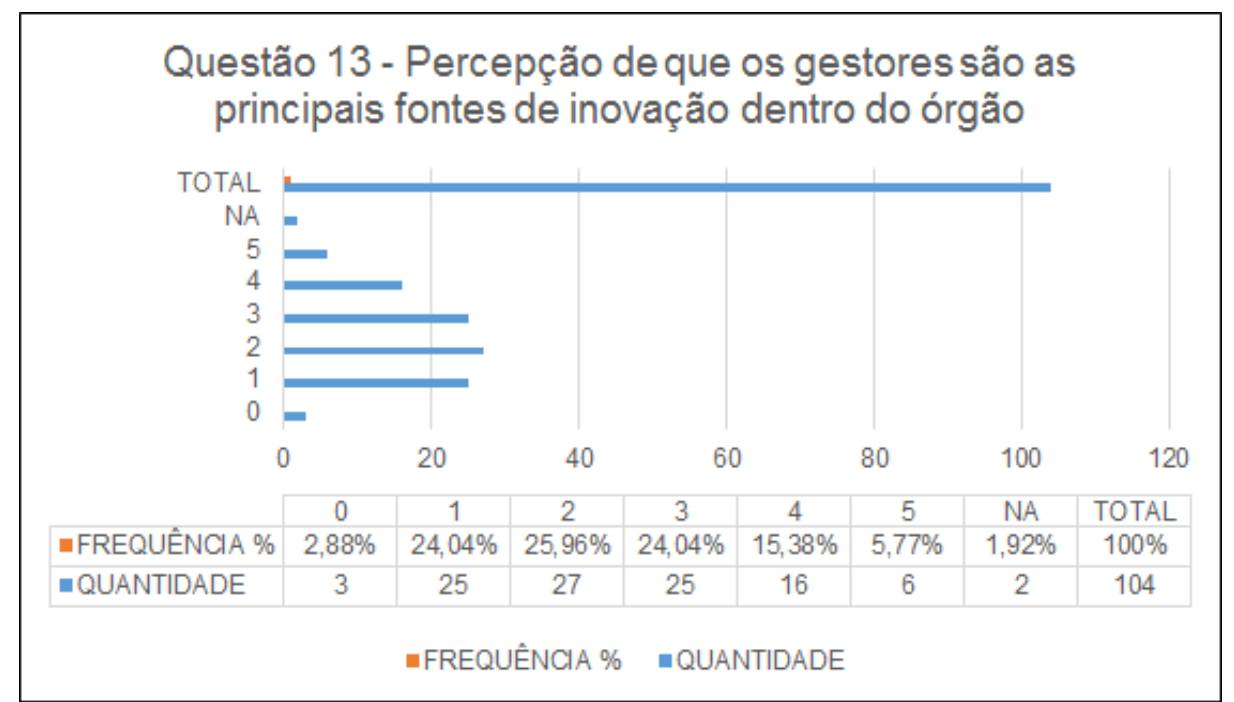

Figura 20 - Dados referentes à questão 13 sobre a percepção que os gestores são as principais fontes de inovação dentro do MS

Fonte: Elaborada pela autora.

Outrossim, a percepção de que os servidores são as principais fontes de inovação no MS foi apontada por $29,81 \%$ dos respondentes, porém 26,92\% afirmam que não concordam com essa premissa, o que mais uma vez reflete a heterogeneidade das opiniões dos servidores do MS quanto à sua participação nos projetos de inovação desenvolvidos pelo órgão, de acordo com Figura 21. Esses dados se contrapõem ao destaque dado pelo FNQ (2015) às pessoas como meios de consolidar uma cultura de inovação, através do estímulo à capacidade criativa, o aprendizado entre os profissionais e à gestão dos conhecimentos disponíveis. 


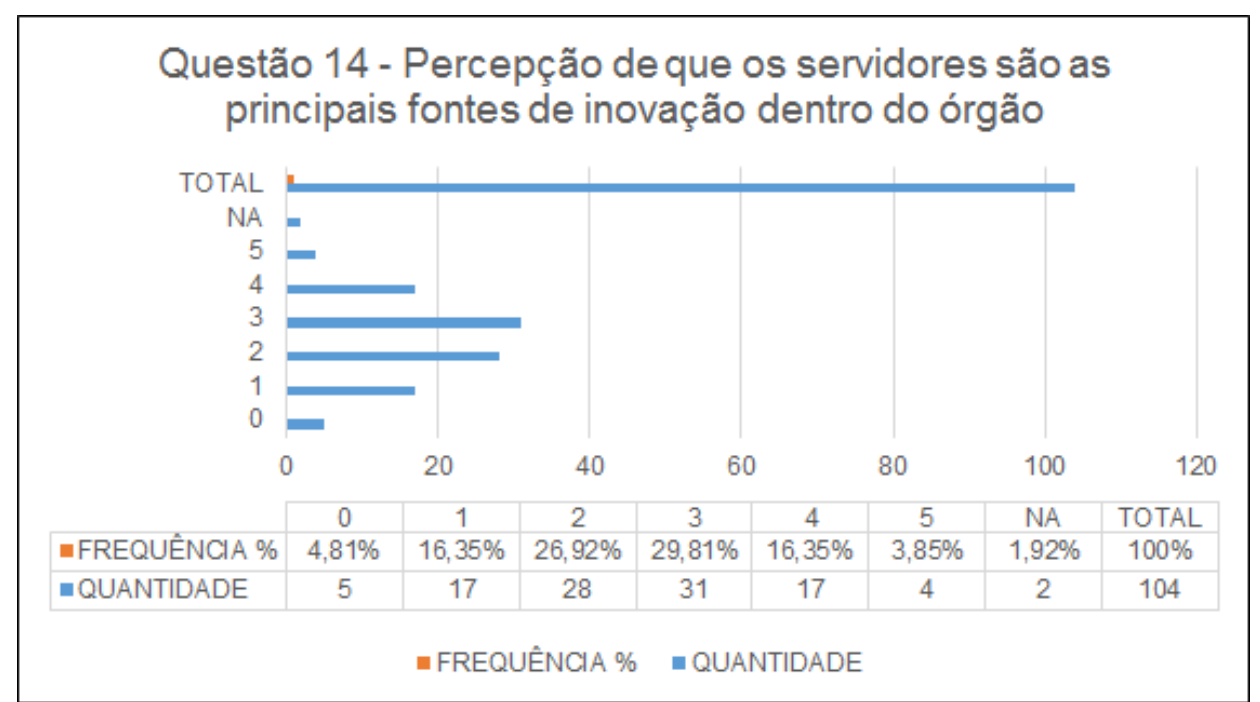

Figura 21 - Dados referentes à questão 14 sobre a percepção que os servidores são as principais fontes de inovação dentro do MS

Fonte: Elaborada pela autora.

Quanto ao desenvolvimento de inovações para atendimento de prioridades políticas, 25,96\% dos servidores apontaram que percebem um favorecimento de projetos inovadores a partir de diretrizes políticas dentro do MS, o que reflete o disposto por Bloch et al. (2009) como uma condição estrutural relevante para o desenvolvimento de inovações no setor público. Esse resultado, explicitado na Figura 22, corrobora a pesquisa de Hollanders et al. (2013), os quais afirmam que as prioridades políticas são um dos principais indutores da inovação no setor público. 


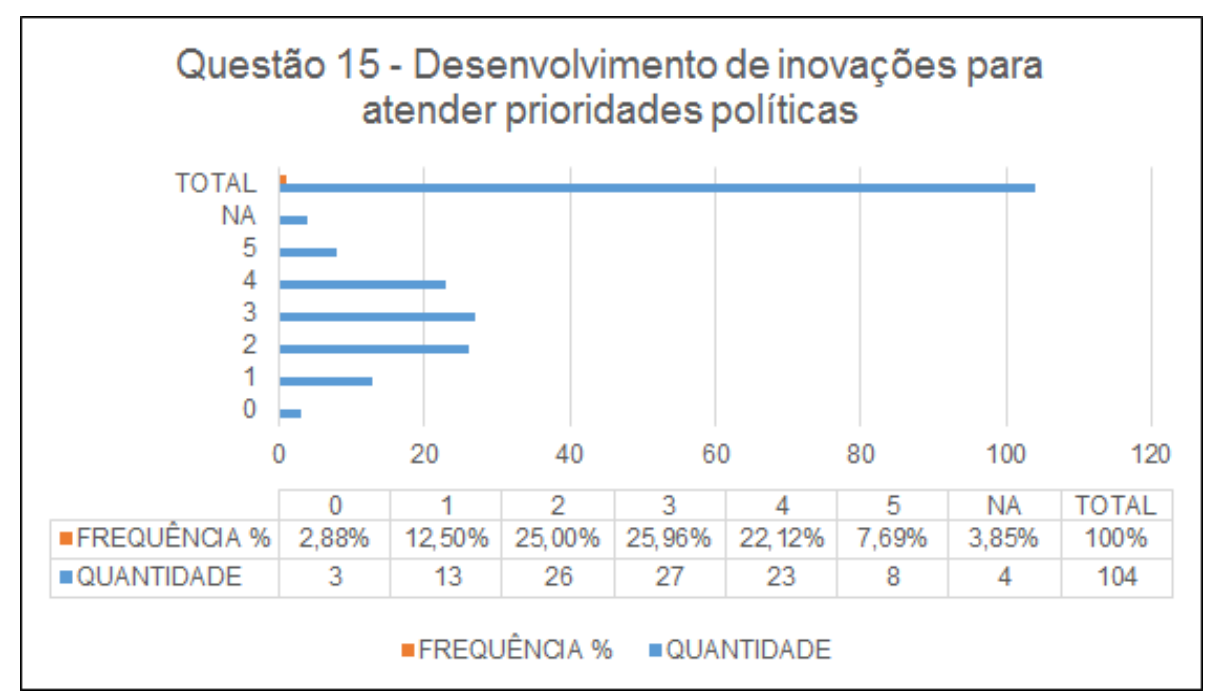

Figura 22 - Dados referentes à questão 15 sobre o desenvolvimento de inovações para atender a prioridades políticas

Fonte: Elaborada pela autora.

Em relação à atuação em redes do MS com outras organizações para o desenvolvimento de inovações que se apresenta na Figura 23, 31,73\% dos servidores analisaram que o órgão não opera de forma a interagir com outras organizações em prol dessa inovação, o que não está em consonância com a importância da utilização das redes como forma de disseminar o conhecimento, promover e assegurar a implementação dos projetos de inovação, de acordo com propostas da FNQ (2015) para a gestão da inovação. 


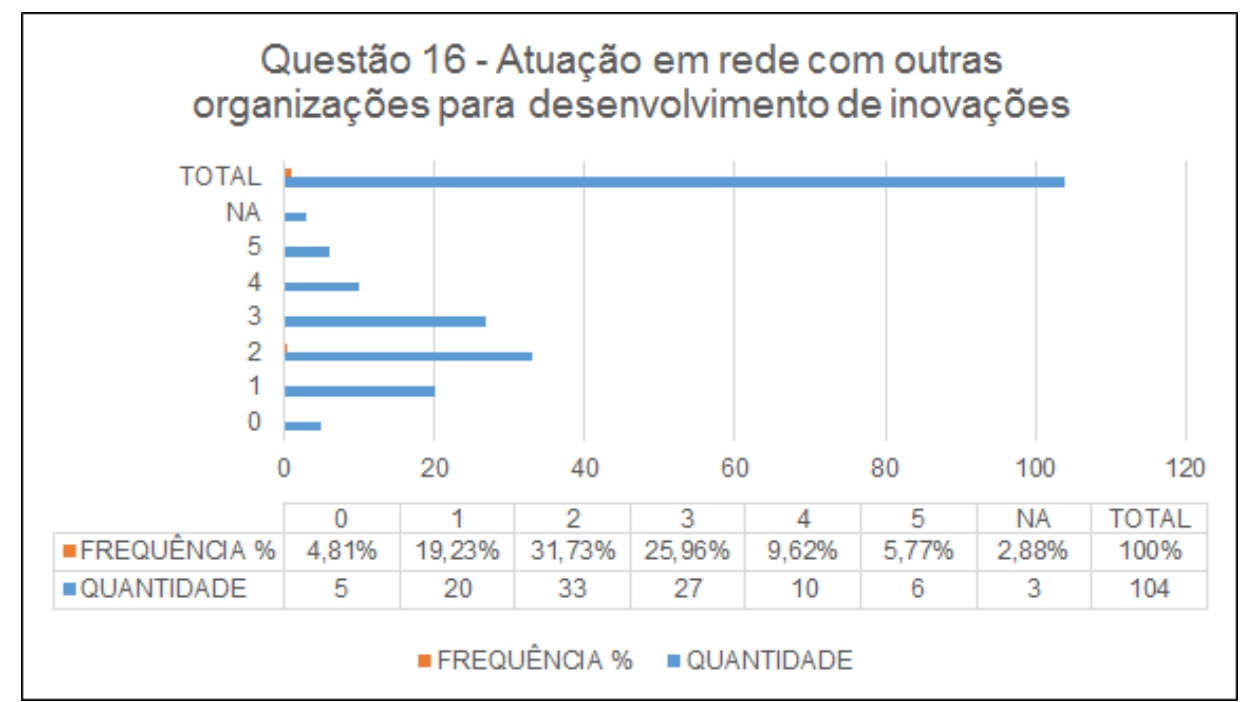

Figura 23 - Dados referentes à questão 16 sobre atuação em rede do MS com outras organizações para o desenvolvimento de inovações

Fonte: Elaborada pela autora.

Para inovar, as organizações públicas precisam observar os aspectos legais, que estão diretamente relacionados com os antecedentes da inovação propostos por De Vries, Bekkers e Tummers (2015). No caso do MS, a Figura 24 apresenta que 25\% dos respondentes apontaram que o órgão observa esses aspectos no desenvolvimento das suas inovações, o que ressalta os dados apresentados pelos referidos autores que consideram a observância da legislação como um antecedente ambiental importante para facilitar ou dificultar a promoção de inovações no setor público. 


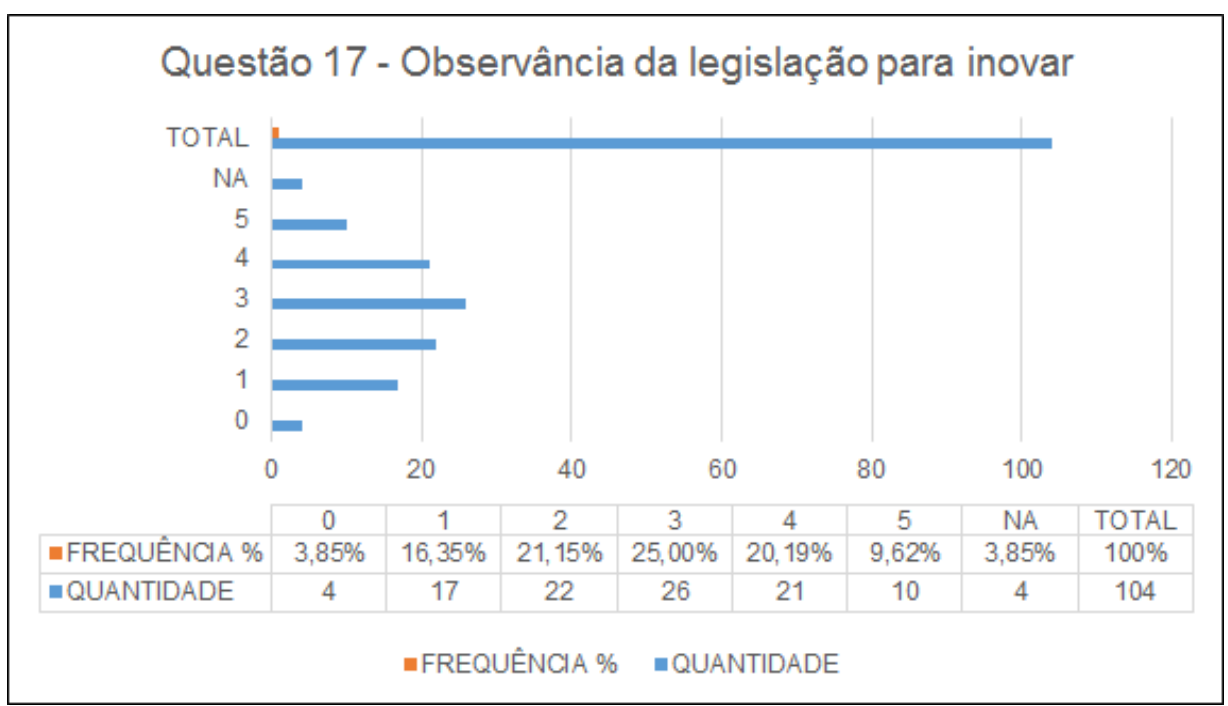

Figura 24 - Dados referentes à questão 17 sobre observância da legislação por parte do MS para o desenvolvimento de inovações

Fonte: Elaborada pela autora

Considerando a variável ambiental denominada utilização de inovações que estão sendo adotadas por organizações compatíveis, o questionário apontou na Figura 25, um conhecimento assimétrico em relação a essa variável por parte dos respondentes. No entanto, o grupo focal do gestor apontou que a inovação do MS, no caso o PEC, foi adotada de outra organização do setor de saúde que já utilizava o software nos seus processos de compras de medicamentos e insumos para a saúde e era uma experiência de sucesso. Dessa forma, essa adoção de inovações proveniente de outras organizações também reflete um isomorfismo mimético das organizações públicas apontado por DiMaggio e Powell (1991). 


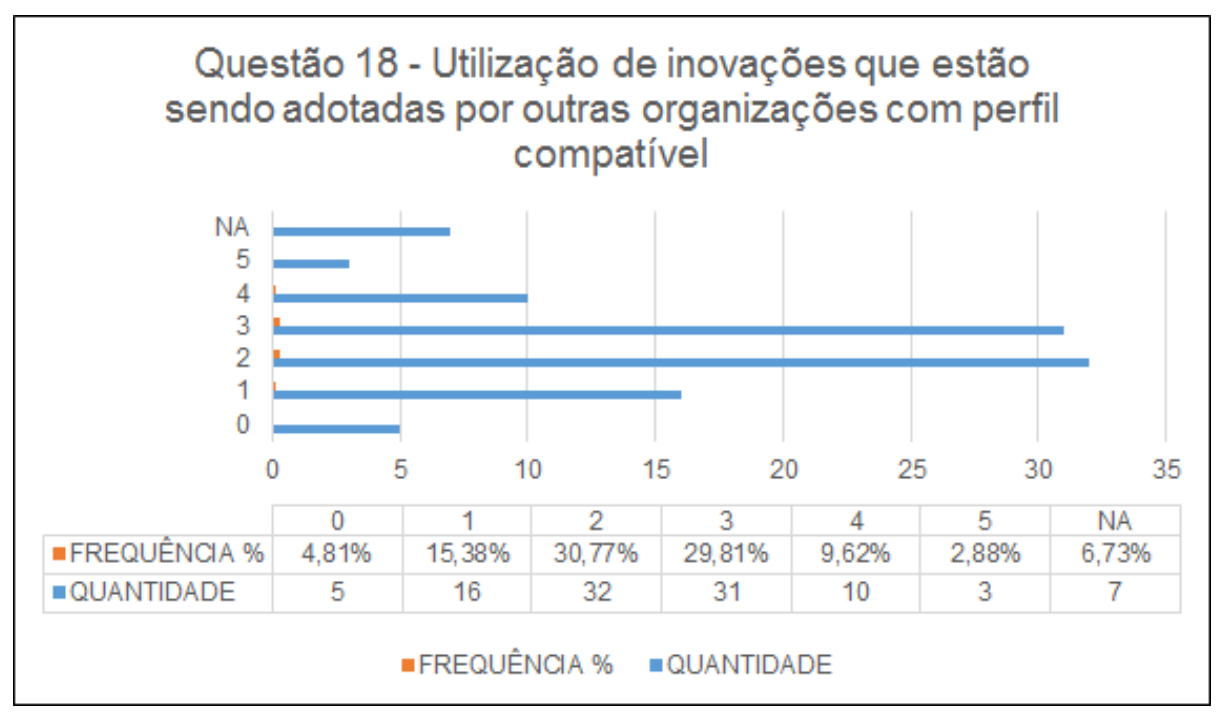

Figura 25 - Dados referentes à questão 18 sobre utilização de inovações que estão sendo adotadas por outras organizações públicas com perfil compatível

Fonte: Elaborada pela autora.

E a disponibilidade de recursos para investimento em inovação foi indicada para $38,46 \%$ dos respondentes como um fator a ser ampliado no MS, de acordo com Figura 26. Essa variável está relacionada com os antecedentes organizacionais, que estão positivamente ligados com o desenvolvimento e adoção de inovações, de acordo como o seminal estudo realizado por Damanpour (1991) para analisar os principais fatores determinantes e moderadores da inovação organizacional. Além disso, Hollanders et al. (2013) evidenciam que a carência de recursos financeiros se evidencia com uma das barreiras mais significativas à inovação no setor público. 


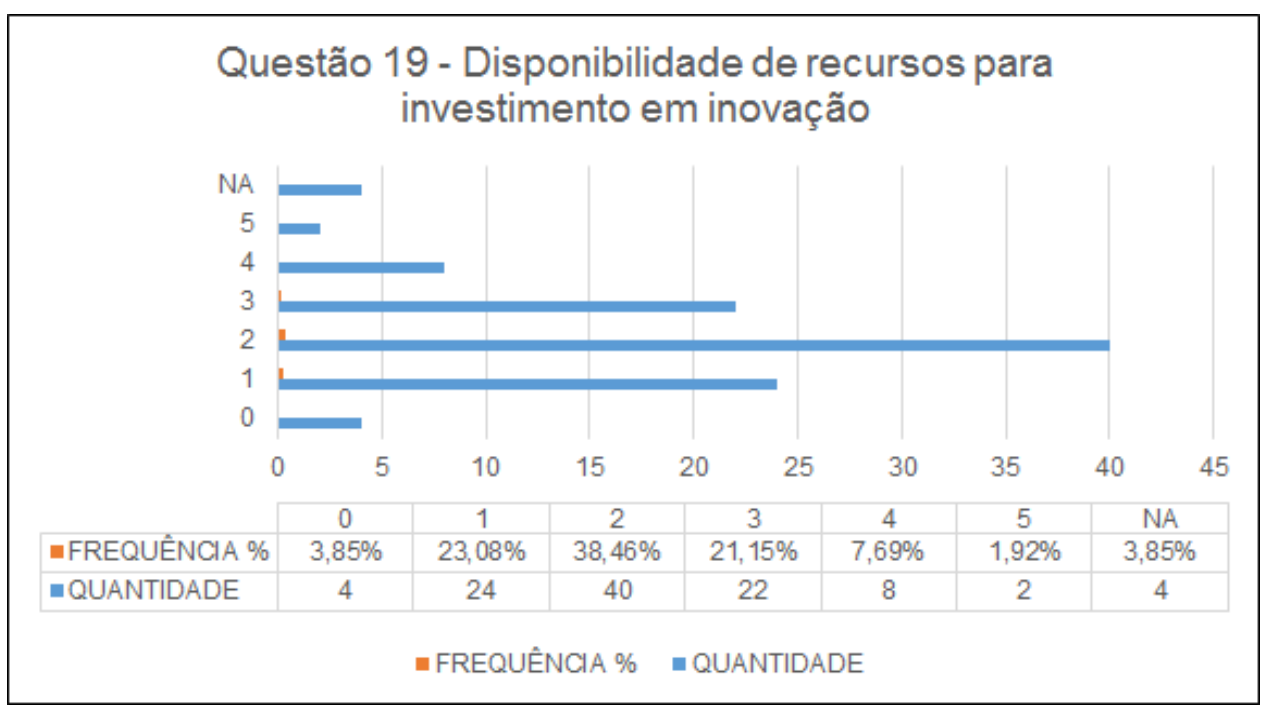

Figura 26 - Dados referentes à questão 19 sobre disponibilidade de recursos para investimento em inovação

Fonte: Elaborada pela autora.

Quanto à variável grau de aversão ao risco proposta por De Vries, Bekkers e Tummers (2015) como um antecedente organizacional para a inovação, para 25,96\% dos respondentes o MS aplica a gestão de riscos para o desenvolvimento de inovações no órgão, no entanto 24,04\% afirmam não existir essa prática, o que reflete um conhecimento assimétrico em relação a essa variável, conforme Figura 27. Segundo o FNQ (2015), todas as organizações devem gerenciar os riscos ao desenvolver inovações como forma de mitigá-los, com a utilização de técnicas de cenários, prototipação, entrevistas com especialistas, entre outras. 


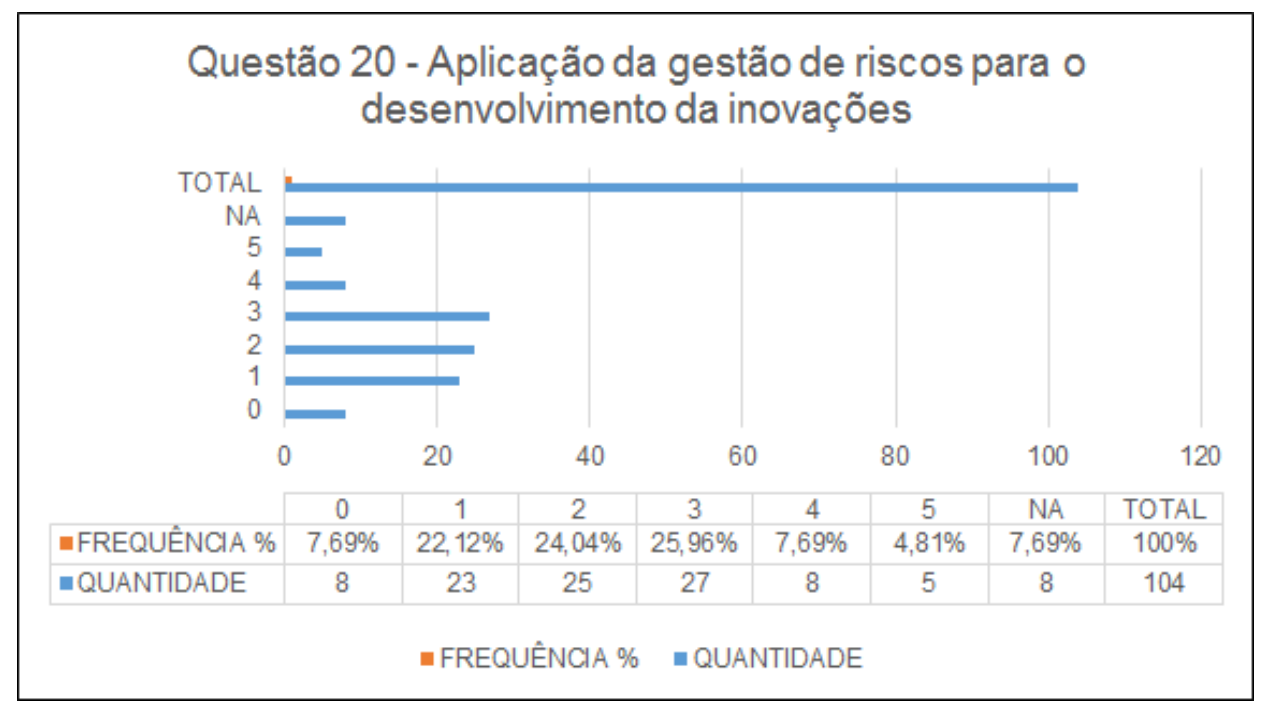

Figura 27 - Dados referentes à questão 20 sobre aplicação da gestão de riscos para o desenvolvimento de inovações no MS

Fonte: Elaborada pela autora.

Em relação às barreiras para o desenvolvimento de inovações, estas foram apontadas por 36,54\% dos respondentes do questionário como preponderantes no contexto do MS, o que representa que essas barreiras ou fatores incidem negativamente para a implementação de inovação dentro do referido órgão, de acordo com Figura 28. A existência de barreiras no contexto do MS vem corroborar o estudo realizado por Isidro-Filho, Guimarães \& Perin (2011) sobre as barreiras como um dos determinantes de inovações baseadas em tecnologia da informação e comunicação adotadas por organizações no setor de saúde, no caso os hospitais. 


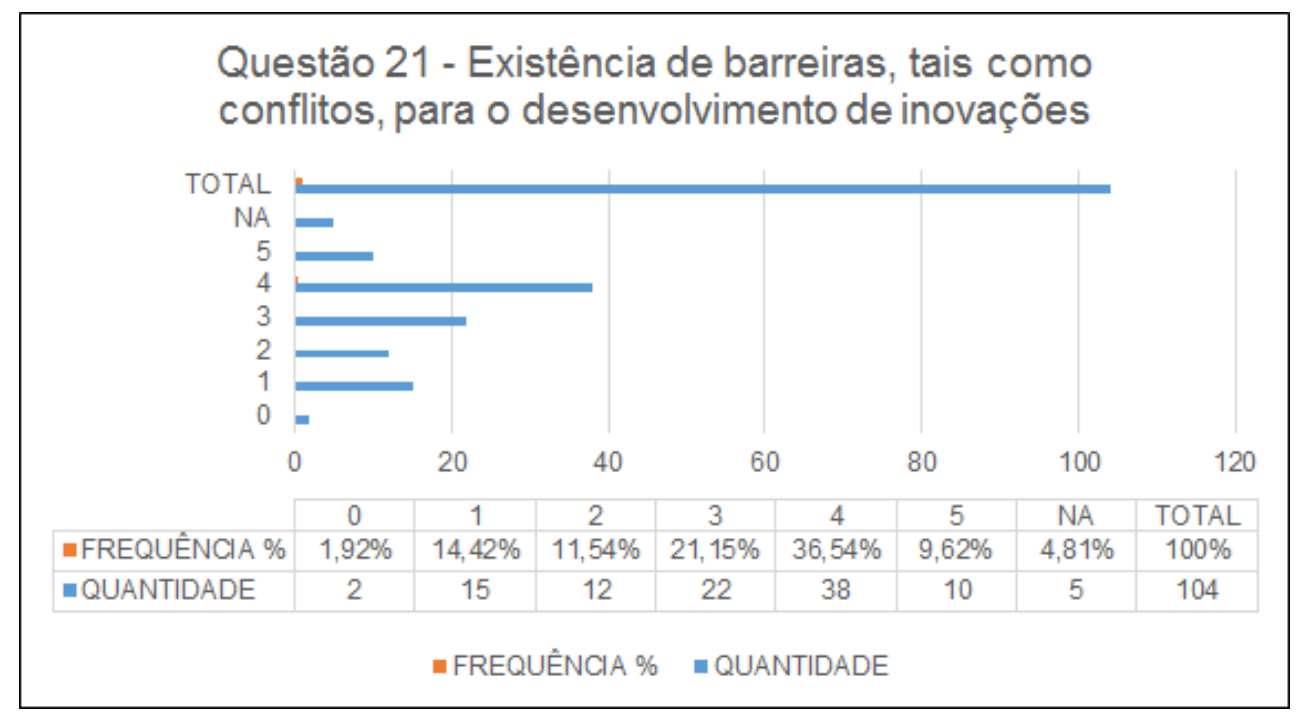

Figura 28 - Dados referentes à questão 21 sobre existência de barreiras para o desenvolvimento de inovações no MS

Fonte: Elaborada pela autora.

Quanto aos facilitadores para o desenvolvimento de inovações no contexto do MS, 28, 85\% dos servidores que responderam ao questionário apontaram como baixa existência desses fatores, consoante Figura 29. Esse resultado não corrobora com a relevância dos facilitadores ou elementos utilizados para estimular o desenvolvimento de inovações dentro do órgão, como identificados por Bloch et al. (2009). 


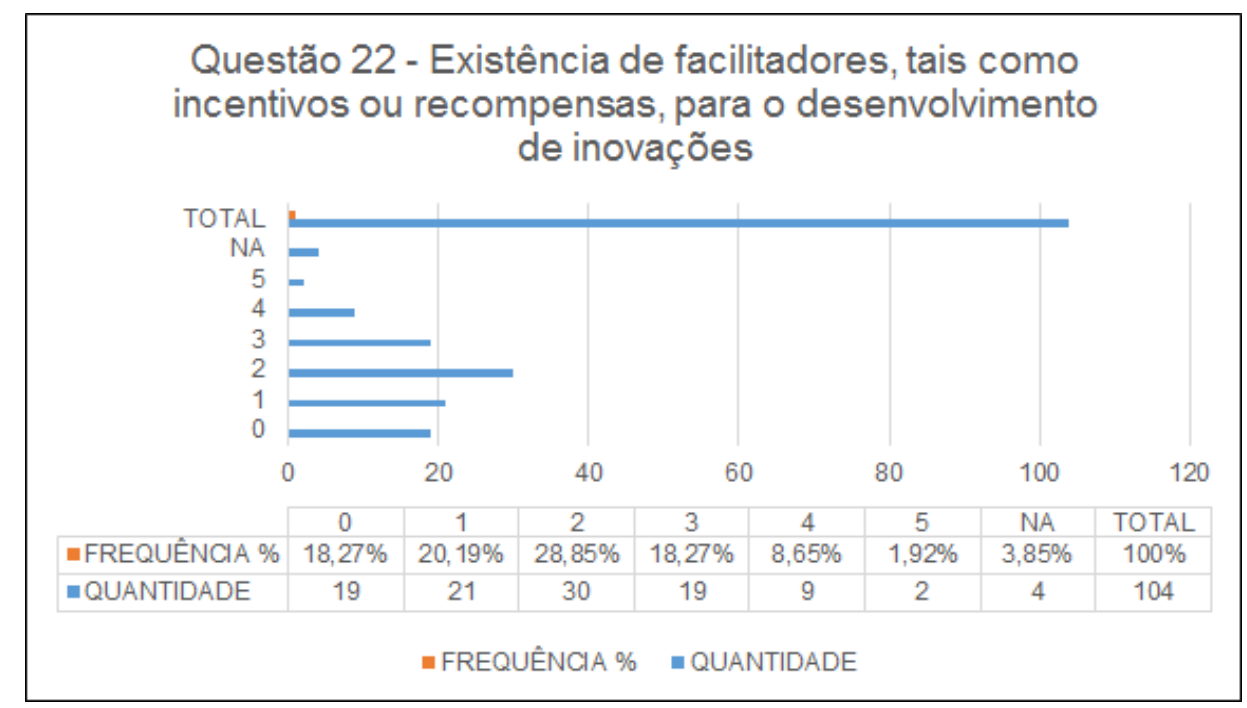

Figura 29 - Dados referentes à questão 22 sobre existência de facilitadores para o desenvolvimento de inovações no MS

Fonte: Elaborada pela autora.

De acordo com Figura 30 e com relação à variável autonomia ao servidor do MS para o desenvolvimento de inovações, $32,69 \%$ apontam que não possuem essa autonomia, fato que é de extrema importância para a criação de inovações, pois os servidores deveriam ser os efetivos agentes de inovação e mudança dentro das organizações públicas, conforme apontado pelo FNQ (2015) no tocante às práticas das organizações inovadoras. Além disso, esse resultado corrobora os achados dos autores Hollanders et al. (2013), em que a abordagem topdown de inovação se mostra prevalente no setor público. 


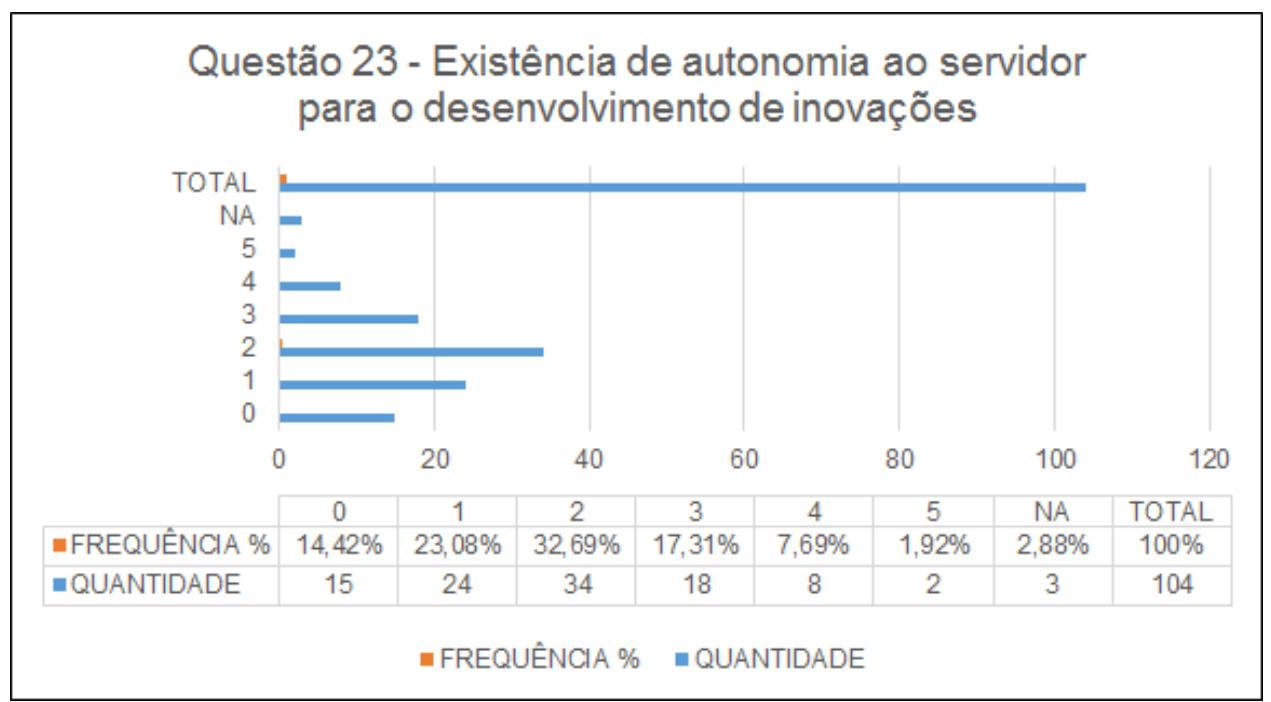

Figura 30 - Dados referentes à questão 23 sobre existência de autonomia ao servidor para o desenvolvimento de inovações no MS

Fonte: Elaborada pela autora.

Da mesma forma que a análise anterior, apresentou-se os dados relativos ao estímulo à criatividade para o desenvolvimento de inovações no MS, nos quais os servidores apontaram que $27,88 \%$ não percebem esse incentivo por parte do órgão, consoante Figura 31. Esse resultado não corrobora com a relação intrínseca entre criatividade e o desenvolvimento de inovações apontadas pelo FNQ (2015) como meio de fomentar as ideias no processo de inovação. 


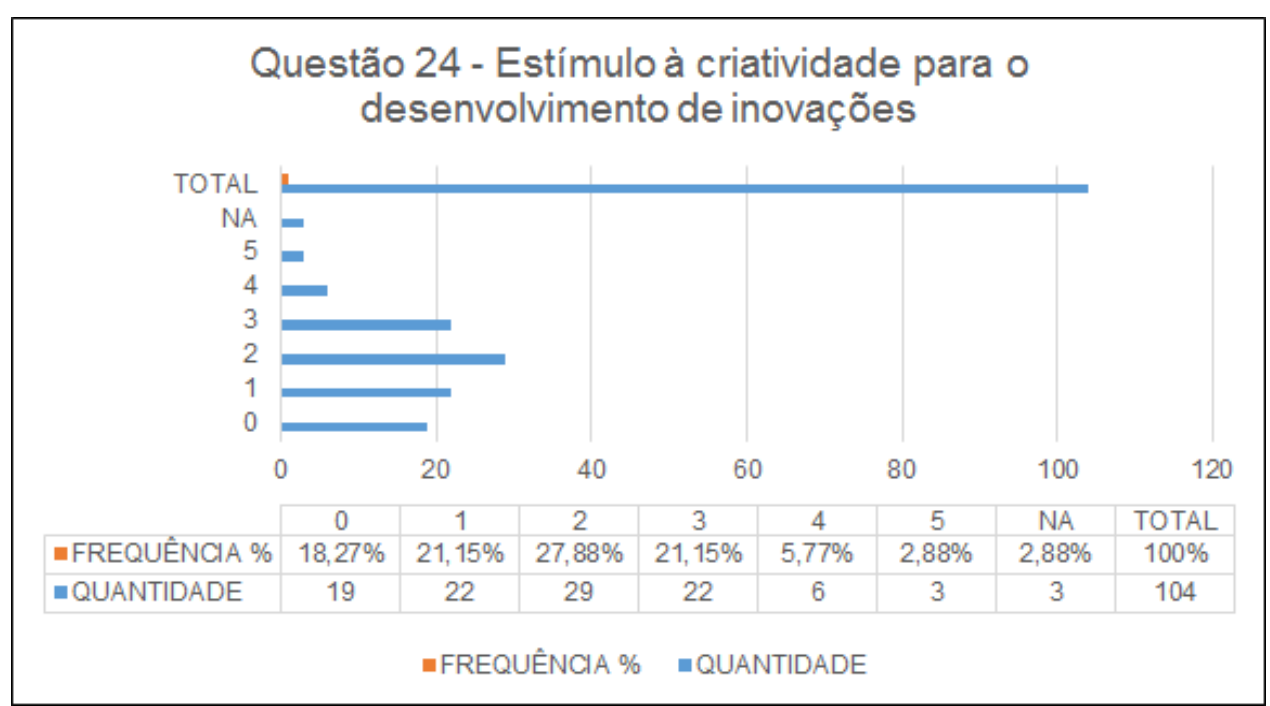

Figura 31 - Dados referentes à questão 24 sobre estímulo à criatividade para o desenvolvimento de inovações no MS

Fonte: Elaborada pela autora.

Quanto à formação de equipes multidisciplinares para o desenvolvimento de inovações no MS, de acordo com Figura 32, 27,88\% dos servidores afirmam que não percebem essa prática como habitual no MS, e essa percepção não está em aderência com a relevância de um ambiente interno inovador, onde a criatividade, a variedade de pensamentos dos indivíduos e a capacidade de relacionamento e articulação sejam estimulados, conforme fator denominado equipes multifuncionais, apontado por Resende (2014) como essencial em organizações orientadas para inovação. 


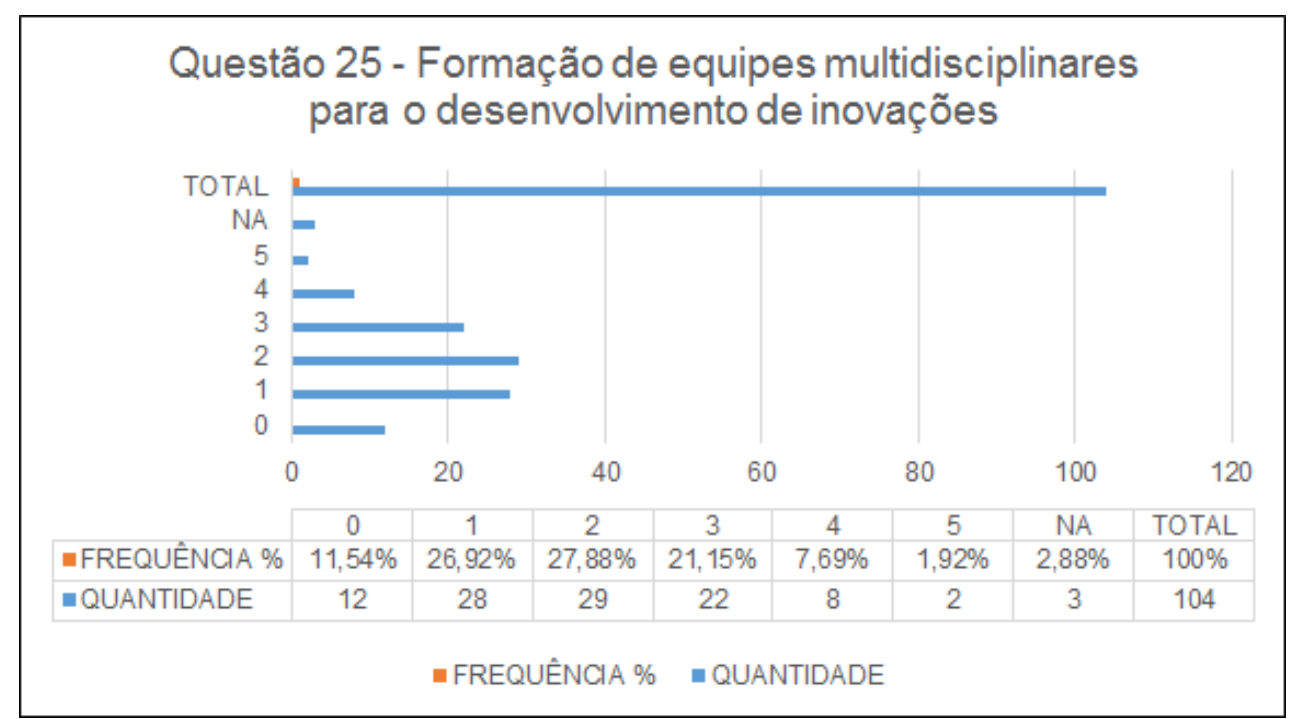

Figura 32 - Dados referentes à questão 25 sobre formação de equipes multidisciplinares para o desenvolvimento de inovações no MS

Fonte: Elaborada pela autora.

A percepção de que o foco no comprometimento com o trabalho influencia positivamente no desenvolvimento de inovações foi percebido por $25,96 \%$ dos servidores respondentes, porém 23,08\% apontam não perceber essa relação, o que reflete uma análise assimétrica por parte dos respondentes, de acordo com Figura 33. Essa variável é apontada pelos autores De Vries, Bekkers e Tummers (2015) como um antecedente individual importante para o processo de inovação e diretamente relacionado com a motivação dos indivíduos para inovar. 


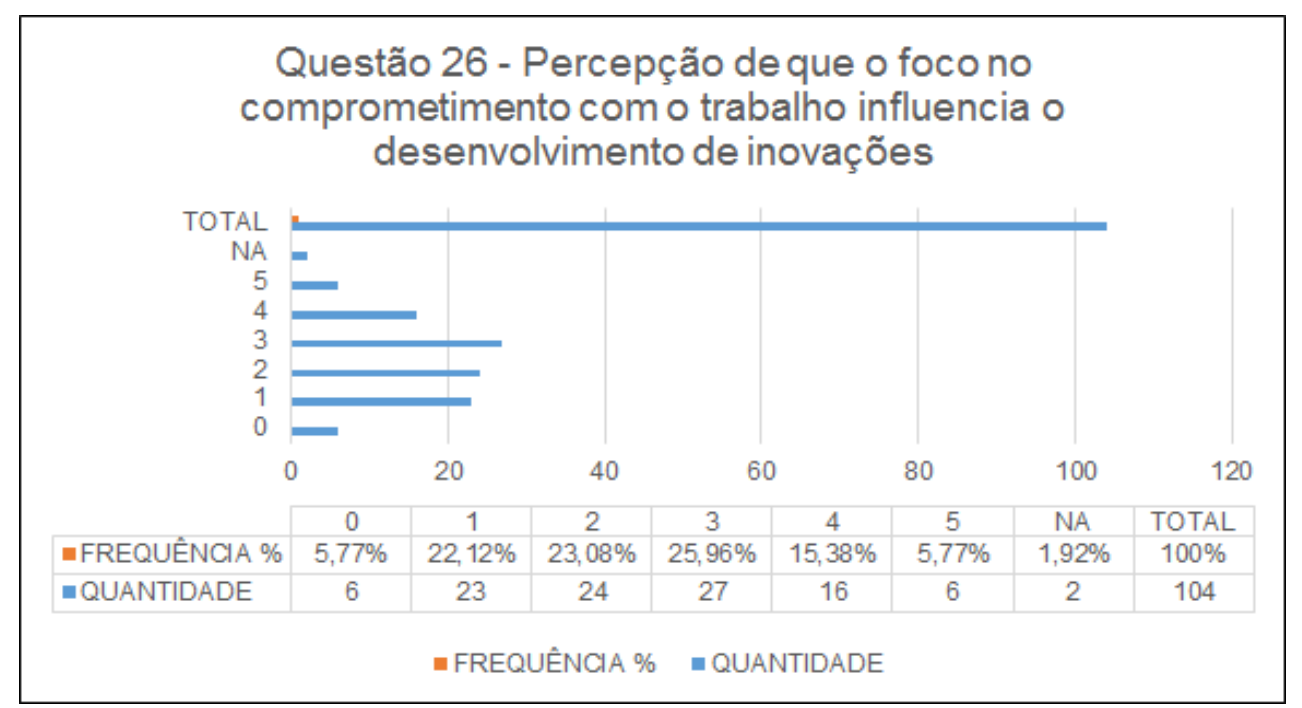

Figura 43 - Dados referentes à questão 26 sobre o comprometimento com o trabalho para o desenvolvimento de inovações no MS

Fonte: Elaborada pela autora.

No mesmo sentido, a satisfação com o trabalho foi apontada por $26,92 \%$ dos servidores como relevante para o desenvolvimento de inovações dentro do MS, de acordo com Figura 34, o que ressalta a importância da satisfação no trabalho proporcionada por fatores diversos encontrados no ambiente de trabalho. Limongi-França (2005) ratifica esse entendimento quando destaca aspectos para promoção da qualidade de vida no trabalho das organizações e que colaboram com a satisfação dos empregados, dentre os quais se destacam: atenção às pessoas, condições de trabalho, sistemas de avaliação e recompensas, e por fim, ambiente interno. 


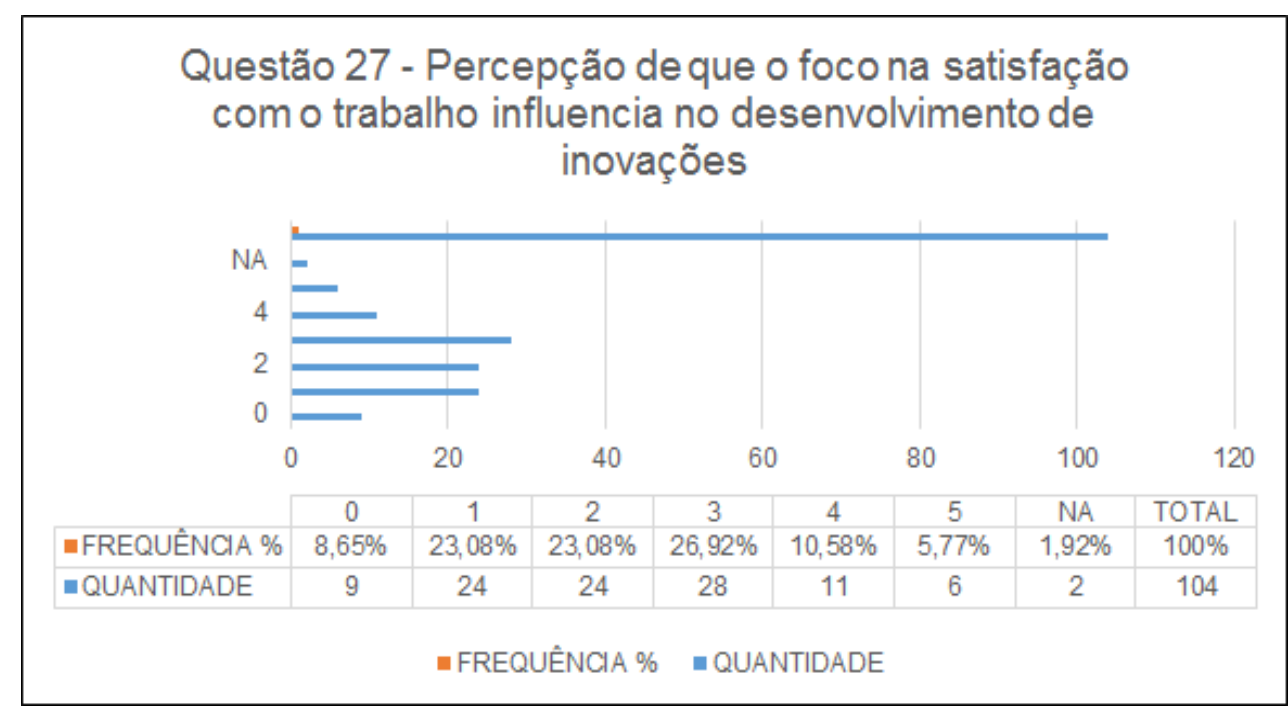

Figura 34 - Dados referentes à questão 27 sobre a satisfação com o trabalho para o desenvolvimento de inovações no MS

Fonte: Elaborada pela autora.

A questão 28 está relacionada com o compartilhamento de conhecimento relativo ao desenvolvimento de inovações dentro do MS, de acordo com Figura 35, e 29,81\% dos respondentes sinalizaram que não percebem essa prática dentro do órgão. Esse resultado contrapõe o fator denominado por Resende (2014) de partilha da informação, o qual consiste no compartilhamento da informação entre equipes de desenvolvimento de projetos nas organizações orientadas para a inovação. 


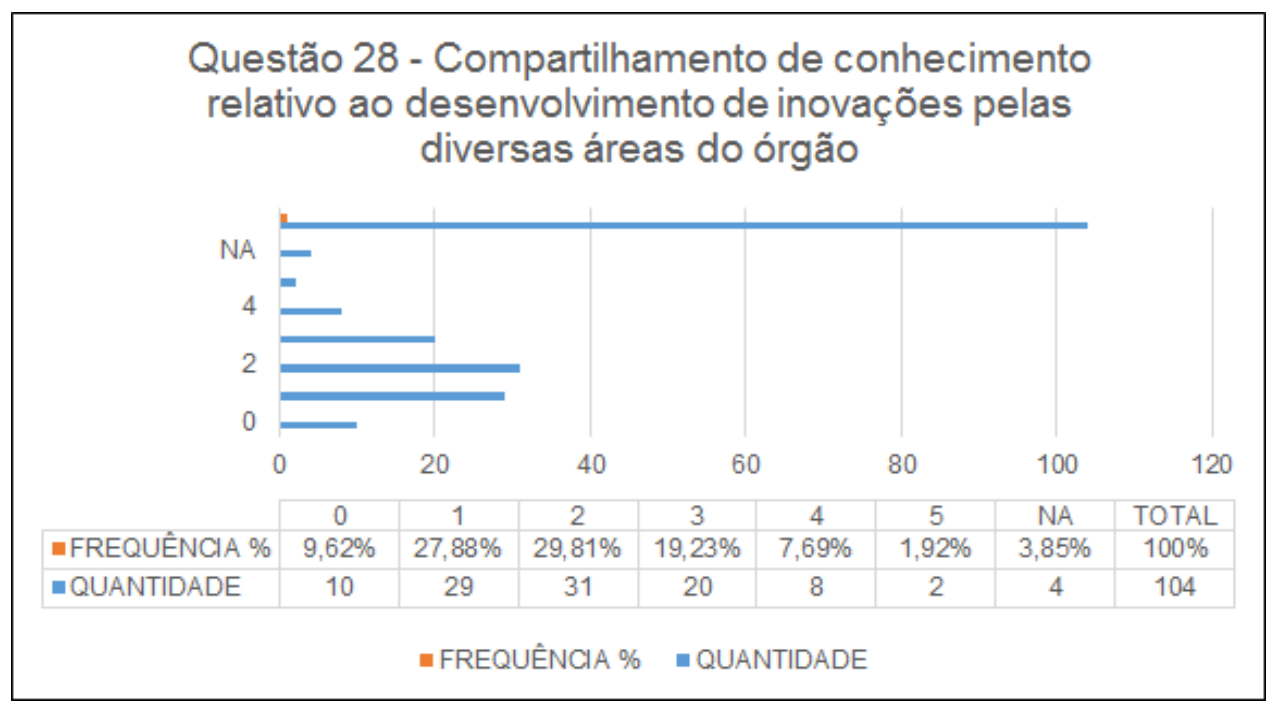

Figura 35 - Dados referentes à questão 28 sobre o compartilhamento de conhecimento sobre inovação dentro do MS

Fonte: Elaborada pela autora.

Já as variáveis relacionadas com o processo de inovação, consoante Figura 36, o desenvolvimento de estratégia para a inovação não foi percebido por 32,69\% dos respondentes como prática de gestão existente no MS. Esses resultados contrariam a relevância que o foco estratégico, através do planejamento de médio e longo prazos, possui para a implementação de inovações, conforme fator identificado por Resende (2014).

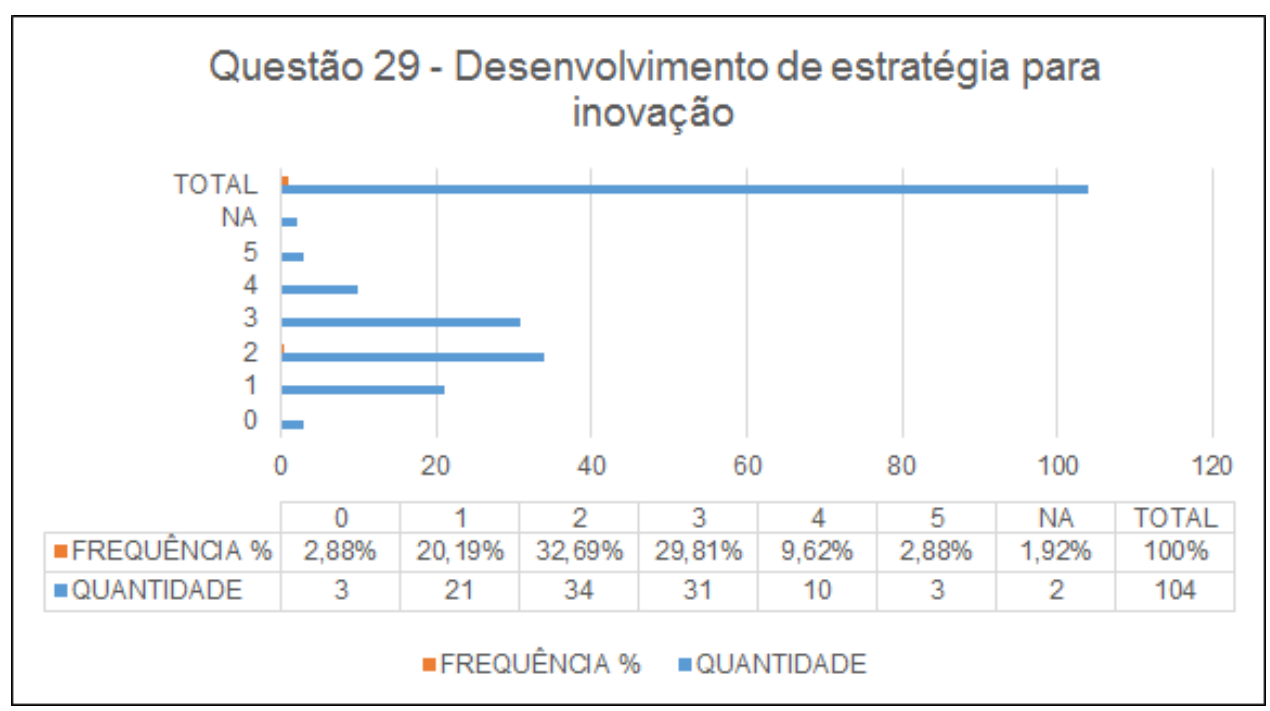

Figura 36 - Dados referentes à questão 29 sobre o desenvolvimento de estratégia para inovação dentro do MS

Fonte: Elaborada pela autora.

Quanto ao desenvolvimento de atividades que visam a difusão da inovação, $29,81 \%$ dos servidores apontam que o MS se utiliza de tais práticas, no entanto, 28,85\% não 
reconhecem esses processos de propagação, o que representa uma falta de consistência nas respostas dadas, conforme Figura 37. A difusão da inovação é considerada por Rogers (2003) essencial para o progresso social, na qual a informação percebida subjetivamente sobre uma nova ideia ou inovação é comunicada aos demais interessados.

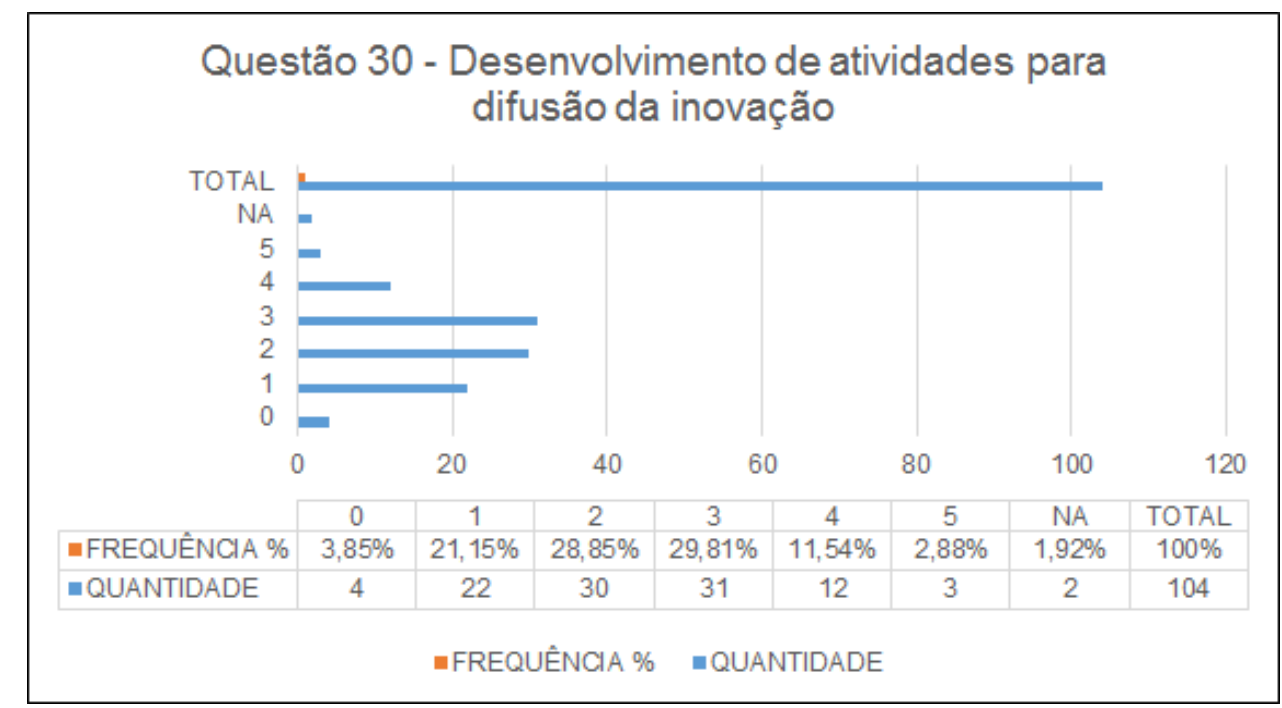

Figura 37 - Dados referentes à questão 30 sobre o desenvolvimento de atividades para difusão da inovação

Fonte: Elaborada pela autora.

A Figura 38 apresenta os resultados referentes ao incentivo às atividades de colaboração e aprendizado para a inovação dentro do processo de inovação, e para 29,81\% o MS apresenta tais incentivos, contudo para 25,96\% o referido órgão não promove tais atividades, o que representa uma discordância entre os servidores que responderam ao questionário. Esse incentivo às atividades de colaboração e aprendizado para a inovação nas organizações públicas está relacionado com os fatores partilha da informação e formação e educação, os quais consistem respectivamente no compartilhamento de informações entre as equipes envolvidas com projetos de inovação e na qualificação dos empregados em processos de inovação e negócios (Resende, 2014). 


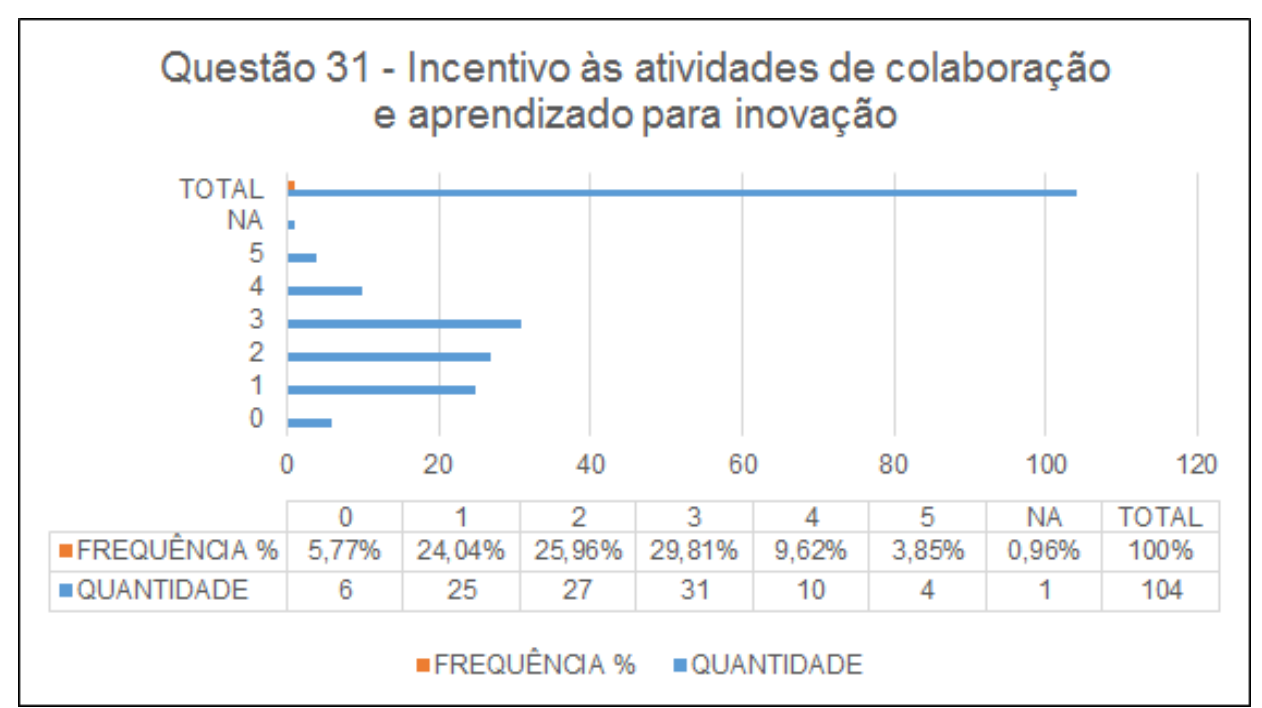

Figura 38 - Dados referentes à questão 31 sobre as atividades de colaboração e aprendizado para inovação

Fonte: Elaborada pela autora.

E, por fim, a variável de cultura organizacional foi abordada na Figura 39 como fator que favorece o desenvolvimento de inovações no MS, porém 31,73\% percebem que a mesma não beneficia os processos de inovação dentro do órgão. Uma cultura organizacional, cujo conjunto de valores e práticas constitui um ambiente que estimula as iniciativas de inovação promovem um meio inovador interno dentro das organizações, de acordo com apontamentos do FNQ (2015) relativos aos pressupostos das organizações consideradas inovadoras. 


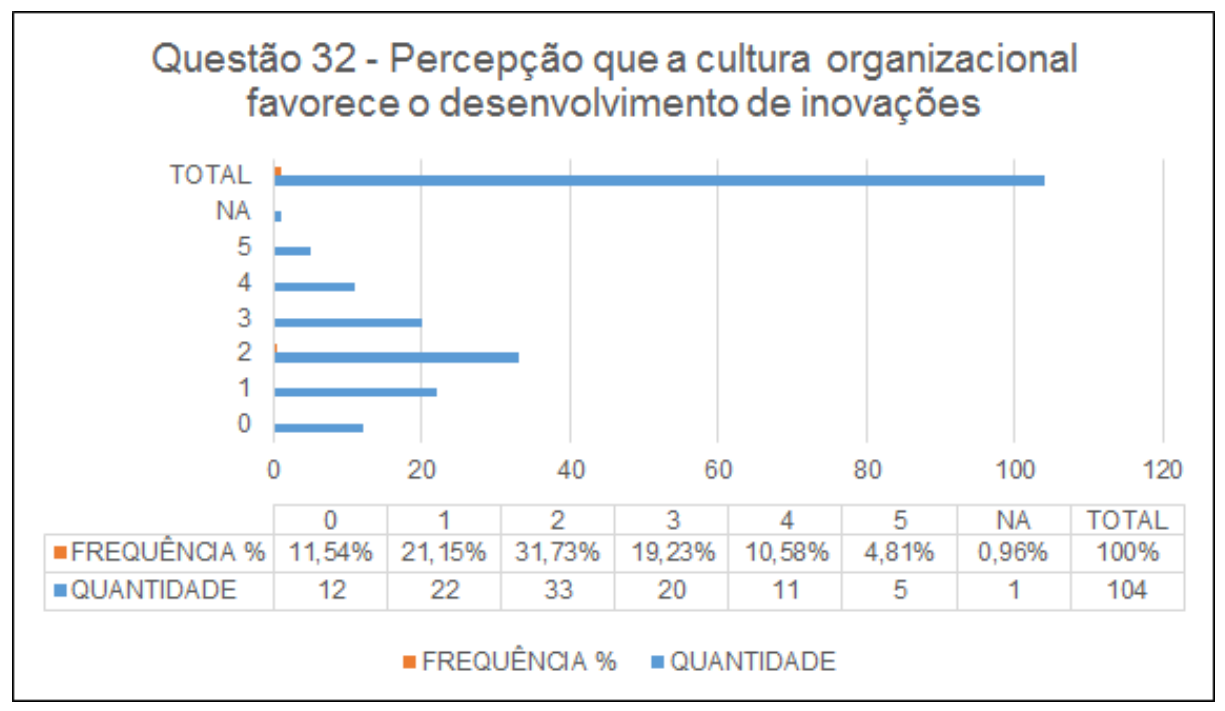

Figura 39 - Dados referentes à questão 32 sobre a cultura organizacional favorecendo o desenvolvimento de inovações

Fonte: Elaborada pela autora.

Quanto aos resultados obtidos com a aplicação dos questionários no MS, os mesmos foram analisados através da AFE com a utilização do software SPSS. No entanto, antes de proceder a AFE, faz-se necessário realizar uma análise descritiva das variáveis estudadas de acordo com dados coletados na pesquisa, conforme Tabela 10.

Tabela 10 - Resultados da análise dos dados do questionário aplicado no MS

\begin{tabular}{|c|c|c|c|c|c|}
\hline Questão & Média & Mediana & Moda & $\begin{array}{l}\text { Desvio- } \\
\text { padrão }\end{array}$ & $\begin{array}{l}\text { Coeficiente de } \\
\text { Variação } \\
\end{array}$ \\
\hline 1) Possui facilidade de uso. & 3,67 & 4 & 4 & 1,08 & $30 \%$ \\
\hline $\begin{array}{l}\text { 2) Proporciona vantagem relativa ao } \\
\text { processo físico (papel). }\end{array}$ & 4,15 & 4 & 5 & 1,11 & $27 \%$ \\
\hline $\begin{array}{l}\text { 3) É compatível com outros sistemas } \\
\text { dentro do Ministério da Saúde. }\end{array}$ & 2,16 & 2 & 3 & 1,56 & $72 \%$ \\
\hline $\begin{array}{l}\text { 4) É considerado uma inovação no } \\
\text { processo de compras }\end{array}$ & 3,99 & 4 & 5 & 1,17 & $29 \%$ \\
\hline $\begin{array}{l}\text { 5) Gera benefícios intangíveis, tais } \\
\text { como melhoria na segurança da } \\
\text { informação, nas compras de } \\
\text { medicamentos do Ministério da } \\
\text { Saúde. }\end{array}$ & 3,71 & 4 & 4 & 1,24 & $33 \%$ \\
\hline $\begin{array}{l}\text { 6) Promove melhoria nos processos } \\
\text { de trabalho dos servidores } \\
\text { envolvidos com as compras de } \\
\text { medicamentos do Ministério da } \\
\text { Saúde. }\end{array}$ & 3,95 & 4 & 4 & 1,16 & $29 \%$ \\
\hline
\end{tabular}


7) Melhora o processo de compra relativo aos medicamentos adquiridos pelo Ministério da Saúde para posterior distribuição aos Estados e Municípios.

8) Proporciona transparência da informação pública relativa aos processos de compras de medicamentos do Ministério da Saúde.

9) Promove sustentabilidade nas compras de medicamentos do Ministério da Saúde?

10) Investimento em Inovação.

11) Apoio ao desenvolvimento de inovações (por meio de ações de educação, incentivos à diversidade).

12) Disponibilização de infraestrutura tecnológica para inovação.

13) Percepção de que os gestores são as principais fontes de inovação dentro do órgão.

14) Percepção de que os servidores são as principais fontes de inovação dentro do órgão.

15) Desenvolvimento de inovações para atender a prioridades políticas.

16) Atuação em rede com outras organizações para desenvolvimento de inovações.

17) Observância da legislação para inovar.

18) Utilização de inovações que estão sendo adotadas por outras organizações públicas com perfil compatível.

19) Disponibilidade de recursos para investimento em inovação. para o desenvolvimento das inovações.

21) Existência de barreiras, tais como conflitos, para o desenvolvimento das inovações.

$\begin{array}{llll}3,1 & 3 & 4 & 1,31\end{array}$

22) Existência de facilitadores, tais como incentivos ou recompensas, para o desenvolvimento de inovações.

23) Existência de autonomia ao servidor para o desenvolvimento de inovações.

24) Estímulo à criatividade para o desenvolvimento de inovações. 
26) Percepção de que o foco no comprometimento com o trabalho influencia o desenvolvimento de inovações.

27) Percepção de que o foco na satisfação com o trabalho influencia o desenvolvimento de inovações.

28) Compartilhamento de conhecimento relativo ao desenvolvimento de inovações pelas diversas áreas do órgão.

29) Desenvolvimento de estratégia para inovação.

$\begin{array}{lllll}2,41 & 2 & 3 & 1,32 & 55 \%\end{array}$

$\begin{array}{lllll}2,25 & 2 & 3 & 1,33 & 59 \%\end{array}$

30) Desenvolvimento de atividades para difusão (propagação) da inovação.

31) Incentivo às atividades de colaboração e aprendizado para inovação.

32) Percepção que a cultura organizacional favorece 0 desenvolvimento de inovações.

$\begin{array}{lllll}2,25 & 2 & 3 & 1,33 & 59 \%\end{array}$

$\begin{array}{lllll}1,93 & 2 & 2 & 1,18 & 61 \%\end{array}$

$\begin{array}{lllll}2,32 & 2 & 2 & 1,09 & 47 \%\end{array}$

$\begin{array}{lllll}2,33 & 2 & 3 & 1,15 & 49 \%\end{array}$

$\begin{array}{lllll}2,25 & 2 & 3 & 1,21 & 54 \%\end{array}$

$\begin{array}{lllll}2,11 & 2 & 2 & 1,32 & 63 \%\end{array}$

Fonte: Elaborada pela autora a partir dos dados do software SPSS.

A análise dos dados indica que, no caso dos questionários aplicados no MS, os maiores coeficientes de variação são observados nas questões de números 3,22 e 24 . A questão 3: é compatível com outros sistemas dentro do Ministério da Saúde, apresentou coeficiente de variação de 72\%; a questão 22: existência de facilitadores, tais como incentivos ou recompensas, para o desenvolvimento de inovações, apresentou coeficiente de variação de 71\%; e por fim, a questão 24: estímulo à criatividade para o desenvolvimento de inovações, apontou um coeficiente de variação de $71 \%$. Esses resultados refletem um conhecimento assimétrico de como essas variáveis de inovação são tratadas e percebidas no MS.

Posteriormente, e em decorrência dessa assimetria, os dados foram analisados separadamente em dois grupos de representam os setores de trabalho dentro do MS: usuários do DLOG, área responsável pelas compras de medicamentos, e usuários das demais áreas de trabalho do órgão relacionadas com essas compras. Os resultados seguem na Tabela 11. 
Tabela 11 - Resultados da análise dos dados no DLOG e outras áreas do MS

\begin{tabular}{|c|c|c|c|c|c|c|c|c|c|c|}
\hline \multirow{3}{*}{ Questão } & \multicolumn{10}{|c|}{ Setor de Trabalho } \\
\hline & \multicolumn{5}{|c|}{ DLOG } & \multicolumn{5}{|c|}{ Outras áreas do MS } \\
\hline & Média & Mediana & Moda & $\begin{array}{l}\text { Desvio- } \\
\text { padrão }\end{array}$ & $\begin{array}{c}\text { Coeficiente } \\
\text { de } \\
\text { Variação } \\
\end{array}$ & Média & Mediana & Moda & $\begin{array}{l}\text { Desvio- } \\
\text { padrão }\end{array}$ & $\begin{array}{c}\text { Coeficiente } \\
\text { de } \\
\text { Variação }\end{array}$ \\
\hline 1) Possui facilidade de uso. & 3,85 & 4 & 4 & 0,84 & $22 \%$ & 3,52 & 4 & 4 & 1,24 & $35 \%$ \\
\hline $\begin{array}{l}\text { 2) Proporciona vantagem relativa } \\
\text { ao processo físico (papel). }\end{array}$ & 4,2 & 5 & 5 & 1,09 & $26 \%$ & 4,11 & 4 & 4 & 1,14 & $28 \%$ \\
\hline $\begin{array}{l}\text { 3) É compatível com outros } \\
\text { sistemas dentro do Ministério da } \\
\text { Saúde. }\end{array}$ & 2,12 & 2 & 0 & 1,53 & $72 \%$ & 2,2 & 2 & 3 & 1,6 & $73 \%$ \\
\hline $\begin{array}{l}\text { 4) É considerado uma inovação no } \\
\text { processo de compras } \\
\text { medicamentos do } \\
\text { Saúde. }\end{array}$ & 4,26 & 5 & 5 & 0,93 & $22 \%$ & 3,76 & 4 & 5 & 1,3 & $35 \%$ \\
\hline $\begin{array}{l}\text { 5) Gera benefícios intangíveis, tais } \\
\text { como melhoria na segurança da } \\
\text { informação, nas compras de } \\
\text { medicamentos do Ministério da } \\
\text { Saúde. }\end{array}$ & 3,85 & 4 & 4 & 1,01 & $26 \%$ & 3,59 & 4 & 5 & 1,4 & $39 \%$ \\
\hline $\begin{array}{l}\text { 6) Promove melhoria nos processos } \\
\text { de trabalho dos servidores } \\
\text { envolvidos com as compras de } \\
\text { medicamentos do Ministério da } \\
\text { Saúde. }\end{array}$ & 4,02 & 4 & 4 & 0,88 & $22 \%$ & 3,89 & 4 & 5 & 1,34 & $35 \%$ \\
\hline $\begin{array}{l}\text { 7) Melhora o processo de compra } \\
\text { relativo aos medicamentos } \\
\text { adquiridos pelo Ministério da Saúde } \\
\text { para posterior distribuição aos } \\
\text { Estados e Municípios. }\end{array}$ & 3,86 & 4 & 4 & 0,91 & $24 \%$ & 3,62 & 4 & 5 & 1,43 & $40 \%$ \\
\hline
\end{tabular}


8) Proporciona transparência da informação pública relativa aos processos de compras de medicamentos do Ministério da Saúde.

9) Promove sustentabilidade nas compras de medicamentos do Ministério da Saúde?

10) Investimento em Inovação.

2,5

11) Apoio ao desenvolvimento de inovações (por meio de ações de educação, incentivos à diversidade).

12) Disponibilização de infraestrutura tecnológica para inovação.

13) Percepção de que os gestores são as principais fontes de inovação dentro do órgão.

14) Percepção de que os servidores são as principais fontes de inovação dentro do órgão.

15) Desenvolvimento de inovações para atender a prioridades políticas.

16) Atuação em rede com outras organizações para desenvolvimento de inovações.

17) Observância da legislação para inovar.

18) Utilização de inovações que estão sendo adotadas por outras organizações públicas com perfil compatível. 
19) Disponibilidade de recursos para investimento em inovação.

20) Aplicação de gestão de riscos para o desenvolvimento das inovações.

21) Existência de barreiras, tais como conflitos, para o desenvolvimento das inovações.

22) Existência de facilitadores, tais como incentivos ou recompensas, para o desenvolvimento de inovações.

23) Existência de autonomia ao servidor para o desenvolvimento de inovações.

24) Estímulo à criatividade para o desenvolvimento de inovações. 25) Formação de equipes
multidisciplinares

desenvolvimento de inovações.

26) Percepção de que o foco no comprometimento com o trabalho influencia o desenvolvimento de inovações.

27) Percepção de que o foco na satisfação com o trabalho influencia o desenvolvimento de inovações.

28) Compartilhamento de conhecimento relativo ao desenvolvimento de inovações pelas diversas áreas do órgão.

29) Desenvolvimento de estratégia para inovação.
2,07

2

1,07

$52 \%$

2,16

2

2

1,05

$49 \%$

1,29

$56 \%$

2,12

2

3

1,28

$60 \%$

3

4

1,26

$42 \%$

3,19

4

1,35

1,91

2

$73 \%$

1,78

2

1,23

$69 \%$

1,87

2

1,32

$71 \%$

1,86

2

2

1,15

$62 \%$

1,87

1,36

$73 \%$

1,8

2

1,26

$70 \%$

1,89

2

1,17

$62 \%$

1,95

2

2

1,26

$65 \%$

256

3

1,27

$50 \%$

2,3

2

1,35

$59 \%$

1,28

$55 \%$

2, 21

$63 \%$

1,91

2

1,29

$68 \%$

1,95

2

2

1,1

$56 \%$

2,38

2

1,17

$49 \%$

2,28

2

2

1,03

$45 \%$ 
30) Desenvolvimento de atividades para difusão (propagação) da inovação.

31) Incentivo às atividades de colaboração e aprendizado para

32) Percepção que a cultura organizacional favorece

Fonte: Elaborada pela autora a partir dos dados do software SPSS. 
Quanto à análise dos dados da Tabela 11, a mesma indica que os maiores coeficientes de variação tanto no DLOG, quanto nas demais áreas do MS que utilizam a inovação, também foram observadas nas questões de números 3, 22 e 24. Esses resultados ratificam a baixa concordância em relação as seguintes variáveis de inovação: compatibilidade do PEC com outros softwares, existência de facilitadores da inovação e estímulo à criatividade para a inovação no MS.

Na sequência, foi feita análise para avaliar se há diferenças significativas entre as séries de dados advindas das pesquisas com servidores do DLOG e com os servidores das demais áreas do MS relacionadas com as compras de medicamentos. Caso não haja diferenças significativas, os grupos podem ser considerados homogêneos e os resultados podem ser analisados de forma agrupada.

Essa avaliação pode ser feita por meio de testes paramétricos ou testes não paramétricos. A diferença é que os testes paramétricos são aplicados a amostras que seguem uma distribuição normal. No caso em que o conjunto de dados não segue o padrão de distribuição normal, são aplicados testes não paramétricos.

Dessa forma, inicialmente, foi feito teste de normalidade dos dados, utilizando-se dois testes: Kolmogorov-Smirnov e Shapiro-Wilk, sendo este último o mais indicado. Os testes foram efetuados para os dados de cada uma das perguntas isoladamente, considerando-se as seguintes hipóteses:

H0: Os dados possuem distribuição normal;

H1: Os dados não possuem distribuição normal.

Para os questionários dos servidores do DLOG e demais usuários da inovação dentro do MS, concluiu-se que o conjunto de dados não segue a distribuição normal, indicando a necessidade de utilização de um teste não paramétrico, assumindo um erro de 5\%. Deste 
modo, a análise foi feita utilizando o teste não-paramétrico de Mann-Whitney. Os resultados são apresentados no Apêndice $H$.

Contudo, conforme descrito acima, foi realizado o teste não paramétrico, especificamente o teste U de Mann-Whitney, conforme indica Ruxton (2006), o qual é usado para avaliar a diferença entre duas médias, a partir de amostras independentes. Nesse caso, foram utilizadas as seguintes hipóteses:

H0: As médias são iguais nas duas populações;

H1: As médias são diferentes nas duas populações estudadas.

Analisando os dados, conclui-se que não há evidências de diferença significativa nas notas atribuídas nas médias das duas populações em nenhuma das questões, o que demonstra que as respostas dos servidores do DLOG e dos demais servidores podem ser tratadas da mesma forma, sem a necessidade de separação em dois grupos distintos, mesmo podendo ser analisados como amostras independentes. Os resultados estão incluídos no apêndice I.

Adicionalmente, foi feito teste de análise de correlação entre as respostas a cada uma das perguntas, emparelhadas uma a uma. O objetivo é demonstrar a maior ou menor correlação existente entre cada uma das respostas e as respectivas variáveis de inovação contidas em cada uma delas. No teste em questão foram utilizadas as seguintes hipóteses:

H0: Há correlação entre as variáveis na população;

H1: Não há correlação entre as variáveis na população.

Na Tabela 12, são apresentadas as matrizes dos coeficientes de correlação de Spearman (coeficiente de correlação de postos), bem como as matrizes com o p-valor do teste. As células destacadas em vermelho foram significativas a 5\%, o que indica que a correlação entre as variáveis é significativa, uma vez que o valor de $5 \%$ é o mais utilizado para indicar tal relação. 
Tabela 12 - Teste de correlação entre as variáveis proveniente da aplicação do questionário no MS

\begin{tabular}{|c|c|c|c|c|c|c|c|c|c|c|c|c|c|c|c|c|c|c|c|c|c|c|c|c|c|c|c|c|c|c|c|c|c|}
\hline \multirow{2}{*}{ Variável } & \multirow{2}{*}{ Medida } & \multicolumn{32}{|c|}{ ado) } \\
\hline & & Q1 & Q2 & Q3 & Q4 & Q5 & Q6 & Q7 & Q8 & Q9 & Q10 & Q11 & Q12 & Q13 & Q14 & Q15 & Q16 & Q17 & Q18 & Q19 & Q20 & Q21 & Q22 & Q23 & Q24 & Q25 & Q26 & Q27 & Q28 & Q29 & Q30 & Q31 & Q32 \\
\hline \multirow{2}{*}{ Q1 } & Spearman & 1 & 0,41 & 0,05 & 0,33 & 0,37 & 0,56 & 0,53 & 0,48 & 0,46 & 0,23 & 0,18 & 0,3 & 0,29 & 0,21 & 0,03 & 0,25 & 0,37 & 0,17 & 0,23 & 0,21 & 0,06 & 0,13 & 0,27 & 0,27 & 0,19 & 0,33 & 0,21 & 0,11 & 0,2 & 0,23 & 0,14 & 0,19 \\
\hline & P-valor & & 0 & 0,61 & 0 & 0 & 0 & 0 & 0 & 0 & 0,02 & 0,08 & 0 & 0 & 0,03 & 0,76 & 0,01 & 0 & 0,11 & 0,02 & 0,04 & 0,53 & 0,21 & 0,01 & 0,01 & 0,06 & 0 & 0,04 & 0,27 & 0,04 & 0,02 & 0,18 & 0,06 \\
\hline \multirow{2}{*}{ Q2 } & Spearman & 0,41 & 1 & 0,1 & 0,45 & 0,53 & 0,66 & 0,58 & 0,44 & 0,39 & 0,24 & 0,17 & 0,21 & 0,22 & 0,18 & 0,06 & 0,2 & 0,24 & 0,13 & 0,06 & $-0,01$ & 0,14 & $-0,08$ & 0,14 & 0,11 & 0,08 & 0,14 & 0,09 & 0,12 & 0,1 & 0,15 & 0,15 & 0,01 \\
\hline & P-valor & 0 & & 0,33 & 0 & 0 & 0 & 0 & 0 & 0 & 0,02 & 0,1 & 0,03 & 0,03 & 0,08 & 0,53 & 0,05 & 0,02 & 0,21 & 0,54 & 0,91 & 0,18 & 0,46 & 0,17 & 0,26 & 0,42 & 0,17 & 0,38 & 0,23 & 0,31 & 0,13 & 0,13 & 0,91 \\
\hline \multirow{2}{*}{ Q3 } & Spearman & 0,05 & 0,1 & 1 & 0,21 & 0,27 & 0,18 & 0,17 & 0,16 & $-0,03$ & $-0,03$ & 0,1 & $-0,01$ & 0,11 & 0,16 & $-0,07$ & 0,12 & 0,04 & 0,1 & $-0,01$ & 0,04 & 0,15 & 0,08 & 0,08 & 0,08 & 0,09 & 0,17 & 0,16 & 0,1 & 0,07 & $-0,02$ & 0,04 & 0,06 \\
\hline & P-valor & 0,61 & 0,33 & & 0,04 & 0,01 & 0,09 & 0,12 & 0,13 & 0,79 & 0,75 & 0,34 & 0,93 & 0,31 & 0,14 & 0,54 & 0,27 & 0,71 & 0,38 & 0,95 & 0,68 & 0,15 & 0,45 & 0,46 & 0,43 & 0,39 & 0,11 & 0,13 & 0,36 & 0,51 & 0,89 & 0,69 & 0,56 \\
\hline \multirow{2}{*}{ Q4 } & Spearman & 0,33 & 0,45 & 0,21 & 1 & 0,63 & 0,63 & 0,51 & 0,5 & 0,33 & 0,18 & 0,27 & 0,23 & 0,31 & 0,14 & 0,2 & 0,26 & 0,32 & 0,17 & 0,09 & 0,2 & 0,29 & 0,07 & 0,12 & 0,13 & 0,23 & 0,27 & 0,24 & 0,25 & 0,16 & 0,15 & 0,17 & 0,2 \\
\hline & P-valor & 0 & 0 & 0,04 & & 0 & 0 & 0 & 0 & 0 & 0,07 & 0,01 & 0,02 & 0 & 0,17 & 0,05 & 0,01 & 0 & 0,1 & 0,36 & 0,06 & 0 & 0,47 & 0,25 & 0,2 & 0,02 & 0,01 & 0,02 & 0,02 & 0,11 & 0,13 & 0,08 & 04 \\
\hline \multirow{2}{*}{ Q5 } & Spearman & 0,37 & 0,53 & 0,27 & 0,63 & 1 & 0,76 & 0,72 & 0,56 & 0,43 & 0,33 & 0,41 & 0,29 & 0,41 & 0,32 & 0,3 & 0,31 & 0,33 & 0,23 & 0,13 & 0,18 & 0,29 & 0,06 & 0,14 & 0,15 & 0,15 & 0,29 & 0,23 & 0,2 & 0,32 & 0,27 & 0,22 & 0,21 \\
\hline & P-valor & 0 & 0 & 0,01 & 0 & & 0 & 0 & 0 & 0 & 0 & 0 & 0 & 0 & 0 & 0 & 0 & 0 & 0,02 & 0,22 & 0,08 & 0 & 0,55 & 0,18 & 0,13 & 0,13 & 0 & 0,02 & 0,05 & 0 & 0,01 & 0,03 & 0,04 \\
\hline \multirow{2}{*}{ Q6 } & Spearman & 0,56 & 0,66 & 0,18 & 0,63 & 0,76 & 1 & 0,81 & 0,58 & 0,54 & 0,33 & 0,34 & 0,33 & 0,36 & 0,32 & 0,18 & 0,32 & 0,4 & 0,32 & 0,13 & 0,16 & 0,19 & 0,1 & 0,23 & 0,28 & 0,17 & 0,34 & 0,28 & 0,25 & 0,27 & 0,33 & 0,26 & 0,25 \\
\hline & P-valor & 0 & 0 & 0,09 & 0 & 0 & & 0 & 0 & 0 & 0 & 0 & 0 & 0 & 0 & 0,07 & 0 & 0 & 0 & 0,21 & 0,13 & 0,06 & 0,35 & 0,02 & 0,01 & 0,1 & 0 & 0 & 0,01 & 0,01 & 0 & 0,01 & 0,01 \\
\hline \multirow{2}{*}{ Q7 } & Spearman & 0,53 & 0,58 & 0,17 & 0,51 & 0,72 & 0,81 & 1 & 0,55 & 0,5 & 0,38 & 0,43 & 0,41 & 0,33 & 0,37 & 0,16 & 0,32 & 0,44 & 0,27 & 0,25 & 0,24 & 0,2 & 0,12 & 0,2 & 0,25 & 0,15 & 0,3 & 0,33 & 0,23 & 0,26 & 0,28 & 0,26 & 0,26 \\
\hline & P-valor & 0 & 0 & 0,12 & 0 & 0 & 0 & & 0 & 0 & 0 & 0 & 0 & 0 & 0 & 0,12 & 0 & 0 & 0,01 & 0,02 & 0,02 & 0,06 & 0,27 & 0,06 & 0,01 & 0,15 & 0 & 0 & 0,03 & 0,01 & 0,01 & 0,01 & 0,01 \\
\hline \multirow{2}{*}{ Q8 } & Spearman & 0,48 & 0,44 & 0,16 & 0,5 & 0,56 & 0,58 & 0,55 & 1 & 0,52 & 0,3 & 0,32 & 0,24 & 0,51 & 0,27 & 0,25 & 0,36 & 0,51 & 0,28 & 0,23 & 0,22 & 0,35 & 0,24 & 0,26 & 0,28 & 0,25 & 0,34 & 0,26 & 0,35 & 0,28 & 0,31 & 0,23 & 0,24 \\
\hline & P-valor & v & 0 & 0,13 & 0 & 0 & 0 & 0 & & 0 & 0 & 0 & 0,02 & 0 & 0,01 & 0,01 & 0 & 0 & 0,01 & 0,02 & 0,03 & 0 & 0,02 & 0,01 & 0,01 & 0,01 & 0 & 0,01 & 0 & 0,01 & 0 & 0,02 & 0,02 \\
\hline \multirow{2}{*}{ Q9 } & Spearman & 0,46 & 0,39 & $-0,03$ & 0,33 & 0,43 & 0,54 & 0,5 & 0,52 & 1 & 0,35 & 0,24 & 0,33 & 0,37 & 0,35 & 0,22 & 0,4 & 0,45 & 0,27 & 0,24 & 0,28 & 0,14 & 0,19 & 0,29 & 0,36 & 0,18 & 0,32 & 0,26 & 0,27 & 0,28 & 0,34 & 0,27 & 0,34 \\
\hline & P-valor & 0 & 0 & 0,79 & 0 & 0 & 0 & 0 & 0 & & 0 & 0,02 & 0 & 0 & 0 & 0,03 & 0 & 0 & 0,01 & 0,02 & 0,01 & 0,19 & 0,07 & 0 & 0 & 0,09 & 0 & 0,01 & 0,01 & 0,01 & 0 & 0,01 & 0 \\
\hline \multirow{2}{*}{ Q10 } & Spearman & 0,23 & 0,24 & $-0,03$ & 0,18 & 0,33 & 0,33 & 0,38 & 0,3 & 0,35 & 1 & 0,8 & 0,74 & 0,66 & 0,47 & 0,43 & 0,64 & 0,54 & 0,56 & 0,64 & 0,6 & 0,17 & 0,46 & 0,44 & 0,5 & 0,51 & 0,45 & 0,47 & 0,51 & 0,64 & 0,5 & 0,57 & 0,59 \\
\hline & P-valor & 0,02 & 0,02 & 0,75 & 0,07 & 0 & 0 & 0 & 0 & 0 & & 0 & 0 & 0 & 0 & 0 & 0 & 0 & 0 & 0 & 0 & 0,1 & 0 & 0 & 0 & 0 & 0 & 0 & 0 & 0 & 0 & 0 & 0 \\
\hline \multirow{2}{*}{ Q11 } & Spearman & 0,18 & 0,17 & 0,1 & 0,27 & 0,41 & 0,34 & 0,43 & 0,32 & 0,24 & 0,8 & 1 & 0,72 & 0,61 & 0,46 & 0,5 & 0,58 & 0,57 & 0,43 & 0,61 & 0,59 & 0,27 & 0,51 & 0,48 & 0,55 & 0,49 & 0,46 & 0,5 & 0,48 & 0,63 & 0,48 & 0,58 & 0,58 \\
\hline & P-valor & 0,08 & 0,1 & 0,34 & 0,01 & 0 & 0 & 0 & 0 & 0,02 & 0 & & 0 & 0 & 0 & 0 & 0 & 0 & 0 & 0 & 0 & 0,01 & 0 & 0 & 0 & 0 & 0 & 0 & 0 & 0 & 0 & 0 & 0 \\
\hline \multirow{2}{*}{ Q12 } & Spearman & 0,3 & 0,21 & $-0,01$ & 0,23 & 0,29 & 0,33 & 0,41 & 0,24 & 0,33 & 0,74 & 0,72 & 1 & 0,6 & 0,45 & 0,48 & 0,61 & 0,57 & 0,44 & 0,63 & 0,68 & 0,12 & 0,43 & 0,44 & 0,53 & 0,47 & 0,53 & 0,57 & 0,49 & 0,54 & 0,46 & 0,49 & 0,57 \\
\hline & P-valor & 0 & 0,03 & 0,93 & 0,02 & 0 & 0 & 0 & 0,02 & 0 & 0 & 0 & & 0 & 0 & 0 & 0 & 0 & 0 & 0 & 0 & 0,23 & 0 & 0 & 0 & 0 & 0 & 0 & 0 & 0 & 0 & 0 & 0 \\
\hline Q13 & Spearman & 0,29 & 0,22 & 0,11 & 0,31 & 0,41 & 0,36 & 0,33 & 0,51 & 0,37 & 0,66 & 0,61 & 0,6 & 1 & 0,54 & 0,57 & 0,72 & 0,61 & 0,56 & 0,61 & 0,62 & 0,39 & 0,51 & 0,5 & 0,57 & 0,58 & 0,61 & 0,54 & 0,61 & 0,6 & 0,58 & 0,57 & 0,57 \\
\hline
\end{tabular}


P-valor

\begin{tabular}{|c|c|c|c|c|c|c|c|c|c|c|c|c|c|c|c|c|c|c|c|c|c|c|c|c|c|c|c|c|c|c|c|c|c|}
\hline & arman & 21 & 18 & 16 & 14 & 32 & 0,32 & 37 & 27 & 35 & 0,47 & 0,46 & 0,45 & 0,54 & 1 & 0,3 & 0,47 & 0,47 & 0,45 & 45 & 0,42 & 19 & ,3 & ,42 & 0,52 & 0,36 & 0,62 & 0,57 & 0,49 & 0,45 & 0,41 & 0,45 &, 5 \\
\hline & & & & & & & 0 & 0 & 0,01 & 0 & 0 & 0 & 0 & $\overline{0}$ & & 0 & 0 & 0 & 0 & 0 & $\overline{0}$ & & & 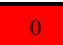 & 0 & 0 & 0 & & 0 & & , & 0 & \\
\hline & & & & & & & ,18 & & & & & & 0,48 & & & & 0 , & 0, & 0,43 & &, 4 & & 0,48 & 35 & 0,41 & 48 & 0,48 & 43 & 0,48 &, 61 & 0,61 & 0,6 & 0,5 \\
\hline & alo & .76 & 3 & & 55 & 0 & 0,07 & 0,12 & 0,01 & 0,03 & 0 & $\overline{0}$ & 0 & 0 & 0 & & 0 & 0 & $\overline{0}$ & 0 & 0 & 0,01 & 0 & 0 & 0 & 0 & 0 & 0 & 0 & 0 & 0 & 0 & 0 \\
\hline \multirow[b]{2}{*}{ Q16 } & rarm & 5 & 0,2 & & 0,26 & 0,31 & 32 & 2 & 0,36 & 0,4 & 0,64 & 0,58 & 0,61 & 0,72 & 0 , & 0,53 & 1 & 0,69 & 0,68 & 0,65 & 0,72 & 0,17 & 0,61 & 0,55 & $\overline{0,61}$ & 0,6 & 0,63 & 0,66 & 0,66 & 0,71 & 0,59 & 0,59 & 0,69 \\
\hline & & 01 & 0,05 & & 01 & 0 & 0 & 0 & 0 & 0 & 0 & 0 & 0 & 0 & 0 & 0 & & 0 & 0 & 0 & 0 & 0,1 & 0 & 0 & 0 & 0 & 0 & 0 & 0 & 0 & 0 & 0 & 0 \\
\hline \multirow{2}{*}{17} & & 0,37 & 4 & & 0,32 & 0,33 & 0,4 & 0,44 & 0,51 & 0,45 & 0,54 & 0,57 & 0,57 & 0,61 & 0,47 & 0,53 & 0,69 & 1 & 0,6 & 0,58 & 0,57 & 0,29 & 0,58 & 0,55 & 0,58 & 0,55 & 0,62 & 0,6 & 0,6 & 0,54 & 0,53 & 0,57 & 0,56 \\
\hline & & 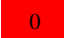 & 02 & & 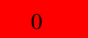 & 0 & 0 & 0 & 0 & 0 & 0 & 0 & 0 & 0 & 0 & 0 & 0 & & v & 0 & 0 & 0 & 0 & 0 & 0 & 0 & 0 & 0 & 0 & 0 & 0 & 0 & 0 \\
\hline & & 7 & & & 0,17 & 0,23 & 0,32 & 27 & 28 & 7 & 0,56 & 0,43 & 0,44 & 56 & 0,45 & 0,43 & 0,68 & 0,6 & 1 & 57 & 0,55 & 16 & 0,56 & 0,47 & 0,53 & 0,5 & 0,53 & 0,57 & 0,63 & 0,58 & 0,55 & 0,49 & 0,64 \\
\hline & alor & 0,11 & & 0.38 & 01 &, 02 & 0 & 0,01 & 0,01 & 0,01 & 0 & 0 & 0 & 0 & 0 & 0 & 0 & 0 & & 0 & 0 & 0,13 & 0 & 0 & 0 & 0 & 0 & 0 & 0 & 0 & 0 & 0 & 0 \\
\hline & arn & 23 & 06 & & 0,09 & 0,13 & 0,13 & 0,25 & 0,23 & 0,24 & 0,64 & 0,61 & 0,63 & 0,61 & 0,45 & 0,4 & 0,65 & 0,58 & 0,57 & 1 & 0,65 & 0,14 & 0,6 & 0,6 & 0,69 & 0,59 & 0,47 & 0,55 & 0,53 & 0,53 & 0,45 & 0,49 & 0,55 \\
\hline & alor &, 02 & 54 & 0 & 0,36 & 0,22 & 0,21 & 0,02 & 0,02 & 0,02 & 0 & 0 & 0 & 0 & 0 & 0 & 0 & 0 & 0 & & 0 & 0,18 & 0 & 0 & 0 & 0 & 0 & 0 & 0 & 0 & 0 & 0 & 0 \\
\hline \multirow{2}{*}{ Q } & arm & 0,21 &, 01 & 0,04 & 0 & 0,18 &, 16 & 0,24 & 0,22 & 0,28 & 0,6 & 0,59 & 0,68 & 0,62 & 0,42 & 0,4 & 0,72 & 0,57 & 0,55 & 0,65 & 1 & 0,1 & 0,58 & 0,54 & 0,61 & 0,58 & 0,54 & 0,58 & 0,51 & 0,58 & 0,52 & 0,55 & 0,63 \\
\hline & alor &, 04 & 91 & 68 & 06 & 0,08 & 0,13 & 0,02 & 0,03 & 0,01 & 0 & 0 & 0 & 0 & 0 & 0 & 0 & 0 & 0 & 0 & & 0,31 & 0 & 0 & 0 & 0 & 0 & 0 & 0 & 0 & 0 & 0 & 0 \\
\hline & arn & 66 & & & 29 & 0,29 & 19 & 0,2 & 35 & 0,14 & 0,17 & 0,27 & 0,12 & 0,39 & 0,19 & 0,25 & 0,17 & 0,29 & 0,16 & 0,14 & 0,1 & 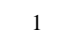 & 0,11 & 0,19 & 0,1 & 0,14 & 0,23 & 0,2 & 0,23 & 0,17 & 0,16 & $5 \quad 0,21$ & 0,13 \\
\hline & & 0,53 & & & 1 & 0 & 06 & 0,06 & & 0,19 & 0 & 0,01 & 0,23 & 0 & 0,05 & 0,01 & 0, & , & 0,13 & 0,18 & 0,31 & & 0,28 & 0,06 & 0,31 & 0,16 & .02 & 0,04 & 0,02 & 0,1 & 0,1 &, 04 & 0,18 \\
\hline & $\mathbf{S}$ & 3 &, 00 & & 07 & 0,06 & & 0,12 & 0,24 & 0,19 & 0,46 & 0,51 & 0,43 & 0,51 & 0,3 & 0,48 & 0,61 & 0,58 & 0,56 & 0,6 & 0,58 & 0,11 & & 0,69 & 0,73 & 0,7 & 0,6 & 0,61 & 0,65 & 0,58 & 0,52 & 0,56 & 0,62 \\
\hline & & & & & & & & 0,27 & 12 & & 0 & 0 & 0 & 0 & 0 & 4 & 0 & v & 0 & 0 & 0 & 0,28 & & 0 & 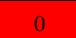 & 0 & 0 & 0 & 0 & 0 & u & 0 & u \\
\hline \multirow{2}{*}{ Q23 } & & 27 & & & & & & & 0,26 & . & 0,44 & 0,48 & 0,44 & 0,5 & 0,42 & 0,35 & 0,55 & 0,55 & 0,47 & 0,6 & 0,54 & 19 & 0,69 & 1 & 0,83 & 0,69 & 0,6 & 0,59 & 0,6 & 0,49 & 0,52 & 0,49 & 0,54 \\
\hline & 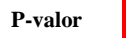 & 01 & 17 & & 025 & 0,18 & 02 & 0,06 & 0,01 & 0 & 0 & 0 & 0 & 0 & 0 & 0 & - & 0 & 0 & 0 & 0 & 0,06 & 0 & & 0 & 0 & 0 & 0 & 0 & 0 & 0 & 0 & 0 \\
\hline & 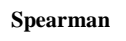 & 0,27 & 0,11 & & 0,13 & 0,15 & 0,28 & 0 , & 0,28 & 0,36 & 0,5 & 0,55 & 0,53 & 0,57 & 0,52 & 0,41 & 0,61 & 0,58 & 0,53 & 0,69 & 0,61 & 0,1 & 0,73 & 0,83 & 1 & 0,77 & 0,65 & 0,68 & 0,67 & 0,63 & 0,59 & 0,63 & 0,68 \\
\hline & yalor & 01 & 0 & & & 0,13 & 01 & 0,01 & 0,01 & 0 & 0 & 0 & 0 & 0 & 0 & 0 & 0 & 0 & 0 & 0 & 0 & 0,31 & 0 & 0 & & 0 & 0 & 0 & 0 & 0 & 0 & 0 & 0 \\
\hline & earm & 0,19 & 08 & 0,09 & 0,23 & 0,15 & 0,17 & 0,15 & 0,25 & 0,18 & 0,51 & 0,49 & 0,47 & 0,58 & 0,36 & 0,48 & 0,6 & 0,55 & 0,5 & 0,59 & 0,58 & 0,14 & 0,76 & 0,69 & 0,77 & 1 & 0,57 & 0,6 & 0,74 & 0,66 & 0,66 & 0,69 & 0,65 \\
\hline & P-valor & 0,06 & 42 & 0 & 0,02 & 0,13 & 0,1 & 0,15 & 0,01 & 0,09 & 0 & 0 & 0 & 0 & 0 & 0 & 0 & 0 & 0 & 0 & 0 & 0,16 & 0 & 0 & 0 & & 0 & 0 & 0 & 0 & 0 & 0 & 0 \\
\hline \multirow{2}{*}{ Q26 } & arman & 0,33 & 0,14 & 0,17 & 0,27 & 0,29 & 0,34 & 0,3 & 0,34 & 0,32 & 0,45 & 0,46 & 0,53 & 0,61 & 0,62 & 0,48 & 0,63 & 0,62 & 0,53 & 0,47 & 0,54 & 0,23 & 0,6 & 0,6 & 0,65 & 0,57 & 1 & 0,82 & 0,62 & 0,57 & 0,56 & 0,58 & 0,69 \\
\hline & P-valor & 0 & 0,17 & 11 & 0,01 & 0 & 0 & 0 & 0 & 0 & 0 & 0 & 0 & 0 & 0 & 0 & 0 & 0 & 0 & 0 & 0 & 0,02 & 0 & 0 & 0 & 0 & & 0 & 0 & 0 & 0 & 0 & 0 \\
\hline \multirow{2}{*}{ Q27 } & eari & 0,21 & 0,09 & 10 & 0,24 & 0,23 & 0,28 & 0,33 & 0,26 & 0,26 & 0,47 & 0,5 & 0,57 & 0,54 & 0,57 & 0,43 & 0,66 & 0,6 & 0,57 & 0,55 & 0,58 & 0,2 & 0,61 & 0,59 & 0,68 & 0,6 & 0,82 & 1 & 0,72 & 0,59 & 0,51 & 0,54 & 0,77 \\
\hline & T-valor & U4 & & 0,13 & & 0,02 & v & v & 0,01 & 0,01 & 0 & 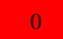 & 0 & v & u & 4 & 0 & 0 & 0 & 0 & 0 & 0,04 & 0 & 0 & 0 & u & 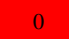 & & v & & & 0 & v \\
\hline & Intain & 0,11 & & & & & $0,2 J$ & 0,23 & 35 & 0,27 & & $0,+0$ & 0,4 & 0 , & & . & 0,66 & 0,6 & 0,63 & 0,53 & 0,51 & 0,25 & 0 & 0,6 & 0,67 & 0, & 0,62 & 0 & 1 & 0,67 & 0,69 & 0,72 & , 73 \\
\hline
\end{tabular}




\begin{tabular}{|c|c|c|c|c|c|c|c|c|c|c|c|c|c|c|c|c|c|c|c|c|c|c|c|c|c|c|c|c|c|c|c|c|c|}
\hline & alor & 27 & 0,23 & 36 & 0,02 & 0,05 & 0,01 & 0,03 & 0 & 0,01 & 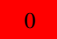 & 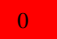 & 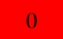 & 0 & 0 & 0 & 0 & 0 & 0 & 0 & 0 & 0,02 & 0 & 0 & 0 & 0 & 0 & 0 & & 0 & 0 & 0 & 0 \\
\hline \multirow{2}{*}{ Q29 } & arman & 0,2 & 0,1 & 0,07 & 0,16 & 0,32 & 0,27 & 0,26 & 0,28 & 0,28 & 0,64 & 0,63 & 0,54 & 0,6 & 0,45 & 0,61 & 0,71 & 0,54 & 0,58 & 0,53 & 0,58 & 0,17 & 0,58 & 0,49 & 0,63 & 0,66 & 0,57 & 0,59 & 0,67 & 1 & 0,8 & 0,8 & 0,78 \\
\hline & alor & 0,04 & 0,31 & 51 & 0,11 & 0 & 0,01 & 0,01 & 0,01 & 0,01 & 0 & 0 & 0 & 0 & 0 & 0 & 0 & 0 & 0 & 0 & 0 & 0,1 & 0 & 0 & 0 & 0 & 0 & 0 & 0 & & 0 & 0 & 0 \\
\hline \multirow{2}{*}{ Q30 } & arman & 0,23 & 0,15 & $-0,02$ & 0,15 & 0,27 & 0,33 & 0,28 & 0,31 & 0,34 & 0,5 & 0,48 & 0,46 & 0,58 & 0,41 & 0,61 & 0,59 & 0,53 & 0,55 & 0,45 & 0,52 & 0,16 & 0,52 & 0,52 & 0,59 & 0,66 & 0,56 & 0,51 & 0,69 & 9,8 & 1 & 0,79 & 0,67 \\
\hline & alor &, 02 & 0,13 & 0,89 & 0,13 &, 01 & 0 & 0 & 0 & 0 & 0 & 0 & 0 & 0 & 0 & 0 & 0 & 0 & 0 & 0 & 0 & 0,1 & 0 & 0 & 0 & 0 & 0 & 0 & 0 & 0 & & 0 & 0 \\
\hline \multirow{2}{*}{ Q. } & $n$ & 0,14 & 0,15 & 0, & 0,17 & 0,22 & 0,26 & 0,26 & 0,23 & 0,27 & 0,57 & 0,58 & 0,49 & 0,57 & 0,45 & 0,6 & 0,59 & 0,57 & 0,49 & 0,49 & 0,55 & 0,21 & 0,56 & 0,49 & 0,63 & 0,69 & 0,58 & 0,54 & 0,72 & 0,8 & 0,79 & 1 & 0,73 \\
\hline & P-valor & 0,10 & 15 & 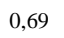 & 0,08 & 0,03 & 0,01 & 0,01 & 0,02 & 0,01 & 0 & 0 & 0 & 0 & 0 & 0 & 0 & 0 & 0 & 0 & 0 & 0,04 & 0 & 0 & 0 & 0 & 0 & 0 & 0 & 0 & 0 & & 0 \\
\hline & in & 0, & 01 & 66 & 23220 & 0,21 & 0,25 & 0,26 & 0,24 & 0,34 & 0,59 & 0,58 & 0,57 & 0,57 & 0,5 & 0,54 & 0,69 & 0,56 & 0,64 & 0,55 & 0,63 & 0,13 & 0,62 & 0,54 & 0,68 & 0,65 & 0,69 & 0,77 & 0,73 & 0,78 & 0,67 & 0,73 & 1 \\
\hline & -valor & 0,06 & 0,91 & 0,56 & 0,04 & 0,04 & 0,01 & 0,01 & 0,02 & 0 & 0 & 0 & 0 & 0 & 0 & 0 & 0 & 0 & 0 & 0 & 0 & 0,18 & & 0 & 0 & 0 & 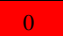 & 0 & 0 & & 0 & 0 & \\
\hline
\end{tabular}

Fonte: Elaborada pela autora a partir do software SPSS. 
Os testes de correlação realizados apontam que as variáveis referentes às questões 1 e 2 têm correlações significativas com as 12 primeiras variáveis do questionário, exceto com as variáveis das questões 3 e 11, estas que cujo p-valores dos testes de correlação não estão pintados de vermelho. A Tabela 12 demonstra todas as outras correlações entre as variáveis utilizadas nesse estudo.

No tocante às análises provenientes da AFE, Hair et al. (2009) recomendam que a amostra deve ser superior a 50 observações, sendo aconselhável no mínimo 100 casos para assegurar resultados mais confiáveis, o que se apresenta no presente estudo, já que a amostra possui 104 respondentes. Ao realizar a AFE no instrumento da pesquisa aplicado no MS com as questões de 1 a 32, chegou-se as seguintes conclusões, de acordo com Tabela 13:

a) observou-se na matriz de correlação das variáveis que aproximadamente $69 \%$ das correlações entre as variáveis são superiores a 0,3, indicando a fatorabilidade da matriz;

b) a correlação média observada foi de 0,43 , sendo desejável um valor que ultrapassasse o índice de 0,50 para que a matriz seja dita fatorável, porém como o valor é próximo, decidiu-se pela continuação da realização da AFE;

c) outra medida importante é o teste Kaiser-Meyer-Olklin (KMO), no qual Friel \& Markworth (2009) sugerem a seguinte escala para interpretação do valor da estatística: entre 0,90 e 1, é considerado um KMO excelente; entre 0,80 e 0,89, um valor bom; entre 0,70 e 0,79, o valor está mediano; entre 0,60 e 0,69, o KMO está medíocre; entre 0,50 e 0,59, está ruim; e, por fim, entre 0 e 0,49, o mesmo está inadequado. Portanto, no modelo analisado tem-se um valor $\mathrm{KMO}=0,884$, o que indica a fatorabilidade do instrumento; e 
d) outro fator que corrobora a possibilidade da análise fatorial é o teste esfericidade de Bartlett, que se apresentou significante.

Tabela 13 - Testes de KMO e esfericidade de Barlett

\begin{tabular}{lcr}
\hline Medida Kaiser-Meyer-Olkin de adequação de amostragem & 0,884 \\
\hline & Qui-quadrado aproximado & $2.108,9$ \\
Teste de esfericidade de Bartlett & df & 496 \\
& Sig. & 0 \\
\hline Fonte: Elaborada pela autora a partir do software SPSS.
\end{tabular}

Fonte: Elaborada pela autora a partir do software SPSS.

Posteriormente, foi gerada a matriz de comunalidades através do método de análise do componente principal, na qual se observou que os valores estão, na sua maioria, acima de 0,60, demonstrando que não há problema para a realização da análise fatorial, de acordo com os dados da Tabela 14.

Tabela 14 - Matriz de comunalidades

\begin{tabular}{|c|c|c|}
\hline Comunalidades & Inicial & Extração \\
\hline 1) Possui facilidade de uso. & 1 & 0,724 \\
\hline 2) Proporciona vantagem relativa ao processo físico (papel). & 1 & 0,532 \\
\hline $\begin{array}{l}\text { 3) É compatível com outros sistemas dentro do Ministério da } \\
\text { Saúde. }\end{array}$ & 1 & 0,771 \\
\hline $\begin{array}{l}\text { 4) É considerado uma inovação no processo de compras de } \\
\text { medicamentos do Ministério da Saúde. }\end{array}$ & 1 & 0,644 \\
\hline $\begin{array}{l}\text { 5) Gera benefícios intangíveis, tais como melhoria na segurança } \\
\text { da informação, nas compras de medicamentos do Ministério da } \\
\text { Saúde. }\end{array}$ & 1 & 0,777 \\
\hline $\begin{array}{l}\text { 6) Promove melhoria nos processos de trabalho dos servidores } \\
\text { envolvidos com as compras de medicamentos do Ministério da } \\
\text { Saúde. }\end{array}$ & 1 & 0,87 \\
\hline $\begin{array}{l}\text { 7) Melhora o processo de compra relativo aos medicamentos } \\
\text { adquiridos pelo Ministério da Saúde para posterior distribuição } \\
\text { aos Estados e Municípios. }\end{array}$ & 1 & 0,812 \\
\hline $\begin{array}{l}\text { 8) Proporciona transparência da informação pública relativa aos } \\
\text { processos de compras de medicamentos do Ministério da Saúde. }\end{array}$ & 1 & 0,674 \\
\hline $\begin{array}{l}\text { 9) Promove sustentabilidade nas compras de medicamentos do } \\
\text { Ministério da Saúde. }\end{array}$ & 1 & 0,707 \\
\hline 10) Investimento em Inovação. & 1 & 0,844 \\
\hline $\begin{array}{l}\text { 11) Apoio ao desenvolvimento de inovações (por meio de ações } \\
\text { de educação, incentivos à diversidade). }\end{array}$ & 1 & 0,772 \\
\hline 12) Disponibilização de infraestrutura tecnológica para inovação. & 1 & 0,691 \\
\hline $\begin{array}{l}\text { 13) Percepção de que os gestores são as principais fontes de } \\
\text { inovação dentro do órgão. }\end{array}$ & 1 & 0,757 \\
\hline $\begin{array}{l}\text { 14) Percepção de que os servidores são as principais fontes de } \\
\text { inovação dentro do órgão. }\end{array}$ & 1 & 0,563 \\
\hline
\end{tabular}


15) Desenvolvimento de inovações para atender a prioridades políticas.

16) Atuação em rede com outras organizações para desenvolvimento de inovações.

17) Observância da legislação para inovar.

18) Utilização de inovações que estão sendo adotadas por outras organizações públicas com perfil compatível.

19) Disponibilidade de recursos para investimento em inovação.

20) Aplicação de gestão de riscos para o desenvolvimento das inovações.

21) Existência de barreiras, tais como conflitos, para o desenvolvimento das inovações.

22) Existência de facilitadores, tais como incentivos ou recompensas, para o desenvolvimento de inovações.

1

1

1

1

1

1

1

1

1

1

1

25) Formação de equipes multidisciplinares para o desenvolvimento de inovações.

26) Percepção de que o foco no comprometimento com o trabalho influencia o desenvolvimento de inovações.

27) Percepção de que o foco na satisfação com o trabalho influencia o desenvolvimento de inovações.

28) Compartilhamento de conhecimento relativo ao desenvolvimento de inovações pelas diversas áreas do órgão.

29) Desenvolvimento de estratégia para inovação.

30) Desenvolvimento de atividades para difusão (propagação) da inovação.

31) Incentivo às atividades de colaboração e aprendizado para inovação.

32) Percepção que a cultura organizacional favorece o desenvolvimento de inovações.

Fonte: Elaborada pela autora a partir do software SPSS.

Feitas as análises para constatar a fatorabilidade do instrumento, procedeu-se com a extração dos fatores que consiste na determinação da quantidade de fatores que melhor representa o padrão de correlação entre as variáveis observadas na pesquisa. Dessa forma, a solução esperada é identificar o número mínimo de fatores que maximiza a quantidade da variância total explicada.

Não se tem um critério consensual para definir quantos fatores devem ser extraídos, a literatura aponta alguns métodos que podem auxiliar a tomada de decisão. Como por exemplo, a regra do Eigenvalue (critério de Kaiser) sugere que devem ser extraídos apenas os fatores com valor de Eigenvalue acima de um. Segundo Tabachinick e Fidell (2007), esse método 
funciona melhor quando o pesquisador utiliza entre 20 e 50 variáveis, o que se evidenciou no presente trabalho, já que foram utilizadas 32 variáveis.

Outro método de auxílio utilizado na tomada de decisão é o Scree Test, uma análise gráfica da dispersão do número de fatores que apresenta a curva da variância individual de cada fator, até que ela se torne horizontal ou sofra uma queda abrupta, conforme Figura 40.

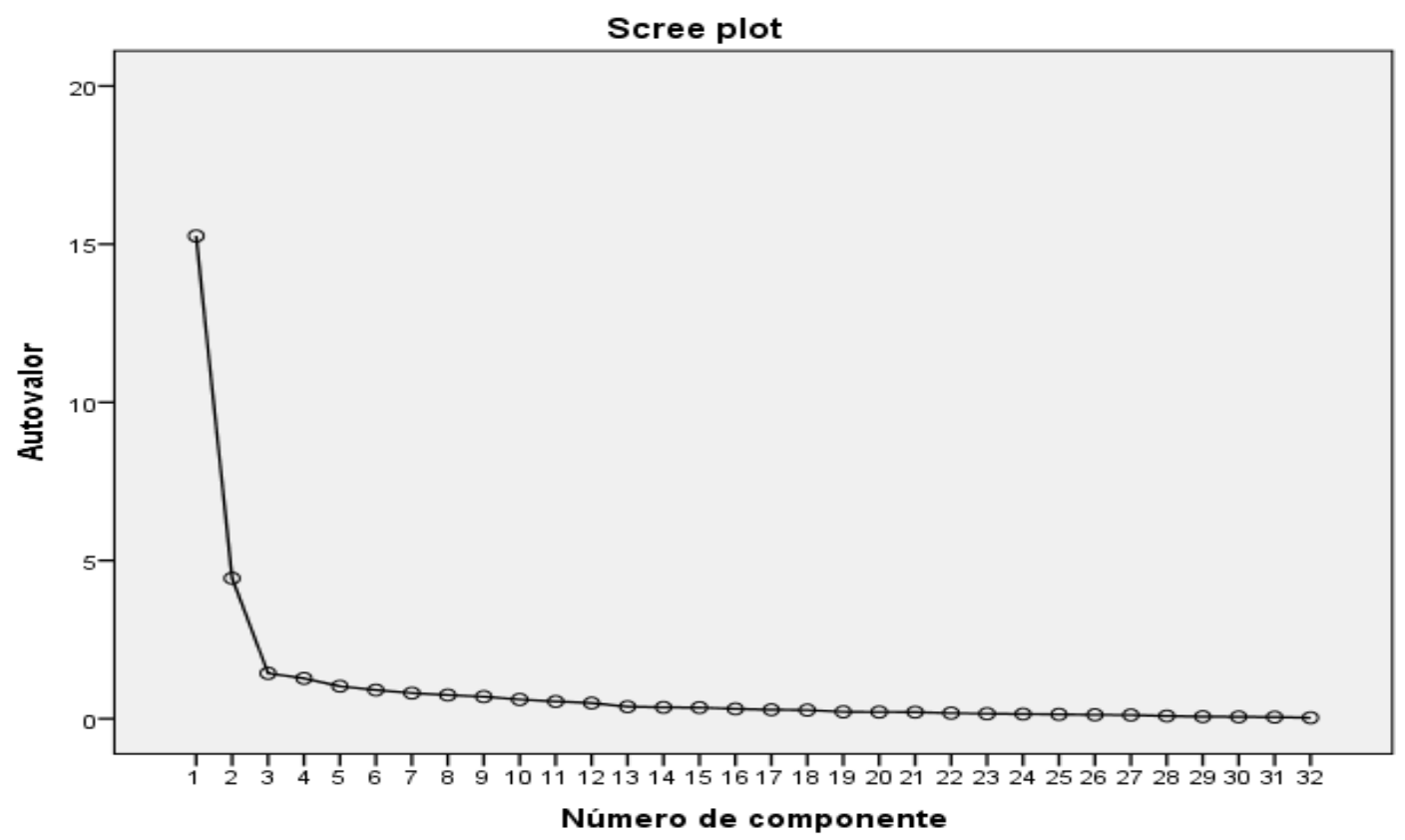

\section{Figura 40 - Gráfico de Scree Plot}

Fonte: Elaborada pela autora a partir do software SPSS.

Em ambos os critérios, tem-se a indicação de quanto da variância foi perdido e, por isso, deve-se parar de extrair fatores. Hair et al. (2009) sugerem variância acumulada acima de 60\% como aceitável, conforme Tabela 15. 
Tabela 15 - Variância total explicada

\begin{tabular}{|c|c|c|c|c|c|c|}
\hline \multirow[b]{2}{*}{ Componente } & \multicolumn{3}{|c|}{ Valores próprios iniciais } & \multicolumn{3}{|c|}{$\begin{array}{c}\text { Somas de extração de carregamentos ao } \\
\text { quadrado }\end{array}$} \\
\hline & Total & $\begin{array}{c}\% \\
\text { variância }\end{array}$ & $\begin{array}{c}\% \\
\text { cumulativa }\end{array}$ & Total & $\begin{array}{c}\% \\
\text { variância }\end{array}$ & $\begin{array}{c}\% \\
\text { cumulativa }\end{array}$ \\
\hline 1 & 15,26 & 47,69 & 47,69 & 15,26 & 47,69 & 47,69 \\
\hline 2 & 4,44 & 13,87 & 61,56 & 4,44 & 13,87 & 61,56 \\
\hline 3 & 1,44 & 4,49 & 66,04 & 1,44 & 4,49 & 66,04 \\
\hline 4 & 1,28 & 3,99 & 70,03 & 1,28 & 3,99 & 70,03 \\
\hline 5 & 1,03 & 3,21 & 73,24 & 1,03 & 3,21 & 73,24 \\
\hline
\end{tabular}

Fonte: Elaborada pela autora a partir do software SPSS.

Analisando a Tabela 15 referente ao total de variância explicada pelos fatores, verifica-se que o modelo com a utilização da extração de componentes principais, mostrou a existência de cinco fatores no grupo das 32 perguntas. Estes cinco fatores explicam aproximadamente $73 \%$ da variância. No entanto, ao aplicar a AFE, houve um problema na interpretabilidade dos fatores gerados, ou seja, as perguntas agrupadas nos fatores não indicavam com clareza qual era o fator que estava presente.

Assim sendo, fixou-se a quantidade de fatores em número de três para verificar como o modelo se comportaria nesta situação. Além disso, o Scree Plot apresenta grandes quedas dos autovalores nas passagens na inserção da $2^{\mathrm{a}}$ e $3^{\mathrm{a}}$ componentes, sendo a queda na passagem para o $4^{\mathrm{a}}$ componente em diante considerada bem pequena, gerando uma reta. Esta situação ajuda a evidenciar que o modelo de três fatores seja o mais adequado.

Procedeu-se a AFE através do método de extração dos Componentes Principais mais uma vez e sem rotação dos fatores. Quanto aos valores de correlação e aos testes de fatorabilidade da matriz, estes continuam os mesmos já listados acima na primeira análise. No entanto, quando se observa os valores das comunalidades pelo método de extração de análise do componente principal, de acordo com Tabela 16, existe valores abaixo de 0,50 para as variáveis das questões 1,2 e 3. Em uma perspectiva mais conservadora, seria aconselhável 
excluí-las da análise e realizar novamente a AFE, mas optou-se por conservá-las no modelo e observar os seus comportamentos.

Tabela 16 - Comunalidades

\begin{tabular}{|c|c|c|}
\hline & Inicial & Extração \\
\hline Q1 & 1 & 0,631 \\
\hline Q2 & 1 & 0,477 \\
\hline Q3 & 1 & 0,194 \\
\hline Q4 & 1 & 0,611 \\
\hline Q5 & 1 & 0,759 \\
\hline Q6 & 1 & 0,855 \\
\hline Q7 & 1 & 0,798 \\
\hline Q8 & 1 & 0,67 \\
\hline Q9 & 1 & 0,618 \\
\hline Q10 & 1 & 0,771 \\
\hline Q11 & 1 & 0,697 \\
\hline Q12 & 1 & 0,649 \\
\hline Q13 & 1 & 0,737 \\
\hline Q14 & 1 & 0,526 \\
\hline Q15 & 1 & 0,591 \\
\hline Q16 & 1 & 0,741 \\
\hline Q17 & 1 & 0,709 \\
\hline Q18 & 1 & 0,547 \\
\hline Q19 & 1 & 0,62 \\
\hline Q20 & 1 & 0,654 \\
\hline Q21 & 1 & 0,225 \\
\hline Q22 & 1 & 0,702 \\
\hline Q23 & 1 & 0,661 \\
\hline Q24 & 1 & 0,816 \\
\hline Q25 & 1 & 0,707 \\
\hline Q26 & 1 & 0,762 \\
\hline Q27 & 1 & 0,709 \\
\hline Q28 & 1 & 0,749 \\
\hline Q29 & 1 & 0,781 \\
\hline Q30 & 1 & 0,659 \\
\hline Q31 & 1 & 0,722 \\
\hline Q32 & 1 & 0,786 \\
\hline
\end{tabular}

Fonte: Elaborada pela autora a partir do software SPSS.

Com relação à Análise Fatorial Rotacionada, realizada através da rotação PROMAX, a Tabela 17 a seguir indica que ao utilizar 3 fatores, o modelo fatorial demonstrou capacidade de explicar $66 \%$ de toda a variabilidade existente nas 32 variáveis analisadas do questionário. 
Tabela 17 - Variância total explicada referente à análise fatorial rotacionada

\begin{tabular}{ccccc}
\hline \multirow{2}{*}{ Fator } & \multicolumn{3}{c}{ Valores próprios iniciais } & $\begin{array}{c}\text { Somas rotativas de } \\
\text { carregamentos ao quadrado }\end{array}$ \\
\cline { 2 - 5 } & Total & \% de variância & \% cumulativa & Total \\
\hline 1 & 15,26 & 47,687 & 47,687 & 13,322 \\
3 & 4,438 & 13,869 & 61,556 & 12,423 \\
& 1,435 & 4,486 & 66,042 & 7,257 \\
\hline
\end{tabular}

Fonte: Elaborada pela autora a partir do software SPSS.

Na matriz padrão, deve-se observar as cargas fatoriais de cada variável e identificar as variáveis que apresentam elevadas cargas fatoriais em ambos os componentes, no caso, valores acima de 0,40 , conforme Tabela 18 , e cujos métodos de extração e rotação foram a fatoração do eixo principal e promax com normalização de Kaiser, com rotação convergida em seis iterações.

Tabela 18 - Matriz de padrão ${ }^{a}$

\begin{tabular}{|c|c|c|c|}
\hline & \multicolumn{3}{|c|}{ Fator } \\
\hline & 1 & 2 & 3 \\
\hline Q24 & 0,956 & & \\
\hline Q26 & 0,956 & & \\
\hline Q27 & 0,906 & & \\
\hline Q23 & 0,866 & & \\
\hline Q28 & 0,753 & & \\
\hline Q25 & 0,739 & & \\
\hline Q22 & 0,678 & & \\
\hline Q14 & 0,656 & & \\
\hline Q32 & 0,633 & 0,333 & \\
\hline Q17 & 0,527 & & \\
\hline Q30 & 0,5 & 0,367 & \\
\hline Q31 & 0,492 & 0,429 & \\
\hline Q18 & 0,42 & 0,359 & \\
\hline Q19 & 0,42 & 0,419 & \\
\hline Q10 & & 0,899 & \\
\hline Q11 & & 0,883 & \\
\hline Q12 & & 0,647 & \\
\hline Q13 & & 0,642 & \\
\hline Q20 & & 0,611 & \\
\hline Q29 & 0,371 & 0,589 & \\
\hline Q15 & & 0,582 & \\
\hline
\end{tabular}




\begin{tabular}{lll} 
Q16 & 0,331 & 0,57 \\
Q6 & 0,925 \\
Q7 & 0,863 \\
Q5 & 0,845 \\
Q4 & 0,754 \\
Q1 & 0,718 \\
Q8 & 0,691 \\
Q2 & 0,669 \\
Q9 & 0,647 \\
Q3 & 0,361 \\
Q21 & \\
\hline Fonte: Elaborada pela autora a partir do software SPSS.
\end{tabular}

Defende-se que a mesma variável não pode contribuir para a construção de fatores distintos. Caso ocorra tal fenômeno, as variáveis devem ser excluídas e a análise fatorial deve ser realizada novamente. A Tabela 19 demonstra a nova matriz padrão, cujos resultados sugerem que as variáveis Q18, Q19, Q30 e Q31 devem ser retiradas da análise. A variável Q21 também foi retirada por não apresentar fator associado.

\begin{tabular}{|c|c|c|c|}
\hline & \multicolumn{3}{|c|}{ Fator } \\
\hline & 1 & 2 & 3 \\
\hline Q26 & 0,939 & & \\
\hline Q24 & 0,915 & & \\
\hline Q27 & 0,896 & & \\
\hline Q23 & 0,845 & & \\
\hline Q28 & 0,722 & & \\
\hline Q25 & 0,704 & & \\
\hline Q22 & 0,647 & & \\
\hline Q14 & 0,644 & & \\
\hline Q32 & 0,592 & & 0,374 \\
\hline Q17 & 0,505 & & \\
\hline Q6 & & 0,933 & \\
\hline Q7 & & 0,869 & \\
\hline Q5 & & 0,834 & \\
\hline Q4 & & 0,743 & \\
\hline Q1 & & 0,728 & \\
\hline Q2 & & 0,686 & \\
\hline Q8 & & 0,685 & \\
\hline Q9 & & 0,653 & \\
\hline Q3 & & 0,352 & \\
\hline
\end{tabular}




\begin{tabular}{ccc} 
Q10 & 0,933 \\
Q11 & 0,914 \\
Q12 & 0,695 \\
Q20 & 0,662 \\
Q13 & & 0,661 \\
Q29 & 0,333 & 0,613 \\
Q16 & 0,302 & 0,6 \\
Q15 & & 0,565 \\
\hline
\end{tabular}

Por conseguinte, de acordo com a matriz padrão produzida pela AFE após a retirada de variáveis que apresentavam cargas fatoriais altas em dois fatores, chegou-se aos três fatores e suas respectivas variáveis agrupadas, de acordo com Tabela 20. Ao analisar os agrupamentos, faz-se necessário caracterizar os fatores de acordo com revisão de literatura e os modelos escolhidos para análise da inovação no setor público que constam no referencial teórico: fator 1, agrupa as variáveis relativas ao ambiente organizacional e práticas de gestão para promoção de inovação; o fator 2, apresenta as variáveis que representam as características e resultados da inovação; e ao final, o fator 3, relaciona variáveis relativas ao processo de inovação.

Tabela 20 - Fatores e variáveis agrupadas

\begin{tabular}{|c|c|c|}
\hline Fator & Questão & Descrição da Questão \\
\hline 1 & Q14 & 14) Percepção de que os servidores são as principais fontes de inovação dentro do órgão. \\
\hline 1 & Q17 & 17) Observância da legislação para inovar. \\
\hline 1 & Q22 & $\begin{array}{l}\text { 22) Existência de facilitadores, tais como incentivos ou recompensas, para o } \\
\text { desenvolvimento de inovações. }\end{array}$ \\
\hline 1 & Q23 & 23) Existência de autonomia ao servidor para o desenvolvimento de inovações. \\
\hline 1 & Q24 & 24) Estímulo à criatividade para o desenvolvimento de inovações. \\
\hline 1 & Q25 & 25) Formação de equipes multidisciplinares para o desenvolvimento de inovações. \\
\hline 1 & Q26 & $\begin{array}{l}\text { 26) Percepção de que o foco no comprometimento com o trabalho influencia o } \\
\text { desenvolvimento de inovações. }\end{array}$ \\
\hline 1 & Q27 & $\begin{array}{l}\text { 27) Percepção de que o foco na satisfação com o trabalho influencia o desenvolvimento de } \\
\text { inovações. }\end{array}$ \\
\hline 1 & Q28 & $\begin{array}{l}\text { 28) Compartilhamento de conhecimento relativo ao desenvolvimento de inovações pelas } \\
\text { diversas áreas do órgão. }\end{array}$ \\
\hline 1 & Q32 & 32) Percepção que a cultura organizacional favorece o desenvolvimento de inovações. \\
\hline
\end{tabular}


2 Q1 1) Possui facilidade de uso.

2 Q2 2) Proporciona vantagem relativa ao processo físico (papel).

2 Q3 3) É compatível com outros sistemas dentro do Ministério da Saúde.

2 Q4 4) É considerado uma inovação no processo de compras de medicamentos do Ministério da Saúde.

$2 \quad$ Q5

5) Gera benefícios intangíveis, tais como melhoria na segurança da informação, nas compras de medicamentos do Ministério da Saúde.

$2 \quad$ Q6

6) Promove melhoria nos processos de trabalho dos servidores envolvidos com as compras de medicamentos do Ministério da Saúde.

7) Melhora o processo de compra relativo aos medicamentos adquiridos pelo Ministério da Saúde para posterior distribuição aos Estados e Municípios.

8) Proporciona transparência da informação pública relativa aos processos de compras de

2 Q9 9) Promove sustentabilidade nas compras de medicamentos do Ministério da Saúde.

3 Q10 10) Investimento em Inovação.

3 Q11 11) Apoio ao desenvolvimento de inovações (por meio de ações de educação, incentivos à

3 Q12 12) Disponibilização de infraestrutura tecnológica para inovação.

3 Q13 13) Percepção de que os gestores são as principais fontes de inovação dentro do órgão.

3 Q15 15) Desenvolvimento de inovações para atender a prioridades políticas.

3 Q16 16) Atuação em rede com outras organizações para desenvolvimento de inovações.

3 Q20 20) Aplicação de gestão de riscos para o desenvolvimento das inovações.

3 Q29 29) Desenvolvimento de estratégia para inovação.

Fonte: Elaborada pela autora a partir do software SPSS.

Ao se realizar a análise da confiabilidade dos fatores definidos, utiliza-se o Alfa de Cronbach, que é a média das correlações entre os itens que fazem parte do instrumento utilizado. O ideal é que o valor da estatística seja superior a 0,7 para assumir que um fator é confiável. Quanto mais próximo de 1, mais confiável é o fator estudado.

O fator 1 apresenta um Alfa de Cronbach igual a 0,944. Além disso, analisando o comportamento desta estatística ao se retirar uma questão qualquer do fator, verifica-se que não há grande perda de confiabilidade, algo desejado e que indica que o fator é estável e confiável, de acordo com Tabelas 21 e 22 a seguir. 
Tabela 21 - Estatísticas de confiabilidade

\begin{tabular}{cc}
\hline Alfa de Cronbach & $\mathbf{N}^{\mathbf{0}}$ de itens \\
\hline 0,944 & 10
\end{tabular}

Fonte: Elaborada pela autora a partir do software SPSS.

Tabela 22 - Estatísticas de item-total

\begin{tabular}{ccccc}
\hline & $\begin{array}{c}\text { Média de escala se o } \\
\text { item for excluído }\end{array}$ & $\begin{array}{c}\text { Variância de escala se o } \\
\text { item for excluído }\end{array}$ & $\begin{array}{c}\text { Correlação de item } \\
\text { total corrigida }\end{array}$ & $\begin{array}{c}\text { Alfa de Cronbach se o } \\
\text { item for excluído }\end{array}$ \\
\hline Q14 & 18,77 & 91,552 & 0,562 & 0,947 \\
Q17 & 18,55 & 87,167 & 0,685 & 0,942 \\
Q22 & 19,39 & 85,782 & 0,773 & 0,937 \\
Q23 & 19,4 & 86,868 & 0,78 & 0,937 \\
Q24 & 19,42 & 84,059 & 0,853 & 0,934 \\
Q25 & 19,31 & 86,466 & 0,815 & 0,936 \\
Q26 & 18,87 & 85,138 & 0,809 & 0,936 \\
Q27 & 19,01 & 85,239 & 0,809 & 0,936 \\
Q28 & 19,29 & 86,666 & 0,818 & 0,936 \\
Q32 & 19,12 & 86,026 & 0,77 & 0,937 \\
\hline
\end{tabular}

Fonte: Elaborada pela autora a partir do software SPSS.

Para o fator 2 o Alfa de Cronbach calculado foi igual a 0,897. Assim como no fator 1 , o comportamento desta estatística quando retiramos uma questão qualquer do fator, não sofre grande perda de confiabilidade, algo desejável e que indica que o fator é confiável, conforme Tabelas 23 e 24.

Tabela 23 - Estatísticas de confiabilidade

\begin{tabular}{cc}
\hline Alfa de Cronbach & $\mathbf{N}^{\mathbf{0}}$ de itens \\
\hline 0,897 & 9
\end{tabular}

Fonte: Elaborada pela autora a partir do software SPSS.

Tabela 24 - Estatísticas de item-total

\begin{tabular}{ccccc}
\hline & $\begin{array}{c}\text { Média de escala se o } \\
\text { item for excluído }\end{array}$ & $\begin{array}{c}\text { Variância de escala se o } \\
\text { item for excluído }\end{array}$ & $\begin{array}{c}\text { Correlação de item } \\
\text { total corrigida }\end{array}$ & $\begin{array}{c}\text { Alfa de Cronbach se o } \\
\text { item for excluído }\end{array}$ \\
\hline Q1 & 29,12 & 58,035 & 0,68 & 0,885 \\
Q2 & 28,69 & 58,841 & 0,591 & 0,891 \\
Q3 & 30,54 & 61,401 & 0,278 & 0,922 \\
Q4 & 28,79 & 56,618 & 0,711 & 0,882 \\
Q5 & 29,02 & 54,724 & 0,805 & 0,874 \\
Q6 & 28,83 & 54,045 & 0,881 & 0,869 \\
Q7 & 29,09 & 53,855 & 0,835 & 0,872 \\
Q8 & 29,06 & 55,159 & 0,709 & 0,881 \\
Q9 & 29,07 & 56,919 & 0,62 & 0,889 \\
\hline
\end{tabular}

Fonte: Elaborada pela autora a partir do software SPSS. 
E por fim, o fator 3 apresenta um Alfa de Cronbach igual a 0,925. Novamente, o comportamento do Alfa de Cronbach não se altera ao se retirar uma questão qualquer do fator, verificando que há confiabilidade no fator, consoante Tabelas 25 e 26.

Tabela 25 - Estatísticas de confiabilidade

\begin{tabular}{cc} 
Alfa de Cronbach & $\mathbf{N}^{\mathbf{o}}$ de itens \\
\hline 0,925 & 8
\end{tabular}

Fonte: Elaborada pela autora a partir do software SPSS.

Tabela 26 - Estatísticas de item-total

\begin{tabular}{ccccc}
\hline & $\begin{array}{c}\text { Média de escala se o } \\
\text { item for excluído }\end{array}$ & $\begin{array}{c}\text { Variância de escala se } \\
\text { o item for excluído }\end{array}$ & $\begin{array}{c}\text { Correlação de item } \\
\text { total corrigida }\end{array}$ & $\begin{array}{c}\text { Alfa de Cronbach se o } \\
\text { item for excluído }\end{array}$ \\
\hline Q10 & 17,02 & 44,967 & 0,811 & 0,911 \\
Q11 & 17,11 & 45,395 & 0,772 & 0,914 \\
Q12 & 17,2 & 44,884 & 0,769 & 0,913 \\
Q13 & 17,18 & 42,965 & 0,768 & 0,914 \\
Q15 & 16,88 & 45,997 & 0,581 & 0,929 \\
Q16 & 17,3 & 42,763 & 0,804 & 0,91 \\
Q20 & 17,43 & 43,435 & 0,736 & 0,916 \\
Q29 & 17,28 & 45,348 & 0,767 & 0,914 \\
\hline
\end{tabular}

Fonte: Elaborada pela autora a partir do software SPSS.

Ademais, os três fatores apontados pela AFE - ambiente organizacional e práticas de gestão para promoção de inovação; características e resultados da inovação; e práticas relativas ao processo de inovação - estão em consonância com as principais dimensões relacionadas nos modelos de Bloch et al. (2009) e De Vries, Bekkers e Tummers (2015). As variáveis do fator 1 estão intrinsicamente relacionado com as dimensões de entradas para inovação ou antecedentes de inovação apontados pelos referidos autores. Já as variáveis relacionadas com o fator 2 dialogam com os atributos da inovação e os resultados por ela gerados. E ao final, o fator 3 apresenta as variáveis relativas ao processo ou meio para a realização da inovação no setor público. 


\subsection{PROPOSIÇÃO E ANÁLISE DOS INDICADORES DE INOVAÇÃO NAS COMPRAS GOVERNAMENTAIS}

A concepção de indicadores de resultados das inovações no setor público se apresenta como um desafio, na medida em que deve traduzir os resultados que satisfaçam às expectativas dos legítimos beneficiários da ação governamental de forma realista, desafiadora e sustentável (Federal, 2010).

De Vries, Bekkers e Tummers (2015) definem resultados de uma inovação como os resultados substantivos da implementação de uma inovação, e, a partir dessa definição, observa-se que os resultados da adoção da inovação no setor público são muito difusos e multifacetados em razão da variedade de objetivos e desafios que as organizações públicas vêm assumindo nos últimos anos. Para esses autores, os principais resultados esperados da inovação no setor público são: o aumento ou diminuição da eficácia; o aumento da eficiência; o envolvimento dos parceiros privados; envolvimento dos cidadãos; o aumento da satisfação do cliente; e outros, tais como segurança, justiça.

Já para Bloch (2011), um dos principais resultados esperados da inovação no setor público é a melhoria na entrega e/ou na qualidade dos serviços públicos e os principais resultados esperados da inovação no setor público são: impactos sociais, melhoria para o empregado, benefício para os usuários e outros efeitos intangíveis, tais como confiança e legitimidade.

Em consonância com esse entendimento, Schooner, Gordon e Clark (2008) definiram alguns indicadores de desempenho e resultados, no âmbito das compras governamentais, conforme apresentado no referencial teórico.

No caso em tela, para a proposição dos indicadores da inovação nas compras governamentais, utilizou-se da técnica de análise categorial proposta por Bardin (2011), na 
qual se realizou uma triangulação das variáveis de resultados de inovação dos autores De Vries, Bekkers e Tummers (2015) e Bloch et al. (2009), bem como dos principais indicadores de desempenho das compras governamentais propostos pelos autores Schooner, Gordon e Clark (2008); juntamente com a análise documental realizada em manuais, relatórios de gestão, dados dos softwares do MS e legislação referente às compras governamentais.

A partir dessa análise de conteúdo técnica, foram definidas categorias de análise da inovação relacionadas aos critérios e às atividades desenvolvidas para a gestão das compras governamentais. Daí decorreu que essas categorias se desdobraram nos indicadores propostos nesse trabalho para medição da inovação, de acordo com Tabela 27.

Tabela 27 - Definição das categorias e descrição para proposição dos indicadores dos resultados da inovação nas compras governamentais

\begin{tabular}{|c|c|c|c|c|}
\hline $\begin{array}{c}\text { Variáveis } \\
\text { resultados da } \\
\text { inovação - Bloch et } \\
\text { al. (2009) }\end{array}$ & $\begin{array}{c}\text { Variáveis } \\
\text { resultados da } \\
\text { inovação - De } \\
\text { Vries, Bekkers \& } \\
\text { Tummers (2015) }\end{array}$ & $\begin{array}{c}\text { Variáveis de } \\
\text { desempenho nas } \\
\text { compras } \\
\text { governamentais - } \\
\text { (Schooner, Gordon } \\
\text { \& Clark (2008) }\end{array}$ & Categoria & Descrição \\
\hline
\end{tabular}

\section{Benefícios para os Aumento da} usuários satisfação do cliente

Economicidade

Economicidade

Aumento da satisfação do empregado

Impactos sociais

Aumento da eficiência

Eficiência

Satisfação final do usuário

Eficácia diminuição da eficácia

E

Adoção de critérios que geram economia aos cofres públicos.

Adoção de critérios que visam à satisfação dos stakeholders envolvidos nas compras governamentais

Adoção de critérios que geram celeridade nas compras governamentais.
Outros efeitos intangíveis (confiança, legitimidade)
Envolvimento dos cidadãos

Transparência
Transparência
Adoção de critérios
que proporcionam
transparência da
informação relativa às
compras
governamentais. 


$\begin{array}{llll}\begin{array}{l}\text { Envolvimento de } \\ \text { parceiros privados }\end{array} & \text { Accountability } & \text { Sustentabilidade } & \begin{array}{l}\text { Adoção de critérios } \\ \text { que } \\ \text { sustentabilidade } \\ \text { compras } \\ \text { governamentais }\end{array} \\ & \text { Integridade } & \\ \text { Competição } & \\ \text { Uniformidade } & \end{array}$

Fonte: Elaborada pela autora, adaptado de Bloch et al. (2009), De Vries, Bekkers e Tummers (2015) e Schooner, Gordon e Clark (2008).

Com base nas categorias constantes na Tabela 27, propõem-se cinco indicadores de inovação nas compras governamentais, que são: economicidade, eficácia, eficiência, transparência e sustentabilidade.

\subsubsection{Indicador de economicidade}

A economicidade é um princípio da Administração Pública, que abrange a qualidade ou caráter do que é econômico ou consome menos em relação aos produtos prestados e tem como objetivo principal realizar o máximo rendimento dos recursos disponíveis, com a utilização de um método que leva em consideração os interesses da coletividade e os fatores sociais do mercado, num determinado tempo e espaço (Citadini, 1989).

A partir dessa definição, as compras governamentais se configuram como um instrumento de economicidade aos cofres públicos através da diretriz de redução do preço do produto ou serviço adquirido pelo setor público.

Essas diretrizes da economicidade nas compras governamentais se desdobram no indicador preço econômico de referência, o qual foi definido como a comparação entre o preço contratado e o preço de referência utilizado para a realização da licitação, e possui objeto de mensuração, conforme Tabela 28. 
Tabela 28 - Indicador de economicidade e formas de mensuração

\begin{tabular}{|c|c|c|c|}
\hline Tipo & Indicador & Aspecto avaliado & Interpretação/sentido \\
\hline Economicidade & $\begin{array}{l}\text { Preço econômico } \\
\text { de referência }\end{array}$ & $\begin{array}{l}\text { Quantidade de itens } \\
\text { contratados que geraram } \\
\text { economia a partir da } \\
\text { comparação entre o preço } \\
\text { unitário do insumo } \\
\text { contratado e o preço } \\
\text { unitário de referência para } \\
\text { aquisição do insumo antes } \\
\text { e após a adoção da } \\
\text { inovação }\end{array}$ & Maior- Melhor \\
\hline
\end{tabular}

Fonte: Elaborada pela autora.

De acordo com a Lei $n^{\circ}$ 8.666/93, o preço unitário de referência do insumo é a estimativa preliminar do preço do item a contratar feita com base no levantamento de mercado, no intuito de apoiar a análise de viabilidade da contratação, em especial com respeito à relação de custo-benefício da contratação.

Com a proposição do indicador de economicidade, a periodicidade de apuração deve ser anual e os dados necessários para a sua validação no DLOG e MS foram coletados e analisados, respectivamente, conforme Tabelas 29 e 30. 
Tabela 29 - Dados do indicador preço econômico de referência dos anos de 2011 a 2013

\begin{tabular}{|c|c|c|c|c|c|c|c|c|c|}
\hline & \multicolumn{3}{|c|}{ Processo Físico } & \multicolumn{3}{|c|}{ Processo Físico } & \multicolumn{3}{|c|}{ Processo Físico/Eletrônico } \\
\hline Ano & & 2011 & & & 2012 & & & 2013 & \\
\hline Modalidade & $\begin{array}{l}\text { Quantidade } \\
\text { de insumos }\end{array}$ & $\begin{array}{l}\text { Quantidade de } \\
\text { insumos que } \\
\text { geraram } \\
\text { economia }\end{array}$ & $\begin{array}{l}\text { Percentual dos } \\
\text { insumos que } \\
\text { geraram } \\
\text { economia }\end{array}$ & $\begin{array}{l}\text { Quantidade } \\
\text { de insumos }\end{array}$ & $\begin{array}{l}\text { Quantidade de } \\
\text { insumos que } \\
\text { geraram } \\
\text { economia }\end{array}$ & $\begin{array}{l}\text { Percentual dos } \\
\text { insumos que } \\
\text { geraram } \\
\text { economia }\end{array}$ & $\begin{array}{l}\text { Quantidade } \\
\text { de insumos }\end{array}$ & $\begin{array}{c}\text { Quantidade } \\
\text { insumos que } \\
\text { geraram } \\
\text { economia }\end{array}$ & $\begin{array}{c}\text { Percentual dos } \\
\text { insumos que } \\
\text { geraram } \\
\text { economia }\end{array}$ \\
\hline Pregão & 418 & 331 & $79,19 \%$ & 359 & 296 & $82,45 \%$ & 113 & 102 & $90,27 \%$ \\
\hline
\end{tabular}

Fonte: Elaborada pela autora a partir dos dados do software DW-SIASG.

Tabela 30 - Dados do indicador preço econômico de referência dos anos de 2014 e 2015

\begin{tabular}{|c|c|c|c|c|c|c|}
\hline \multirow{3}{*}{$\frac{\text { Ano }}{\text { Modalidade }}$} & \multicolumn{3}{|c|}{ Processo Eletrônico } & \multicolumn{3}{|c|}{ Processo Eletrônico } \\
\hline & & 2014 & & & 2015 & \\
\hline & $\begin{array}{l}\text { Quantidade de } \\
\text { insumos }\end{array}$ & $\begin{array}{l}\text { Quantidade de insumos } \\
\text { que geraram economia }\end{array}$ & $\begin{array}{l}\text { Percentual dos insumos } \\
\text { que geraram economia }\end{array}$ & $\begin{array}{l}\text { Quantidade de } \\
\text { insumos }\end{array}$ & $\begin{array}{l}\text { Quantidade de insumos } \\
\text { que geraram economia }\end{array}$ & $\begin{array}{c}\text { Percentual dos insumos } \\
\text { que geraram economia }\end{array}$ \\
\hline Pregão & 222 & 209 & $94,14 \%$ & 189 & 140 & $74,07 \%$ \\
\hline
\end{tabular}

Fonte: Elaborada pela autora a partir dos dados do software DW-SIASG. 
Os dados das Tabelas 29 e 30 apontam que os insumos adquiridos pela modalidade pregão apresentaram uma economia no decorrer dos anos e após a adoção da inovação, com exceção do ano de 2015, em que apenas $74,07 \%$ dos medicamentos adquiridos geraram economicidade para o MS em relação ao preço de referência.

Quanto aos insumos adquiridos pelo DLOG nas modalidades dispensa e inexigibilidade de licitação, a análise documental apontou que não há registros dos preços de referência ou de pesquisas de preço que balizem essas contratações para os processos físicos, o que inviabilizou a coleta de dados para as referidas contratações e consequentemente a comparação entre os preços econômicos de referência antes e após a adoção da inovação no MS.

Contudo, observa-se que as contratações pela modalidade pregão representam uma média de $70 \%$ de todas as contratações de medicamentos e outros insumos para a saúde do MS, no decorrer dos anos de 2011 a 2015, o que demonstra a representatividade das mesmas frente às outras modalidades, bem como que a economia gerada foi significativa até o ano de 2014, após a utilização do processo eletrônico, no qual 94,14\% de todos os insumos adquiridos pela modalidade pregão geraram economia aos cofres públicos do MS.

\subsubsection{Indicadores de eficiência}

A eficiência possui várias definições aplicadas a distintas perspectivas teóricas, porém na Administração Pública pode ser entendida como norma destinada a conferir aos agentes públicos o dever de utilizar os melhores meios a serem empregados no cumprimento das atividades necessárias à boa administração, voltada para o atingimento da sua finalidade legal e do interesse público (Leite, 2001).

Nesse sentido, o indicador de eficiência nas compras governamentais tem de ser visto como um objetivo maior e esse conceito está relacionado com agilidade em realizar essas 
compras, evitar o desperdício e garantir a economicidade, estabelecer um ambiente de aprendizado e relacionamento com os fornecedores, e por fim, criar uniformidade no processo de compra (Schooner, Gordon \& Clark, 2008).

Dessa forma, o indicador de eficiência proposto está relacionado com o tempo de tramitação dos processos de compra governamentais antes e depois da adoção da inovação.

Para as compras de insumos realizadas por meio de contratação direta, que envolve as modalidades inexigibilidade e dispensa de licitação, o tempo de tramitação do processo deverá ser calculado desde a inserção do Termo de Referência (TR), no processo físico ou no PEC, até a finalização da instrução processual, que se apresenta com a ratificação da licitação e publicação no Diário Oficial da União (DOU).

Quanto às compras realizadas por meio de concorrência, que envolvem a modalidade de pregão, seja ele presencial ou eletrônico, o tempo de tramitação do processo será calculado desde a inserção do TR, no processo físico ou no PEC, até a finalização da instrução processual, que se efetiva com a homologação do item que é objeto do pregão e a devida publicação no DOU.

A Tabela 31 apresenta os indicadores de eficiência para os processos de compra por contratação direta e por concorrência, cuja periodicidade de apuração deverá ser anual, antes e depois da adoção da inovação, com os respectivos meios de apuração. 
Tabela 31 - Indicadores de eficiência da inovação nas compras governamentais

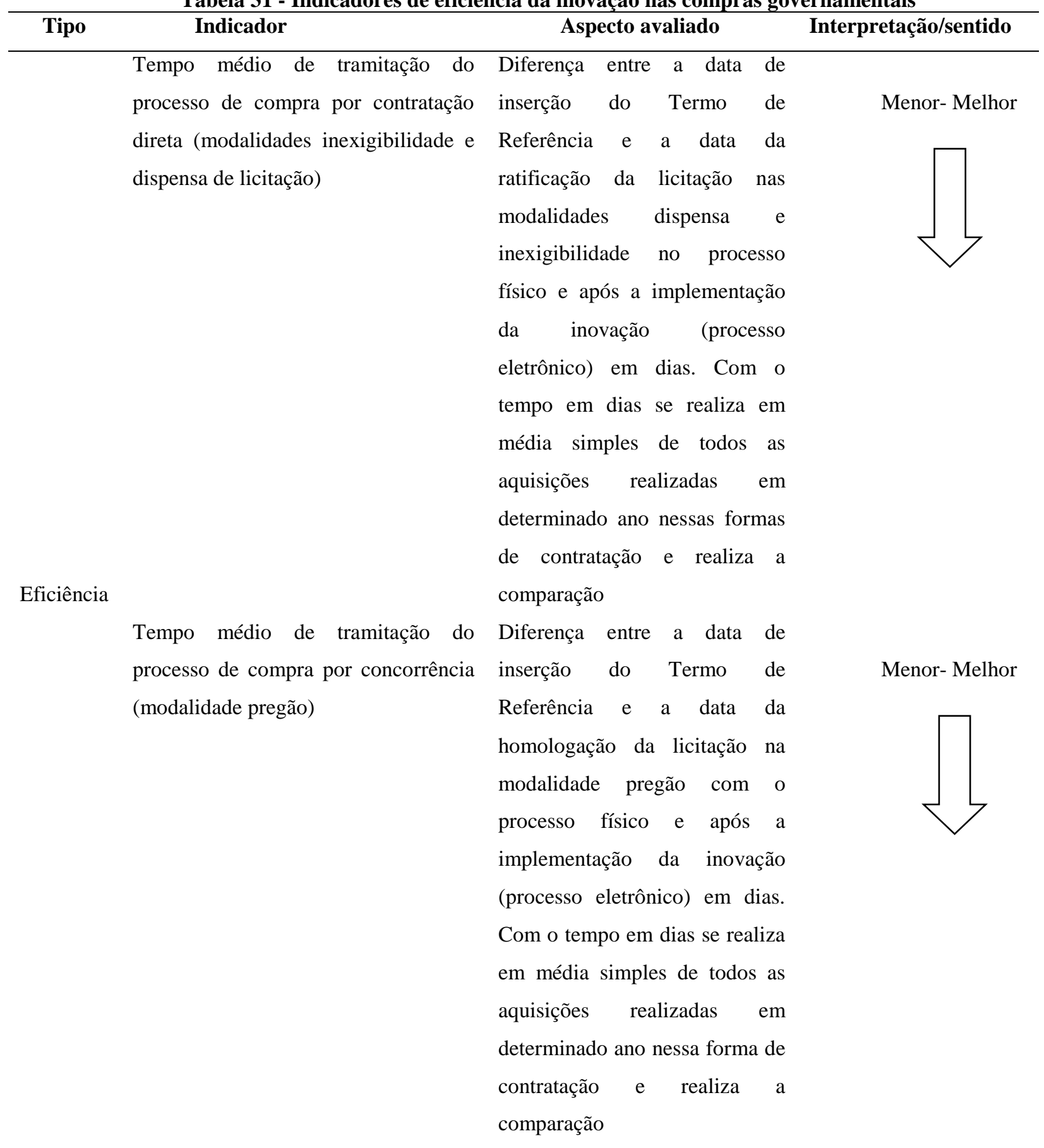

Fonte: Elaborada pela autora.

Com a adoção do software PEC nas compras de medicamentos e insumos para a saúde do MS, foi levantado o tempo médio de tramitação de todos os processos de compra realizados de 2011 a 2015, nas modalidades dispensa, inexigibilidade e pregão, de acordo com Tabela 32. 
Tabela 32 - Tempo médio de tramitação dos processos de compra de medicamentos realizados de 2011 a 2015

\begin{tabular}{|c|c|c|c|c|c|c|c|c|c|c|}
\hline & \multicolumn{2}{|c|}{2011} & \multicolumn{2}{|c|}{2012} & \multicolumn{2}{|c|}{2013} & \multicolumn{2}{|c|}{2014} & \multicolumn{2}{|c|}{2015} \\
\hline & \multicolumn{2}{|c|}{ Processo Físico } & \multicolumn{2}{|c|}{ Processo Físico } & \multicolumn{2}{|c|}{ Processo Físico/Eletrônico } & \multicolumn{2}{|c|}{ Processo Eletrônico } & \multicolumn{2}{|c|}{ Processo Eletrônico } \\
\hline Modalidade & $\begin{array}{c}\text { Quantidade de } \\
\text { insumos dos } \\
\text { processos }\end{array}$ & $\begin{array}{c}\text { Tempo } \\
\text { médio (dias) }\end{array}$ & $\begin{array}{l}\text { Quantidade de } \\
\text { insumos dos } \\
\text { processos }\end{array}$ & $\begin{array}{l}\text { Tempo } \\
\text { médio } \\
\text { (dias) }\end{array}$ & $\begin{array}{l}\text { Quantidade de } \\
\text { insumos dos } \\
\text { processos }\end{array}$ & $\begin{array}{l}\text { Tempo } \\
\text { médio } \\
\text { (dias) }\end{array}$ & $\begin{array}{l}\text { Quantidade de } \\
\text { insumos dos } \\
\text { processos }\end{array}$ & $\begin{array}{c}\text { Tempo } \\
\text { médio (dias) }\end{array}$ & $\begin{array}{l}\text { Quantidade } \\
\text { de insumos } \\
\text { dos } \\
\text { processos }\end{array}$ & $\begin{array}{l}\text { Tempo } \\
\text { médio } \\
\text { (dias) }\end{array}$ \\
\hline Dispensa & 62 & 149 & 8 & 483 & 8 & 350 & 41 & 299 & 37 & 173 \\
\hline Inexigibilidade & 49 & 195 & 23 & 171 & 48 & 143 & 54 & 186 & 49 & 173 \\
\hline Pregão & 75 & 185 & 145 & 166 & 83 & 371 & 52 & 210 & 92 & 383 \\
\hline
\end{tabular}

Fonte: Elaborada pela autora a partir dos softwares DW-SIASG, SIPAR e PEC. 
De acordo com a Tabela 32, observou-se que o tempo médio de tramitação dos processos de compra apresentou um aumento nas modalidades dispensa e pregão, considerando os anos de 2011, com a utilização do processo físico, e 2015, com o processo eletrônico. Os processos que tramitaram pela modalidade inexigibilidade apresentaram uma pequena redução no prazo dos anos de 2011 para 2015, porém se relacionados com o ano de 2013, esses processos também tiveram um aumento no prazo de tramitação.

Os dados apresentados corroboram com os autores De Vries, Bekkers e Tummers (2015) quando os mesmos afirmam que os resultados da inovação, no caso a busca pela eficiência, podem ser indesejáveis ou negativos e que a adoção de uma inovação não pode ser vista como um valor em si mesma, mas deve ser a introdução de algo novo orientada para a melhoria dos resultados no setor público, o que não se evidenciou no MS e no DLOG com relação aos prazos médios de tramitação dos processos de compra de medicamentos e outros insumos para a saúde.

\subsubsection{Indicadores de eficácia}

Eficácia está relacionada com a quantidade de produtos ou serviços entregues aos usuários, que são os beneficiários diretos dos mesmos. Sendo assim, com relação às compras governamentais, utiliza-se a terminologia melhor valor agregado, que se refere às vantagens socioeconômicas tangíveis ou intangíveis obtidas nas compras e contratações governamentais, e implica essencialmente que o Estado, como comprador, deve assegurar que as análises anteriores à efetivação da compra se estendam além do preço para garantir que os resultados obtidos sejam os melhores para a sociedade.

Para tal, propõe-se o indicador de inovação valor agregado, que implica no atendimento da inovação às necessidades dos usuários, que no caso das compras governamentais se desdobram em: usuários dos medicamentos e insumos para a saúde no 
âmbito do SUS; usuários internos da inovação no MS; e, ao final, usuários fornecedores. A Tabela 33 propõe os três indicadores de eficácia da inovação nas compras governamentais, bem como a forma de apuração, que deverá ser realizada anualmente antes e depois da adoção da inovação.

Tabela 33 - Indicadores de eficácia e formas de mensuração

\begin{tabular}{|c|c|c|c|}
\hline Tipo & Indicador & Aspecto avaliado & Interpretação/sentido \\
\hline \multirow{3}{*}{ Eficácia } & $\begin{array}{l}\text { Valor agregado aos } \\
\text { usuários cidadãos }\end{array}$ & $\begin{array}{l}\text { Índice de satisfação dos } \\
\text { cidadãos com o recebimento } \\
\text { dos bens e serviços no prazo } \\
\text { previsto }\end{array}$ & Maior - Melhor \\
\hline & $\begin{array}{l}\text { Valor agregado aos } \\
\text { usuários da inovação }\end{array}$ & $\begin{array}{l}\text { Índice de satisfação dos } \\
\text { usuários com a inovação }\end{array}$ & Maior - Melhor \\
\hline & $\begin{array}{l}\text { Valor agregado aos } \\
\text { fornecedores }\end{array}$ & $\begin{array}{l}\text { Índice de satisfação dos } \\
\text { fornecedores com a } \\
\text { utilização da inovação }\end{array}$ & Maior - Melhor \\
\hline
\end{tabular}

Fonte: Elaborada pela autora.

Quanto à sistemática para coleta de dados referente ao indicador valor agregado aos usuários dos medicamentos e insumos para a saúde adquiridos pelo MS, propõe-se a utilização da estrutura existente na Ouvidoria do SUS, que presta, desde 2011, o serviço de Ouvidoria Ativa, e consiste em ações estratégias para avaliar as ações dos serviços de saúde e solucionar dificuldades apresentadas. Assim, através da Ouvidoria Ativa, os usuários do SUS que se utilizam da PNAF e dos seus medicamentos e insumos para a saúde, podem ser contatados para avaliação do nível de satisfação em relação ao recebimento dos mesmos. Para esta pesquisa, já havia decorrido três anos da adoção do PEC e não foi possível a realização das avaliações por meio da Ouvidoria do SUS.

Em relação ao indicador de valor agregado aos usuários da inovação do MS, este se refere à satisfação dos usuários da inovação dentro do MS. O questionário aplicado no MS para o desenvolvimento desta pesquisa apontou um índice de usuários satisfeitos com a 
utilização da inovação através da questão de número 6, que indagava se a inovação promovia melhorias nos processos de trabalho dos servidores envolvidos com a compra de medicamentos do Ministério. O questionário apontou na Figura 12 apresenta que 37,5\% e $36,54 \%$ apontaram as notas 4 e 5 da escala do questionário respectivamente, o que reflete a percepção de melhorias nos processos de trabalho com a utilização do processo eletrônico.

E para mensurar o indicador de valor agregado aos fornecedores, sugere-se a realização de pesquisa de satisfação através de e-mail com todos os fornecedores que assinaram contrato com o órgão antes e depois da adoção da inovação, com o intuito de verificar a percepção dos mesmos em relação aos processos de compras e se a inovação impactou em melhorias para esses stakeholders responsáveis pelo fornecimento de medicamentos do MS. No caso do MS, em função de haver decorrido três anos da implementação da inovação, este índice de satisfação não pode ser levantado.

\subsubsection{Indicadores de sustentabilidade}

A sustentabilidade implica num conjunto de medidas que são necessários para uma inter-relação entre equilíbrio ambiental, justiça social, qualidade de vida e a necessidade de desenvolvimento com capacidade de suporte (Jacobi, 1999).

Com base nesse critério, as compras governamentais podem ser utilizadas como instrumentos de fomento às iniciativas voltadas para a promoção de bens e serviços sustentáveis.

Nesse sentido, os indicadores de sustentabilidade nas compras governamentais que adotam a inovação estão relacionados com a busca pela incorporação de princípios e critérios de gestão ambiental em suas atividades rotineiras, levando à economia de recursos naturais e redução de gastos institucionais por meio do uso racional de recursos públicos (Valente, 2011). 
$\mathrm{Na}$ Tabela 34, apresentam-se os indicadores propostos para medir a sustentabilidade da inovação nas compras governamentais, que buscam aferir a economia de recursos, sejam eles materiais ou humanos, bem como a redução de gastos institucionais. A periodicidade de apuração deverá ser anual e realizada antes e depois da adoção da inovação.

Tabela 34 - Indicadores de sustentabilidade da inovação nas compras governamentais

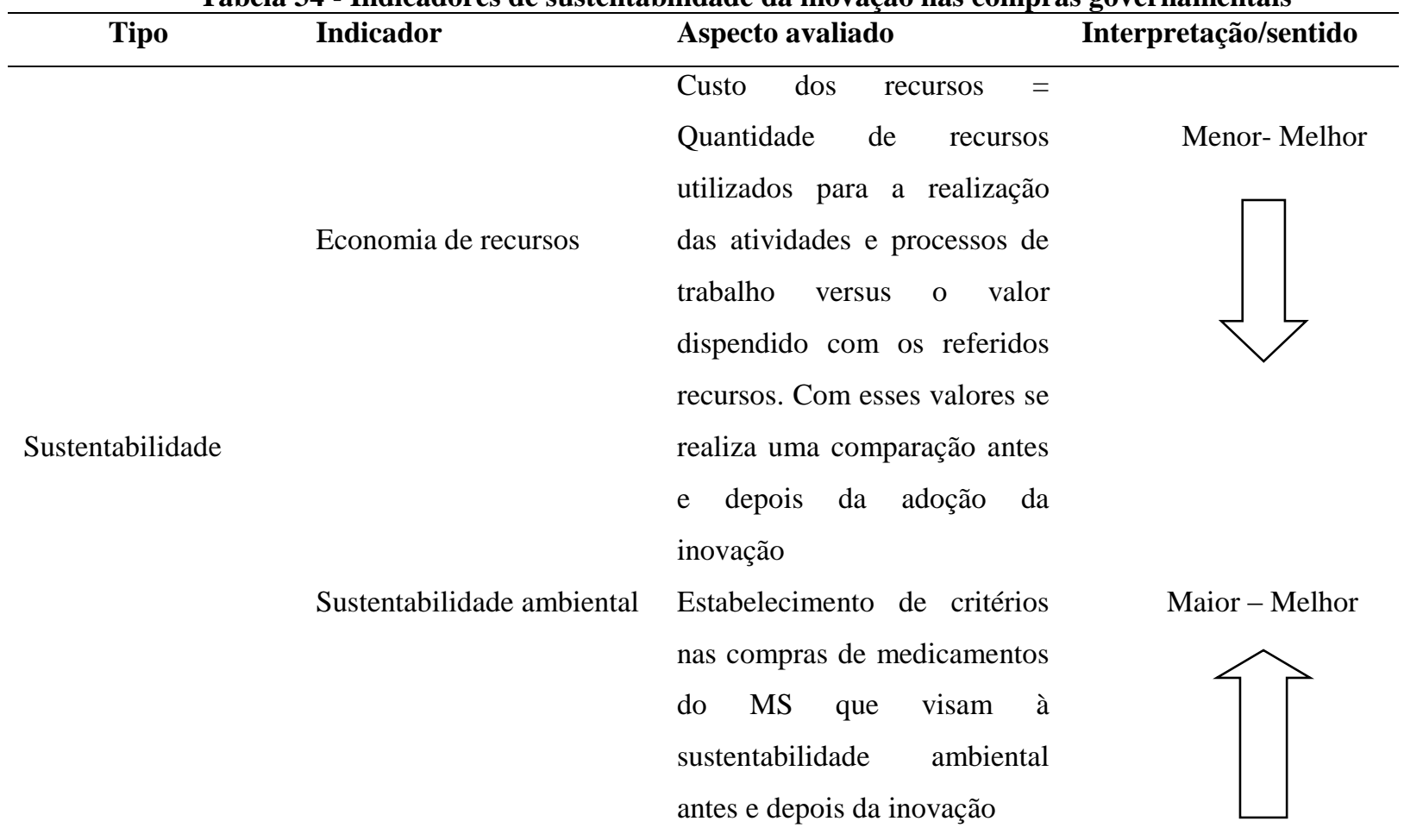

Fonte: Elaborada pela autora.

Com base no indicador proposto, foram calculados os custos do recurso papel, uma vez que o mesmo é um recurso relevante para a Administração Pública na constituição dos processos físicos para as compras de medicamentos, o que se aplica também no contexto do MS e ao DLOG, conforme Tabela 35. 
Tabela 35 - Dados do indicador de sustentabilidade da inovação nas compras governamentais referente ao recurso papel

\begin{tabular}{|c|c|c|c|c|c|c|c|c|}
\hline \multirow{3}{*}{ Recurso } & \multicolumn{4}{|c|}{ Antes da adoção da inovação } & \multicolumn{4}{|c|}{ Após a adoção da inovação } \\
\hline & \multicolumn{2}{|c|}{2012} & \multicolumn{2}{|c|}{2013} & \multicolumn{2}{|c|}{2014} & \multicolumn{2}{|c|}{2015} \\
\hline & $\begin{array}{c}\text { Quantidade } \\
\text { total } \\
\text { (unidade) }\end{array}$ & $\begin{array}{c}\text { Custo } \\
\text { total }(\mathbf{R} \$)\end{array}$ & $\begin{array}{c}\text { Quantidade } \\
\text { total } \\
\text { (unidade) }\end{array}$ & $\begin{array}{c}\text { Custo } \\
\text { total }(\mathbf{R} \$)\end{array}$ & $\begin{array}{c}\text { Quantidade } \\
\text { total } \\
\text { (unidade) }\end{array}$ & $\begin{array}{c}\text { Custo } \\
\text { total }(\mathbf{R} \$)\end{array}$ & $\begin{array}{l}\text { Quantidade } \\
\text { total } \\
\text { (unidade) }\end{array}$ & $\begin{array}{c}\text { Custo } \\
\text { total }(\mathbf{R} \$)\end{array}$ \\
\hline $\begin{array}{l}\text { Papel para máquina copiadora } \\
75 \mathrm{~g} / \mathrm{m} 2-210 \times 297 \mathrm{~mm} \text { - res ma - } \\
500 \text { folhas }\end{array}$ & 1261 & $9.331,40$ & 1086 & $7.712,41$ & 790 & $5.720,30$ & 364 & $2.992,28$ \\
\hline
\end{tabular}

Fonte: Elaborada pela autora com base nos dados do software SISMAT.

Os dados levantados pelo indicador de sustentabilidade da inovação apontam que a mudança relativa à instrução processual das licitações de forma física para eletrônica implicou numa economia de 448.500 folhas de papel para o MS, através do DLOG, o que representa uma redução de aproximadamente $70 \%$ em termos de gastos públicos com o referido recurso.

Com relação ao indicador sustentabilidade ambiental, a análise documental apontou que a partir de 02 de julho de 2014, após a adoção do PEC, todas as compras realizadas pelo DLOG inseriram como critério a proibição da compra de substâncias que destroem a camada de ozônio, de acordo com o Protocolo de Montreal e da Resolução do CONAMA nº 267, de 14 de novembro de 2000.

Esses dados sugerem que a inovação adotada estabeleceu critérios de sustentabilidade através de um menor consumo de papel, bem como do estabelecimento de cláusulas que visam proteger ao meio ambiente e, com isso, conferiu coerência ao comprador público relativo ao dever do Estado no sentido prover a máquina pública de bens e serviços em consonância com equilíbrio ambiental, o que ratifica os resultados encontrados por Hollanders et al. (2013), cuja pesquisa realizada pelo Innobarometer 2010, indicou que mais da metade das organizações públicas se utilizam das compras governamentais para entregar soluções inovadoras em produtos e serviços, e objetivam também a redução de custos e a minimização de impactos ambientais. 


\subsubsection{Indicadores de transparência}

A transparência pode ser entendida como meio pelo qual a Administração Pública proporciona o acesso à informação pública, de modo a garantir mais eficiência e eficácia às políticas públicas, tornando os gastos públicos mais efetivos (Lopes, 2007).

Nesse sentido, propõem-se indicadores de acesso à informação referente às compras governamentais para três stakeholders: cidadãos, fornecedores e órgãos de controle, por se trataram das principais partes interessadas nas informações relativas aos processos.

A Tabela 36 apresenta os indicadores de transparência e as formas de medição, que devem ser realizadas anualmente, antes e depois da inovação.

Tabela 36 - Indicadores de transparência da inovação e formas de mensuração

\begin{tabular}{|c|c|c|c|}
\hline Tipo & Indicador & Aspecto avaliado & Interpretação/sentido \\
\hline \multirow{3}{*}{ Transparência } & $\begin{array}{l}\text { Acesso aos } \\
\text { fornecedores }\end{array}$ & $\begin{array}{l}\text { Quantidade de acessos dos } \\
\text { fornecedores aos dados dos } \\
\text { processos de compra antes e } \\
\text { depois da adoção da inovação }\end{array}$ & Maior - Melhor \\
\hline & Acesso ao cidadão & $\begin{array}{l}\text { Quantidade de acessos dos } \\
\text { cidadãos aos dados dos } \\
\text { processos de compra antes e } \\
\text { depois da adoção da inovação }\end{array}$ & Maior - Melhor \\
\hline & $\begin{array}{l}\text { Acesso aos órgãos de } \\
\text { controle }\end{array}$ & $\begin{array}{l}\text { Quantidade de acessos dos } \\
\text { Órgãos de Controle aos dados } \\
\text { dos processos de compra antes } \\
\text { e depois da adoção da } \\
\text { inovação }\end{array}$ & Maior - Melhor \\
\hline
\end{tabular}

Fonte: Elaborada pela autora.

No caso do MS, já havia decorrido três anos da implementação do PEC e, portanto, não foi possível levantar os dados de acesso aos processos físicos para posterior comparação com os acessos realizados de forma eletrônica, os quais desde o ano de 2013 estão consolidados na Tabela 37. 
Tabela 37 - Indicadores de transparência da inovação nas compras governamentais

\begin{tabular}{lccccc}
\hline & \multicolumn{2}{c}{ Antes da adoção da inovação } & \multicolumn{3}{c}{ Após a adoção da inovação } \\
\cline { 2 - 5 } Indicador & $\mathbf{2 0 1 1}$ & $\mathbf{2 0 1 2}$ & $\mathbf{2 0 1 3}$ & $\mathbf{2 0 1 4}$ & $\mathbf{2 0 1 5}$ \\
\hline Acesso aos & - & - & 10 & 27 & 36 \\
fornecedores & - & & 10 & 22 & 36 \\
Acesso ao cidadão & - & - & 2 & 1 & 3 \\
Acesso aos órgãos de & & & & & \\
controle & & & & & \\
\hline
\end{tabular}

Fonte: Elaborada pela autora com base nos dados dos softwares PEC e e-SIC em 03/11/2016.

Ressalta-se que, apesar da ausência de registro de dados referente aos pedidos de vistas aos processos físicos e de acesso às informações antes da adoção da inovação, nos anos de 2011 e 2012, os dados da Tabela 37 apontam que os fornecedores interessados e os órgãos de controle possuem acesso aos processos de compra de medicamentos e insumos para a saúde de forma eletrônica, via PEC, o que sugere que a inovação adotada proporciona transparência aos atos do MS e do DLOG, e releva aderência ao princípio da transparência da informação pública, que no referido caso é disponibilizada de forma confiável e oportuna (Jardim, 1999).

No entanto, a análise documental demonstrou que, desde 2013, não houve solicitação de acesso ao PEC por parte do cidadão e este quando o fez, conforme Tabela 37, realizou essa solicitação de acesso às informações pelo software eletrônico do Serviço de Informação ao Cidadão (e-SIC). 


\section{CONCLUSÕES E RECOMENDAÇÕES}

A presente pesquisa buscou analisar a inovação no processo de compras governamentais de medicamentos e insumos para a saúde e teve com lócus o MS, órgão da Administração Federal Direta responsável pela política do SUS e pelas ações que visam a promoção, proteção e recuperação da saúde dos cidadãos brasileiros, o DLOG e as áreas envolvidas com esses processos dentro do referido órgão.

Para realizar a análise dessa inovação no contexto do MS foram definidos cinco objetivos específicos, os quais se valeram de abordagens qualitativas e quantitativas como meios de incrementar a confiabilidade dos dados relativos ao fenômeno escolhido.

Quanto ao objetivo específico um, que consiste em caracterizar a inovação desenvolvida no processo de compras governamentais de medicamentos do MS, o mesmo foi concretizado por meio de revisão de literatura e análise documental, e definiu o PEC como uma inovação no setor de serviços, no contexto do setor público, caracterizada como incremental, além de ser classificada como inovação de processo administrativo ou tecnológico e organizacional, a depender da tipologia da literatura utilizada, corroborando os estudos de Gallouj e Weinstein (1997), Bloch et al. (2009), De Vries, Bekkers e Tummers (2015), e Rogers (2003).

Para identificar as dimensões e variáveis de inovação presentes e ausentes no fenômeno estudado, que consiste no objetivo específico dois, foi realizada análise conteúdo proveniente de dois grupos focais com gestores e usuários da inovação, que revelou a oportunidade de identificar através dos discursos destes stakeholders, essas dimensões e variáveis, e por fim, novas variáveis relacionadas ao tipo de inovação desenvolvida.

O objetivo específico de número três, o qual consta na identificação dos fatores relacionados com o fenômeno de inovação do MS, o mesmo foi alcançado pela aplicação de 
questionários com os usuários da inovação do MS envolvidos com o processo de compras governamentais de medicamentos. Os resultados apontam relações significativas entre diversas variáveis de inovação apontadas por Bloch et al. (2009) e De Vries, Bekkers e Tummers (2015), e que foram reconhecidas pelos usuários do PEC no MS como aderentes ao contexto do MS. Além disso, a AFE utilizou esses padrões de correlações para agrupar suas variáveis em três fatores principais, os quais são considerados representantes de dimensões da inovação no setor público: características e resultados da inovação, no caso em questão o PEC; práticas de gestão e percepções sobre o ambiente organizacional para promoção de inovações; e, por fim, práticas relativas ao processo de inovação no MS.

Para cumprir o quarto objetivo específico, que consiste na proposição de indicadores de inovação no processo de compras governamentais, foram elaborados e analisados cinco tipos de indicadores para mensurar o desempenho da inovação adotada, que são: eficiência, eficácia, sustentabilidade, transparência e economicidade.

Em relação ao quinto e último objetivo específico, os indicadores analisados no contexto do MS destacaram que a inovação apresentou ganhos nos aspectos da transparência da informação pública, da sustentabilidade e no valor agregado aos processos de trabalho dos servidores do MS. Contudo, os indicadores de eficiência e economicidade demonstraram que a inovação adotada não evidenciou resultados positivos ao MS, o que ratifica o entendimento dos autores De Vries, Bekkers e Tummers (2015) quando afirmam que investimentos organizacionais em inovações podem trazer resultados tanto positivos quanto negativos, além de demonstrar a complexidade de mensuração dos resultados efetivos dessas inovações no contexto do setor público.

A partir do cumprimento dos cinco objetivos específicos e no que diz respeito às contribuições teóricas da pesquisa, a mesma investigou a inovação adotada no MS, 
delimitando, com base na literatura proposta pelos autores Bloch et al. (2009), Bloch (2011) e De Vries, Bekkers e Tummers (2015), dimensões e variáveis para analisar o construto inovação no setor público, além de identificar novas variáveis categorizadas como características da inovação do MS: transparência da informação e sustentabilidade.

Dessa forma, a triangulação entre as análises apresentadas nas abordagens qualitativa, quantitativa e análise documental realizada para elaboração e apuração dos indicadores de inovação apontou que a inovação do MS trouxe resultados positivos, no tocante à promoção de transparência da informação relativa às compras governamentais de medicamentos e da adoção de critérios que incentivam à sustentabilidade ambiental. Entretanto, o PEC trouxe alguns resultados indesejáveis, uma vez que não possibilitou melhoria em alguns processos relacionados com a eficiência, eficácia e economicidade para a realização dessas compras. A literatura ratifica os dados da pesquisa quando afirma que os resultados da inovação podem ser positivos, negativos, desejáveis ou indesejáveis (Rogers, 2003; De Vries, Bekkers e Tummers, 2015).

Já as contribuições gerenciais da pesquisa, estas perpassam pela identificação e análise da influência das dimensões e variáveis presentes e ausentes na inovação implementada, desenvolvimento de indicadores que podem ser utilizados como métricas para o desempenho da inovação, bem como pelo entendimento e disseminação por parte dos gestores públicos das práticas de inovação incorporadas no setor público brasileiro.

Ressalta-se que, no decorrer da realização da pesquisa, o ambiente de mudanças políticas e econômicas que o Brasil atravessou nos anos de 2015 e 2016 se refletiu em modificações institucionais no MS, o que implicou em mudanças de gestão e na falta de entendimento quanto ao desenvolvimento das coletas de dados com amostras mais significativas e que demonstrassem maiores evidências relacionadas aos objetivos do estudo. 
Faz-se necessário destacar que a análise da inovação, à luz dos resultados apresentados, contém algumas limitações. O estudo de caso realizado no MS, como é de comum conhecimento, não pode obviamente oferecer generalizações no aspecto estatístico, porém mesmo o estudo de caso único pode ser muito útil para obtenção de melhorias na gestão dos processos de inovação desenvolvidos no setor público, especialmente no contexto das compras governamentais, cujas especificidades exigem substanciais e continuados investimentos em infraestrutura, capacitação de pessoal e métodos de trabalho mais eficazes e transparentes.

Além disso, em função da necessidade de mensuração do desempenho das inovações nas organizações públicas, sugere-se a aplicação do método utilizado em outras organizações, como forma de explorar e validar as categorias desenvolvidas e variáveis utilizadas. Sugeremse ainda estudos quantitativos que testem a correlação entre as variáveis apresentadas através da técnica estatística da regressão múltipla, considerando a percepção de um número maior de stakeholders relacionados com a inovação dentro do MS; a relação entre essas variáveis e o desempenho organizacional do MS no tocante aos objetivos da PNAF; e por fim, uma análise confirmatória dos fatores propostos pela AFE.

Entretanto, sugere-se que outras organizações do setor público utilizem os resultados do presente trabalho fundamentalmente como um meio de aprendizado com a experiência de inovação, visando a maximização dos resultados pretendidos. Ajuda a organização a focalizar o que deve ser feito e como, de forma sistematizada. Assim, formaliza-se a ideia de aprendizagem com a experiência de outra organização, analisando os fatores relevantes, para então compreender os processos utilizados para se alcançar níveis superiores de desempenho a partir da implementação de inovações no setor público e, a seguir, refletir como as lições 
aprendidas deverão ser adaptadas à realidade específica da organização que necessita melhorar seus resultados.

Ademais, cumpre destacar que as práticas de inovações em organizações públicas devem consistir em buscas deliberadas e organizadas de mudanças que visam atingir um propósito determinado, planejado, de forma contínua e permanente, e, com isso, devem buscar institucionalizar uma cultura de inovação no contexto do setor público, como meio de gerar valor coletivo para a sociedade. 


\section{REFERÊNCIAS}

Abrucio, F. L. (1997). O impacto do modelo gerencial na administração pública: um breve estudo sobre a experiência internacional recente.

Adams, R., Bessant, J., \& Phelps, R. (2006). Innovation management measurement: a review. International Journal of Management Reviews, 8(1), p. 21-47.

APSII. (2011). Working towards a measurement framework for public sector innovation in Australia. APSII Draft Discussion Paper for SRG Meeting 156.doc.

Baily, P. (2000). Compras: princípios e administração. São Paulo: Atlas.

Bardin, L. (2011). Análise de conteúdo. $3^{\text {a }}$ Reimpressão. Lisboa: Edições.

Bermudez, J. A. Z. (2006). A produção pública de medicamentos no Brasil. Cadernos de Saúde Pública, 22(11), p. 2.379-2.389.

Bevilacqua, G., Farias, M. R., \& Blatt, C. R. (2011). Aquisição de medicamentos genéricos em município de médio porte. Revista de Saúde Pública, 45(3), p. 583-589.

Biderman, R., \& Macedo, L. (2008). Guia de compras públicas sustentáveis. Uso do poder de compra do governo para a promoção do desenvolvimento sustentável.

Bloch, C. (2011). Measuring Public Innovation in the Nordic Countries (MEPIN).

Bloch, C., Jørgensen, L. L., Norn, M. T., \& Vad, T. B. (2009). Public sector innovation index - A diagnostic tool for measuring innovative performance and capability in public sector organisations. Technology and the Arts (NESTA).

Brasil. Política Nacional de Medicamentos. Brasília: Secretaria de Políticas Públicas, Ministério da Saúde, 1999.

Bresser-Pereira, L. C. (2006). Gestão do setor público: estratégia e estrutura para um novo Estado. In: Pereira, L. C. B. (Org.). Reforma do Estado e administração pública gerencial (7a ed.). Rio de Janeiro: $F G V$.

Bugge, M., Mortensen, P. S., \& Bloch, C. (2011). Measuring public innovation in nordic countries. Report on the Nordic Pilot studies-Analyses of methodology and results.

Câmara, L. M., \& Frossard, L. B. D. M. (2010). Poder de compras da administração pública federal: novas perspectivas para o debate acadêmico. Encontro de Administração Pública e Governança, 4, p. 2-16.

Cappelle, M. C. A., Melo, M. C. D. O. L., \& Gonçalves, C. A. (2011). Análise de conteúdo e análise de discurso nas ciências sociais. Organizações Rurais \& Agroindustriais, 5(1).

Citadini, A. R. (1989). A economicidade nos gastos públicos. São Paulo: Jornal O Estado de São Paulo, p. 40. 
Conde, M. V. F., \& Araújo-Jorge, T. C. D. (2003). Modelos e concepções de inovação: a transição de paradigmas, a reforma da C\&T brasileira e as concepções de gestores de uma instituição pública de pesquisa em saúde. Ciência \& Saúde Coletiva, 8(3), p. 727741.

Cruz, V; Dantas, I. (2008). Política Industrial eleva compras públicas. Folha Online, Brasília, DF. Recuperado em 21 de abril, 2015, de http:www1.folha.uol.com.br/folha/dinheiro/ult91u387205.shtml.

Damanpour, F. (1991). Organizational innovation: A meta-analysis of effects of determinants and moderators. Academy of management journal, 34(3), p. 555-590.

Decreto n. 7.336, de 19 de outubro de 2010. Aprova a Estrutura Regimental e o Quadro Demonstrativo dos Cargos em Comissão e das Funções Gratificadas do Ministério da Saúde, e dá outras providências. Brasília, DF. Recuperado em 24 de outubro, 2015, de http://www.planalto.gov.br/ccivil_03/_Ato2007-2010/2010/Decreto/D7336.htm.

Decreto $n$. 53.612, de 26 de fevereiro de 1964. Aprova relação de medicamentos essenciais para os fins previstos no Decreto $\mathrm{n}^{\circ} 52.471$, de 1963 , e dispõe sobre a aquisição de medicamentos pela Administração Pública Federal. Brasília, DF. Recuperado em 24 de outubro, 2015, de http://www2.camara.leg.br/legin/fed/decret/1960-1969/decreto53612-26-fevereiro-1964-393693-norma-pe.html.

De Vries, H., Bekkers, V., \& Tummers, L. (2015). Innovation in the public sector: A systematic review and future research agenda. Public Administration.

DiMaggio, P. J., \& Powell, W. W. (Eds.). (1991). The new institutionalism in organizational analysis (Vol. 17). Chicago, IL: University of Chicago Press.

Donaldson, T., \& Preston, L. E. (1995). The stakeholder theory of the corporation: Concepts, evidence, and implications. Academy of management Review, 20(1), p. 65-91.

Dosi, G. (1988). Sources, procedures, and microeconomic effects of innovation. Journal of Economic Literature, p. 1120-1171.

Drejer, I. (2004). Identifying innovation in surveys of services: a Schumpeterian perspective. Research Policy, 33(3), p. 551-562.

European Commission. (2005). Public procurement for research and innovation: developing procurement practices favorable to R\&D and innovation.

Farrel, P. V. H., \& Stuart, F. (1983). Compras: princípios e aplicações. São Paulo: Atlas.

Federal, G. (2010). Ministério do Planejamento Orçamento e Gestão. Guia referencial para medição de desempenho e Manual para construção de indicadores. Recuperado em 04 de outubro de 2016, de http://www.gespublica.gov.br/ferramentas/pasta, p. 05-24.

Fernandes, C. C. C. (2014). Abrangência, inserção e impacto transformador dos sistemas de compras eletrônicas na administração pública - Análise do Siasg/Comprasnet. Revista do Serviço Público, 56(2), p. 195-216. 
FNQ - Fundação Nacional da Qualidade (2015). Gestão da inovação. São Paulo: $F N Q$.

Freeman, C. (1984). Inovação e ciclos longos de desenvolvimento econômico. Ensaios FEE, 5(1), p. 5-20.

Freitas, J. (2012). Sustentabilidade: direito ao futuro (2a ed.). Belo Horizonte: Fórum.

Friel, S. N., \& Markworth, K. A. (2009). A framework for analyzing geometric pattern tasks. MatheMatics teaching in the Middle school, 15(1), p. 24-33.

Gallouj, F., \& Weinstein, O. (1997). Innovation in services. Research Policy, 26(4), p. $537-$ 556.

Gatti, B. A. (2005). Grupo focal na pesquisa em ciências sociais e humanas. Brasília: Líber Livro.

Hair, J. F., Black, W. C., Babin, B. J., Anderson, R. E., \& Tatham, R. L. (2009). Análise multivariada de dados. Bookman Editora.

Halvorsen, T. (2005). On innovation in the public sector. In: Halvorsen, T.; Hauknes, J.; Miles I.; \& Roste, R. On the differences between public and private sector innovation. Oslo: NIFU STEP.

Hernandez-Nieto, R. A. (2002). Contributions to statistical analysis. Mérida: Universidade de Los Andes.

Hollanders, H., Arundel, A., Buligesco, B., Peter, V., Roman, L., Simmonds, P. (2013). European Public Sector Innovation Scoreboard 2013: a pilot exercise. European Union Publications Office.

Hood, C. (1991). A public management for all seasons? Public Administration, 69(1), p. 3-19.

Hughes, A., Moore, K., \& Kataria, N. (2011). Innovation in Public Sector Organisations: A pilot survey for measuring innovation across the public sector. London: NESTA.

Isidro-Filho, A., Guimarães, T. A., \& Perin, M. G. (2011). Determinants of innovations in information and communication technologies adopted by hospitals. RAI, 8(4), p. 142.

Jacobi, P. (1999). Meio ambiente e sustentabilidade. O município no século XXI: cenários e perspectivas. Cepam - Centro de Estudos e Pesquisas de Administração Municipal.

Jardim, J. M. (1999). Transparência e opacidade do Estado no Brasil: usos e desusos da informação governamental. Editora da Universidade Federal Fluminense.

Kattel, R., Cepilovs, A., Drechsler, W., Kalvet, T., Lember, V., \& Tõnurist, P. (2013). Can we measure public sector innovation? A literature review. LIPSE project paper.

Kim, J., Lee, S., Geum, Y., \& Park, Y. (2012). Patterns of innovation in digital content services: the case of App Store applications. Innovation, 14(4), p. 540-556. 
Kline, S. J., \& Rosenberg, N. (1986). An overview of innovation. The positive sum strategy: harnessing technology for economic growth, 14, p. 640

Kon, A. (2004). Economia de serviços: teoria e evolução no Brasil. Rio de Janeiro: Campus.

Kornis, G. E., Braga, M. H., \& Zaire, C. E. (2008). Os marcos legais das políticas de medicamentos no Brasil contemporâneo (1990-2006). Rev. APS, 11(1), 85-99.

Korteland, E., \& Bekkers, V. (2008). The diffusion of electronic service delivery innovations in Dutch E-policing: the case of digital warning systems. Public Management Review, 10(1), p. 71-88.

Lei n. 5.991, de 17 de dezembro de 1973. Dispõe sobre o Controle Sanitário do Comércio de Drogas, Medicamentos, Insumos Farmacêuticos e Correlatos, e dá outras providências. Brasília, DF. Recuperado em 24 de outubro, 2015, de http://www.planalto.gov.br/ccivil_03/leis/L5991.htm.

Lei n. 8.666, de 21 de julho de 1993. Regulamenta o art. 37, inciso XXI, da Constituição Federal, institui normas para licitações e contratos da Administração Pública e dá outras providências. Brasília, DF. Recuperado em 24 de outubro, 2015, de http://www.planalto.gov.br/ccivil_03/Leis/L8666cons.htm

Lei $n^{o}$. 13.243, de 11 de janeiro de 2016. Dispõe sobre estímulos ao desenvolvimento científico, à pesquisa, à capacitação científica e tecnológica e à inovação e dá outras providências. Disponível em:_http://www.planalto.gov.br/ccivil_03/_ato20152018/2016/lei/113243.htm.

Leite, R. V. (2001). O princípio da eficiência na administração pública. Revista de Direito Administrativo, 226, p. 251-264.

Lopes, C. A. (2007). Acesso à informação pública para a melhoria da qualidade dos gastos públicos - literatura, evidências empíricas e o caso brasileiro. Caderno de Finanças Públicas (8).

Luiza, V. L., Castro, C. G. S. O., \& Nunes, J. M. (1999). Aquisição de medicamentos no setor público: o binômio qualidade-custo. Cad. Saúde Pública, 15(4), p. 769-776.

Management Advisory Committee. (2010). Empowering change: fostering innovation in the Australian public service. Canberra: Australian Government.

Martin, J. (1990). Breaking up the mono-method monopolies in organizational. The theory and philosophy of organizations: critical issues and new perspectives, 30.

Matos Pinto, I. C. (2015). Mudanças nas políticas públicas: a perspectiva do ciclo de política. Revista Políticas Públicas, 12(1).

Moreira, M. F., \& Vargas, E. R. (2009). O papel das compras governamentais na indução de inovações. Contabilidade, Gestão e Governança, 12 (2). 
Nelson, R. R., \& Winter, S. G. (1977). In search of a useful theory of innovation. Research Policy, 6 (1), 36-76.

Nelson, R. R., \& Yates, D. (1978). Innovation and implementation in public organizations. Lexington Books.

Novaes, M. L. D. O., Gonçalves, A. A., \& Simonetti, V. M. M. (2006). Gestão das farmácias hospitalares através da padronização de medicamentos e utilização da curva ABC. SIMPEP, 13, p. 3-8.

OECD (1997). The measurement of scientific and technological activities. Proposed guidelines for collecting and interpreting technological innovation data. Oslo Manual. European Commission Eurostat.

Oliveira, B. C. S., \& Santos, L. M. L. (2015). Compras públicas como política para o desenvolvimento sustentável. RAP: Revista Brasileira de Administração Pública, 49(1).

Oliveira, E. A., Labra, M. E., \& Bermudez, J. (2006). A produção pública de medicamentos no Brasil: uma visão geral. Cad. Saúde Pública, 22(11), p. 2.379-2.389.

Oliveira, L. G. D., Santana, R. L. F. D., \& Gomes, V. C. (2014). Inovação no setor público: uma reflexão a partir das experiências premiadas no concurso inovação na gestão pública federal. Brasília, DF. Recuperado em 24 de outubro, 2015, de http://www.enap.gov.br/documents/52930/707328/150311_caderno_enap_38_.pdf/64c 8f38c-33ff-4e33-ac7d-1ed05d3630aa.

Pihir, I., \& Detelj, K. (2015). Measuring public procurement for innovation at country level and the role of ICT Support. Journal of Information and Organizational Sciences, 39(1), p. 21-32.

Portaria $n^{o}$. 2.758, de 19 de novembro de 2013. Institui o Processo Eletrônico de Compras (PEC) no âmbito do Ministério da Saúde e dá outras providências. Brasília, DF. Recuperado em 20 de julho, 2016, de http://bvsms.saude.gov.br/bvs/saudelegis/gm/2013/prt2758_18_11_2013.html.

Resende, P. C. (2014). Sistemas organizacionais promotores de aprendizado \& inovação. São Paulo: Scortecci.

Resende Junior, P. C., Guimarães, T. A., \& Bilhim, J. A.F. (2013). Escala de orientação para inovação em organizações públicas: estudo exploratório e confirmatório no Brasil e em Portugal. RAI: Revista de Administração e Inovação, 10(1), p. 257-277.

Resolução $n .267$ de 14 de setembro de 2000. Dispõe sobre a proibição da utilização de substâncias que destroem a Camada de Ozônio. Recuperado em 16 de novembro de 2016, de http://www.mma.gov.br/port/conama/legiabre.cfm?codlegi=265.

Resolução n. 338, de 06 de maio de 2004. Aprova a política nacional de assistência farmacêutica. Brasília, DF. Recuperado em 24 de outubro, 2015, de http://bvsms.saude.gov.br/bvs/saudelegis/cns/2004/res0338_06_05_2004.html. 
Rogers, E. M. (2003). Diffusion of innovations. New York: Free Press.

Ruxton, G. D. (2006). The unequal variance t-test is an underused alternative to Student's ttest and the Mann-Whitney U test. Behavioral Ecology, 17(4), p. 688-690.

Saunila, M., \& Ukko, J. (2012). A conceptual framework for the measurement of innovation capability and its effects. Baltic Journal of Management, 7(4), p. 355-375.

Schooner, S. L., Gordon, D. I., \& Clark, J. L. (2008). Public Procurement Systems: Unpacking Stakeholder Aspirations and Expectations. GWU Law School Public Law Research Paper.

Schooner, S. L., \& Yukins, C. R. (2009). Public procurement: focus on people, value for money and systemic integrity, not protectionism. The collapse of global trade, murky protectionism, and the crisis: recommendations for the $G, 20$.

Schumpeter, J.A. (1982). Teoria do desenvolvimento econômico. Rio de Janeiro: Fundo de Cultura.

Silva Neto, J. M., \& Ribeiro, R. P. (2012). Gestão estratégica de recursos públicos: avaliação das variáveis restritivas à efetividade na execução do programa. Revista Eletrônica de Administração, 18(1), p. 191-210.

Sousa, R., \& Oliveira, J. (2010). Compras governamentais: análise de aspectos da demanda pública por equipamentos de telecomunicações.

Squeff, F. D. H. S. (2014). O poder de compras governamental como instrumento de desenvolvimento tecnológico: análise do caso brasileiro. Brasília, DF. Recuperado em 24 de outubro, 2015, de http://www.ipea.gov.br/portal/index.php?option=com_content $\&$ view=article \&id=2111 6.

Statistical Office of the European Communities. (2005). Oslo Manual: guidelines for collecting and interpreting innovation data. $O C D E$.

Tabachnick, B. G., \& Fidell, L. S. (2007). Multivariate analysis of variance and covariance. Using multivariate statistics, 3, p. 402-407.

Tarapanoff, K. (2006). Inteligência, informação e conhecimento em corporações. Instituto Brasileiro de Informação em Ciência e Tecnologia (IBICT).

União, T. D. C. (2014). Relatório Sistêmico de Fiscalização da Saúde (Fiscsaúde).

União, T. D. C. (2015). Relatório Sistêmico de Fiscalização da Saúde (Fiscsaúde).

Valente, M. A. L. (2011). Marco legal das licitações e compras sustentáveis na Administração Pública. Brasília: Câmara dos Deputados. 
Varge Maldonado, J. M. S. (2008). O papel do comprador no processo de compras em instituições públicas de ciência e tecnologia em saúde (C\&T/S). RAP, 42(4). Rio de Janeiro, p. 681-99.

Vergara, S. C. (2000). Começando a definir a metodologia. Projetos e relatórios de pesquisa em Administração, 3, p. 46-53.

Vieira, F. S. (2009). Gasto do Ministério da Saúde com medicamentos: tendência dos programas de 2002 a 2007. Revista Saúde Pública, 43(4), p. 674-81.

Vieira, F. S., \& Zucchi, P. (2013). Financiamento da assistência farmacêutica no sistema único de saúde. Saúde e Sociedade, 22(1), p. 73-84.

Vitoriano, M. A. V., \& Souza Neto, J. (2016). Information technology service management processes maturity in the Brazilian Federal direct administration. JISTEM - Journal of Information Systems and Technology Management, 12(3), p. 663-686.

World Health Organization. (2000). The world health report 2000: health systems: improving performance. World Health Organization.

Yin, R. K. (2015). Estudo de caso: planejamento e métodos. Porto Alegre: Bookman Editora. 


\section{APÊNDICE A - CARTA DE APRESENTAÇÃO DA PESQUISADORA AO MINISTÉRIO DA SAÚDE}

\section{CARTA DE APRESENTAÇÃO}

Por meio desta, apresentamos a acadêmica DAYSE KARENINE DE OLIVEIRA CARNEIRO, que se encontra em fase de elaboração de Dissertação do Mestrado Profissional em Administração Pública, devidamente matriculada nesta Instituição de Ensino Superior, e está realizando a pesquisa intitulada "INOVAÇÃO NO PROCESSO DE COMPRAS DE MEDICAMENTOS: ESTUDO DE CASO DO MINISTÉRIO DA SAÚDE”.

A acadêmica também é Servidora Pública Federal, vinculada ao Ministério da Saúde, exercendo suas atividades no Departamento de Logística em Saúde, na Coordenação-Geral de Gestão e Planejamento Logístico em Saúde.

O objetivo do estudo é analisar a inovação no processo de compras governamentais de medicamentos e insumos para a saúde do MS.

Informamos que esta pesquisa foi qualificada para que pudesse ser desenvolvida, por uma banca formada por professores desta Instituição, em dezembro de 2015.

Na oportunidade, solicitamos autorização para que realize a pesquisa através da coleta de dados por meio dos seguintes instrumentos: realização de entrevistas em grupo, com gravação de voz, observação das atividades desenvolvidas, aplicação de questionários, acesso a documentos pertinentes ao assunto e informações de bancos de dados.

Queremos informar que o caráter ético desta pesquisa assegura a preservação da identidade das pessoas participantes.

Uma das metas para a realização deste estudo é o comprometimento da pesquisadora em possibilitar, ao órgão público participante, um retorno dos resultados da pesquisa. 
Solicitamos ainda a permissão para a divulgação desses resultados e suas respectivas conclusões, em forma de pesquisa, preservando sigilo e ética.

Agradecemos vossa compreensão e colaboração no processo de desenvolvimento desta profissional. Em caso de dúvida, procurar a coordenação do Mestrado Profissional em Administração - MPA - vinculado ao Programa de Pós-Graduação em Administração da Faculdade de Economia, Administração e Contabilidade - FACE - pelo telefone (61) 31070759 ou pelo e-mail: ppgaunb@gmail.com.

Atenciosamente,

Brasília, 20 de março de 2016.

\section{Prof. Dr. Pedro Carlos Resende Junior}

Professor orientador

E-mail: pcrj73@gmail.com 


\section{APÊNDICE B - ROTEIRO DOS GRUPOS FOCAIS}

Público-alvo: Gestores e usuários que atuam com compras governamentais de medicamentos e insumos para a saúde, no Departamento de Logística em Saúde (DLOG) e em outras áreas do Ministério da Saúde (MS).

Objetivo da moderação: Avaliar a percepção sobre a inovação na compra governamental de medicamentos e insumos no MS, seus principais atributos e variáveis.

Objetivos específicos:

a) analisar o nível de conhecimento sobre inovação;

b) analisar se o sistema PEC é reconhecido pelo público-alvo como uma inovação;

c) analisar quais as variáveis presentes na literatura os gestores e usuários da inovação percebem nos seus processos de trabalho;

d) levantar os atributos positivos e negativos do uso da inovação; e

e) analisar quais os principais resultados advindos com a utilização da referida inovação.

Roteiro:

Rapport (3 minutos)

- Apresentação do moderador;

- Agradecer a presença;

- Falar sobre a pesquisa Grupo Focal - Técnica de pesquisa qualitativa, derivada das entrevistas grupais, que coleta informações por meio das interações grupais, baseada na comunicação e na interação. Seu principal objetivo é reunir informações detalhadas sobre um tópico específico (sugerido por um pesquisador, coordenador ou moderador do grupo) a partir de um grupo de participantes 
selecionados. Além disso, busca colher informações que possam proporcionar a compreensão de percepções, crenças, atitudes sobre um tema, produto ou serviços;

- Não há certo nem errado;

- Explicação da sala, do espelho (se houver);

- Explicar a função do gravador ou da câmera;

- Falar do lanche.

Aquecimento: Apresentação do grupo (1'30 cada - total 15 minutos)

- Nome;

- Idade;

- Cargo.

\section{Introdução ao tema:}

A inovação no processo de compras governamentais de medicamentos e insumos para a saúde e a introdução de sistemas que auxiliam a gestão dessas compras, podem contribuir significativamente para a redução de falhas no abastecimento dos mesmos e garantia de economicidade aos cofres públicos. Atualmente, as organizações públicas estão adotando abordagens de vantagem competitiva, isto é, a busca pela capacidade de a organização inovar, aprender e continuamente se reposicionar no contexto onde atua de uma maneira mais efetiva. E o assunto de hoje trata exatamente da utilização do PEC, sistema implementado pelo DLOG, no MS.

Levantamento inicial:

a) Todos usam o sistema PEC? Com que frequência?

b) Os que não usam o PEC, por que não usam? 


\section{Desenvolvimento}

1) O que vocês entendem por inovação?

2) Baseado na definição de inovação apresentada, vocês veem o PEC como uma inovação? Por quê?

3) Qual a sua percepção sobre as condições ambientais para desenvolvimento das inovações no DLOG? Esse ambiente é favorável ou não?

4) De acordo com a literatura, as inovações são classificadas como: produto ou serviço, processo (administrativo ou tecnológico), governança, conceitual, organizacional e de comunicação. Como vocês classificam o PEC? Por quê?

5) Quais as principais características que vocês avaliam no PEC?

6) Quais são as vantagens do PEC? E as desvantagens?

7) Quais os principais resultados que o PEC trouxe para os processos de trabalho do MS?

8) Alguém prefere o processo de trabalho tradicional, com a utilização do processo físico (papel)? Por quê?

\section{Encerramento}

Vocês gostariam de falar mais alguma coisa para a gente finalizar?

Encerrar agradecendo a presença mais uma vez e vamos desfrutar do lanche como forma de agradecimento pelo tempo dispensado. 


\section{APÊNDICE C - MÉTODO PARA CÁLCULO COMPLETO DO CVC}

O método de cálculo do coeficiente de validação de conteúdo (CVC) utilizado para validação do questionário foi feito a partir da descrição de Hernandéz-Nieto (2002), e se estruturou através das seguintes etapas:

1) A partir das notas dos juízes (1 a 5), calculou-se a média das notas de cada item (Mx):

$$
\mathrm{Mx}=\frac{\sum \mathrm{i}=1 \mathrm{Xij}}{\mathrm{J}}
$$

onde, $\mathrm{i}=1$ e $\mathrm{J}$ representam a soma das notas dos juízes e o número de juízes que avaliaram o item respectivamente.

2) Com base na média, calcula-se o CVC inicial para cada item (CVCi):

$$
\mathrm{CVCi}=\underline{\mathrm{Mx}}
$$

onde, o Vmáx apresenta o valor máximo que o item pode receber, o qual no caso da escala Likert utilizada de 1 a 5, o valor máximo seria 5.

3) Faz-se necessário o cálculo do erro (Pei), para desconto de possíveis vieses dos juízes, para cada item:

$$
\text { Pei }=\left(\begin{array}{l}
1 \\
J
\end{array}\right)^{J}
$$

4) Dessa forma, o CVC final $(\mathrm{CVCc})$ para cada item do questionário será:

$$
\mathrm{CVCc}=\mathrm{CVCi}-\mathrm{Pei}
$$

5) Calcula-se, o CVC total do questionário $(\mathrm{CVCt})$ em cada um dos critérios de avaliação (clareza de linguagem, relevância teórica e pertinência prática): 


$$
\text { CVCc }=\text { Mcvci }- \text { Mpei }
$$

onde, Mcvci apresenta a média dos coeficientes de validade de conteúdo dos itens e Mpei a média dos erros dos itens do questionário.

6) Calcula-se, ao final, a média dos CVCc de cada item do questionário para proceder a avaliação, com base na recomendação do referido autor, que atribui nota de corte CVCc $>0,8$. 


\section{APÊNDICE D - FORMULÁRIO DE VALIDAÇÃO DE QUESTIONÁRIO EM PESQUISA CIENTÍFICA ACADÊMICA}

Este formulário destina-se à validação do instrumento que será utilizado na coleta de dados em minha pesquisa de campo cujo tema é: INOVAÇÃO NO PROCESSO DE COMPRA DE MEDICAMENTOS: ESTUDO DE CASO DO MINISTÉRIO DA SAÚDE, que será realizada com servidores do Ministério da Saúde, os quais são usuários do software Processo Eletrônico de Compras (PEC), sendo este utilizado para a realização das compras governamentais de medicamentos e insumos para a saúde.

Solicito sua análise no sentido de verificar se há 1) Clareza da linguagem: o (a) senhor (a) acredita que a linguagem de cada item é suficientemente clara e adequada? 2) Pertinência prática: o (a) senhor (a) acredita que os itens propostos são pertinentes para o contexto pesquisado? e 3) Relevância teórica: o (a) senhor (a) acredita que o conteúdo deste item é pertinente ao estudo realizado?

As questões devem ser avaliadas quanto ao nível de adequação com base na escala de 1 a 5 pontos, onde 5 indica maior intensidade da dimensão avaliada (clareza, pertinência e relevância teórica). Caso julgue necessário, fique à vontade para sugerir melhorias, utilizando para isso, a coluna observações. Antecipadamente agradeço por sua atenção e pela presteza em contribuir com o desenvolvimento da pesquisa.

\section{A - Nesta seção, as questões verificam a percepção sobre os atributos do Processo Eletrônico de Compras (PEC).}

Indique a ocorrência e intensidade em que o software PEC apresenta as seguintes características e resultados. 


\begin{tabular}{|c|c|c|c|c|c|}
\hline Variável & Características e Resultados & $\begin{array}{l}\text { 1) Clareza da } \\
\text { linguagem }\end{array}$ & 2) Pertinência dos itens & 3) Relevância teórica & Observações \\
\hline Fácil uso da inovação & 1) Possui fácil utilização. & 12345 & 12345 & 12345 & \\
\hline Vantagem relativa & $\begin{array}{l}\text { 2) Proporciona uma vantagem relativa ao processo } \\
\text { físico (papel). }\end{array}$ & 12345 & 12345 & 12345 & \\
\hline Testado & 3) Pode ser testado. & 12345 & 12345 & 12345 & \\
\hline Compatibilidade & $\begin{array}{l}\text { 4) É compatível com outros sistemas dentro do } \\
\text { Ministério da Saúde. }\end{array}$ & 12345 & 12345 & 12345 & \\
\hline $\begin{array}{l}\text { Nível de novidade e alcance da } \\
\text { inovação }\end{array}$ & $\begin{array}{l}\text { 5) É considerado uma inovação no processo de } \\
\text { compras de medicamentos do Ministério da Saúde. }\end{array}$ & 12345 & 12345 & 12345 & \\
\hline $\begin{array}{l}\text { Outros efeitos intangíveis } \\
\text { (confiança, legitimidade) }\end{array}$ & $\begin{array}{l}\text { 6) Gera ativos intangíveis, tais como melhoria na } \\
\text { segurança da informação, nas compras de } \\
\text { medicamentos. }\end{array}$ & 12345 & 12345 & 12345 & \\
\hline Melhoria para o empregado & $\begin{array}{l}\text { 7) Promove melhorias nos processos de trabalho } \\
\text { dos servidores envolvidos com as compras de } \\
\text { medicamentos. }\end{array}$ & 12345 & 12345 & 12345 & \\
\hline Aumento da satisfação do cliente & $\begin{array}{l}\text { 8) Promove melhorias na satisfação do usuário do } \\
\text { Sistema Único de Saúde em relação aos } \\
\text { medicamentos adquiridos pelo Ministério da Saúde } \\
\text { para posterior distribuição aos Estados e Municípios. }\end{array}$ & 12345 & 12345 & 12345 & \\
\hline Transparência da informação & $\begin{array}{l}\text { 9) Proporciona transparência da informação relativa } \\
\text { aos processos de compras de medicamentos do } \\
\text { Ministério da Saúde. }\end{array}$ & 12345 & 12345 & 12345 & \\
\hline Sustentabilidade & $\begin{array}{l}\text { 10) Promove sustentabilidade nas compras de } \\
\text { medicamentos do Ministério da Saúde. }\end{array}$ & 12345 & 12345 & 12345 & \\
\hline
\end{tabular}


B - Nesta seção, as questões verificam a percepção sobre o ambiente e condições estruturais onde o software Processo Eletrônico de

\section{Compras (PEC) foi desenvolvido e funciona.}

No âmbito do Ministério da Saúde, indique a ocorrência e a intensidade das práticas de gestão e de percepções sobre o ambiente organizacional para promoção de inovações.

\begin{tabular}{|c|c|c|c|c|c|}
\hline Variável & Prática & $\begin{array}{l}\text { 1) Clareza da } \\
\text { linguagem }\end{array}$ & 2) Pertinência dos itens & 3) Relevância teórica & Observações \\
\hline $\begin{array}{l}\text { Investimento em Pesquisa \& Desenvolvimento e } \\
\text { Inovação }\end{array}$ & 11) Investimento em Pesquisa \& Desenvolvimento e Inovação. & 12345 & 12345 & 12345 & \\
\hline Apoio (educação, diversidade) & $\begin{array}{l}\text { 12) Apoio ao desenvolvimento de inovações (através de ações de } \\
\text { educação, incentivos, etc.). }\end{array}$ & 12345 & 12345 & 12345 & \\
\hline Infraestrutura tecnológica para inovação & 13)Disponibilização de infraestrutura tecnológica para inovação. & 12345 & 12345 & 12345 & \\
\hline Fontes de inovação (gestores) & $\begin{array}{l}\text { 14) Percepção de que os gestores são as principais fontes de inovação } \\
\text { dentro do órgão. }\end{array}$ & 12345 & 12345 & 12345 & \\
\hline Fontes de inovação (usuários) & $\begin{array}{l}\text { 15) Percepção de que os usuários são as principais fontes de inovação } \\
\text { dentro do órgão. }\end{array}$ & 12345 & 12345 & 12345 & \\
\hline Demandas dos fornecedores & $\begin{array}{l}\text { 16) Gestão das demandas dos fornecedores para promoção de } \\
\text { inovações. }\end{array}$ & 12345 & 12345 & 12345 & \\
\hline Demandas dos usuários & 17)Gestão das demandas dos usuários para promoção de inovações. & 12345 & 12345 & 12345 & \\
\hline Prioridades políticas & 18)Desenvolvimento de inovações em função de prioridades políticas. & 12345 & 12345 & 12345 & \\
\hline Participação em redes & $\begin{array}{l}\text { 19) Atuação em rede com outras organizações para desenvolvimento } \\
\text { de inovações. }\end{array}$ & 12345 & 12345 & 12345 & \\
\hline Aspectos regulatórios & 20) Observância da legislação para inovar. & 12345 & 12345 & 12345 & \\
\hline
\end{tabular}




\begin{tabular}{|c|c|c|c|c|c|}
\hline Variável & Prática & $\begin{array}{l}\text { 1) Clareza da } \\
\text { linguagem }\end{array}$ & 2) Pertinência dos itens & 3) Relevância teórica & Observações \\
\hline $\begin{array}{l}\text { Agências, organizações, e estados compatíveis e } \\
\text { adotando a mesma inovação }\end{array}$ & $\begin{array}{l}\text { 21) Utilização de inovações que estão sendo adotadas por outras } \\
\text { organizações com perfil compatível. }\end{array}$ & 12345 & 12345 & 12345 & \\
\hline Competição com outras organizações & $\begin{array}{l}\text { 22) Desenvolvimento de inovações em função da competição com } \\
\text { outras organizações públicas. }\end{array}$ & 12345 & 12345 & 12345 & \\
\hline Disponibilidade de recursos & 23) Disponibilidade de recursos para investimentos em inovação. & 12345 & 12345 & 12345 & \\
\hline Estilos de liderança & $\begin{array}{l}\text { 24)Influência da alta liderança (cargos de Direção e Assessoramento } \\
\text { Superior 6, Direção e Assessoramento Superior } 5 \text { e Direção e } \\
\text { Assessoramento Superior 4) no desenvolvimento de inovações. } \\
\text { 25)Influência da média liderança (cargos de Direção e Assessoramento }\end{array}$ & 12345 & 12345 & 12345 & \\
\hline Estilos de liderança & $\begin{array}{l}\text { Superior 3, Direção e Assessoramento Superior 2) no desenvolvimento } \\
\text { de inovações. }\end{array}$ & 12345 & 12345 & 12345 & \\
\hline Estilos de liderança & $\begin{array}{l}\text { 26)Influência da baixa liderança (cargos de Direção e Assessoramento } \\
\text { Superior } 1 \text { e chefes de divisão) no desenvolvimento de inovações. }\end{array}$ & 12345 & 12345 & 12345 & \\
\hline Grau de aversão ao risco & $\begin{array}{l}\text { 27)Aplicação de gestão de riscos para o desenvolvimento das } \\
\text { inovações. }\end{array}$ & 12345 & 12345 & 12345 & \\
\hline Barreiras para inovação & 28)Existência de barreiras para o desenvolvimento das inovações. & 12345 & 12345 & 12345 & \\
\hline Facilitadores para inovação & 29)Existência de facilitadores para o desenvolvimento de inovações. & 12345 & 12345 & 12345 & \\
\hline Incentivos/Recompensas & 30)Existência de incentivos e recompensas para quem inova. & 12345 & 12345 & 12345 & \\
\hline Conflitos & $\begin{array}{l}\text { 31) Existência de conflitos que dificultam o desenvolvimento } \\
\text { inovações. }\end{array}$ & 12345 & 12345 & 12345 & \\
\hline Autonomia do empregado & $\begin{array}{l}\text { 32) Existência de autonomia ao servidor para o desenvolvimento de } \\
\text { inovações. }\end{array}$ & 12345 & 12345 & 12345 & \\
\hline $\begin{array}{l}\text { Habilidades e conhecimento relacionados ao } \\
\text { trabalho }\end{array}$ & $\begin{array}{l}\text { 33) Desenvolvimento de inovações baseadas nas competências } \\
\text { relacionadas ao trabalho. }\end{array}$ & 12345 & 12345 & 12345 & \\
\hline Criatividade & 34) Estímulo à criatividade para o desenvolvimento de inovações. & 12345 & 12345 & 12345 & \\
\hline Aspectos demográficos & $\begin{array}{l}\text { 35) Formação de equipes multidisciplinares para o desenvolvimento } \\
\text { de inovaços. }\end{array}$ & 12345 & 12345 & 12345 & \\
\hline Comprometimento e satisfação com o trabalho & $\begin{array}{l}\text { 36) Percepção de que o comprometimento com o trabalho influencia } \\
\text { o desenvolvimento de inovações. }\end{array}$ & 12345 & 12345 & 12345 & \\
\hline Comprometimento e satisfação com o trabalho & $\begin{array}{l}\text { 37) Percepção de que a satisfação com o trabalho influencia o } \\
\text { desenvolvimento de inovações. }\end{array}$ & 12345 & 12345 & 12345 & \\
\hline Perspectivas e normas compartilhadas & $\begin{array}{l}\text { 38) Compartilhamento de conhecimento relativo ao desenvolvimento } \\
\text { de inovações pelas diversas áreas do órgão. }\end{array}$ & 12345 & 12345 & 12345 & \\
\hline
\end{tabular}


C - Nesta seção, as questões verificam a percepção sobre o processo de inovação do Ministério da Saúde.

Indique a frequência em que o Ministério da Saúde apresenta as seguintes práticas relativas ao processo de inovação.

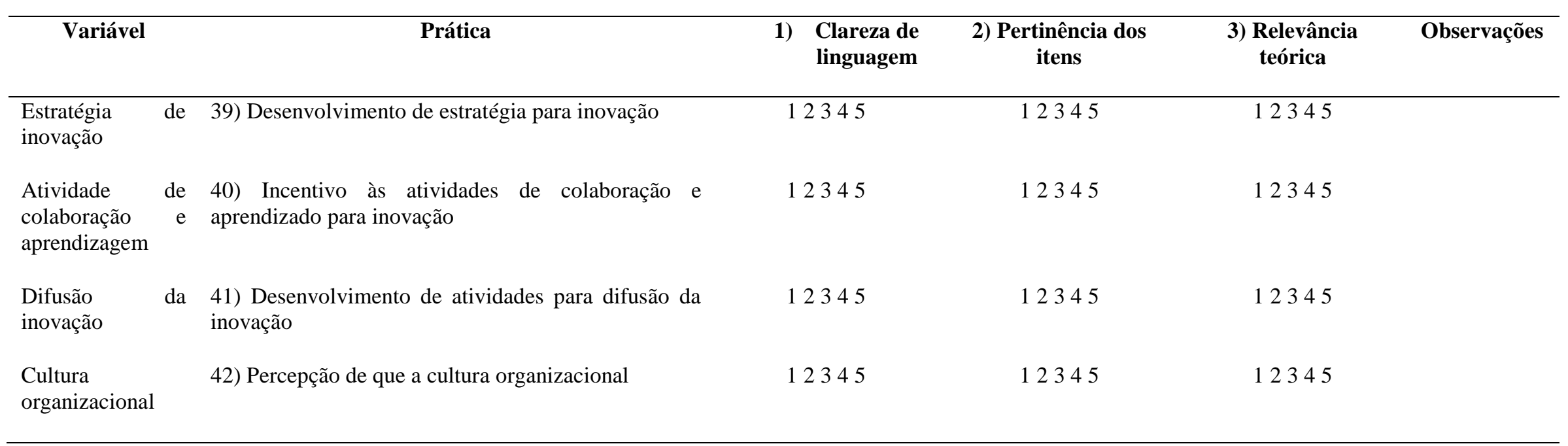

Assinatura do Avaliador: 


\section{APÊNDICE E - PLANILHA DE CÁLCULO DE VALIDAÇÃO DE CONTEÚDO (CVC)}

1. Possui fácil utilização.

\begin{tabular}{|c|c|c|c|c|c|c|c|c|c|c|}
\hline & \multirow[b]{2}{*}{ Juízes } & \\
\hline & & 1 & 2 & 3 & 4 & 5 & Média & $\mathrm{CVCi}$ & Erro & $\mathrm{CVCc}$ \\
\hline Clareza de linguagem & & 4 & 4 & 4 & 5 & 5 & 4,4 & 0,88 & 0,00032 & 0,87968 \\
\hline Pertinência prática & & 4 & 5 & 5 & 5 & 5 & 4,8 & 0,96 & 0,00032 & 0,95968 \\
\hline Relevância Teórica & & 4 & 5 & 5 & 5 & 5 & 4,8 & 0,96 & 0,00032 & 0,95968 \\
\hline
\end{tabular}

2. Proporciona uma vantagem relativa ao processo físico (papel).

\begin{tabular}{|c|c|c|c|c|c|c|c|c|c|c|}
\hline & Juízes & 1 & 2 & 3 & 4 & 5 & Média & $\mathrm{CVCi}$ & Erro & $\mathrm{CVCc}$ \\
\hline Clareza de linguagem & & 4 & 5 & 5 & 4 & 5 & 4,6 & 0,92 & 0,00032 & 0,91968 \\
\hline Pertinência prática & & 4 & 5 & 5 & 5 & 5 & 4,8 & 0,96 & 0,00032 & 0,95968 \\
\hline Relevância Teórica & & 4 & 5 & 5 & 5 & 5 & 4,8 & 0,96 & 0,00032 & 0,95968 \\
\hline
\end{tabular}

3. Pode ser testado.

\begin{tabular}{|c|c|c|c|c|c|c|c|c|c|c|}
\hline & \multirow[b]{2}{*}{ Juízes } & & & & & & & & & \\
\hline & & 1 & 2 & 3 & 4 & 5 & Média & CVCi & Erro & $\mathrm{CVCc}$ \\
\hline Clareza de linguagem & & 4 & 5 & 5 & 5 & 2 & 4,2 & 0,84 & 0,00032 & 0,83968 \\
\hline Pertinência prática & & 4 & 5 & 4 & 5 & 5 & 4,6 & 0,92 & 0,00032 & 0,91968 \\
\hline Relevância Teórica & & 4 & 5 & 4 & 5 & 5 & 4,6 & 0,92 & 0,00032 & 0,91968 \\
\hline
\end{tabular}

4. É compatível com outros sistemas dentro do Ministério da Saúde.

\begin{tabular}{|c|c|c|c|c|c|c|c|c|c|c|}
\hline & Juízes & 1 & 2 & 3 & 4 & 5 & Média & $\mathrm{CVCi}$ & Erro & $\mathrm{CVCc}$ \\
\hline Clareza de linguagem & & 4 & 5 & 5 & 5 & 5 & 4,8 & 0,96 & 0,00032 & 0,95968 \\
\hline Pertinência prática & & 4 & 5 & 5 & 5 & 5 & 4,8 & 0,96 & 0,00032 & 0,95968 \\
\hline Relevância Teórica & & 4 & 5 & 5 & 5 & 5 & 4,8 & 0,96 & 0,00032 & 0,95968 \\
\hline
\end{tabular}

5. É considerado uma inovação no processo de compras de medicamentos do Ministério da Saúde.

\begin{tabular}{|c|c|c|c|c|c|c|c|c|c|c|}
\hline & Juízes & 1 & 2 & 3 & 4 & 5 & Média & $\mathrm{CVCi}$ & Erro & CVCc \\
\hline Clareza de linguagem & & 4 & 5 & 5 & 5 & 5 & 4,8 & 0,96 & 0,00032 & 0,95968 \\
\hline Pertinência prática & & 4 & 5 & 5 & 5 & 5 & 4,8 & 0,96 & 0,00032 & 0,95968 \\
\hline Relevância Teórica & & 4 & 5 & 5 & 5 & 5 & 4,8 & 0,96 & 0,00032 & 0,95968 \\
\hline
\end{tabular}


6. Gera ativos intangíveis, tais como melhoria na segurança da informação, nas compras de medicamentos.

\begin{tabular}{lccccccccc}
\cline { 2 - 9 } \multicolumn{1}{c}{ Juízes } & 1 & 2 & 3 & 4 & 5 & Média & CVCi & Erro & CVCc \\
\hline Clareza de linguagem & 4 & 5 & 5 & 2 & 3 & 3,8 & 0,76 & 0,00032 & 0,75968 \\
Pertinência prática & 4 & 5 & 5 & 5 & 5 & 4,8 & 0,96 & 0,00032 & 0,95968 \\
Relevância Teórica & 4 & 5 & 5 & 5 & 5 & 4,8 & 0,96 & 0,00032 & 0,95968 \\
\hline
\end{tabular}

7. Promove melhorias nos processos de trabalho dos servidores envolvidos com as compras de medicamentos.

\begin{tabular}{lccccccccc}
\cline { 2 - 9 } \multicolumn{1}{c}{ Juízes } & 1 & 2 & 3 & 4 & 5 & Média & CVCi & Erro & CVCc \\
\hline Clareza de linguagem & 4 & 5 & 5 & 5 & 5 & 4,8 & 0,96 & 0,00032 & 0,95968 \\
Pertinência prática & 4 & 5 & 5 & 5 & 5 & 4,8 & 0,96 & 0,00032 & 0,95968 \\
Relevância Teórica & 4 & 5 & 5 & 5 & 5 & 4,8 & 0,96 & 0,00032 & 0,95968 \\
\hline
\end{tabular}

8. Promove melhorias na satisfação do usuário do SUS em relação aos medicamentos adquiridos pelo Ministério da Saúde para posterior distribuição aos Estados e Municípios.

\begin{tabular}{lccccccccc}
\cline { 2 - 9 } \multicolumn{1}{c}{ Juízes } & 1 & 2 & 3 & 4 & 5 & Média & CVCi & Erro & CVCc \\
\hline Clareza de linguagem & 4 & 5 & 5 & 3 & 5 & 4,4 & 0,88 & 0,00032 & 0,87968 \\
Pertinência prática & 4 & 5 & 5 & 5 & 5 & 4,8 & 0,96 & 0,00032 & 0,95968 \\
Relevância Teórica & 4 & 5 & 5 & 5 & 5 & 4,8 & 0,96 & 0,00032 & 0,95968 \\
\hline
\end{tabular}

9. Proporciona transparência da informação relativa aos processos de compras de medicamentos do Ministério da Saúde.

\begin{tabular}{|c|c|c|c|c|c|c|c|c|c|}
\hline Juízes & 1 & 2 & 3 & 4 & 5 & Média & $\mathrm{CVCi}$ & Erro & $\mathrm{CVCc}$ \\
\hline Clareza de linguagem & 4 & 5 & 5 & 3 & 5 & 4,4 & 0,88 & 0,00032 & 0,87968 \\
\hline Pertinência prática & 4 & 5 & 5 & 5 & 5 & 4,8 & 0,96 & 0,00032 & 0,95968 \\
\hline Relevância Teórica & 4 & 5 & 5 & 5 & 5 & 4,8 & 0,96 & 0,00032 & 0,95968 \\
\hline
\end{tabular}

10. Promove sustentabilidade nas compras de medicamentos do Ministério da Saúde.

\begin{tabular}{|c|c|c|c|c|c|c|c|c|c|}
\hline Juízes & 1 & 2 & 3 & 4 & 5 & Média & $\mathrm{CVCi}$ & Erro & $\mathrm{CVCc}$ \\
\hline Clareza de linguagem & 4 & 5 & 5 & 3 & 5 & 4,4 & 0,88 & 0,00032 & 0,87968 \\
\hline Pertinência prática & 4 & 5 & 5 & 5 & 5 & 4,8 & 0,96 & 0,00032 & 0,95968 \\
\hline Relevância Teórica & 4 & 5 & 5 & 5 & 5 & 4,8 & 0,96 & 0,00032 & 0,95968 \\
\hline
\end{tabular}

11. Investimento em Pesquisa \&

Desenvolvimento e Inovação.

\begin{tabular}{lccccccccc}
\cline { 2 - 8 } \multicolumn{1}{c}{ Juízes } & 1 & 2 & 3 & 4 & 5 & Média & CVCi & Erro & CVCc \\
\hline Clareza de linguagem & 4 & 5 & 5 & 2 & 5 & 4,2 & 0,84 & 0,00032 & 0,83968 \\
Pertinência prática & 4 & 5 & 5 & 5 & 5 & 4,8 & 0,96 & 0,00032 & 0,95968 \\
Relevância Teórica & 4 & 5 & 5 & 5 & 5 & 4,8 & 0,96 & 0,00032 & 0,95968 \\
\hline
\end{tabular}


12. Apoio ao desenvolvimento de inovações (através de ações de educação, incentivos, etc.).

\begin{tabular}{lccccccccc}
\cline { 2 - 9 } \multicolumn{1}{c}{ Juízes } & 1 & 2 & 3 & 4 & 5 & Média & CVCi & Erro & CVCc \\
\hline Clareza de linguagem & 4 & 5 & 3 & 5 & 3 & 4 & 0,8 & 0,00032 & 0,79968 \\
Pertinência prática & 4 & 5 & 3 & 5 & 5 & 4,4 & 0,88 & 0,00032 & 0,87968 \\
Relevância Teórica & 4 & 5 & 4 & 5 & 4 & 4,4 & 0,88 & 0,00032 & 0,87968 \\
& & & & & & & & & \\
\hline
\end{tabular}

13. Disponibilização de infraestrutura tecnológica para inovação.

\begin{tabular}{lccccccccc}
\cline { 2 - 9 } \multicolumn{1}{c}{ Juízes } & 1 & 2 & 3 & 4 & 5 & Média & CVCi & Erro & CVCc \\
\hline Clareza de linguagem & 4 & 5 & 4 & 3 & 5 & 4,2 & 0,84 & 0,00032 & 0,83968 \\
Pertinência prática & 4 & 5 & 5 & 5 & 5 & 4,8 & 0,96 & 0,00032 & 0,95968 \\
Relevância Teórica & 4 & 5 & 5 & 5 & 5 & 4,8 & 0,96 & 0,00032 & 0,95968 \\
\hline
\end{tabular}

14. Percepção de que os gestores são as principais fontes de inovação dentro do órgão.

\begin{tabular}{lccccccccc}
\cline { 2 - 9 } \multicolumn{1}{c}{ Juízes } & 1 & 2 & 3 & 4 & 5 & Média & CVCi & Erro & CVCc \\
\hline Clareza de linguagem & 4 & 5 & 3 & 4 & 2 & 3,6 & 0,72 & 0,00032 & 0,71968 \\
Pertinência prática & 4 & 5 & 5 & 4 & 5 & 4,6 & 0,92 & 0,00032 & 0,91968 \\
Relevância Teórica & 4 & 5 & 4 & 4 & 5 & 4,4 & 0,88 & 0,00032 & 0,87968 \\
\hline
\end{tabular}

15. Percepção de que os usuários são as principais fontes de inovação dentro do órgão.

\begin{tabular}{lccccccccc}
\cline { 2 - 9 } \multicolumn{1}{c}{ Juízes } & 1 & 2 & 3 & 4 & 5 & Média & CVCi & Erro & CVCc \\
\hline Clareza de linguagem & 4 & 5 & 2 & 4 & 2 & 3,4 & 0,68 & 0,00032 & 0,67968 \\
Pertinência prática & 4 & 5 & 5 & 4 & 5 & 4,6 & 0,92 & 0,00032 & 0,91968 \\
Relevância Teórica & 4 & 5 & 5 & 4 & 5 & 4,6 & 0,92 & 0,00032 & 0,91968 \\
\hline
\end{tabular}

16. Gestão das demandas dos fornecedores para promoção de inovações.

\begin{tabular}{|c|c|c|c|c|c|c|c|c|c|}
\hline \multirow[b]{2}{*}{ Juízes } & & & & & & & & & \\
\hline & 1 & 2 & 3 & 4 & 5 & Média & $\mathrm{CVCi}$ & Erro & $\mathrm{CVCc}$ \\
\hline Clareza de linguagem & 4 & 5 & 1 & 3 & 3 & 3,2 & 0,64 & 0,00032 & 0,63968 \\
\hline Pertinência prática & 4 & 5 & 3 & 4 & 5 & 4,2 & 0,84 & 0,00032 & 0,83968 \\
\hline Relevância Teórica & 4 & 5 & 3 & 5 & 5 & 4,4 & 0,88 & 0,00032 & 0,87968 \\
\hline
\end{tabular}

17. Gestão das demandas dos usuários para promoção de inovações.

\begin{tabular}{lccccccccc}
\cline { 2 - 9 } \multicolumn{1}{c}{ Juízes } & 1 & 2 & 3 & 4 & 5 & Média & CVCi & Erro & CVCc \\
\hline Clareza de linguagem & 4 & 5 & 1 & 3 & 3 & 3,2 & 0,64 & 0,00032 & 0,63968 \\
Pertinência prática & 4 & 5 & 5 & 4 & 5 & 4,6 & 0,92 & 0,00032 & 0,91968 \\
Relevância Teórica & 4 & 5 & 5 & 5 & 5 & 4,8 & 0,96 & 0,00032 & 0,95968 \\
\hline
\end{tabular}


18. Desenvolvimento de inovações em função de prioridades políticas.

\begin{tabular}{lccccccccc}
\cline { 2 - 9 } \multicolumn{1}{c}{ Juízes } & 1 & 2 & 3 & 4 & 5 & Média & CVCi & Erro & CVCc \\
\hline Clareza de linguagem & 4 & 5 & 3 & 3 & 5 & 4 & 0,8 & 0,00032 & 0,79968 \\
Pertinência prática & 4 & 5 & 5 & 5 & 5 & 4,8 & 0,96 & 0,00032 & 0,95968 \\
Relevância Teórica & 4 & 5 & 5 & 5 & 5 & 4,8 & 0,96 & 0,00032 & 0,95968 \\
\hline
\end{tabular}

19. Atuação em rede com outras organizações para desenvolvimento de inovações.

\begin{tabular}{lccccccccc}
\hline \multicolumn{1}{c}{ Juízes } & 1 & 2 & 3 & 4 & 5 & Média & CVCi & Erro & CVCc \\
\hline Clareza de linguagem & 4 & 5 & 5 & 5 & 5 & 4,8 & 0,96 & 0,00032 & 0,95968 \\
Pertinência prática & 4 & 5 & 4 & 5 & 5 & 4,6 & 0,92 & 0,00032 & 0,91968 \\
Relevância Teórica & 4 & 5 & 4 & 5 & 5 & 4,6 & 0,92 & 0,00032 & 0,91968 \\
\hline
\end{tabular}

20. Observância da legislação para ino'

\begin{tabular}{|c|c|c|c|c|c|c|c|c|c|}
\hline Juízes & 1 & 2 & 3 & 4 & 5 & Média & $\mathrm{CVCi}$ & Erro & $\mathrm{CVCc}$ \\
\hline Clareza de linguagem & 4 & 5 & 4 & 3 & 5 & 4,2 & 0,84 & 0,00032 & 0,83968 \\
\hline Pertinência prática & 4 & 5 & 2 & 5 & 5 & 4,2 & 0,84 & 0,00032 & 0,83968 \\
\hline Relevância Teórica & 4 & 5 & 2 & 5 & 5 & 4,2 & 0,84 & 0,00032 & 0,83968 \\
\hline
\end{tabular}

21. Utilização de inovações que estão sendo adotadas por outras organizações com perfil compatível.

\begin{tabular}{lccccccccc}
\cline { 2 - 9 } \multicolumn{1}{c}{ Juízes } & 1 & 2 & 3 & 4 & 5 & Média & CVCi & Erro & CVCc \\
\hline Clareza de linguagem & 4 & 5 & 4 & 3 & 5 & 4,2 & 0,84 & 0,00032 & 0,83968 \\
Pertinência prática & 4 & 5 & 4 & 5 & 5 & 4,6 & 0,92 & 0,00032 & 0,91968 \\
Relevância Teórica & 4 & 5 & 4 & 5 & 5 & 4,6 & 0,92 & 0,00032 & 0,91968 \\
\hline
\end{tabular}

22. Desenvolvimento de inovações em função da competição com outras organizações públicas.

\begin{tabular}{lccccccccc}
\cline { 2 - 9 } \multicolumn{1}{c}{ Juízes } & 1 & 2 & 3 & 4 & 5 & Média & CVCi & Erro & CVCc \\
\hline Clareza de linguagem & 4 & 5 & 3 & 5 & 5 & 4,4 & 0,88 & 0,00032 & 0,87968 \\
Pertinência prática & 4 & 5 & 4 & 5 & 5 & 4,6 & 0,92 & 0,00032 & 0,91968 \\
Relevância Teórica & 4 & 5 & 4 & 5 & 5 & 4,6 & 0,92 & 0,00032 & 0,91968 \\
\hline
\end{tabular}

23. Disponibilidade de recursos para investimentos em inovação.

\begin{tabular}{|c|c|c|c|c|c|c|c|c|c|}
\hline Juízes & 1 & 2 & 3 & 4 & 5 & Média & $\mathrm{CVCi}$ & Erro & $\mathrm{CVCc}$ \\
\hline Clareza de linguagem & 4 & 5 & 3 & 3 & 4 & 3,8 & 0,76 & 0,00032 & 0,75968 \\
\hline Pertinência prática & 4 & 5 & 4 & 5 & 5 & 4,6 & 0,92 & 0,00032 & 0,91968 \\
\hline Relevância Teórica & 4 & 5 & 4 & 5 & 5 & 4,6 & 0,92 & 0,00032 & 0,91968 \\
\hline
\end{tabular}


24. Influência da alta liderança (cargos de Direção e Assessoramento Superior 6, Direção e Assessoramento Superior 5 e Direção e Assessoramento Superior 4) no desenvolvimento de inovações.

\begin{tabular}{lccccccccc}
\cline { 2 - 9 } \multicolumn{1}{c}{ Juízes } & 1 & 2 & 3 & 4 & 5 & Média & CVCi & Erro & CVCc \\
\hline Clareza de linguagem & 4 & 5 & 3 & 3 & 2 & 3,4 & 0,68 & 0,00032 & 0,67968 \\
Pertinência prática & 4 & 5 & 3 & 5 & 5 & 4,4 & 0,88 & 0,00032 & 0,87968 \\
Relevância Teórica & 4 & 5 & 3 & 5 & 5 & 4,4 & 0,88 & 0,00032 & 0,87968 \\
\hline
\end{tabular}

25. Influência da média liderança (cargos de Direção e Assessoramento Superior 3, Direção e Assessoramento Superior 2) no desenvolvimento de inovações.

\begin{tabular}{|c|c|c|c|c|c|c|c|c|c|}
\hline Juízes & 1 & 2 & 3 & 4 & 5 & Média & $\mathrm{CVCi}$ & Erro & $\mathrm{CVCc}$ \\
\hline Clareza de linguagem & 4 & 5 & 3 & 3 & 2 & 3,4 & 0,68 & 0,00032 & 0,67968 \\
\hline Pertinência prática & 4 & 5 & 3 & 5 & 5 & 4,4 & 0,88 & 0,00032 & 0,87968 \\
\hline Relevância Teórica & 4 & 5 & 3 & 5 & 5 & 4,4 & 0,88 & 0,00032 & 0,87968 \\
\hline
\end{tabular}

26. Influência da baixa liderança (cargos de Direção e Assessoramento Superior 1 e chefes de divisão) no desenvolvimento de inovações.

\begin{tabular}{|c|c|c|c|c|c|c|c|c|c|}
\hline Juízes & $\overline{1}$ & 2 & 3 & 4 & 5 & Média & $\mathrm{CVCi}$ & Erro & $\mathrm{CVCc}$ \\
\hline Clareza de linguagem & 4 & 5 & 3 & 3 & 2 & 3,4 & 0,68 & 0,00032 & 0,67968 \\
\hline Pertinência prática & 4 & 5 & 3 & 5 & 5 & 4,4 & 0,88 & 0,00032 & 0,87968 \\
\hline Relevância Teórica & 4 & 5 & 3 & 5 & 5 & 4,4 & 0,88 & 0,00032 & 0,87968 \\
\hline
\end{tabular}

27. Aplicação de gestão de riscos para o desenvolvimento das inovações.

\begin{tabular}{lccccccccc}
\cline { 2 - 8 } \multicolumn{1}{c}{ Juízes } & 1 & 2 & 3 & 4 & 5 & Média & CVCi & Erro & CVCc \\
\hline Clareza de linguagem & 4 & 5 & 3 & 5 & 2 & 3,8 & 0,76 & 0,00032 & 0,75968 \\
Pertinência prática & 4 & 5 & 3 & 5 & 3 & 4 & 0,8 & 0,00032 & 0,79968 \\
Relevância Teórica & 4 & 5 & 3 & 5 & 3 & 4 & 0,8 & 0,00032 & 0,79968 \\
\hline
\end{tabular}

28. Existência de barreiras para o desenvolvimento das inovações.

\begin{tabular}{|c|c|c|c|c|c|c|c|c|c|}
\hline Juízes & 1 & 2 & 3 & 4 & 5 & Média & $\mathrm{CVCi}$ & Erro & $\mathrm{CVCc}$ \\
\hline Clareza de linguagem & 4 & 5 & 4 & 5 & 5 & 4,6 & 0,92 & 0,00032 & 0,91968 \\
\hline Pertinência prática & 4 & 5 & 4 & 5 & 5 & 4,6 & 0,92 & 0,00032 & 0,91968 \\
\hline Relevância Teórica & 4 & 5 & 3 & 5 & 5 & 4,4 & 0,88 & 0,00032 & 0,87968 \\
\hline
\end{tabular}


29. Existência de facilitadores para o desenvolvimento de inovações.

\begin{tabular}{|c|c|c|c|c|c|c|c|c|c|c|}
\hline & Juízes & 1 & 2 & 3 & 4 & 5 & Média & $\mathrm{CVCi}$ & Erro & CVCc \\
\hline Clareza de linguagem & & 4 & 5 & 4 & 5 & 5 & 4,6 & 0,92 & 0,00032 & 0,91968 \\
\hline Pertinência prática & & 4 & 5 & 4 & 5 & 5 & 4,6 & 0,92 & 0,00032 & 0,91968 \\
\hline Relevância Teórica & & 4 & 5 & 3 & 5 & 5 & 4,4 & 0,88 & 0,00032 & 0,87968 \\
\hline
\end{tabular}

30. Existência de incentivos e recompensas para quem inova.

\begin{tabular}{|c|c|c|c|c|c|c|c|c|c|c|}
\hline & Juízes & 1 & 2 & 3 & 4 & 5 & Média & $\mathrm{CVCi}$ & Erro & $\mathrm{CVCc}$ \\
\hline Clareza de linguagem & & 4 & 5 & 4 & 4 & 5 & 4,4 & 0,88 & 0,00032 & 0,87968 \\
\hline Pertinência prática & & 4 & 5 & 4 & 5 & 5 & 4,6 & 0,92 & 0,00032 & 0,91968 \\
\hline Relevância Teórica & & 4 & 5 & 4 & 5 & 5 & 4,6 & 0,92 & 0,00032 & 0,91968 \\
\hline
\end{tabular}

31. Existência de conflitos que dificultam o desenvolvimento inovações.

\begin{tabular}{|c|c|c|c|c|c|c|c|c|c|c|}
\hline & Juízes & 1 & 2 & 3 & 4 & 5 & Média & $\mathrm{CVCi}$ & Erro & $\mathrm{CVCc}$ \\
\hline Clareza de linguagem & & 4 & 5 & 5 & 5 & 5 & 4,8 & 0,96 & 0,00032 & 0,95968 \\
\hline Pertinência prática & & 4 & 5 & 1 & 5 & 5 & 4 & 0,8 & 0,00032 & 0,79968 \\
\hline Relevância Teórica & & 4 & 5 & 3 & 5 & 5 & 4,4 & 0,88 & 0,00032 & 0,87968 \\
\hline
\end{tabular}

32. Existência de autonomia ao servidor para o desenvolvimento de inovações.

\begin{tabular}{|c|c|c|c|c|c|c|c|c|c|c|}
\hline & Juízes & 1 & 2 & 3 & 4 & 5 & Média & CVCi & Erro & $\mathrm{CVCc}$ \\
\hline Clareza de linguagem & & 4 & 5 & 5 & 5 & 5 & 4,8 & 0,96 & 0,00032 & 0,95968 \\
\hline Pertinência prática & & 4 & 5 & 5 & 5 & 5 & 4,8 & 0,96 & 0,00032 & 0,95968 \\
\hline Relevância Teórica & & 4 & 5 & 5 & 5 & 5 & 4,8 & 0,96 & 0,00032 & 0,95968 \\
\hline
\end{tabular}

33. Desenvolvimento de inovações baseadas nas competências relacionadas ao trabalho.

\begin{tabular}{|c|c|c|c|c|c|c|c|c|c|c|}
\hline & Juízes & 1 & 2 & 3 & 4 & 5 & Média & $\mathrm{CVCi}$ & Erro & $\mathrm{CVCc}$ \\
\hline Clareza de linguagem & & 4 & 5 & 3 & 2 & 2 & 3,2 & 0,64 & 0,00032 & 0,63968 \\
\hline Pertinência prática & & 4 & 5 & 2 & 5 & 5 & 4,2 & 0,84 & 0,00032 & 0,83968 \\
\hline Relevância Teórica & & 4 & 5 & 2 & 5 & 5 & 4,2 & 0,84 & 0,00032 & 0,83968 \\
\hline
\end{tabular}

34. Estímulo à criatividade para o desenvolvimento de inovações.

\begin{tabular}{|c|c|c|c|c|c|c|c|c|c|c|}
\hline & Juízes & 1 & 2 & 3 & 4 & 5 & Média & $\mathrm{CVCi}$ & Erro & $\mathrm{CVCc}$ \\
\hline Clareza de linguagem & & 4 & 5 & 3 & 5 & 5 & 4,4 & 0,88 & 0,00032 & 0,87968 \\
\hline Pertinência prática & & 4 & 5 & 5 & 5 & 5 & 4,8 & 0,96 & 0,00032 & 0,95968 \\
\hline Relevância Teórica & & 4 & 5 & 5 & 5 & 5 & 4,8 & 0,96 & 0,00032 & 0,95968 \\
\hline
\end{tabular}


35. Formação de equipes multidisciplinares para o desenvolvimento de inovações.

\begin{tabular}{|c|c|c|c|c|c|c|c|c|c|c|}
\hline & Juízes & 1 & 2 & 3 & 4 & 5 & Média & $\mathrm{CVCi}$ & Erro & $\mathrm{CVCc}$ \\
\hline Clareza de linguagem & & 4 & 5 & 4 & 5 & 2 & 4 & 0,8 & 0,00032 & 0,79968 \\
\hline Pertinência prática & & 4 & 5 & 4 & 5 & 5 & 4,6 & 0,92 & 0,00032 & 0,91968 \\
\hline Relevância Teórica & & 4 & 5 & 4 & 5 & 5 & 4,6 & 0,92 & 0,00032 & 0,91968 \\
\hline
\end{tabular}

36. Percepção de que o comprometimento com o trabalho influencia o desenvolvimento de inovações.

\begin{tabular}{|c|c|c|c|c|c|c|c|c|c|c|}
\hline & Juízes & 1 & 2 & 3 & 4 & 5 & Média & $\mathrm{CVCi}$ & Erro & $\mathrm{CVCc}$ \\
\hline Clareza de linguagem & & 4 & 5 & 4 & 3 & 3 & 3,8 & 0,76 & 0,00032 & 0,75968 \\
\hline Pertinência prática & & 4 & 5 & 5 & 5 & 5 & 4,8 & 0,96 & 0,00032 & 0,95968 \\
\hline Relevância Teórica & & 4 & 5 & 5 & 5 & 5 & 4,8 & 0,96 & 0,00032 & 0,95968 \\
\hline
\end{tabular}

37. Percepção de que a satisfação com o trabalho influencia o desenvolvimento de inovações.

\begin{tabular}{|c|c|c|c|c|c|c|c|c|c|c|}
\hline & Juízes & 1 & 2 & 3 & 4 & 5 & Média & $\mathrm{CVCi}$ & Erro & $\mathrm{CVCc}$ \\
\hline Clareza de linguagem & & 4 & 5 & 4 & 3 & 3 & 3,8 & 0,76 & 0,00032 & 0,75968 \\
\hline Pertinência prática & & 4 & 5 & 5 & 5 & 5 & 4,8 & 0,96 & 0,00032 & 0,95968 \\
\hline Relevância Teórica & & 4 & 5 & 5 & 5 & 5 & 4,8 & 0,96 & 0,00032 & 0,95968 \\
\hline
\end{tabular}

38. Compartilhamento de conhecimento relativo ao desenvolvimento de inovações pelas diversas áreas do órgão.

\begin{tabular}{|c|c|c|c|c|c|c|c|c|c|c|}
\hline & Juízes & 1 & 2 & 3 & 4 & 5 & Média & $\mathrm{CVCi}$ & Erro & CVCc \\
\hline Clareza de linguagem & & 4 & 5 & 3 & 2 & 5 & 3,8 & 0,76 & 0,00032 & 0,75968 \\
\hline Pertinência prática & & 4 & 5 & 3 & 4 & 5 & 4,2 & 0,84 & 0,00032 & 0,83968 \\
\hline Relevância Teórica & & 4 & 5 & 3 & 4 & 5 & 4,2 & 0,84 & 0,00032 & 0,83968 \\
\hline
\end{tabular}

39. Desenvolvimento de estratégia para inovação.

\begin{tabular}{|c|c|c|c|c|c|c|c|c|c|c|}
\hline & Juízes & 1 & 2 & 3 & 4 & 5 & Média & $\mathrm{CVCi}$ & Erro & CVCc \\
\hline Clareza de linguagem & & 4 & 5 & 3 & 5 & 5 & 4,4 & 0,88 & 0,00032 & 0,87968 \\
\hline Pertinência prática & & 4 & 5 & 5 & 5 & 5 & 4,8 & 0,96 & 0,00032 & 0,95968 \\
\hline Relevância Teórica & & 4 & 5 & 5 & 5 & 5 & 4,8 & 0,96 & 0,00032 & 0,95968 \\
\hline
\end{tabular}

40. Incentivo às atividades de colaboração e aprendizado para inovação.

\begin{tabular}{|c|c|c|c|c|c|c|c|c|c|c|}
\hline & Juízes & 1 & 2 & 3 & 4 & 5 & Média & $\mathrm{CVCi}$ & Erro & $\mathrm{CVCc}$ \\
\hline Clareza de linguagem & & 4 & 5 & 3 & 5 & 5 & 4,4 & 0,88 & 0,00032 & 0,87968 \\
\hline Pertinência prática & & 4 & 5 & 3 & 5 & 5 & 4,4 & 0,88 & 0,00032 & 0,87968 \\
\hline Relevância Teórica & & 4 & 5 & 3 & 5 & 5 & 4,4 & 0,88 & 0,00032 & 0,87968 \\
\hline
\end{tabular}


41. Desenvolvimento de atividades para difusão da inovação.

\begin{tabular}{|c|c|c|c|c|c|c|c|c|c|c|}
\hline & Juízes & 1 & 2 & 3 & 4 & 5 & Média & $\mathrm{CVCi}$ & Erro & $\mathrm{CVCc}$ \\
\hline Clareza de linguagem & & 4 & 4 & 4 & 3 & 5 & 4 & 0,8 & 0,00032 & 0,79968 \\
\hline Pertinência prática & & 4 & 5 & 4 & 5 & 5 & 4,6 & 0,92 & 0,00032 & 0,91968 \\
\hline Relevância Teórica & & 4 & 5 & 5 & 5 & 5 & 4,8 & 0,96 & 0,00032 & 0,95968 \\
\hline
\end{tabular}

42. Percepção de que a cultura organizacional favorece o desenvolvimento de inovações.

\begin{tabular}{|c|c|c|c|c|c|c|c|c|c|c|}
\hline & Juízes & 1 & 2 & 3 & 4 & 5 & Média & $\mathrm{CVCi}$ & Erro & $\mathrm{CVCc}$ \\
\hline Clareza de linguagem & & 4 & 5 & 5 & 2 & 5 & 4,2 & 0,84 & 0,00032 & 0,83968 \\
\hline Pertinência prática & & 4 & 5 & 4 & 5 & 5 & 4,6 & 0,92 & 0,00032 & 0,91968 \\
\hline Relevância Teórica & & 4 & 5 & 5 & 5 & 5 & 4,8 & 0,96 & 0,00032 & 0,95968 \\
\hline
\end{tabular}




\section{APÊNDICE F - PLANILHA DAS MÉDIAS DE CÁLCULO DE VALIDAÇÃo DE CONTEÚDO (CVC)}

\begin{tabular}{|c|c|c|c|c|}
\hline Cálculo do CVCt & Clareza & Pertinência Prática & Relevância Teórica & Média Item \\
\hline 1) Possui fácil utilização. & 0,88 & 0,96 & 0,96 & 0,93 \\
\hline 2) Proporciona uma vantagem relativa ao processo físico (papel). & 0,92 & 0,96 & 0,96 & 0,95 \\
\hline 3) Pode ser testado. & 0,84 & 0,92 & 0,92 & 0,89 \\
\hline 4) É compatível com outros sistemas dentro do Ministério da Saúde. & 0,96 & 0,96 & 0,96 & 0,96 \\
\hline $\begin{array}{l}\text { 5) É considerado uma inovação no processo de compras de medicamentos do } \\
\text { Ministério da Saúde. }\end{array}$ & 0,96 & 0,96 & 0,96 & 0,96 \\
\hline $\begin{array}{l}\text { 6) Gera ativos intangíveis, tais como melhoria na segurança da informação, nas } \\
\text { compras de medicamentos. }\end{array}$ & 0,76 & 0,96 & 0,96 & 0,89 \\
\hline $\begin{array}{l}\text { 7) Promove melhorias nos processos de trabalho dos servidores envolvidos com } \\
\text { as compras de medicamentos. }\end{array}$ & 0,96 & 0,96 & 0,96 & 0,96 \\
\hline $\begin{array}{l}\text { 8) Promove melhorias na satisfação do usuário do Sistema Único de Saúde em } \\
\text { relação aos medicamentos adquiridos pelo Ministério da Saúde para posterior } \\
\text { distribuição aos Estados e Municípios. }\end{array}$ & 0,88 & 0,96 & 0,96 & 0,93 \\
\hline $\begin{array}{l}\text { 9) Proporciona transparência da informação relativa aos processos de compras } \\
\text { de medicamentos do Ministério da Saúde. }\end{array}$ & 0,96 & 0,96 & 0,96 & 0,96 \\
\hline $\begin{array}{l}\text { 10) Promove sustentabilidade nas compras de medicamentos do Ministério da } \\
\text { Saúde. }\end{array}$ & 0,8 & 0,92 & 0,92 & 0,88 \\
\hline 11) Investimento em Pesquisa \& Desenvolvimento e Inovação. & 0,84 & 0,96 & 0,96 & 0,92 \\
\hline $\begin{array}{l}\text { 12) Apoio ao desenvolvimento de inovações (através de ações de educação, } \\
\text { incentivos, etc.). }\end{array}$ & 0,8 & 0,88 & 0,88 & 0,85 \\
\hline 13) Disponibilização de infraestrutura tecnológica para inovação. & 0,84 & 0,96 & 0,96 & 0,92 \\
\hline $\begin{array}{l}\text { 14) Percepção de que os gestores são as principais fontes de inovação dentro } \\
\text { do órgão. }\end{array}$ & 0,72 & 0,92 & 0,88 & 0,84 \\
\hline $\begin{array}{l}\text { 15) Percepção de que os usuários são as principais fontes de inovação dentro } \\
\text { do órgão. }\end{array}$ & 0,68 & 0,92 & 0,92 & 0,84 \\
\hline 16) Gestão das demandas dos fornecedores para promoção de inovações. & 0,64 & 0,84 & 0,88 & 0,79 \\
\hline 17) Gestão das demandas dos usuários para promoção de inovações. & 0,64 & 0,92 & 0,96 & 0,84 \\
\hline 18) Desenvolvimento de inovações em função de prioridades políticas. & 0,8 & 0,96 & 0,96 & 0,91 \\
\hline $\begin{array}{l}\text { 19) Atuação em rede com outras organizações para desenvolvimento de } \\
\text { inovações. }\end{array}$ & 0,96 & 0,92 & 0,92 & 0,93 \\
\hline 20) Observância da legislação para inovar. & 0,84 & 0,84 & 0,84 & 0,84 \\
\hline
\end{tabular}




\begin{tabular}{|c|c|c|c|c|}
\hline Cálculo do CVCt & Clareza & Pertinência Prática & Relevância Teórica & Média Item \\
\hline $\begin{array}{l}\text { 21) Utilização de inovações que estão sendo adotadas por outras organizações } \\
\text { com perfil compatível. }\end{array}$ & 0,84 & 0,92 & 0,92 & 0,89 \\
\hline $\begin{array}{l}\text { 22) Desenvolvimento de inovações em função da competição com outras } \\
\text { organizações públicas. }\end{array}$ & 0,88 & 0,92 & 0,92 & 0,91 \\
\hline 23) Disponibilidade de recursos para investimentos em inovação. & 0,76 & 0,92 & 0,92 & 0,87 \\
\hline $\begin{array}{l}\text { 24) Influência da alta liderança (cargos de Direção e Assessoramento Superior } \\
\text { 6, Direção e Assessoramento Superior } 5 \text { e Direção e Assessoramento Superior } \\
\text { 4) no desenvolvimento de inovações. } \\
\text { 25) Influência da média liderança (cargos de Direção e Assessoramento }\end{array}$ & 0,68 & 0,88 & 0,88 & 0,81 \\
\hline $\begin{array}{l}\text { Superior } 3 \text {, Direção e Assessoramento Superior 2) no desenvolvimento de } \\
\text { inovações. }\end{array}$ & 0,68 & 0,88 & 0,88 & 0,81 \\
\hline $\begin{array}{l}\text { 26) Influência da baixa liderança (cargos de Direção e Assessoramento Superior } \\
1 \text { e chefes de divisão) no desenvolvimento de inovações. }\end{array}$ & 0,68 & 0,92 & 0,92 & 0,84 \\
\hline 27) Aplicação de gestão de riscos para o desenvolvimento das inovações. & 0,76 & 0,8 & 0,8 & 0,79 \\
\hline 28) Existência de barreiras para o desenvolvimento das inovações. & 0,92 & 0,92 & 0,88 & 0,91 \\
\hline 29) Existência de facilitadores para o desenvolvimento de inovações. & 0,92 & 0,92 & 0,88 & 0,91 \\
\hline 30) Existência de incentivos e recompensas para quem inova. & 0,88 & 0,92 & 0,92 & 0,91 \\
\hline 31) Existência de conflitos que dificultam o desenvolvimento inovações. & 0,96 & 0,8 & 0,88 & 0,88 \\
\hline 32) Existência de autonomia ao servidor para o desenvolvimento de inovações. & 0,96 & 0,96 & 0,96 & 0,96 \\
\hline $\begin{array}{l}\text { 33) Desenvolvimento de inovações baseadas nas competências relacionadas ao } \\
\text { trabalho. }\end{array}$ & 0,64 & 0,84 & 0,84 & 0,77 \\
\hline 34) Estímulo à criatividade para o desenvolvimento de inovações. & 0,88 & 0,96 & 0,96 & 0,93 \\
\hline $\begin{array}{l}\text { 35) Formação de equipes multidisciplinares para o desenvolvimento de } \\
\text { inovações. }\end{array}$ & 0,8 & 0,92 & 0,92 & 0,88 \\
\hline $\begin{array}{l}\text { 36) Percepção de que o comprometimento com o trabalho influencia o } \\
\text { desenvolvimento de inovações. }\end{array}$ & 0,76 & 0,96 & 0,96 & 0,89 \\
\hline $\begin{array}{l}\text { 37) Percepção de que a satisfação com o trabalho influencia o desenvolvimento } \\
\text { de inovações }\end{array}$ & 0,76 & 0,96 & 0,96 & 0,89 \\
\hline $\begin{array}{l}\text { 38) Compartilhamento de conhecimento relativo ao desenvolvimento de } \\
\text { inovações pelas diversas áreas do órgão. }\end{array}$ & 0,76 & 0,96 & 0,96 & 0,89 \\
\hline 39) Desenvolvimento de estratégia para inovação. & 0,76 & 0,84 & 0,84 & 0,81 \\
\hline 40) Incentivo às atividades de colaboração e aprendizado para inovação. & 0,88 & 0,88 & 0,88 & 0,88 \\
\hline 41) Desenvolvimento de atividades para difusão da inovação. & 0,8 & 0,92 & 0,96 & 0,89 \\
\hline $\begin{array}{l}\text { 42) Percepção de que a cultura organizacional favorece o desenvolvimento de } \\
\text { inovações. }\end{array}$ & 0,84 & 0,92 & 0,96 & 0,91 \\
\hline Totais & 0,8 & 0,91 & 0,91 & 0,87 \\
\hline
\end{tabular}




\section{APÊNDICE G - QUESTIONÁRIO APLICADO AOS SERVIDORES DO MS}

Público-alvo: Os usuários do software PEC, no DLOG e em todas as áreas envolvidas com o processo de compras de medicamentos e insumos para a saúde do MS.

Objetivo: Avaliar a percepção do software PEC, enquanto inovação nas compras governamentais de medicamentos e insumos no MS, seus principais atributos e variáveis.

INSTRUÇÕES:

Você está convidado (a) a participar da pesquisa "Inovação no Processo de Compra de Medicamentos: Estudo de Caso do Ministério da Saúde”, elaborada pela aluna do Mestrado Profissional em Administração Pública (MPA), Dayse Karenine de Oliveira Carneiro, sob supervisão do Professor Doutor Pedro Carlos Resende Júnior, do Programa de Pós-Graduação em Administração (PPGA), da Universidade de Brasília (UnB).

Gostaria de contar com sua colaboração no sentido de responder o questionário anexo, cujo tempo estimado é de 15 minutos. Lembre-se: não há respostas certas ou erradas, apenas devem expressar suas percepções em relação a um fato.

Este tipo de pergunta é composto por uma lista de afirmações que devem ser avaliadas com base na escala de 0 a 5 apresentada no item, onde 0 representa "Nunca" e 5 representa "Sempre", a partir da qual você deverá selecionar a opção que representa mais fielmente sua experiência. Caso as opções não se adequem a sua realidade, você deverá marcar a opção "Não se Aplica (NA)".

Além disso, a participação nesse estudo é voluntária e ressalto que as informações fornecidas neste questionário são confidenciais e serão utilizadas exclusivamente para fins acadêmicos. Você não será identificado (a). 
A - Nesta seção, as questões verificam a percepção sobre os atributos do software Processo Eletrônico de Compras (PEC).

Indique a ocorrência e intensidade em que o software Processo Eletrônico de Compras (PEC) apresenta as seguintes características e resultados.

1) Possui facilidade de uso;

2) Proporciona vantagem relativa ao processo físico (papel);

3) É compatível com outros sistemas dentro do Ministério da Saúde;

4) É considerado uma inovação no processo de compras de medicamentos do Ministério da Saúde;

5) Gera benefícios intangíveis, tais como melhoria na segurança da informação, nas compras de medicamentos do Ministério da Saúde;

6) Promove melhoria nos processos de trabalho dos servidores envolvidos com as compras de medicamentos do Ministério da Saúde;

7) Melhora o processo de compra dos medicamentos adquiridos pelo Ministério da Saúde para posterior distribuição aos Estados e Municípios;

8) Proporciona transparência da informação pública relativa aos processos de compras de medicamentos do Ministério da Saúde;

9) Promove sustentabilidade nas compras de medicamentos do Ministério da Saúde, considerando que sustentabilidade é um conjunto de medidas instituídas que respeitam as normas ecológicas, de forma a não prejudicar as gerações futuras. 


\begin{tabular}{lllllll}
\hline 0 (NUNCA) & 1 & 2 & 3 & 4 & 5 (SEMPRE) & $\begin{array}{c}\text { NA (NÃO SE } \\
\text { APLICA) }\end{array}$ \\
\hline
\end{tabular}

B - Nesta seção, as questões verificam a percepção sobre o ambiente e condições estruturais onde o software Processo Eletrônico de Compras foi desenvolvido e funciona.

No âmbito do Ministério da Saúde, indique a ocorrência e a intensidade das práticas de gestão e de percepções sobre o ambiente organizacional para promoção de inovações.

10) Investimento em inovação;

11) Apoio ao desenvolvimento de inovações (por meio de ações de educação, incentivos à diversidade);

12) Disponibilização de infraestrutura tecnológica para inovação;

13) Percepção de que os gestores são as principais fontes de inovação dentro do órgão;

14) Percepção de que os servidores são as principais fontes de inovação dentro do órgão;

15) Desenvolvimento de inovações para atender a prioridades políticas;

16) Atuação em rede com outras organizações para desenvolvimento de inovações;

17) Observância da legislação para inovar;

18) Utilização de inovações que estão sendo adotadas por outras organizações públicas com perfil compatível;

19) Disponibilidade de recursos para investimento em inovação;

20) Aplicação de gestão de riscos para o desenvolvimento das inovações;

21) Existência de barreiras, tais como conflitos, para o desenvolvimento das inovações;

22) Existência de facilitadores, tais como incentivos ou recompensas, para o desenvolvimento de inovações;

23) Existência de autonomia ao servidor para o desenvolvimento de inovações.

24) Estímulo à criatividade para o desenvolvimento de inovações;

25) Formação de equipes multidisciplinares para o desenvolvimento de inovações; 
26) Percepção de que o foco no comprometimento com o trabalho influencia o desenvolvimento de inovações;

27) Percepção de que o foco na satisfação com o trabalho influencia o desenvolvimento de inovações;

28) Compartilhamento de conhecimento relativo ao desenvolvimento de inovações pelas diversas áreas do órgão.

\begin{tabular}{lllllll}
\hline 0 (NUNCA) & 1 & 2 & 3 & 4 & 5 (SEMPRE) & $\begin{array}{c}\text { NA (N ÃO SE } \\
\text { APLICA) }\end{array}$ \\
\hline
\end{tabular}

C - Nesta seção, as questões verificam a percepção sobre o processo de inovação do

\section{Ministério da Saúde.}

Indique a ocorrência e intensidade em que o Ministério da Saúde apresenta as seguintes práticas relativas ao processo de inovação.

29) Desenvolvimento de estratégia para inovação;

30) Desenvolvimento de atividades para difusão (propagação) da inovação;

31) Incentivo às atividades de colaboração e aprendizado para inovação;

32) Percepção que a cultura organizacional favorece o desenvolvimento de inovações.

\begin{tabular}{lllllll}
\hline 0 (NUNCA) & 1 & 2 & 3 & 4 & 5 (SEMPRE) & $\begin{array}{c}\text { NA (NÃO SE } \\
\text { APLICA) }\end{array}$ \\
\hline
\end{tabular}

D - Nesta última seção, as questões dizem respeito ao seu perfil e a área do Ministério da Saúde que você está vinculado(a). Responda algumas questões sobre suas características, levando em consideração a sua realidade. 
33) Qual seu sexo?

( ) Masculino

( ) Feminino

34) Qual é a sua faixa etária?

( ) Até 30 anos.

( ) De 31 a 39 anos.

( ) De 40 a 49 anos.

( ) De 50 a 54 anos.

( ) 55 anos ou mais.

35) Das opções a seguir, assinale a que melhor descreve o seu nível máximo de escolaridade.

( ) Ensino Médio incompleto (antigo $2^{\circ}$ grau).

( ) Ensino Médio completo (antigo $2^{\circ}$ grau).

( ) Ensino Superior incompleto.

( ) Ensino Superior completo.

( ) Especialização.

( ) Mestrado.

( ) Doutorado. 
36) Há quantos anos você exerce funções no Ministério da Saúde?

( ) Até 2 anos.

( ) De 3 a 7 anos e 11 meses.

( ) De 8 a 14 anos e 11 meses.

( ) De 15 a 20 anos.

( ) Mais de 20 anos.

37) Qual a área do Ministério da Saúde a qual está vinculado (a)?

( ) Departamento de Logística em Saúde.

( ) Secretaria de Ciência, Tecnologia e Insumos Estratégicos.

( ) Secretaria de Atenção à Saúde.

( ) Departamento de Assistência Farmacêutica.

( ) Secretaria de Vigilância em Saúde.

( ) Secretaria de Saúde Indígena.

( ) Central de Atendimento ao Servidor.

( ) Fundo Nacional de Saúde.

( ) Secretaria Executiva.

( ) Subsecretaria de Planejamento e Orçamento.

( ) Subsecretaria de Assuntos Administrativos.

( ) Consultoria Jurídica.

( ) Gabinete do Ministro 


\section{APÊNDICE H - RESULTADOS DOS TESTES DE NORMALIDADE}

\begin{tabular}{|c|c|c|c|c|c|c|c|}
\hline \multirow{2}{*}{ Variável } & & \multicolumn{3}{|c|}{ Kolmogorov-Smirnov ${ }^{a}$} & \multicolumn{3}{|c|}{ Shapiro-Wilk } \\
\hline & & Estatística & df & P-valor & Estatística & df & P-valor \\
\hline & DLOG & 0,29 & 33 & 0 & 0,85 & 33 & 0 \\
\hline 1) Possui facilidade de uso. & $\begin{array}{l}\text { Outra } \\
\text { área }\end{array}$ & 0,21 & 39 & 0 & 0,9 & 39 & 0 \\
\hline 2) Proporciona vantagem & DLOG & 0,26 & 33 & 0 & 0,75 & 33 & 0 \\
\hline $\begin{array}{l}\text { relativa ao processo físico } \\
\text { (papel). }\end{array}$ & $\begin{array}{l}\text { Outra } \\
\text { área }\end{array}$ & 0,34 & 39 & 0 & 0,72 & 39 & 0 \\
\hline 3) É compatível com outros & DLOG & 0,19 & 33 & 0 & 0,9 & 33 & 0,01 \\
\hline $\begin{array}{l}\text { sistemas dentro do } \\
\text { Ministério da Saúde. }\end{array}$ & $\begin{array}{l}\text { Outra } \\
\text { área }\end{array}$ & 0,18 & 39 & 0 & 0,91 & 39 & 0 \\
\hline 4) É considerado uma & DLOG & 0,35 & 33 & 0 & 0,69 & 33 & 0 \\
\hline $\begin{array}{l}\text { inovação no processo de } \\
\text { compras de medicamentos } \\
\text { do Ministério da Saúde. }\end{array}$ & $\begin{array}{l}\text { Outra } \\
\text { área }\end{array}$ & 0,2 & 39 & 0 & 0,86 & 39 & 0 \\
\hline 5) Gera benefícios & DLOG & 0,26 & 33 & 0 & 0,83 & 33 & 0 \\
\hline $\begin{array}{l}\text { intangíveis, tais como } \\
\text { melhoria na segurança da } \\
\text { informação, nas compras de } \\
\text { medicamentos }\end{array}$ & $\begin{array}{l}\text { Outra } \\
\text { área }\end{array}$ & 0,21 & 39 & 0 & 0,86 & 39 & 0 \\
\hline $\begin{array}{l}\text { Ministério da Saúde. } \\
\text { 6) Promove melhoria nos } \\
\text { processos de trabalho dos } \\
\text { servidores envolvidos com }\end{array}$ & DLOG & 0,29 & 33 & 0 & 0,8 & 33 & 0 \\
\hline $\begin{array}{ll}\text { as compras } & \text { de } \\
\text { medicamentos } & \text { do }\end{array}$ & $\begin{array}{l}\text { Outra } \\
\text { área }\end{array}$ & 0,25 & 39 & 0 & 0,81 & 39 & 0 \\
\hline $\begin{array}{l}\text { Ministério da Saúde. } \\
\text { 7) Melhora o processo de } \\
\text { compra relativo aos }\end{array}$ & DLOG & 0,21 & 33 & 0 & 0,87 & 33 & 0 \\
\hline $\begin{array}{l}\text { medicamentos adquiridos } \\
\text { pelo Ministério da Saúde } \\
\text { para posterior distribuição } \\
\text { aos Estados e Municípios. }\end{array}$ & $\begin{array}{l}\text { Outra } \\
\text { área }\end{array}$ & 0,22 & 39 & 0 & 0,86 & 39 & 0 \\
\hline $\begin{array}{lr}8) & \text { Proporciona } \\
\text { transparência } & \text { da }\end{array}$ & DLOG & 0,23 & 33 & 0 & 0,85 & 33 & 0 \\
\hline $\begin{array}{l}\text { informação pública relativa } \\
\text { aos processos de compras } \\
\text { de medicamentos do } \\
\text { Ministério da Saúde. }\end{array}$ & $\begin{array}{l}\text { Outra } \\
\text { área }\end{array}$ & 0,3 & 39 & 0 & 0,83 & 39 & 0 \\
\hline $\begin{array}{lr}\text { 9) } & \text { Promove } \\
\text { sustentabilidade } & \text { nas }\end{array}$ & DLOG & 0,23 & 33 & 0 & 0,81 & 33 & 0 \\
\hline $\begin{array}{l}\text { compras de medicamentos } \\
\text { do Ministério da Saúde, } \\
\text { considerando que } \\
\text { sustentabilidade é um } \\
\text { conjunto de medidas } \\
\text { instituídas que respeitam as } \\
\text { normas ecológicas, de } \\
\text { forma a não prejudicar as } \\
\text { gerações futuras. }\end{array}$ & $\begin{array}{l}\text { Outra } \\
\text { área }\end{array}$ & 0,22 & 39 & 0 & 0,87 & 39 & 0 \\
\hline 10) Investimento & DLOG & 0,22 & 33 & 0 & 0,9 & 33 & 0,01 \\
\hline $\begin{array}{l}\text { I0) Investimento em } \\
\text { Inovação. }\end{array}$ & $\begin{array}{l}\text { Outra } \\
\text { área }\end{array}$ & 0,23 & 39 & 0 & 0,9 & 39 & 0 \\
\hline Apoio & DLOG & 0,2 & 33 & 0 & 0,91 & 33 & 0,01 \\
\hline
\end{tabular}




\begin{tabular}{|c|c|c|c|c|c|c|c|}
\hline $\begin{array}{l}\text { desenvolvimento } \\
\text { inovações (por meio de } \\
\text { ações de educação, } \\
\text { incentivos à diversidade). }\end{array}$ & $\begin{array}{l}\text { Outra } \\
\text { área }\end{array}$ & 0,26 & 39 & 0 & 0,89 & 39 & 0 \\
\hline 12) Disponibilização de & DLOG & 0,24 & 33 & 0 & 0,9 & 33 & 0 \\
\hline $\begin{array}{l}\text { infraestrutura tecnológica } \\
\text { para inovação. }\end{array}$ & $\begin{array}{l}\text { Outra } \\
\text { área }\end{array}$ & 0,22 & 39 & 0 & 0,9 & 39 & 0 \\
\hline 13) Percepção de que os & DLOG & 0,18 & 33 & 0,01 & 0,94 & 33 & 0,06 \\
\hline $\begin{array}{l}\text { fontes de inovação dentro } \\
\text { do órgão. }\end{array}$ & $\begin{array}{l}\text { Outra } \\
\text { área }\end{array}$ & 0,19 & 39 & 0 & 0,9 & 39 & 0 \\
\hline $\begin{array}{l}\text { 14) Percepção de que os } \\
\text { servidores são as principais }\end{array}$ & DLOG & 0,25 & 33 & 0 & 0,91 & 33 & 0,01 \\
\hline $\begin{array}{l}\text { fontes de inovação dentro } \\
\text { do órgão. }\end{array}$ & $\begin{array}{l}\text { Outra } \\
\text { área }\end{array}$ & 0,19 & 39 & 0 & 0,9 & 39 & 0 \\
\hline 15) Desenvolvimento de & DLOG & 0,2 & 33 & 0 & 0,92 & 33 & 0,01 \\
\hline $\begin{array}{l}\text { inovações para atender a } \\
\text { prioridades políticas. }\end{array}$ & $\begin{array}{l}\text { Outra } \\
\text { área }\end{array}$ & 0,2 & 39 & 0 & 0,91 & 39 & 0 \\
\hline 16) Atuação em rede com & DLOG & 0,17 & 33 & 0,02 & 0,94 & 33 & 0,09 \\
\hline $\begin{array}{lr}\text { outras organizaçoes } & \text { para } \\
\text { desenvolvimento } & \text { de } \\
\text { inovações. } & \end{array}$ & $\begin{array}{l}\text { Outra } \\
\text { área }\end{array}$ & 0,2 & 39 & 0 & 0,9 & 39 & 0 \\
\hline 17) Observância da & DLOG & 0,16 & 33 & 0,02 & 0,92 & 33 & 0,02 \\
\hline legislação para inovar. & $\begin{array}{l}\text { Outra } \\
\text { área }\end{array}$ & 0,18 & 39 & 0 & 0,93 & 39 & 0,02 \\
\hline $\begin{array}{l}\text { 18) Utilização de inovações } \\
\text { que estão sendo adotadas }\end{array}$ & DLOG & 0,18 & 33 & 0,01 & 0,94 & 33 & 0,07 \\
\hline $\begin{array}{l}\text { por outras } \text { organizações } \\
\text { públicas com } \text { perfil } \\
\text { compatível. }\end{array}$ & $\begin{array}{l}\text { Outra } \\
\text { área }\end{array}$ & 0,19 & 39 & 0 & 0,92 & 39 & 0,01 \\
\hline 19) Disponibilidade de & DLOG & 0,25 & 33 & 0 & 0,9 & 33 & 0,01 \\
\hline $\begin{array}{l}\text { recursos para investimento } \\
\text { em inovação. }\end{array}$ & $\begin{array}{l}\text { Outra } \\
\text { área }\end{array}$ & 0,2 & 39 & 0 & 0,93 & 39 & 0,01 \\
\hline 20) Aplicação de gestão de & DLOG & 0,16 & 33 & 0,04 & 0,92 & 33 & 0,02 \\
\hline $\begin{array}{lr}\text { riscos para } & \text { o } \\
\text { desenvolvimento } & \text { das } \\
\text { inovações. } & \end{array}$ & $\begin{array}{l}\text { Outra } \\
\text { área }\end{array}$ & 0,17 & 39 & 0,01 & 0,93 & 39 & 0,02 \\
\hline 21) Existência de barreiras, & DLOG & 0,18 & 33 & 0,01 & 0,93 & 33 & 0,03 \\
\hline $\begin{array}{l}\text { desenvolvimento } \\
\text { inovações. }\end{array}$ & $\begin{array}{l}\text { Outra } \\
\text { área }\end{array}$ & 0,3 & 39 & 0 & 0,82 & 39 & 0 \\
\hline 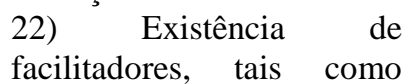 & DLOG & 0,17 & 33 & 0,02 & 0,93 & 33 & 0,05 \\
\hline $\begin{array}{l}\text { incentivos ou recompensas, } \\
\text { para o desenvolvimento de } \\
\text { inovações. }\end{array}$ & $\begin{array}{l}\text { Outra } \\
\text { área }\end{array}$ & 0,17 & 39 & 0,01 & 0,93 & 39 & 0,01 \\
\hline $\begin{array}{l}\text { 23) Existência de } \\
\text { autonomia ao servidor para }\end{array}$ & DLOG & 0,22 & 33 & 0 & 0,92 & 33 & 0,02 \\
\hline $\begin{array}{l}\text { o desenvolvimento de } \\
\text { inovações. }\end{array}$ & $\begin{array}{l}\text { Outra } \\
\text { área }\end{array}$ & 0,18 & 39 & 0 & 0,92 & 39 & 0,01 \\
\hline 24) Estímulo à criatividade & DLOG & 0,16 & 33 & 0,03 & 0,92 & 33 & 0,02 \\
\hline $\begin{array}{l}\text { para o desenvolvimento de } \\
\text { inovações. }\end{array}$ & $\begin{array}{l}\text { Outra } \\
\text { área }\end{array}$ & 0,15 & 39 & 0,03 & 0,93 & 39 & 0,01 \\
\hline $\begin{array}{l}\text { 25) Formação de equipes } \\
\text { multidisciplinares para o }\end{array}$ & DLOG & 0,19 & 33 & 0 & 0,93 & 33 & 0,03 \\
\hline $\begin{array}{l}\text { desenvolvimento } \\
\text { inovações. }\end{array}$ & $\begin{array}{l}\text { Outra } \\
\text { área }\end{array}$ & 0,16 & 39 & 0,01 & 0,93 & 39 & 0,02 \\
\hline 26) Percepção de que o & DLOG & 0,22 & 33 & 0 & 0,93 & 33 & 0,03 \\
\hline
\end{tabular}


foco no comprometimento com o trabalho influencia o desenvolvimento de Outra inovações.

27) Percepção de que o foco na satisfação com o trabalho influencia $\mathrm{o}$ desenvolvimento de inovações.

28) Compartilhamento de conhecimento relativo ao desenvolvimento de inovações pelas diversas áreas do órgão.

29) Desenvolvimento de estratégia para inovação.

área

0,2

39

0

0,9

39

0

DLOG

0,21

33

0

0,93

33

0,04

Outra

30) Desenvolvimento de

área

0,18

39

0

0,92

39

0,01

DLOG

0,19

33

0

0,92

33

0,02

Outra

área

0,2

39

0

0,92

39

0,01

atividades para difusão (propagação) da inovação.

\section{DLOG}

0,16

33

0,03

0,94

$33 \quad 0,05$

Outra

0,23

39

0

0,87

39

0

DLOG

$0,17 \quad 33$

0,01

0,94

33

0,06

Outra

$0,22 \quad 39$

0

0,92

39

0,01

31) Incentivo às atividades

DLOG

$0,21 \quad 33$

0,92

0,02

aprendizado para inovação.

32) Percepção que a cultura

Outra

0,21

39

$$
0
$$

0,91

33

0

organizacional favorece $o$

DLOG

0,22

33

0

0,92

39

0,02

desenvolvimento

Outra inovações.

$0,16 \quad 39$

0,02

0,94

39

0,03 


\section{APÊNDICE I - RESULTADOS DO TESTE DE MANN-WHITNEY}

\begin{tabular}{|c|c|c|c|}
\hline Variável & P-valor & Variável & P-valor \\
\hline 1) Possui facilidade de uso. & 0,26 & 17) Observância da legislação para inovar. & 0,79 \\
\hline $\begin{array}{l}\text { 2) Proporciona vantagem relativa ao } \\
\text { processo físico (papel). }\end{array}$ & 0,63 & $\begin{array}{l}\text { 18) Utilização de inovações que estão } \\
\text { sendo adotadas por outras organizações } \\
\text { públicas com perfil compatível. }\end{array}$ & 0,7 \\
\hline $\begin{array}{l}\text { 3) É compatível com outros sistemas } \\
\text { dentro do Ministério da Saúde. }\end{array}$ & 0,84 & $\begin{array}{l}\text { 19) Disponibilidade de recursos para } \\
\text { investimento em inovação. }\end{array}$ & 0,46 \\
\hline $\begin{array}{l}\text { 4) É considerado uma inovação no } \\
\text { processo de compras de medicamentos do } \\
\text { Ministério da Saúde. }\end{array}$ & 0,05 & $\begin{array}{l}\text { 20) Aplicação de gestão de riscos para o } \\
\text { desenvolvimento das inovações. }\end{array}$ & 0,59 \\
\hline $\begin{array}{l}\text { 5) Gera benefícios intangíveis, tais como } \\
\text { melhoria na segurança da informação, nas } \\
\text { compras de medicamentos do Ministério } \\
\text { da Saúde. }\end{array}$ & 0,55 & $\begin{array}{l}\text { 21) Existência de barreiras, tais como } \\
\text { conflitos, para o desenvolvimento das } \\
\text { inovações. }\end{array}$ & 0,33 \\
\hline $\begin{array}{l}\text { 6) Promove melhoria nos processos de } \\
\text { trabalho dos servidores envolvidos com as } \\
\text { compras de medicamentos do Ministério } \\
\text { da Saúde. }\end{array}$ & 0,72 & $\begin{array}{l}\text { 22) Existência de facilitadores, tais como } \\
\text { incentivos ou recompensas, para o } \\
\text { desenvolvimento de inovações. }\end{array}$ & 0,69 \\
\hline $\begin{array}{l}\text { 7) Melhora o processo de compra relativo } \\
\text { aos medicamentos adquiridos pelo } \\
\text { Ministério da Saúde para posterior } \\
\text { distribuição aos Estados e Municípios. }\end{array}$ & 0,8 & $\begin{array}{l}\text { 23) Existência de autonomia ao servidor } \\
\text { para o desenvolvimento de inovações. }\end{array}$ & 0,82 \\
\hline $\begin{array}{l}\text { 8) Proporciona transparência da } \\
\text { informação pública relativa aos processos } \\
\text { de compras de medicamentos do } \\
\text { Ministério da Saúde. }\end{array}$ & 0,89 & $\begin{array}{l}\text { 24) Estímulo à criatividade para o } \\
\text { desenvolvimento de inovações. }\end{array}$ & 0,84 \\
\hline $\begin{array}{l}\text { 9) Promove sustentabilidade nas compras } \\
\text { de medicamentos do Ministério da Saúde, } \\
\text { considerando que sustentabilidade é um } \\
\text { conjunto de medidas instituídas que } \\
\text { respeitam as normas ecológicas, de forma } \\
\text { a não prejudicar as gerações futuras. }\end{array}$ & 0,65 & $\begin{array}{l}\text { 25) Formação de equipes } \\
\text { multidisciplinares para o desenvolvimento } \\
\text { de inovações. }\end{array}$ & 0,75 \\
\hline 10) Investimento em Inovação. & 0,45 & $\begin{array}{l}\text { 26) Percepção de que o foco no } \\
\text { comprometimento com o trabalho } \\
\text { influencia o desenvolvimento de } \\
\text { inovacões. }\end{array}$ & 0,24 \\
\hline $\begin{array}{l}\text { 11) Apoio ao desenvolvimento de } \\
\text { inovações (por meio de ações de educação, } \\
\text { incentivos à diversidade). }\end{array}$ & 0,52 & $\begin{array}{l}\text { 27) Percepção de que o foco na satisfação } \\
\text { com o trabalho influencia o } \\
\text { desenvolvimento de inovações. }\end{array}$ & 0,54 \\
\hline $\begin{array}{l}\text { 12) Disponibilização de infraestrutura } \\
\text { tecnológica para inovação. }\end{array}$ & 0,6 & $\begin{array}{l}\text { 28) Compartilhamento de conhecimento } \\
\text { relativo ao desenvolvimento de inovações } \\
\text { pelas diversas áreas do órgão. }\end{array}$ & 0,82 \\
\hline $\begin{array}{l}\text { 13) Percepção de que os gestores são as } \\
\text { principais fontes de inovação dentro do } \\
\text { órgão. }\end{array}$ & 0,99 & $\begin{array}{l}\text { 29) Desenvolvimento de estratégia para } \\
\text { inovação. }\end{array}$ & 0,74 \\
\hline $\begin{array}{l}\text { 14) Percepção de que os servidores são as } \\
\text { principais fontes de inovação dentro do } \\
\text { órgão. }\end{array}$ & 0,85 & $\begin{array}{l}\text { 30) Desenvolvimento de atividades para } \\
\text { difusão (propagação) da inovação. }\end{array}$ & 0,65 \\
\hline $\begin{array}{l}\text { 15) Desenvolvimento de inovações para } \\
\text { atender a prioridades políticas. }\end{array}$ & 0,93 & $\begin{array}{l}\text { 31) Incentivo às atividades de colaboração } \\
\text { e aprendizado para inovação. }\end{array}$ & 0,63 \\
\hline $\begin{array}{l}\text { 16) Atuação em rede com outras } \\
\text { organizações para desenvolvimento de } \\
\text { inovações. }\end{array}$ & 0,8 & $\begin{array}{l}\text { 32) Percepção que a cultura organizacional } \\
\text { favorece o desenvolvimento de inovações. }\end{array}$ & 0,84 \\
\hline
\end{tabular}

